UNIVERSIDAdE DE SÃo PAULO

FACULDADE DE FILOSOFIA, LETRAS E CIÊNCIAS HUMANAS DEPARTAMENTO DE LINGUísTICA

\title{
Análise Forense de Autoria Textual: ESTILOS SOCIAIS E INDIVIDUAIS
}

\author{
(VERSÃo CORRIGIDA)
}

DAYANE CELESTINO DE ALMEIDA

SÃo PAULO

2015 
DAYANE CELESTINO DE ALMEIDA

\section{ANÁlise Forense de Autoria TeXTuAl: ESTILOS SOCIAIS E INDIVIDUAIS}

\section{(VERSÃo CORRIGIDA)}

TESE apresentada ao Programa de PósGraduação em Semiótica e Linguística Geral do Departamento de Linguística da Faculdade de Filosofia, Letras e Ciências Humanas da Universidade de São Paulo, para obtenção do título de Doutor em Letras.

Orientador: Prof. Dr. Ronald Beline Mendes

De acordo:

SÃO PAULO

2015 
Nome: ALMEIDA, Dayane Celestino de.

Título: Análise forense de autoria textual: estilos sociais e individuais

TESE apresentada ao Programa de Pós-Graduação em Semiótica e Linguística Geral do Departamento de Linguística da Faculdade de Filosofia, Letras e Ciências Humanas da Universidade de São Paulo, para obtenção do título de Doutor em Letras.

Aprovada em: / 2015

\section{BANCA EXAMINADORA}

Prof. Dr. Ivã Carlos Lopes

Instituição: Universidade de São Paulo (USP)

Julgamento:

Assinatura:

Profa. Dra. Elizabeth Harkot-de-La-Taille

Instituição: Universidade de São Paulo (USP)

Julgamento:

Assinatura:

Prof. Dr. Richard Malcolm Coulthard

Instituição: Universidade Federal de Santa Catarina / Universidade de Birmingham

Julgamento: Assinatura:

Profa. Dra. Anna Christina Bentes

Instituição: Universidade Estadual de Campinas (UNICAMP)

Julgamento: Assinatura: 
Para a Dryelle: minha irmãzinha, "nosso Digui".

Para o Ricardo: meu chão, minha força. 


\section{AGRADECIMENTOS}

Ao Ricardo Piantola, meu marido, cuja existência faz a minha vida mais feliz, pelo companheirismo, amor e encorajamento; pela paciência e serenidade que me mantêm no caminho. Obrigada também pelo grande auxílio com as questões de informática e estatística relacionadas a este trabalho.

Aos meus pais, Maria Aparecida e Sebastião, meu alicerce, pelo amor incondicional e incentivo. Agradeço ainda pela sua acolhida por vários fins de semana nos meses finais de desenvolvimento desta pesquisa.

Ao meu orientador, o professor Ronald Beline Mendes, pela confiança e apoio, pelas leituras atentas, e por se dispor a me orientar mesmo em um tema distante, a priori, dos que via de regra orienta.

Ao professor e amigo Marcos Lopes pela ideia de tema de pesquisa, bem como pelas conversas e discussões que contribuem para o meu crescimento pessoal e profissional.

Ao professor e amigo Ivã Carlos Lopes, cujo exemplo, carinho, paciência e apoio - que me acompanham desde os tempos de Iniciação Científica - instauraram em mim o "quererseguir" na vida acadêmica.

Aos Drs. Malcolm Coulthard, Tim Grant, Krzyszztof Kredens e Rui Sousa-Silva, pela presteza e gentileza com que sempre responderam aos meus e-mails e enviaram textos e indicações bibliográficas sobre a área de Linguística Forense. Ainda ao Dr. Coulthard, um agradecimento especial pela leitura "extra-oficial" do meu relatório de qualificação; e ao Dr. Kredens, pela disposição em conversar comigo oferecendo sugestões e contribuindo para os insights de um dos estudos quantitativos.

Às amigas Carolinas (Tomasi e Lemos), Juliana Di Fiori e Mariana Luz pelo apoio e amizade crescente. A elas agradeço também pelas sessões de "consultoria semiótica".

Aos Tomasi e seus "agregados": Carolina, Saulo, Sueli, Domingos, Rosa, Felipe e Daniela. A eles agradeço pelo carinho e pelos momentos de "pasta \& vino", fundamentais para atenuar a tensão.

A Dryelle Almeida, Maikon de Pieri e Camila Quintela pela paciência em me ouvir mesmo nos meus dias mais "reclamões" e por compreender as minhas ausências durante o período de desenvolvimento desta tese. A eles agradeço ainda pelos muitos momentos de risadas e por estarem sempre prontos a me ajudar durante o desenvolvimento de alguns "testespiloto". 
Aos amigos Edison Gomes Jr. e Clarissa Mariano, ao meu lado desde os tempos de graduação, pelo afeto e pelos encontros repletos de alegria, que certamente colaboraram para deixar esses quatro anos mais leves.

Aos meus cunhadinhos Juliana Piantola e João Ricardo Almeida, aos amigos Heloísa Brites e Beto Bisca, e aos meus sogros Edna Piantola e Roberto Silva, pela paciência em tolerar as minhas esquisitices e pelos momentos de descontração com cinema, séries e "comes e bebes".

À "Julinha" Piantola que, mesmo sem saber, me acalmou e alegrou, tornando minha vida mais serena.

À Maria Carolina Kherlakian, cujo carinho e dedicação profissional me permitiram passar mais facilmente por esses quatro anos.

Aos colegas do Grupo de Estudos Sociolinguísticos da USP (GESOL), pelo companheirismo, profissionalismo, e por ouvirem as minhas lamentações cancerianas de vez em quando; um agradecimento especial à Júlia França que me auxiliou coletando textos para uma das análises.

Aos professores Ivã Carlos Lopes e Elizabeth Harkot-de-la-Taille, pela leitura atenta do relatório de qualificação.

Ao professor $W$ aldir Beividas, por te me "adotado burocraticamente" no início deste doutorado.

À Faculdade de Filosofia, Letras e Ciências Humanas da Universidade de São Paulo e ao Departamento de Linguística, pela oportunidade da realização da Pós-Graduação.

Ao Conselho Nacional de Desenvolvimento Cientifico e Tecnológico ( $C N P q)$, pela bolsa concedida.

Aos meus coordenadores na Universidade Paulista por compreenderem minhas ausências devido a participações em congressos e outros eventos, ou em outros momentos em virtude desta pesquisa.

A todos os autores que forneceram textos que constituem os corpora aqui examinados.

A Deus, pelas oportunidades, pela força nos momentos mais difíceis e por colocar no meu caminho pessoas maravilhosas que contribuíram para a realização deste trabalho. 
The Unabomber sent us a 35.000 word essay claiming to explain his motives and views of the ills of modern society [...]. After the manifesto appeared in The

Washington Post and The New York Times, thousands of people suggested possible suspects. One stood out: David Kaczynski described his troubled brother Ted [...]. Most importantly, David provided letters and documents written by his brother. Our linguistic analysis determined that the author of those papers and the manifesto were almost certainly the same. When combined with facts gleaned from the bombings and Kaczynski's life, that analysis provided the basis for a search warrant.

(FBI 100. The Unabomber.)

Reid: Garcia's been digging through William's computer. She found an encrypted link to a web page.

Morgan: Where'd it take you?

Reid: Uh, an unsearchable, untraceable blog with tons of journals entries. It's like some sort of diary.

Rossi: You find anything incriminating?

Reid: I was able to differentiate between 2 distinct voices, 2 authors. I found various idiosyncratic words, phrases, punctuation, and orthography within the blog entries consistent with each separate person. Words like "soda" and "pop". One guys uses dashes while the other uses ellipses. 


\section{RESUMO}

ALMEIDA, Dayane Celestino de. Análise forense de autoria textual: estilos sociais e individuais. 2015. 256 f. Tese (Doutorado) - Faculdade de Filosofia, Letras e Ciências Humanas, Universidade de São Paulo, 2015.

O interesse pela autoria de textos escritos é tão antigo quanto a própria escrita. Desde que o homem passou a registrar a sua língua dessa forma, podem ser muitas as circunstâncias em que emerge a pergunta "Quem escreveu este texto?". Ela pode surgir porque os textos são anônimos, assinados por pseudônimos ou porque há uma disputa com relação a sua autoria. Mais recentemente, saber quem escreveu um determinado texto ou conjunto de textos tem ajudado a solucionar crimes ou dirimir contendas judiciais. Nesses contextos, entra em cena o linguista forense, cujo trabalho pode elucidar tais casos uma vez que sua análise é capaz de depreender estilos linguísticos que se relacionam tanto a um grupo social (elaboração de perfis sociolinguísticos) quanto a um indivíduo (atribuição de autoria). Este trabalho preocupa-se particularmente com noções de estilo da Sociolinguística e da Semiótica Discursiva nas análises forenses de autoria e almeja demonstrar de que modo a incorporação da análise do plano do conteúdo pode render frutos a essas análises. Assim, no que diz respeito à depreensão de perfis sociolinguísticos, sugere-se que o pertencimento a um grupo social, aqui proposto como um "universo discursivo", pode ser revelado por meio da análise da recorrência semântica e não apenas de variáveis linguísticas (que seriam uma ou mais maneiras de se dizer a mesma "coisa"). Para isso, analisa-se um conjunto de escritos provenientes da investigação do que ficou conhecido como "Massacre de Realengo" e sugere-se que seus autores compartilham o mesmo grupo, neste caso o dos "Fiéis" (em oposição aos "Infiéis"). Quanto à atribuição de autoria, faz-se necessário saber se as categorias examinadas em análises semióticas podem realmente distinguir autores. Para isso, realizou-se um estudo quantitativo com 4 autores, em que cada autor contribuiu com 20 textos, divididos em dois grupos de 10 (Autor 1A, Autor 1B, e assim por diante). A hipótese era a de que os textos dos grupos A e B de um mesmo autor seriam mais semelhantes entre si do que comparativamente aos subconjuntos de textos dos outros autores, no que diz respeito a elementos do plano do conteúdo. Os resultados corroboram essa hipótese e indicam, portanto, que as categorias semióticas podem ser utilizadas com sucesso em casos de autoria questionada.

Palavras-chave: Análise de Autoria. Estilo. Linguística Forense. Semiótica Discursiva. Sociolinguística. 


\section{ABSTRACT}

ALMEIDA, Dayane Celestino de. Forensic authorship analysis: social and individual styles. 2015. 256 f. Tese (Doutorado) - Faculdade de Filosofia, Letras e Ciências Humanas, Universidade de São Paulo, 2015.

Interest in the authorship of written texts is as old as writing itself. Ever since men started recording language in this way, there can be various circumstances in which the question "Who wrote this text?" emerges. Such a question can arise because the texts are anonymous, signed by pseudonyms or because its authorship is being disputed. More recently, knowing who wrote a particular text or set of texts has been helping to solve crimes or settle legal disputes. In these contexts, the forensic linguist stands out, working to elucidate such cases, since linguistic analysis is able to infer writing styles that relate either to a social group (sociolinguistic profiling) or to an individual (authorship attribution). This work is particularly concerned with the ideas on style proposed by Sociolinguistics and Discourse Semiotics and their relation to forensic authorship analysis. It seeks to demonstrate how the incorporation of the analysis of the content plane can assist authorship examination. Regarding sociolinguistic profiling, this work suggested that the membership in a social group - proposed here as a "discourse universe" - can be revealed through the analysis of semantic recurrence (and not only by observing linguistic variables, that is, one or more ways to say the same "thing"). In order to accomplish that, we analyze a set of writings from the investigation of what became known as "Realengo Massacre". Such an analysis indicates that the texts under scrutiny seem to have been written, if not by the same author, at least by authors within the same social group. As for authorship attribution, it is necessary to know if the features examined in semiotic analysis can really distinguish authors. Hence, we performed a quantitative study with 4 authors, wherein each author contributed with 20 texts divided into 2 groups of 10 (Author 1A, Author 1B, and so on). The hypothesis was that texts from a single author would be more similar to each other than texts from different authors, when it comes to an analysis of the content plane. The results seem to confirm the hypothesis; thus semiotic features may successfully be used in questioned authorship scenarios.

Keywords: Authorship Analysis. Style. Forensic Linguistics. Sociolinguistics. Discourse Semiotics. 


\section{SUMÁRIO}

Introdução .....................................................................................12

1 Preâmbulo: breve introdução à Linguística Forense ................................................13

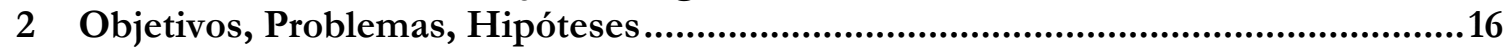

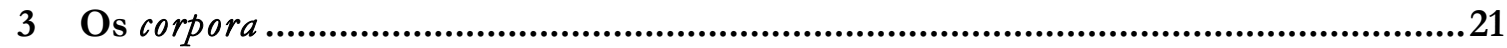

4 Contribuições e relevância deste trabalho ……..........................................................25

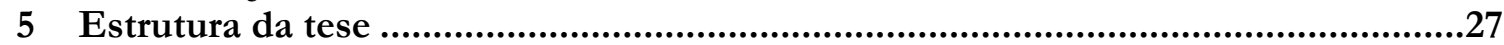

1 Análise de Autoria Textual no Contexto Forense ............................... 29

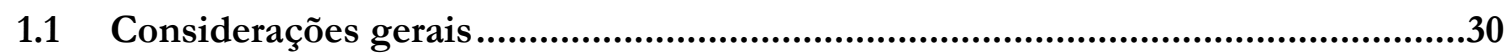

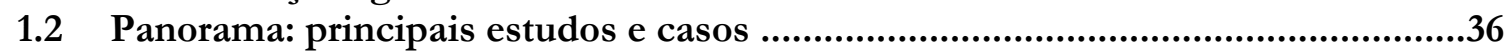

1.2.1 Estilometria versus Estilística. Estudos quantitativos ou qualitativos? ................................ 37

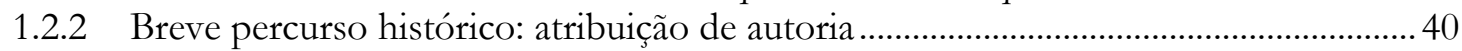

1.2.3 Breve percurso histórico: perfis sociolinguísticos ................................................................ 48

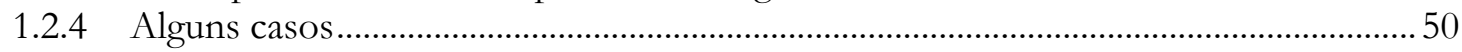

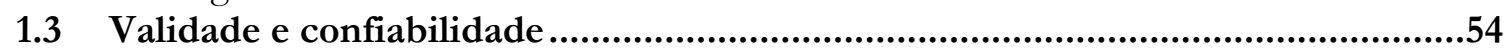

1.4 Processamento de linguagem, consciência metalinguística e tentativas de

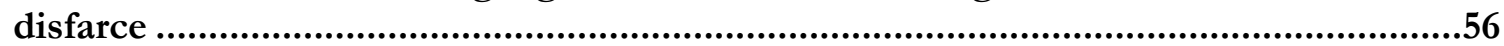

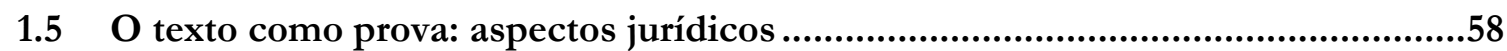

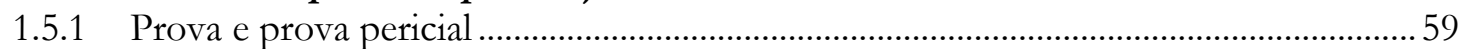

1.5.2 Exemplos brasileiros da aplicabilidade da análise de autoria forense ............................ 67

2 Estilo e Autoria................................................................................71

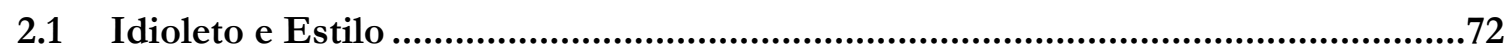

2.2 Estilo como distinção, cosseleção e recorrência...................................................74

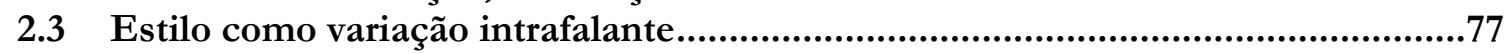

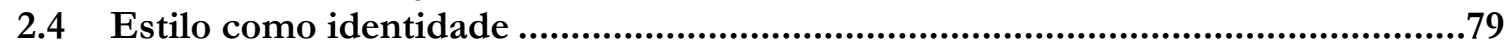

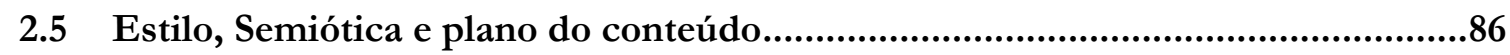

2.6 Implicações e propostas para análises de autoria..............................................90

2.6.1 Plano do conteúdo na atribuição de autoria ........................................................................... 90

2.6.2 Estilos sociais e perfis sociolinguísticos: os universos discursivos ................................ 93

3 Análises de Estilos Sociais para Elaborar Perfis Sociolinguísticos ........100

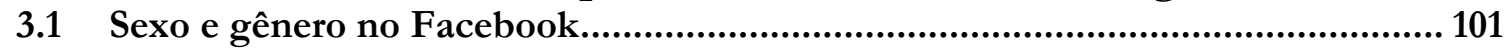

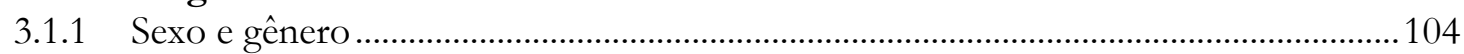

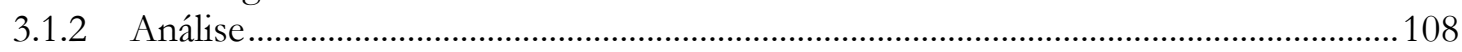

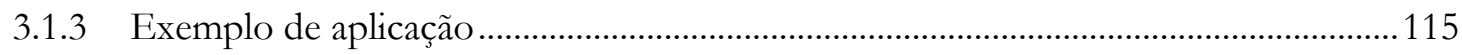

3.2 O Universo discursivo em cartas do "Massacre de Realengo" ............................ 118

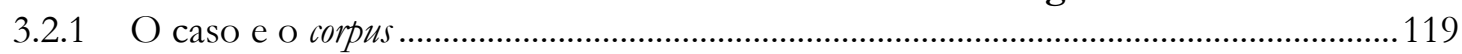

3.2.2 Oposições semânticas e o estabelecimento do universo discursivo.............................120

4 Estilos Individuais e Atribuição de Autoria: análise qualitativa ............126

4.1 Objetivos e Corpus ................................................................................................127

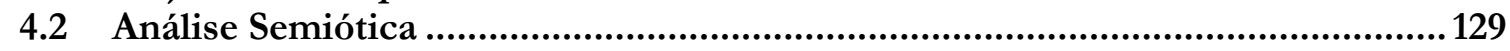

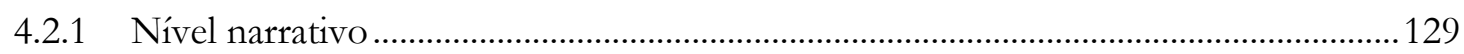

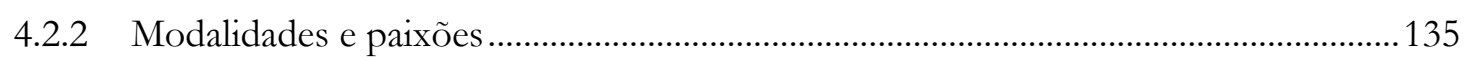

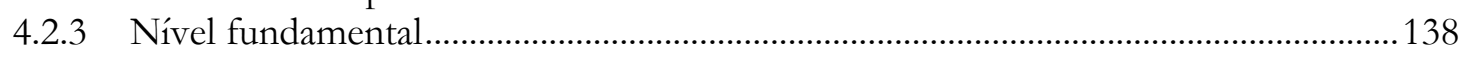

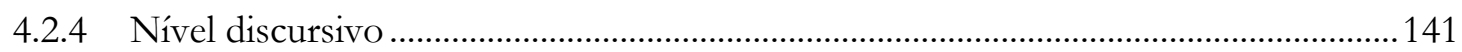

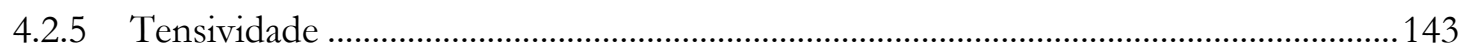

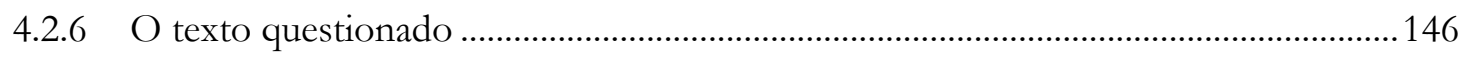


5 Estilos Individuais e Atribuição de Autoria: análise quantitativa ..........148

5.1 Medindo semelhanças e diferenças entre textos a partir do plano do conteúdo 149

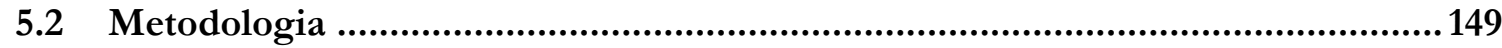

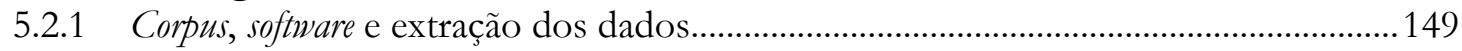

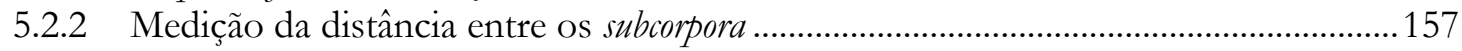

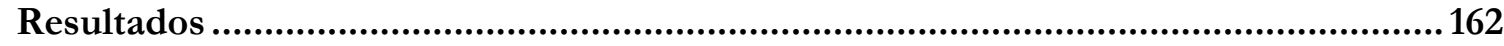

6 Exercício de Atribuição "às Cegas"................................................ 181

6.1 Considerações gerais e metodologia.......................................................................182

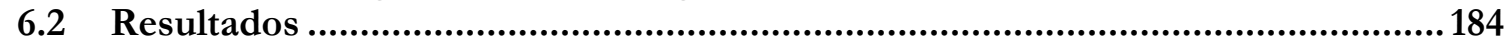

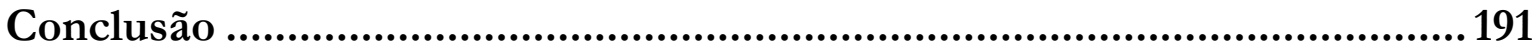

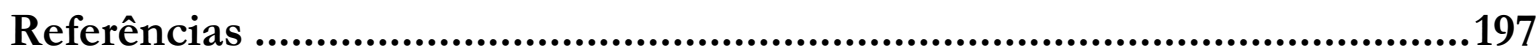

Apêndices ................................................................................209

Anexos ..........................................................................................219

Índice Remissivo .........................................................................253 


\section{INTRODUÇÃO}

Death, drugs, and disaster; bodies and blood, guns and glass; semen and saliva; bullets, bombs, and bite marks; tool marks and trauma; poisons, homicides, safe paint, footprints, fingerprints and psychoses. These are the kinds of events and evidence that challenge forensic scientists (...). But there also are nonviolent - very subtle - tools of crime. They do not bruise, batter, slash, or shoot. Yet they are used to steal our money or

threaten our security more often than guns, knives, pry bars, or bombs. They are just pieces of paper.

(William Storer. "Questioned Documents". IN: Introduction to Forensic Sciences) 


\section{Preâmbulo: breve introdução à Linguística Forense}

Nas últimas décadas, houve um crescimento do interesse de linguistas pelas relações entre a Linguagem e o Direito, conforme afirma Butters (2007, p. 318). O autor salienta que tal interesse, antes restrito à "linguagem legal" por si mesma, expandiu-se na medida em que os linguistas passaram a fazer uso de seus conhecimentos "para ajudar advogados a preparar e apresentar seus casos, e a polícia a processar criminosos e resolver crimes”1. Tal aplicação da Linguística tem sido chamada de Linguística Forense.

Embora tenha nascido "oficialmente" como disciplina em 1968, com a publicação de The Evans statements: a case for forensic linguistics, por Jan Svartvik (COULTHARD; JOHNSON, 2007, p. 5), o desenvolvimento da Linguística Forense foi inicialmente lento e apenas nas últimas duas décadas vem-se observando seu notável crescimento (COULTHARD; JOHNSON, 2007, p. 5). Nas palavras de Coulthard (2004a, p.159) "os tribunais e as cortes em vários países têm usado, com frequência crescente, a experiência de linguistas em casos nos quais há disputa com relação a algum aspecto de textos escritos”. Segundo Shuy (2001, p. 691, tradução nossa)2, “cada vez mais advogados e agências governamentais convocam linguistas forenses para ajudá-los a analisar evidências de língua falada ou escrita tanto na esfera civil quanto criminal".

O termo "forense" vem do latim forum - local em que os romanos se reuniam para debater assuntos legislativos e judiciais (OLSSON, 2008, p. 6). Em inglês, "forensic"3 passou também a ser associado a uma ciência capaz de ajudar a desvendar crimes (OLSSON, 2008, p.6)4. Assim, se de um lado a Linguística Forense se define como a

\footnotetext{
1 Texto original: “to assist lawyers in preparing and presenting their clients' cases, and by law-enforcement personnel interested in solving crimes and prosecuting criminals" (BUTTERS, 2007, p.318).

2 Texto original: "more and more attorneys and government agencies are calling on forensic linguists to assist them in analyzing the spoken and written language that frames the evidence in both civil and criminal law suits" (SHUY, 2001, p. 691).

${ }^{3}$ No site Cambridge Dictionaries Online, encontra-se a seguinte acepção para "forensic": "related to scientific methods of solving crimes, involving examining the objects or substances that are involved in the crime". Disponível em <http://dictionary.cambridge.org/dictionary/british/forensic?q=forensic >. Acesso em 20/11/2012.

${ }^{4}$ Em Português, esse papel é assumido pelo que se conhece por "Criminalística". Uma das acepções para o termo, segundo o dicionário Houaiss é "disciplina que reúne os conhecimentos e técnicas necessários à elucidação dos crimes e à descoberta de seus autores, mediante a coleta e interpretação dos vestígios, fatos e consequências sobrevenientes".
} 
interface entre a Linguística e o Direito, em sentido lato, e se ocupa de qualquer análise linguística nos âmbitos criminal e judicial5 ${ }^{5}$, de outro, uma definição em sentido strictu posiciona-a não como a disciplina que compreende qualquer relação entre Linguagem e Direito, mas como uma subárea destes estudos: especificamente aquela interessada na aplicação dos conhecimentos linguísticos com vistas a ajudar a solucionar crimes e disputas judiciais ${ }^{6}$.

Os estudos do campo mais amplo de "Linguagem e Direto" podem ser subdivididos de acordo com três grandes interesses ${ }^{7}$, que são:

a) O estudo dos textos legais, isto é, o estudo da linguagem jurídica e da linguagem da polícia;

b) O estudo das práticas linguísticas na esfera criminal e judicial (como, por exemplo, as interações nos tribunais e nas delegacias, a interpretação no contexto forense); e

c) $\mathrm{O}$ fornecimento de evidências linguísticas que possam ajudar a resolver crimes ou dirimir contendas judiciais - a Linguística Forense propriamente $\operatorname{dita}^{8}$, que inclui, por exemplo, análises de textos ambíguos e identificação de autoria textual ${ }^{9}$.

Desse modo, considerando a Linguística Forense em seu sentido mais específico ${ }^{10}$, verifica-se que ela se ocupa de análises de autoria textual, de identificação de falantes, de crimes de linguagem ${ }^{11}$, de textos cujo significado é "questionável"12 ou ambíguo e de

\footnotetext{
${ }^{5}$ Segundo Sardinha (2009, p. 69), a Linguística Forense "se ocupa da análise da linguagem jurídica, de um lado, e do fornecimento de evidências linguísticas em processos judiciais, de outro".

${ }^{6}$ Solan e Tiersma (2005) usam o termo "linguistic evidence" no lugar de "forensic linguistics". Gibbons (2011) propõe o termo "communication evidence".

${ }^{7}$ Cf. Kredens (2012) "Defining the scope of forensic linguistics"; Coulthard (2012) "Early famous cases of disputed authorship". Informação oral/Slides de aula. In: 12th International Summer School in Forensic Linguistic Analysis, Barcelona.

8 Cf. Tiersma, [20--?]. Disponível em <http://www.languageandlaw.org/FORENSIC.HTM>. Acesso em 23/08/2013.

9 Turell (2012) também faz tal subdivisão e chama as três subáreas de Language of the Law, Language of the Court e Language as Evidence, respectivamente. "Idiolectal similitude (or distance) in authorship analysis". Informação oral/Slides de aula. 12th International Summer School in Forensic Linguistic Analysis, Barcelona.

${ }^{10}$ De acordo com Leonard (2005, tradução nossa), por exemplo, a Linguística Forense é a disciplina que "responde a questões legais que envolvem linguagem, por exemplo: Quem escreveu o bilhete de resgate? Quem ligou avisando sobre uma ameaça de bomba? Qual é o significado de uma expressão num contrato? (...)".

${ }^{11}$ Crimes cometidos por meio da linguagem, como, por exemplo, injúria, difamação, assédio, suborno, ameaça, extorsão, etc. Para uma revisão de tais crimes, ver Solan e Tiersma (2005).
} 
disputas envolvendo marcas registradas (COULTHARD, 2004a; BUTTERS, 2007). Também fazem parte de seu escopo os casos em que seja necessária uma opinião especializada acerca da adequação de advertências presentes em embalagens de produtos (e.g. nas embalagens de cigarro, como mostram Coulthard e Hagemeyer [2013]) e da compreensibilidade de instruções escritas (BUTTERS; 2001). É possível representar essa subdivisão com o esquema que se apresenta na (Figura 1):

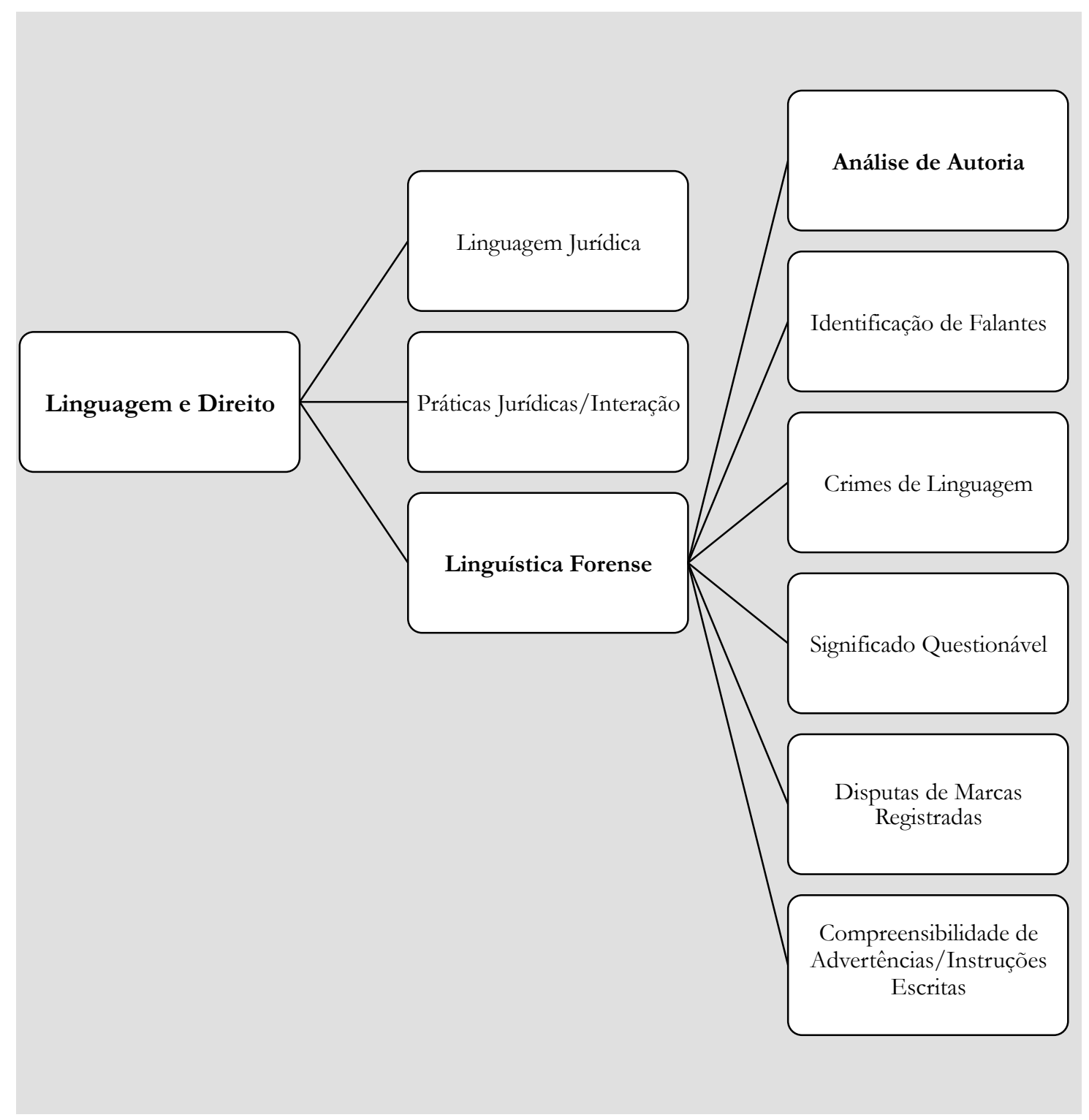

Figura 1 - A Linguística Forense como subárea dos estudos de Linguagem e Direito

${ }^{12}$ Cf. Kredens (2012). "Defining the scope of forensic linguistics". Informação oral/Slides de aula. 12th International Summer School in Forensic Linguistic Analysis, Barcelona. Termo original: “Disputed meaning”. 


\section{Objetivos, Problemas, Hipóteses}

Este trabalho preocupa-se com a análise de autoria textual em contextos forenses. Seu primeiro objetivo é verificar de que maneira as concepções de estilo oriundas da Sociolinguística e da Semiótica discursiva podem ser incorporadas a esse tipo de análise, com destaque para a importância da inclusão da análise do plano do conteúdo ${ }^{13}$. Um segundo objetivo é reunir, em um único trabalho brasileiro diversos pontos importantes a respeito da análise de autoria - incluindo seus aspectos jurídicos - dispersos na literatura estrangeira sobre o tema.

Duas tarefas podem ser desempenhadas pelo linguista forense preocupado com a autoria textual. Uma delas consiste em analisar o texto cuja autoria esteja sendo questionada, comparando-o com uma amostra de outros textos de autores suspeitos. A outra diz respeito à elaboração de um perfil sociolinguístico de um autor ${ }^{14}$, uma vez que certos usos linguísticos podem ser indicativos de determinados grupos sociais. Essa tarefa se impõe quando não existem textos para comparar com aquele cuja autoria é questionada ${ }^{15}$.

Qualquer que seja a tarefa, a ideia de que é possível determinar o autor de um texto ou pelo menos um grupo social ao qual ele pertence está diretamente relacionada à noção de estilo. Love (2002, p.12) afirma que a hipótese central dos estudos de autoria repousa justamente nessa ideia. No primeiro caso (quando há textos para comparação), trata-se de determinar um "estilo idioletal" (TURELL, 2010), ou seja, individual. No segundo (quando a comparação não é possível), trata-se de depreender o estilo de um grupo. Muitas são as acepções de estilo nos estudos linguísticos e literários, porém, neste trabalho, servem de norte a Semiótica Discursiva e a Sociolinguística. As ideias acerca do estilo nesses campos teórico-metodológicos são discutidas mais adiante no capítulo 2.

\footnotetext{
${ }^{13}$ Conforme distinção entre "expressão e conteúdo", de Hjelmslev (2003 [1943]), seguida pela Semiótica Discursiva (GREIMAS; COURTÉS, 1979).

${ }^{14}$ Em inglês, usam-se os termos "author profiling" (Cf. KREDENS, 2012; CORNEY, 2003), "authorship characterization" (Cf. CORNEY, 2003, p. 15) ou "sociolinguistic profiling" (GRANT, 2008; 2004).

${ }^{15}$ Daqui em diante, algumas vezes será empregado o termo "texto questionado", no lugar de "texto cuja autoria é questionada".
} 
À guisa de introdução, vale ressaltar que a Semiótica francesa (GREIMAS; COURTÉS, 1979), na esteira de Hjelmslev (2003 [1943]), considera a língua como a junção de dois planos: o da expressão e o do conteúdo. Assim, para esse campo teórico o estilo se depreende tanto de um plano quanto do outro. Entretanto, os trabalhos existentes em atribuição de autoria analisam apenas elementos linguísticos observados no plano da expressão. As características comumente examinadas são a pontuação, a utilização de maiúsculas, o modo de datação, a saudação inicial, o modo de anotar os números, os erros de ortografia, as expressões e palavras de elevada frequência, a forma de escrever as abreviaturas, variáveis morfológicas e sintáticas, o "design" geral das páginas, etc., conforme resume a Figura 2, a seguir:

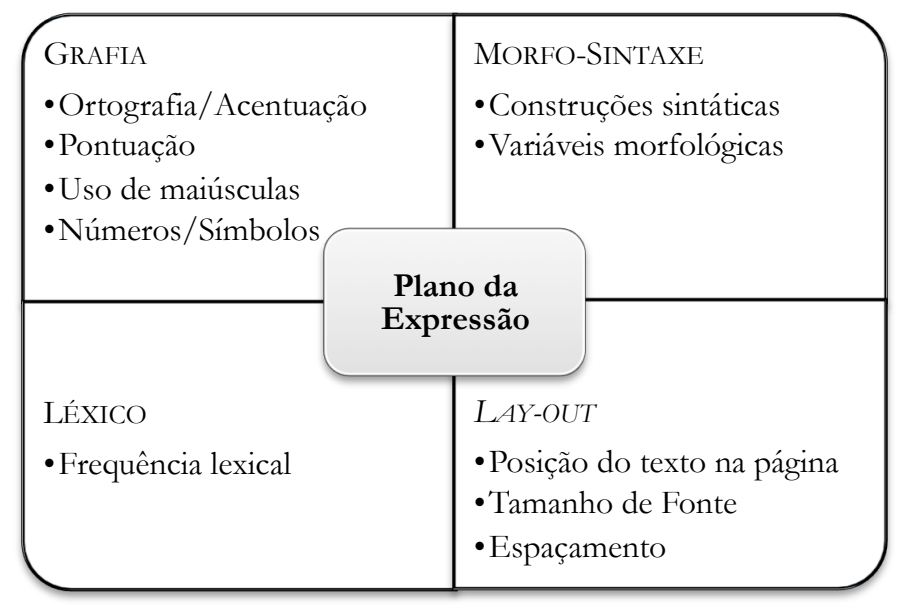

Figura 2 - Elementos do plano da expressão

Para Fiorin (2008) e Discini (2009), o estilo é o conjunto das marcas de um modo de dizer e tais marcas estão presentes desde os níveis mais “enraizados” dos textos e não só na sua manifestação. Segundo Discini (2009, p. 26, grifo nosso) “O estilo deve ser tratado como fenômeno do conteúdo mais a expressão, não podendo restringir-se a fenômenos de textualização". Assim, a proposta deste trabalho é que a análise de autoria pode ser mais acurada se considerar os dois planos da linguagem, em vez de apenas o da 
expressão. Os elementos mais "profundos" examinados na análise semiótica são os que seguem na Figura $3^{16}$.

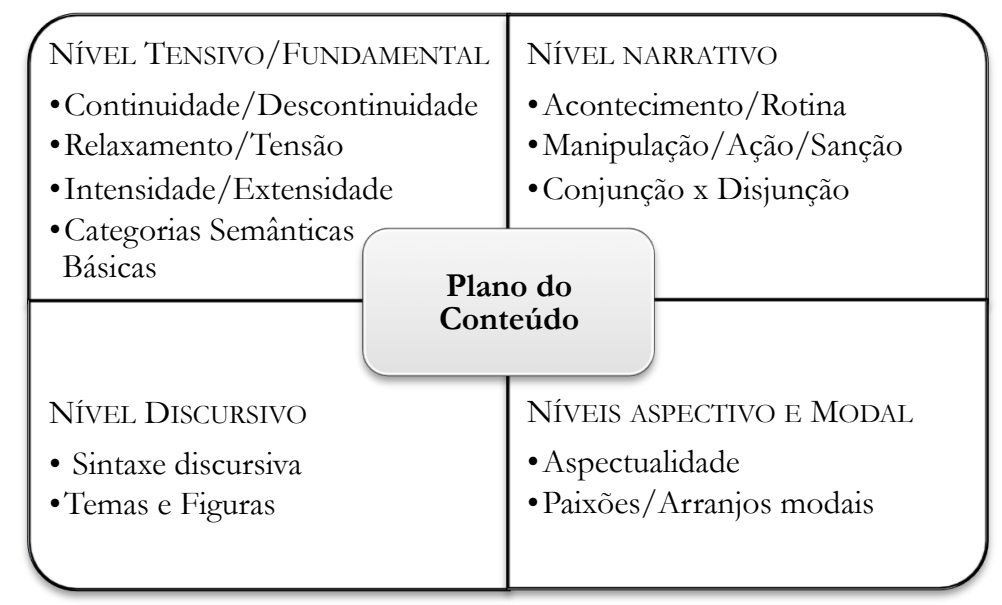

Figura 3 - Elementos do plano do conteúdo

Com relação à identificação de um estilo individual, os trabalhos existentes deixam de apresentar uma solução no que diz respeito à variação intrafalante (ou estilística), isto é, à variação no uso linguístico por parte de um mesmo indivíduo. A Sociolinguística tem demostrado que uma mesma pessoa emprega formas linguísticas diferentes em contextos diferentes (LABOV, 1966 e 2008; BELL, 1984; SCHILLING-ESTES, 2001; ECKERT e RICKFORD, 2001, etc.) e, segundo alguns autores, esse princípio pode ser aplicado à língua escrita (e.g. McMENANIM, 2002, 2010; OLSSON, 2008, LILLIS, 2013). Partindo desses pressupostos, como determinar que alguém é o autor de vários textos redigidos em situações diferentes e destinados a interlocutores diferentes? Essa interrogação emerge particularmente no contexto forense, cujos textos recolhidos para comparação são frequentemente de naturezas distintas. Por exemplo, o texto de autoria questionada pode ser uma carta de suicídio e os textos coletados para a comparação podem diferir quanto ao propósito, tema, grau de formalidade, destinatários, gênero, etc. (podem ser mensagens de celular, posts em redes sociais, e-mails formais, cartas comerciais, e-mails para amigos,

\footnotetext{
${ }^{16}$ Detalhes acerca da análise semiótica do plano do conteúdo são discutidos mais adiante, ao longo do trabalho e principalmente no capítulo 4. Uma revisão detalhada da teoria semiótica e seu modelo de análise pode ser vista em Barros (2001; 2003), Fiorin ([20--?] ; 2005; 2008), Greimas e Courtés (1979 [2008]).
} 
textos de blogs, diários, entre outros). Ou seja, não há nenhuma garantia - e é até mesmo improvável - que se consigam textos que foram escritos no mesmo tom informal que a carta de autoria questionada e muito menos provável é que se consigam outras cartas de suicídio do mesmo autor para a comparação.

Sendo assim, o presente trabalho propõe que é mais eficiente e eficaz o aproximarse de uma resposta a essa pergunta quando se inclui o exame do plano do conteúdo nas análises de autoria. Assume-se, ao lado da Semiótica francesa, que tal plano pode ser abordado sob a forma de um "percurso gerativo do sentido" (GREIMAS; COURTÉS, 1979), um simulacro metodológico de uma estrutura analisável, uma "gramática” que está subjacente aos textos. A partir disso, esta pesquisa pressupõe que a variação intrafalante, abundante no plano da expressão, tende a ser menor conforme se "avança" para os níveis mais "profundos" do plano do conteúdo. Quanto mais abstrato/simples o nível no plano do conteúdo, menos opções de escolha há para os usuários da língua, o que pode resultar em maior chance de que se façam sempre as mesmas escolhas. Dessa maneira, se dois indivíduos distintos empregam recorrentemente os mesmos elementos, diferentemente um em relação ao outro, isso significa que as opções de cada um têm grande poder discriminatório. Os capítulos 4, 5 e 6 apresentam análises que testam a aplicabilidade das categorias da análise semiótica para a distinção autoral.

Já no âmbito da depreensão de perfis sociolinguísticos, o problema que se coloca é determinar o que pode ser considerado como grupo social. Sabe-se que a Sociolinguística vem trabalhando com correlações entre usos linguísticos a categorias sociais, usualmente as demográficas, tais como sexo/gênero, escolaridade, idade, classe social e etnia (e.g. LABOV, 1966; TRUDGILL, 1974). Os textos que aparecem em casos forenses, contudo, são via de regra curtos e as variáveis linguísticas que poderiam indicar pertencimento a essas categorias demográficas são, por consequência, pouco frequentes - o que torna bastante difícil a tarefa de depreender um perfil sociolinguístico, sem uma espécie de "base de dados" prévia ${ }^{17}$ das possíveis correlações. Entretanto, outros elementos do(s) texto(s) (que não necessariamente constituem "variantes de variáveis", em termos sociolinguísticos) podem apontar para um outro tipo de agrupamento social, mais

${ }^{17}$ A confecção de uma tal base de dados seria, por si só, uma pesquisa independente. 
relacionado a identidades sociais "não demográficas" que os autores revelam em seus textos. Trata-se da recorrência semântica, que também emerge a partir da análise do plano do conteúdo, como indicadora de pertencimento a um determinado "universo" ou "grupo" social, que compartilha os mesmos valores, práticas, ideologias, etc. Essa questão é desenvolvida nos capítulos 2 e 3.

Em suma, pode-se dizer que partindo de certos pressupostos provenientes da Sociolinguística (existe variação intrafalante) e da Semiótica (o estilo se depreende tanto do plano da expressão quanto do conteúdo), alguns problemas se apresentam para a análise de autoria, a ver:

a) Por que considerar apenas elementos linguísticos do plano da expressão nas análises de autoria, se a língua é tanto expressão quanto conteúdo (HJELMSLEV, 1943) e o conteúdo pode ser estruturado numa gramática (GREIMAS; COURTÉS, 1979)?

b) Como determinar que alguém é o autor de diversos textos quando a Sociolinguística demonstra que existe variação intrafalante, dependente de tantos fatores?

c) Como determinar algum tipo de grupo social em que se insere o autor dos textos sob exame, para se selecionar ou "desselecionar" suspeitos quando esses textos são em geral curtos e não apresentam variáveis linguísticas suficientes para que se estabeleçam categorias sociais com confiança?

Ao se deparar com tais dificuldades, este trabalho procura resolvê-las por meio da incorporação da análise do plano do conteúdo - nos moldes da semiótica discursiva francesa - aos estudos de atribuição, lançando mão das hipóteses que se descreveram em parágrafos anteriores. 


\section{Os corpora}

As análises que se apresentam nos capítulos a seguir foram realizadas a partir de textos "reais", escritos semiespontânea ou espontaneamente, ou seja, trata-se de textos que não foram produzidos sob demanda. A princípio, análises de autoria poderiam levar em conta qualquer texto escrito desde que houvesse uma dúvida sobre quem o escreveu (de fato, a análise estilística de textos com vistas à identificação de um autor vem sendo, há tempos, uma preocupação dos estudos literários, históricos, religiosos, etc.), mas, a fim de direcionar melhor esta pesquisa, as análises se restringiram a textos que podem ser chamados de "textos forenses", conforme se explica adiante.

Os textos sujeitos à atribuição ou caracterização de autoria na esfera forense podem ser de dois tipos: alguns são claramente "criminosos", tais como cartas de ameaças, bilhetes de resgate, conversas na internet sobre sexo envolvendo menores, cartas de suicídio, etc.; outros são mais "cotidianos" e não inerentemente criminais, como diários, e-mails pessoais, cartas. Estes últimos podem ser utilizados como base para análises comparativas ou fornecer um álibi em uma investigação (Cf. GRANT, 2008, p. 216). Ainda sobre essa diversidade de tipos de textos, Olsson (2008, p. 1), afirma:

\footnotetext{
Literalmente, qualquer texto é um texto forense em potencial. Se um texto é de algum modo implicado em um contexto criminal ou legal, então ele é um texto forense. Uma multa por estacionamento proibido poderia se tornar um texto forense, bem como um testamento, uma carta, um livro, um artigo, um contrato, uma tese - quase tudo ${ }^{18}$.
}

Grant (2008, p.216) argumenta que devido à variedade de tipos de texto que ocorrem no contexto forense, generalizações sobre as suas características devem ser cautelosas. No entanto, é possível observar alguns aspectos que distinguem esses textos daqueles tipicamente analisados em investigações de autoria no âmbito literário, histórico ou religioso. Chamemos estes últimos textos de "não forenses". Uma das principais diferenças é que os textos "não forenses" são mais bem elaborados. Nas palavras de

\footnotetext{
${ }^{18}$ Texto original: "Literally any text or item of spoken language has the potential of being a forensic text. If a text is somehow implicated in a legal or criminal context then it is a forensic text. A parking ticket could become a forensic text, a will, a letter, a book, an essay, a contract, a health department letter, a thesis - almost anything" (OLSSON, 2008, p. 1).
} 
Grant (2008, p. 216) , “o autor provavelmente gastou um tempo considerável pensando no texto e compondo-o" ${ }^{19}$. Outra consideração é que os textos não forenses são, via de regra, escritos por profissionais ou pelo menos por pessoas com um nível alto de educação. Ao contrário, os textos forenses são mais espontâneos, escritos na maioria das vezes por "naïve writers"20 (BAAYEN et al., 2002). Na atribuição de autoria não forense há, frequentemente, grandes quantidades de textos a serem analisados, enquanto nos contextos forenses isso quase nunca ocorre. O Quadro 1 resume as principais diferenças entre as duas classes de textos:

\begin{tabular}{l} 
TEXTOS “FORENSES" \\
\hline Curtos \\
Espontâneos/não-planejados \\
\hline Direcionados a uma pequena audiência \\
Autores não são profissionais \\
\hline
\end{tabular}

\section{TEXTOS "NÃO FORENSES" \\ (LITERÁRIOS, RELIGIOSOS, HISTÓRICOS, ETC.)}

Longos

Não espontâneos/planejados

Direcionados a grandes audiências

Autores geralmente "profissionais da escrita" ou com nível de escolaridade maior

Quadro 1 - Diferenças entre textos forenses e não forenses Fonte: Grant (2008, p. 216-217); Turell (2012, slide 8)

Os textos analisados neste trabalho podem ser categorizados como "forenses", de acordo com as características elencadas no quadro acima, que orientaram a sua coleta para os corpora aqui utilizados.

Um dos estudos apresentados no capítulo 3 baseia-se num corpus constituído por uma série de textos encontrados pela polícia brasileira durante a investigação do que ficou conhecido como o "Massacre de Realengo", ocorrido em Abril de 2011, numa escola pública do Rio de Janeiro. Tais materiais são empregados aqui como exemplo de um conjunto textual que poderia ter tido sua autoria questionada pela polícia, uma vez que foi assumido que eles pertenciam à mesma pessoa - o atirador -, embora tenham sido encontrados em locais diferentes. A polícia encontrou um grupo de textos na casa do atirador e uma única "carta de suicídio" (ou carta-testamento) com ele logo após o

\footnotetext{
19 Texto original: "the author may have spent some time and thought in their composition" (GRANT, 2008, p. 216).

20 Algo como "autores ingênuos", ou seja, não profissionais da escrita.
} 
massacre. Nesta pesquisa, a carta de suicídio é tomada como texto questionado e s demais como textos para comparação.

Já a outra análise apresentada no mesmo capítulo diz respeito a um conjunto de posts da rede social Facebook. Foram coletados 200 posts (mensagens privadas, mensagens de status e comentários), de 20 autores diferentes (10 homens e 10 mulheres na faixa etária de 20 a 35 anos). Todos os textos foram coletados entre autores que podem ser considerados, nos termos de Baayen et. al. (2002), "naïve writers", ou seja, não são, de modo algum, profissionais da escrita. Produzidos, então, por indivíduos "normais", esses textos são bastante próximos daqueles que via de regra aparecem em casos forenses reais: são curtos, escritos para uma audiência limitada, não muito planejados. Quando da coleta dos textos, os informantes/autores foram solicitados a nos enviar textos que já tivessem produzido a priori, coletados aleatoriamente de seu perfil na rede social. As solicitações foram feitas a indivíduos com os quais me relaciono, tais como amigos, familiares, alunos.

As análises apresentadas nos capítulos 4, 5 e $6^{21}$ foram realizadas com textos extraídos de um corpus maior denominado Corpus Geral para Análise de Autoria (doravante, CGAA). Este conjunto conta atualmente com 542 textos $^{22}$, de 36 autores, homens e mulheres, com idades que variam entre 13 e 55 anos e nível de escolaridade que vai desde o nível fundamental até o superior. Também neste caso, os autores são todos "naïve writers". Cada autor no CGAA contribuiu com 10 a 25 textos $^{23}$. Com vários textos de um

\footnotetext{
${ }^{21}$ Existem particularidades sobre a coleta dos textos analisados no capítulo 6; elas são tratadas na seção de metodologia do próprio capítulo.

${ }^{22}$ Esta pesquisa fez uso de apenas alguns conjuntos de textos do CGAA. Entretanto, a ideia de compor uma amostra de textos escritos que pudesse servir de corpus de referência ou que pudesse ser utilizada futuramente em outros estudos - sobre autoria ou não - nos acompanhou desde o primeiro momento do desenvolvimento desta pesquisa. Pretende-se ampliar este corpus e mantê-lo constantamente em construção, além de disponibilizá-lo para outros pesquisadores. A maior parte dos textos coletados, incluindo aqueles aqui utilizados, foi enviada pelos informantes por e-mail, juntamente com uma Ficha do Informante (Apêndice C). No entanto, textos coletados mais na fase final foram obtidos por meio do formulário disponível $<$ https://docs.google.com/forms/d/1wyH_hevWolRcMXReqk9u22KOyebk7DofzdPZ4nwebkw/viewform?c=0\& $\mathrm{w}=1>$. Pretende-se utilizar tal formulário para a coleta de dados no futuro, substituindo a ficha do informante e facilitando o manuseio das informações, que podem ser "lidas" facilmente por computadores e importadas para um banco de dados.

${ }^{23}$ No início da coleta de dados, não se estipulou um número exato de textos a ser recebido por autor. Contudo, em um segundo momento, estabeleceu-se 25 textos como padrão. Tanto essse número quanto o número de textos utilizados em cada análise foi arbitrariamente escolhido, já que não existem parâmetros estabelecidos sobre qual seria o tamanho ideal de uma amostra para este tipo de estudos: "A Análise Forense de Autoria não conta com um número pré-estabelecido do que seria uma boa amostra de textos ou qual o tamanho dos textos examinados para se atribuir autoria" (TURELL, 2012, slide 22, tradução nossa).
} 
mesmo autor, garante-se uma amostra relativamente variada da sua produção linguística, podendo-se testar a consistência de seu estilo ao longo dos diferentes tipos de textos. Com diferentes autores, pode-se testar a semelhança e diferença dos estilos de diferentes indivíduos, atendendo ao que Grant e Baker (2001, p. 69) propõem ser a divisão fundamental de uma amostra em experimentos de atribuição de autoria ${ }^{24}$. O método de coleta dos textos foi similar ao descrito anteriormente: os informantes/autores foram solicitados a nos enviar textos que já tivessem produzido a priori e que tivessem guardado por qualquer motivo. A seleção deveria ser aleatória e poderia incluir qualquer tipo de texto de escrita espontânea, tais como posts e comentários da rede social Facebook, emails pessoais e profissionais, textos escritos em sites, comentário de sites, redações escolares, cartas, anotações de aula, bilhetes e mensagens de celular (SMS). Além de solicitar que amigos, familiares e alunos participassem, também foi solicitado que estes indicassem conhecidos seus, no método de abordagem de informantes chamado de “amigos de amigos” (MILROY, 1980). Informações sociolinguísticas dos autores também foram coletadas para possibilitar futuros estudos a partir do mesmo corpus $^{25}$.

Os materiais do CGAA são textos dos tipos que mais provavelmente seriam coletados como amostra para comparação com um texto de autoria questionada, em casos reais de atribuição de autoria em contextos forenses. Diante do momento atual de clara expansão da comunicação digital, a maior parte deles é proveniente de redes sociais e são, conforme já se mencionou aqui, bastante curtos. Chaski (2001) também realiza estudos com textos curtos "destinados a testar os limites mais baixos no que diz respeito ao tamanho e à quantidade de textos, já que os documentos da esfera forense [para atribuição de autoria] são geralmente curtos e disponíveis em pouca quantidade" (CHASKI, 2001, p. 4, tradução nossa ${ }^{26}$ ).

\footnotetext{
${ }^{24}$ Cf. Grant and Baker (2001, p. 69): "The most basic division [of samples] is that between sampling language within an individual and selecting samples for comparisons between individuals".

25 O modelo da "Ficha do Informante" pode ser visto no Apêndice C.

${ }^{26}$ Texto original: "intended to test the lower limits of text length and quantity because forensically significant documents are often short and cannot be amplified; indeed, even known documents are often short in length and limited in quantity" (CHASKI, 2001, p. 4).
} 
Turell (2012) ${ }^{27}$ divide o objeto de estudos da Linguística Forense em dois tipos:

a) "Dados Reais" ("Real World Data");

b) "Dados de Casos de Linguística Forense" ("Real Forensic Linguistics Case Data).

Os textos aqui analisados são do tipo "dados reais" ("Real World Data", na classificação proposta por Turell). Observe-se que os textos que fazem parte dos corpora não foram objeto de disputa judicial - e no caso dos textos do CGAA, nem de investigação criminal. Entretanto, isso não representa um problema, já que muitos dos métodos conhecidos nesta área foram testados em um outro tipo de corpus, antes de serem usados em contendas judicias; tal opção é até mesmo preferida por alguns autores (Cf. GRANT, 2004, p.22). Além disso, os casos reais de autoria questionada no Brasil que se conseguiram rastrear (como, por exemplo, os que se citam no capítulo 2) traziam apenas o texto questionado, sem o conjunto de textos dos suspeitos para comparação, imprescindível para esta análise, o que impossibilitou o uso de textos do tipo "b" acima. Ressalta-se novamente que os textos coletados para o CGAA são os textos que normalmente se conseguiriam numa busca por textos para comparar com um texto questionado ou "criminoso".

\section{Contribuições e relevância deste trabalho}

Além da contribuição de caráter mais prático que esta pesquisa deve trazer à Linguística Forense, buscando auxiliar na supressão das dificuldades elencadas na seção 2, ela também prevê contribuições para as áreas da Linguística que a embasam, por meio das questões que afloram a partir das análises realizadas. Por exemplo, lançar mão dos conhecimentos da Sociolinguística para resolver problemas forenses - neste caso, especificamente de autoria - pode apontar para novos direcionamentos da disciplina, para diferentes tipos de usos linguísticos que não são comumente estudados nesta área. De acordo com Butters (2007, p. 320), as abordagens variacionistas mais tradicionais

${ }^{27}$ Turell (2012). In: "Idiolectal similitude (or distance) in authorship analysis". Informação oral/Slides de aula. 12th International Summer School in Forensic Linguistic Analysis, Barcelona. 
frequentemente centram seus estudos em variáveis fonológicas, morfológicas ou sintáticas, mas quando se trata da análise na esfera forense, outros níveis da linguagem vêm à tona, como por exemplo a semântica, a pragmática ou o discurso. Assim, o autor ressalta que uma contribuição dos estudos de Linguística Forense para a Sociolinguística reside justamente na "ênfase em subcampos linguísticos que geralmente são menos frequentemente estudados no mainstream da pesquisa variacionista"28 (BUT'TERS, 2007, p. 320, tradução nossa). Numa perspectiva mais local, pode resultar desta pesquisa a ampliação do escopo de atuação da Sociolinguística brasileira, paralelamente ao que se observa no cenário internacional, uma vez que é do interesse de sociolinguistas aplicar os seus conhecimentos à Linguística Forense, como é o caso de Butters (2007) ${ }^{29}$, Schilling [20-- $]^{30}$ e o próprio Labov (LABOV, 1988 e LABOV; HARRIS, 1994) ${ }^{31}$. No que diz respeito à Semiótica, essa ampliação de escopo é igualmente desejável, já que não há, ao que parece, um trabalho acadêmico que aplique os conhecimentos da teoria à Linguística Forense.

Com relação à relevância deste trabalho, vale ressaltar que apesar da Linguística ter sido institucionalizada no Brasil nos anos 1960 (ALTMAN, 1998) e de ter havido um considerável aumento de pesquisas na área desde então, os estudos em Linguística Forense são ainda incipientes. Embora haja muitos trabalhos de estudiosos brasileiros que se ocupam da interface entre a Linguagem e o Direito, raros são aqueles que se ocupam da Linguística Forense stricto senso e este trabalho é, de fato, uma das primeiras pesquisas no âmbito desta subdisciplina no país. Além disso, a maior parte dos estudos linguísticos brasileiros, quando direcionados a uma aplicação direta na sociedade, estão voltados ao ensino e à aprendizagem de línguas, observando-se um hiato quanto a aplicações em

\footnotetext{
28 Texto original: "emphasis on linguistic subfields that generally are less frequently examined in the mainstream of variationist research" (BUTTERS, 2007, p.320).

${ }^{29}$ Conforme Butters (2007, p. 318), “A sociolinguística é uma subdisciplina que é especialmente importante para pesquisadores trabalhando no campo de linguística forense". Texto original: "Sociolinguistics is a sub-discipline that is especially important to scholars working in the general field of linguistics and law".

${ }^{30}$ Cf. página pessoal da autora. Disponível em

<http://explore.georgetown.edu/people/ns3/?PageTemplateID=129>. Acesso em 12/09/2011.

${ }^{31}$ Um exemplo de caso em que William Labov trabalhou é o caso Prinzivalli, que tratou de identificação da origem geográfica do falante por meio da fala.. Labov testemunhou no tribunal sobre a origem de um suspeito, comparando as gravações da fala desse suspeito com as de telefonemas dados por um terrorista.
} 
outros campos. Dessa forma, esta pesquisa contribui para a expansão dos estudos linguístico-forenses no Brasil.

Aplicar a linguística a questões diretamente relacionadas a resolver problemas da vida social vai ao encontro de um anseio que vem sendo expresso por alguns linguistas nos últimos anos. Segundo Labov e Harris (1994, p. 265, tradução nossa) "Em muitos dos encontros recentes de sociedades linguísticas, expressou-se o sentimento de que os linguistas deveriam ser capazes de aplicar o seu conhecimento fora da universidade e da sala de aula $[\ldots]^{\prime \prime 32}$.

\section{$5 \quad$ Estrutura da tese}

Esta tese está organizada em 6 capítulos. O primeiro expõe a questão da autoria textual na esfera forense e expõe os principais tipos de problemas e tarefas relacionados à análise de autoria nesse domínio. Traz ainda um panorama dos principais estudos já realizados e dos casos existentes, traçando um breve percurso histórico e ressaltando as diferenças e convergências entre a chamada Estilometria e a Estilística Forense, os estudos qualitativos e quantitativos. Introduz também a questão da validade e confiabilidade dos marcadores de autoria e trata brevemente do papel do processamento de linguagem, da consciência metalinguística e das tentativas de disfarce na produção de textos. Por fim, discorre sobre os aspectos jurídicos do texto enquanto prova em processos criminais e judiciais.

O segundo capítulo dedica-se à ideia de estilo, fundamental para análises de autoria. Ele trata da relação entre idioleto e estilo, num primeiro momento, e em seguida parte para a exposição de diferentes facetas da ideia de estilo empregadas neste trabalho: estilo como distinção, cosseleção e recorrência; estilo como variação intrafalante; estilo como identidade (individual ou de grupo); e estilo na Semiótica Discursiva. A observação dessas noções de estilo evidencia dificuldades para uma análise forense de autoria textual que

\footnotetext{
32 Texto original: "In many recent meetings of linguistic societies, the feeling has been expressed that linguists should be able to apply their knowledge outside of the university and the classroom [...]"(LABOV; HARRIS, 1994, p.265).
} 
seja adequada. Então, o capítulo retoma essas dificuldades (rapidamente expostas no item 2 desta Introdução) e sugere meios para superá-las.

O capítulo 3 apresenta análises relacionadas ao que se pode chamar de estilo de grupo, importantes para a elaboração de perfis sociolinguísticos. O primeiro exercício funda-se em uma categoria sócio-demográfica (sexo/gênero) e seus índices em textos provenientes da rede social Facebook. O segundo estuda textos coletados pela polícia do Rio de Janeiro durante a investigação do episódio que ficou conhecido como "Massacre de Realengo" e propõe a noção de "universo discursivo" (útil em certos casos de identificação de autoria) enquanto tipo de "grupo social", em complementação às noções correntes de comunidades de práticas ou comunidades de fala.

Nos capítulos 4, 5 e 6, desenvolvem-se análises que enfocam especificamente o estilo individual. O capítulo 4 traz um estudo qualitativo que procura mostrar de que modo se pode realizar uma análise do plano do conteúdo para fins de atribuição de autoria. No capítulo 5, realiza-se uma análise quantitativa: trata-se de um estudo que objetivou verificar, por meio da análise de textos de 4 indivíduos de um mesmo perfil sociolinguístico, se as características do plano do conteúdo, que foram medidas estatisticamente, são realmente profícuas para distinguir autores. Os resultados sugerem que a análise semiótica empreendida pode indicar a distância ou a proximidade entre os autores.

O sexto e último capítulo é complemenar aos que o antecedem, já que continua tratando da atribuição de autoria e busca depreender estilos individuais. No entanto, enquanto os capítulos 4 e 5 trazem análises que intencionam mostrar se as características do plano do conteúdo poderiam distinguir autores, este último discute os resultados de uma análise feita “às cegas", com a intenção de simular um caso real de atribuição de autoria. 


\section{Análise de Autoria Textual no CONTEXTO Forense}

In February 2008, linguistic evidence contributed to the conviction of David Hodgson in the murder of Jenny Nicholls [...]. Forensic linguists showed that text messages sent from Jenny's phone after she went missing had a style that was more similar to that of David Hodgson [...].

(BBC News, 2008)1

MITCHEL (2008). "The case for forensic linguistics". BBC News. Disponível em <http://news.bbc.co.uk/2/hi/science/nature/7600769.stm>. Acesso em 08/02/2014. 


\subsection{Considerações gerais}

Pesquisadores de diversas áreas, tais como estudiosos de textos sagrados, históricos e literários, têm se dedicado a estudar maneiras de confirmar a autoria de um texto. Mais recentemente, surgiu o interesse nessa tarefa com o intuito de ajudar a resolver crimes ou contendas judiciais, já que no curso de uma investigação criminal ou do julgamento de um processo judicial, pode ser necessário responder: "Quem escreveu este(s) texto(s)?”. Responder a essa pergunta requer uma análise que identifique ou exclua um suspeito como autor e, algumas vezes, determinar quem pode ou quem não pode ser o autor de um escrito é crucial para o deslinde de um caso, a exemplo daquele citado na primeira epígrafe deste capítulo.

A análise linguística pode ajudar a determinar a autoria de textos como cartas de suicídio, cartas e mensagens anônimas (por exemplo, em caso de sequestros, chantagens, ameaças, mensagens via celular, etc.), websites com conteúdo ilegal, e-mails anônimos com conteúdo ofensivo, entre outros ${ }^{2}$.

Os casos que podem ser submetidos a análise de autoria na esfera forense dividem-se grosso modo em duas grandes categorias, segundo Butters (2007, p.329):

a) Casos de plágio, ou seja, quando alguém se apropria parcial ou integralmente das palavras de outrem. Isto é, quando alguém tenta passar como suas as palavras de outra pessoa.

b) Casos em que textos sejam anônimos, assinados por pseudônimos, ou com autoria questionada ou erroneamente atribuída ${ }^{3}$.

Este trabalho se ocupa dos casos que se enquadram na segunda categoria e uma das razões para isso (em vez de trabalhar com plágio) está no fato de que aí podem figurar

\footnotetext{
2 Diante de textos divulgados pela Internet, pode surgir a seguinte questão: "Uma análise no âmbito da computação (redes) não seria capaz de rastrear o computador fonte de tais textos?”. A resposta é sim, mas esse é o limite de tal análise, pois, como afirma Juola (2006, p.2) "Uma investigação da rede de computadores vai no máximo revelar o computador específico em que o documento foi produzido. É quase impossível descobrir quem estava ao teclado, quem o escreveu" ("A network investigation will at best only reveal the specific computer on which the document was written. It is almost impossible to figure out who was at the keyboard — who wrote it").

${ }^{3}$ Cf. Butters (2007, p.329): “anonymous, pseudonymous, and falsely attributed documents and messages”.
} 
textos mais relacionados ao cotidiano e que não tenham sido especialmente elaborados, trabalhados, como são, por exemplo, os textos literários. Tal escolha vai ao encontro dos interesses da Sociolinguística, um dos campos que norteiam esta investigação, que se preocupa em estudar a linguagem cotidiana em seu contexto social (LILLIS, 2013).

Duas tarefas diferentes, mas complementares, podem ser realizadas para responder a pergunta “Quem escreveu este texto?". E elas estão relacionadas à existência ou não de outros textos para comparação.

Se há textos para comparar, a tarefa é chamada de "atribuição de autoria" e consiste em analisar o texto cuja autoria esteja sendo questionada, comparando-o com uma amostra de textos dos autores-suspeitos. A esse respeito, Coulthard e Johnson (2007, p. 162, tradução nossa) afirmam:

A tarefa do detetive linguístico nunca é identificar o autor dentre milhões de candidatos com base apenas nos elementos linguísticos, mas sim selecionar (e, claro, desselecionar) um número pequeno de candidatos a autores ${ }^{4}$.

Nesses casos, a pergunta acima pode ser mais especificamente elaborada como "O autor do texto anônimo [ou questionado] é a mesma pessoa que escreveu este outro texto [ou textos] cuja autoria é conhecida?”5 (GRANT, 2004, p. 13). McMenamin (2002, p.181205) apresenta um caso que serve de exemplo: uma garota de seis anos de idade, Jon Benét Ramsey, desapareceu, e algum tempo depois foi descoberta morta no porão de sua casa, após terem encontrado uma carta anônima de resgate dentro da residência. Os pais da garota foram considerados suspeitos, e McMenamin ficou encarregado de analisar o bilhete de resgate, comparando-o com outros textos do casal (bilhetes pessoais, cartas, etc.). Sua análise indicou que não era provável que nenhum dos dois suspeitos tivesse escrito o bilhete. Mesmo que a identificação do autor não tenha sido possível, ao menos indicou-se quem não poderia ter escrito o texto.

\footnotetext{
4 Texto original: "Thus, the task of the linguistics detective is never one of identifying an author from millions of candidates on the basis of the linguistic evidence alone, but rather of selecting (and, of course, deselecting) from a very small number of candidate authors" (COULTHARD; JOHNSON, 2007, p. 162).

5 Texto original: "The author of the anonymous text is the same person as this other text of known authorship" (GRANT, 2004, p. 13)
} 
Pode-se, ainda, subdividir a atribuição de autoria em três tipos de problemas (Cf. McMENAMIN, 2002, p.42):

a) precisa-se saber se todos os textos de um conjunto cuja autoria é questionada foram escritos pelo mesmo autor;

b) pretende-se verificar se um texto cuja autoria é questionada foi ou não escrito por um dos indivíduos de um conjunto de autores possíveis;

c) pretende-se saber se um texto cuja autoria questionada foi ou não escrito por um determinado autor, indicado como suspeito com base em evidências não linguísticas.

A segunda tarefa em análises de autoria é caracterizada como de natureza sociolinguística (GRANT, 2004, p. 13), já que consiste na elaboração de um perfil sociolinguístico de um autor ${ }^{6}$, uma vez que certos usos linguísticos podem ser indicativos de determinados grupos sociais. Pode ser possível dizer, por exemplo, que “o autor de um texto faz parte de um determinado grupo profissional, tem um certo nível de escolaridade e talvez seja de um certo quadro social”' (GRANT, 2004, p. 13, tradução nossa)7. Essa é a técnica utilizada em casos em que não é possível fazer uma análise comparativa, seja porque não há textos para comparar com o texto cuja autoria é questionada, seja porque a lista de suspeitos é muito extensa. Se por algum motivo não se pode realizar uma análise que avente hipóteses acerca de quem seja o autor de um texto, pode-se, pelo menos, levantar possibilidades a propósito do grupo social ao qual o autor pertence, reduzindo o número de suspeitos. Um caso que se destaca na literatura sobre Linguística Forense é o do bilhete de resgate que continha a expressão "devil strip", em que trabalhou o linguista Roger Shuy (SHUY, 2001 e 2005; LEONARD, 2005). Segue a transcrição do bilhete (grifo nosso):

\footnotetext{
${ }^{6}$ Em inglês, usam-se os termos "author profiling" (Cf. KREDENS, 2012; CORNEY, 2003) ou "authorship characterization" (Cf. CORNEY, 2003, p. 15), ou "sociolinguistic profiling” (GRANT, 2008, 2004).

${ }^{7}$ Texto original: "[...]the writer of this text is from a certain professional group, educated to a certain level, and perhaps from a certain social background. In this case, a socio-linguistic profile might be able to establish authorship" (GRANT, 2004, p.13).
} 
Do you ever want to see your precious little girl again? Put $\$ 10,000$ cash in a diaper bag. Put it in the green trash kan on the devil strip at corner 18th and Carlson. Don't bring anybody along/ No kops!! Come alone! I'll be watching you all the time. Anyone with you,deal is off and dautter is dead!!!

Segundo Leonard (2005), devil strip é o "caminho" de grama existente entre a calçada e a rua, mas essa palavra é usada apenas na cidade de Akron, no estado de Ohio, EUA. Sabendo disso, Shuy questionou a polícia sobre a existência de um suspeito que fosse dessa cidade e, de fato, havia um indivíduo de Akron na lista. A evidência linguística ajudou a polícia para que se concentrasse na investigação desse suspeito.

A Figura 4 ilustra os tipos de análise de autoria8:

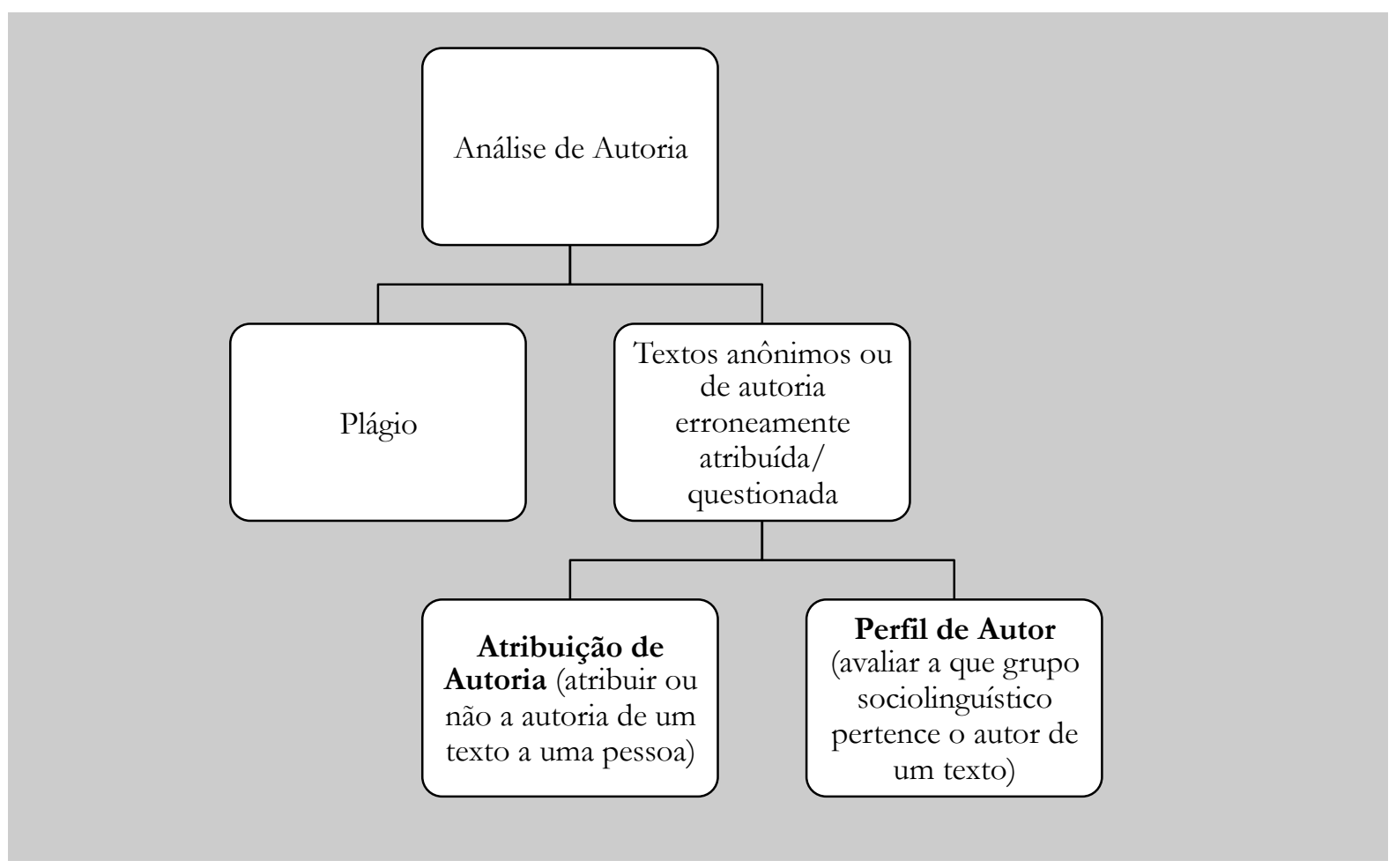

Figura 4 - Tipos de análises de autoria

Vale ressaltar que ainda que existam diferenças entre esses dois tipos de análise de autoria e eles apareçam frequentemente separados na literatura sobre o tema, há vezes em que eles se sobrepõem, já que há situações em que o perfil sociolinguístico de um autor serve como parte do material de cotejo em casos de atribuição. Pode-se partir de uma

\footnotetext{
${ }^{8}$ Kredens (2012)."Introduction to forensic authorship analysis". Slides de aula. 12th International Summer School in Forensic Linguistic Analysis, Barcelona; Gibbons (2011, p. 244); Butters (2007, p.329).
} 
grande quantidade de suspeitos, passar pela depreensão de um perfil e ao final, já com um menor número de suspeitos, empreender a tarefa de identificação de autor. A Figura 5, a seguir, mostra a relação entre essas duas tarefas (baseado em CORNEY, 2003, p.5):
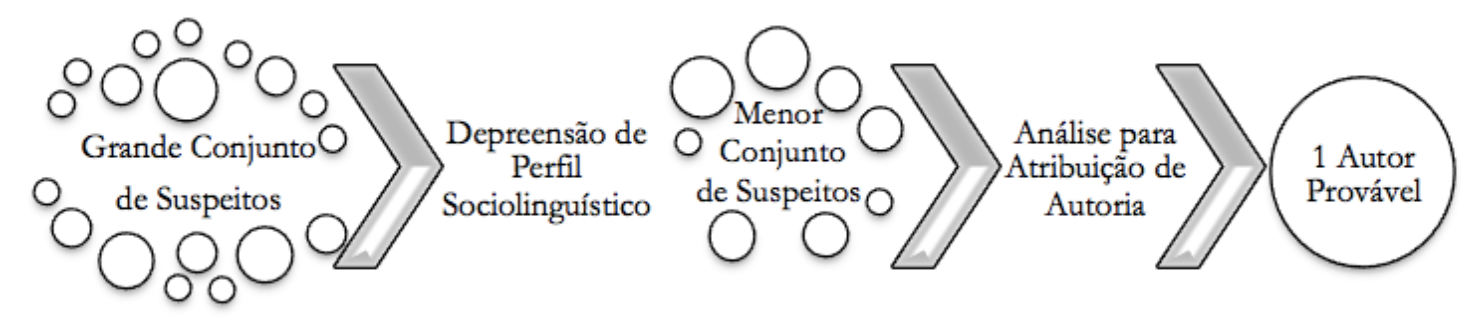

Figura 5 - De um grande conjunto de suspeitos a um único autor provável

Ainda sobre a possibilidade de depreensão de perfis sociolinguísticos e de como eles são importantes para as análises de autoria - afirmam Coulthard, Grant e Kredens (2010, p. 526, tradução nossa):

[...] descobertas sociolinguísticas sobre como certas formas linguísticas associam-se a certas variáveis sociais podem ser de grande ajuda no trabalho em Linguística Forense, simplesmente porque, ao abordar problemas de autoria, o linguista precisa garantir que elementos potencialmente reveladores são individuais, ou seja, idioletais e não dialetais, socioletais ou resultantes da diferença de gêneros, etc. Ademais, um padrão linguístico recorrente nos textos sob investigação pode ser relativo ao gênero textual ou resultado de acomodação. De modo simples, a Sociolinguística pode ajudar a revelar as fontes de variação?.

Muito se fala da análise grafotécnica como instrumento para determinar a autoria textual no âmbito forense. No entanto, uma vez que atualmente grande parte dos textos que circulam não são manuscritos, esse tipo de análise não é sempre possível. Juola (2006, p. 2, tradução nossa) afirma: “Com o advento da tecnologia moderna da computação, uma quantidade substancial de 'escritos' hoje em dia nunca envolve caneta, tinta ou

\footnotetext{
9 Texto original: “[...] sociolinguistic findings about how particular linguistic forms are associated with certain social variables can be of great help in forensic linguistic casework, simply because, in addressing authorship issues, the linguist needs to ensure that potentially telling features are individual, i.e. idiolectal, and not dialectal, sociolectal, genderlectal, etc. A linguistic pattern found to recur regularly in the texts under investigation may also be genrespecific or the result of accommodation effects. Put simply, sociolinguistics can help reveal the sources of variation" (COULTHARD; GRANT; KREDENS, 2010, p. 526).
} 
papel"10 e "a análise grafotécnica pode olhar para a letra (...) e determinar autoria com uma sofisticação que beira um milagre, olhando, por exemplo, para o ponto de um 'i' ou o corte de um 't'. Documentos eletrônicos não contêm essas pistas"'11 (JUOLA, 2006, p. 1, tradução nossa). Em outras palavras, muitas vezes não há vestígios físicos de autoria para serem examinados. Entra em cena, então, uma análise que busque variantes textuais/discursivas que possam vir a distinguir autores.

Encontram-se abordagens diferentes para o problema de identificação de autoria e, segundo Grant (2004), isso parece refletir diferentes ideias sobre a natureza da linguagem e sobre a Linguística. Vários dos trabalhos existentes apoiam-se em métodos quantitativos computacionais, no paradigma conhecido como Estilometria, tendo como base, por exemplo, a frequência lexical de palavras ou expressões, o comprimento das sentenças e o comprimento de palavras. São exemplos desses trabalhos Winter e Woolls (1996), Tambouratzis et al. (2004) e Baayen et al. (2002). Chaski (1997, 2001, 2004), por sua vez, concentra-se na análise sintática e no uso da pontuação como medida de diferenciação entre autores. Outras pesquisas, numa vertente considerada mais qualitativa, apoiam-se, principalmente, na observação da variação linguística. Exemplos seriam a Estilística Forense (McMENAMIN, 2002), a noção de “estilo idioletal” (TURELL, 2010, 2012), e os estudos de Olsson (2004). Há ainda trabalhos mais voltados para uma análise de vocabulário (WOOLLS; COULTHARD, 1998; COULTHARD, 2004b) e a chamada "Forensic discourse analysis" - análise forense do discurso - Coulthard (1992, 1993, 200112 apud COULTHARD, 2006). Esses trabalhos serão descritos mais detalhadamente na seção 1.2 .

10 Texto original: "With the advent of modern computer technology, a substantial amount of "writing" today never involves pen, ink, or paper” (JUOLA, 2006, p. 2).

11 Texto original: "Document examiners can look at handwriting (or typewriting) and determine authorship with near miraculous sophistication from the dot of an ' $i$ ' or the cross of a ' $t$ '. Electronic documents do not contain these clues"' (JUOLA, 2006, p.1).

12

- COUlThARD, M. Forensic discourse analysis. In: COULTHARD, M (ed.). Advances in spoken Discourse Analysis. London: Routledge, 1992.

- COULTHARD, M. Beginning the study of forensic texts: corpus, concordance, collocation. In: HOEY, M.P. (ed.). Data description discourse. London: HarperCollins, 1993.

- COULTHARD, M. Forensic linguistics. In: The Linguistics Encyclopedia, $2^{\text {nd }}$ edition, S.l.: Routledge, 2001. 


\title{
1.2 Panorama: principais estudos e casos
}

A Introdução mostrou que são muitas as tarefas de que se pode ocupar um linguista inserido em um trabalho forense. Dentre elas, a análise de autoria destaca-se como aquela que inaugurou a própria disciplina Linguística Forense, com o caso de Timothy Evans, em que Svartvik (1968) conduziu um estudo dos seus depoimentos policiais ${ }^{13}$. Olsson (2008, p. 20, tradução nossa, grifo do autor) resume o caso, como segue:

\begin{abstract}
John Christie assassinara uma série de mulheres na sua casa, em Londres, e havia enganado Evans para que pensasse que ele próprio havia sido parcialmente responsável pela morte de sua própria mulher e filho, o que havia na verdade sido obra de Christie. Evans viajara para a casa de seu tio, em Merthyr Tydfil, ao sul do País de Gales, mas depois de um curto tempo ele retornou e se entregou à polícia alegando ser o responsável pela morte de sua família. Dois depoimentos foram dados em Merthyr Tydfil e dois na delegacia de Notting Hill, Londres, onde Evans foi levado no dia seguinte à sua prisão. Em sua análise, Svartvik demonstrou a presença de dois registros muito diferentes nos depoimentos. Embora esse caso não tenha sido um estudo de autoria como se vê atualmente, sua importância está na técnica pioneira de Svartvik que analisou as alterações textuais realizadas nos depoimentos, e o nome que ele deu para a nova ciência: linguística forense ${ }^{14}$.
\end{abstract}

Como já se mencionou, a tarefa de identificar o autor de um texto pode surgir em outros contextos, além do judicial. Estudos de textos literários, históricos ou religiosos estão entre aqueles que enfocam essa questão. Além desses campos, há situações mais cotidianas que poderiam suscitar a pergunta "Quem escreveu este texto?", como, por exemplo, conforme indica Grant (2004, p. 17), em assuntos políticos atuais ou na área de Educação. Disso decorre que há muitos trabalhos publicados sobre o tema, derivados tanto da pesquisa de estudiosos da linguagem quanto de outros, ligados à computação;

\footnotetext{
${ }^{13} \mathrm{O}$ estudo de Svartvik só foi realizado aproximadamente 15 anos depois do enforcamento de Evans.

14 Texto original: "John Christie had murdered a succession of women at his home in 10 Rillington Place, west London, and had duped Evans into believing he, Evans, was partly responsible for the death of his own wife and child which had actually taken place at Christie's hands. Evans had gone to his uncle's home in Merthyr Tydfil, south Wales,but after a short period he had handed himself into the police and confessed to having killed his wife. Two statements were given at Merthyr Tydfil and two at Notting Hill police station, London, where Evans was taken on the day following his arrest. In his analysis Svartvik demonstrated the presence of two very different registers in the Evans' statements. However, this case was not an authorship study as such: its importance lies in Svartvik's pioneering technique in analysing textual alteration, and his name for the new science, forensic linguistics" (OLSSON, 2008 , p. 20, grifo do autor).
} 
apesar de tal abundância, este panorama põe em foco os estudos mais importantes ou que possam ser aplicados especificamente no contexto forense.

\subsubsection{Estilometria versus Estilística. Estudos quantitativos ou qualitativos?}

A seção anterior informou que as análises de autoria podem ser, basicamente, quantitativas ou qualitativas. Grant (2013, p. 470) também propõe uma categorização das análises separando-as em duas grandes vertentes: a Estilometria e a Estilística. A primeira procura descobrir marcadores quantificáveis de autoria, medindo-os para verificar as similaridades e diferenças entre autores diferentes (HOLMES, 1998; GRANT, 2004) ${ }^{15}$; aqui, parte-se da premissa de que os marcadores de autoria variam mais entre autores do que em um mesmo autor ${ }^{16}$. A segunda engloba todas as outras análises em que a quantificação de características não seja o ponto principal.

Outra diferença relevante entre essas duas vertentes é que os estudos estilométricos geralmente tentam encontrar apenas um ou outro marcador linguístico que seja capaz de distinguir autores, independentemente do caso, como um universal; já as abordagens estilísticas advogam que cada pessoa apresenta um conjunto de características linguísticas que a identifica e que este conjunto pode variar entre indivíduos.

Adotar uma ou outra abordagem também pode depender do tipo de texto que se quer analisar. A Estilometria é bem sucedida em casos em que haja textos mais extensos, com milhares de palavras (GRANT, 2013). Já quando a análise encontra textos curtos ou fragmentários (o que é mais comum ocorrer no contexto forense), os analistas têm empregado a Estilística Forense e não a estilometria. Coulthard e Johnson (2007) afirmam que não é raro que um especialista utilize mais de uma abordagem. Para Grant (2008, p.216), "não existe uma técnica única que resolva todos os casos de atribuição de autoria".

\footnotetext{
${ }^{15}$ Chaski (2013, p. 50) inclui uma terceira categoria, que chama de "forensic computational linguistics" (linguística forense computacional). Aqui, ao lado da maior parte dos trabalhos existentes, a linguística computacional está inserida no paradigma estilométrico.

${ }^{16}$ Isto é, a variação interfalante - ou interautor - é maior do que a variação intrafalante- ou intra-autor (TURELL, 2010; GRANT, 2012).
} 
Este trabalho alinha-se à vertente estilística no que diz respeito ao pressuposto de que o estilo de um autor é dado por uma combinação de elementos que pode variar a cada indivíduo; também se alinha a essa vertente na medida em que tem por objeto textos curtos e fragmentários, com os quais os estudos estilométricos tradicionais não obtêm êxito. Por outro lado, alinha-se aos estudos estilométricos, uma vez que pretende realizar uma medição (quantitativa) de categorias do plano do conteúdo. Este caráter híbrido é desejável, já que metodologias quantitativas e qualitativas são frequentemente utilizadas em conjunto, pois enquanto uma análise qualitativa identifica e descreve elementos característicos de um autor, uma análise quantitativa separa e computa de alguma forma esses elementos. Estilometria e Estilística Forense podem ser consideradas divisões paradigmáticas, ao passo que a categorização em análises qualitativas ou quantitativas se dá mais por um viés metodológico.

Muitas das análises mais recentes combinam essas duas abordagens. Segundo Gibbons (2011, p. 249), “as variáveis selecionadas para análises quantitativo-estatísticas ou computacionais são normalmente provenientes de conhecimento qualitativo por parte do especialista [...]"17. Grieve (2005, p. 3) afirma demonstrar que, mesmo em análises quantitativas de autoria (portanto, mais alinhadas à estilometria), as melhores abordagens são aquelas que levam em conta combinações de diferentes medidas textuais ${ }^{18}$. Dessa forma, melhor do que ver essas duas abordagens como diferentes métodos de análise é considerá-las como passos da análise, já que a análise qualitativa é geralmente necessária para identificar as similaridades e diferenças entre os textos, mas pode não ter caráter probatório - daí entra a parte quantitativa da análise (GIBBONS, 2011, pp. 249-250). Turell (2010) e McMenamin (2002) também reconhecem que esses dois tipos de análise são complementares.

De acordo com McMenamin (2002), os resultados qualitativos são mais fáceis de demonstrar em julgamentos. Segundo ele, essas evidências apelam para o senso de

\footnotetext{
17 Texto original: "The variables selected for quantitative statistical or machine analysis are usually derived from the qualitative knowledge and understanding of the expert [...]” (GIBBONS, 2011, p. 249).

${ }^{18}$ Segundo o autor, essa é "uma conclusão que desafia a maior parte dos estudos quantitativos de atribuição de autoria, que analisam somente um tipo de medida textual" (GRIEVE, 2005, p. 3, tradução nossa). Texto original: "a conclusion that challenges most quantitative authorship attribution studies, which only analyze the values of one type of textual measurement".
} 
probabilidade não matemático das pessoas. Outro motivo para a apresentação de análises qualitativas tem relação com o fato de que a quantidade de textos para analisar é normalmente pequena nos contextos forenses, muitas vezes impossibilitando o fornecimento de evidências quantitativas. Segundo Olsson (2008), grande parte dos trabalhos em Linguística Forense é de observação e análise em oposição a medidas de probabilidade.

No entanto, junto ao aumento do interesse na análise de autoria no âmbito forense, surge uma dúvida sobre quão "científica" ela pode ser. De acordo com Grant (2007), o "científico" nas discussões em torno da questão geralmente está ligado à quantificação ou ao tratamento estatístico dos dados, principalmente nos Estados Unidos, onde há regras, conhecidas como "the Daubert criteria", que regulam a apresentação de evidências técnicas ou científicas em um tribunal ${ }^{19}$. Desses critérios, o que estabelece ser necessária uma quantificação do erro conhecido ou potencial de um certo método é o que está relacionado mais diretamente a uma quantificação dos dados. Diferentemente do que se observa nos Estados Unidos, no Reino Unido confia-se mais na expertise do perito do que no método em si (COULTHARD, 2012).

Para McMenamin (2002), apesar das limitações relacionadas às análises quantitativas de autoria, elas são muito relevantes, na medida em que métodos quantitativos podem tornar os testes de hipóteses mais confiáveis e mais fáceis de se fazer, atendendo aos requisitos externos por evidências científicas.

Uma precaução em afirmar qual das duas vertentes é a mais adequada figura em Solan (2013, p. 573, tradução nossa), como segue:

Como se percebe, parece haver uma divisão metodológica e cultural entre análises [de autoria] computacionais e estilísticas, sendo que a vertente computacional aborda os problemas de atribuição de autoria de modo mais consistente com o que se espera dos testemunhos de especialistas do que a

\footnotetext{
19 De acordo com "the Daubert Criteria", os critérios a que evidências apresentadas pelos peritos devem atender são: a) A teoria foi testada? b) O método ou a teoria foi avaliada por outras pessoas da área (peer reviewed)? c) Há uma taxa de erro conhecida? d) O método é geralmente aceito? (GRANT, 2007; SOLAN; TIERSMA, 2005).
} 
vertente estilística. Contudo, não há evidência de que uma delas seja melhor do que outra ${ }^{20}$.

A partir dessa exposição, parece sensato considerar que esses dois grandes blocos de análises apresentam vantagens e desvantagens e que podem algumas vezes ser utilizados complementarmente.

\title{
1.2.2 Breve percurso histórico: atribuição de autoria
}

Estudos que se enquadrem no paradigma conhecido por Estilometria são antigos e têm sido bastante frequentes. Segundo Baayen et al. (2002):

\begin{abstract}
As tentativas estilométricas de rastrear a autoria de textos de autores desconhecidos ou contestados vêm de longa data. Elas têm sido aplicadas a textos importantes, tais como a Bíblia, as obras de Shakespeare os Federalist Papers. Uma grande variedade de técnicas oriundas de diversas disciplinas têm sido consideradas, desde análises estatísticas multivariadas até redes neurais e aprendizado de máquinas. Muitos aspectos textuais diferentes têm sido analisados, desde o comprimento das palavras ou sentenças até as palavras ou características linguísticas mais comuns ou mais raras (BAAYEN et al, 2002, tradução nossa) ${ }^{21}$.
\end{abstract}

A Estilometria não seria um método propriamente dito, mas um paradigma que abriga diversos trabalhos de identificação de autoria (não apenas em contextos forenses) que têm em comum a análise estatística, com a quantificação de características linguísticas, frequentemente com auxílio computacional (GRANT, 2004).

Uma das primeiras tentativas ${ }^{22}$ de atribuição de autoria de que se tem notícia é a de Edmond Malone (178723 apud Grieve, 2005). Malone se valeu do metro e da rima como

\footnotetext{
${ }^{20}$ Texto original: "As noted, there seems to be a methodological, and for that matter, cultural division between computational and stylistic analysts, with the former approaching authorship attribution problems in a manner more consistent with conventional views of expert testimony than the latter but with no evidence that either approach does a better job” (SOLAN, 2013, p.573).

21 Texto original: "Stylometric attempts to trace the authorship of texts by unknown or contested authors have a long history. They have been applied to influential texts such as the Bible, the works of Shakespeare, and the Federalist Papers. A wide variety of techniques from many disciplines have been considered, from multivariate statistical analysis to neural networks and machine learning. Many different facets of texts have been analysed, from sentence and word length to the most common or the rarest words, or linguistic features" (Baayen et al, 2002).

22 Ao que parece, esta foi a primeira tentativa de um estudo a respeito de autoria questionada. Porém, segundo Olsson (2008, p. 17), a controvérsia mais antiga relacionada a autoria data de 1711, quando um padre alemão (H. B.
} 
marcadores de autoria ao estudar peças shakespearianas. Sua conclusão foi a de que Shakespeare não escreveu Henry VI.

Quanto a atributos de textos em prosa, o primeiro estudioso a propor um marcador de autoria foi Augustus de Morgan, em 185124. Ele sugeria que o tamanho das palavras usadas por diferentes autores seria um marcador passível de comprovar se algumas cartas imputadas a São Paulo haviam realmente sido escritas por apenas uma pessoa (HOLMES, 1998; COULTHARD; JOHNSON, 2007; GRIEVE, 2005). Em 1887, Mendenhall25 testou tal suposição no problema da autoria das epístolas paulinas (GRANT, 2004, p. 20; COULTHARD; JOHNSON, 2007, p. 164), contando manualmente o tamanho das palavras nas cartas e comparando essa medida com aquela de mais de trezentas mil palavras provenientes de escritos bíblicos, de trabalhos de Bacon, Marlowe e Shakespeare. Seu trabalho sugeriu que havia semelhança entre as epístolas verificadas e os escritos de Marlowe e Shakespeare ${ }^{26}$. A principal característica do método de Mendenhall, isto é, isolar uma propriedade linguística como marcador de autoria, é bastante reiterada em estudos estilométricos. Diz-se que esse trabalho deu início ao que se conhece hoje por Estilometria. Em 1888, Smith também investigou as cartas de São Paulo, concentrando-se no tamanho das sentenças, na frequência dos sinais de pontuação e, ainda, na frequência lexical, valendo-se da frequência das palavras funcionais (GRIEVE, 2005, p. 32).

Nas décadas que seguiram o trabalho de Mendehall e Smith, pouco foi feito em estilometria até 1932, quando Zipf publicou seu trabalho sobre a frequência lexical nos textos, o que ficou conhecido como "Zipf's Law” (Lei de Zipf) (ZIPF, 1932, 1935, 1949). De acordo com Grant (2004), essas medidas de frequência lexical encorajaram a pesquisa

Witter) especulou que nomes diferentes para divindades que apareciam no Pentateuco poderiam indicar que vários autores o compuseram.

${ }^{23}$ MALONE, E. A dissertation on parts one, two and three of Henry the Sixth tending to show that those plays were not written originally by Shakespeare, [S.l.: s.n.], 1787.

${ }^{24}$ DE MORGAN, A. Letter to Rev. Heald 18/08/1851. In: DE MORGAN, S. E. (Ed.). Memoir of Augustus de Morgan by his wife Sophia Elizabeth de Morgan with selections from his letters. London: Longman's Green and Co, 1882.

${ }^{25}$ MENDENHALL, T. C. The characteristic curves of composition. Science, 11, p. 237-249, 1887.

${ }^{26}$ Mendenhall expandiu a técnica original de de Morgan. Enquanto este trabalhava com as médias dos tamanhos das palavras, aquele passou a considerar a distribuição de frequência de palavras de variados tamanhos (em inglês, wordlength frequency distributions). Mendenhall também conduziu experimentos com outro corpora (Cf. GRIEVE, 2005, p. 9$10)$. 
de vários outros métodos e medidas estilométricas ao longo dos anos 1940, 1950 e 1960, o que culminou no exame da autoria dos Federalist Papers, conduzido por Mosteller e Wallace, em 196327. The Federalist Papers são tratados políticos publicados em 1787 e 1788 nos Estados Unidos, durante o que ficou conhecido como o "constitutional referendum" do estado de Nova Iorque (85 textos publicados anonimamente). Atualmente, sabe-se que são três os seus autores: Alexander Hamilton, John Jay e James Madison. Entretanto, há 12 desses textos cuja autoria foi questionada: a dúvida era se ou autor teria sido Madison ou Hamilton. Mosteller e Wallace conduziram uma investigação linguística que procurou diferenças idioletais em textos conhecidos desses dois autores, comparando-as com os 12 textos questionados. Seu estudo concluiu que todos os 12 textos pertenciam a Madison, o que encontrou respaldo em outras pesquisas feitas por historiadores (COULTHARD; JOHNSON, 2007; GRANT, 2004).

Os anos 1980 assistiram a uma virada nos estudos estilométricos, representada principalmente pelos trabalhos de John Burrows e, já nos anos 1990, Holmes (GRANT, 2004). Esses trabalhos passaram a fazer uso de corpora sintaticamente anotados e de análises estatísticas e computacionais diferentes das realizadas até o momento, tais como as cadeias de Markov, a Análise de Componentes Principais, e abordagens relacionadas ao aprendizado de máquinas (CORNEY, 2003).

A década de 1990 foi praticamente dominada pelas discussões acerca do método CUSUM (Cumulative Sum), de Andrew Morton 28 (1990, 1991, 1992, 1995 apud GRANT, 2004; COULTHARD; JOHNSON, 2007). Uma síntese do método, sobre o qual houve muitas controvérsias, é apresentada por Coulthard e Johnson (2007, p. 167). Essencialmente, o CUSUM levava em conta não o texto, mas a sentença como unidade

${ }^{27}$ MOSTELLER, F.; WALLACE, D. L. Inference in an authorship problem. Journal of the American Statistical Association, 58, p. 275-309, 1963.

28

- MORTON, A. Q. ; MICHAELSON, S. The Qsum plot. Edinburgh: Department of Computer Science, University of Edinburgh, 1990.

- MORTON, A. Q. Proper words in proper places. Glasgow: Department of Computer Science, University of Glasgow, 1991.

- MORTON, A. Q.; FARRINGDON, M. G. Identifying utterance. Expert Evidence, v. 1, n. 3, p. 93 -99, 1992.

- MORTON, A. Q. Response [to Sanford et al (1994)]. Forensic Linguistics: the international journal of speech language and the Law, v. 2, n. 2, 1995. 
básica e calculava a frequência com que apareciam substantivos, palavras começadas com vogais ou palavras compostas com duas, três ou quatro letras.

Outro marcador sugerido nos anos 1990 foi uma combinação do tamanho médio das sentenças com a "riqueza" lexical (WINTER; WOOLLS, 1996). Entra-se aí em estudos que passaram a ser conhecidos como "Análise de vocabulário". Tais estudos têm suas raízes na proposição de Honoré (1979), que postulou que a frequência de hapax legomena (isto é, palavras que aparecem uma única vez no texto) seria um modo eficaz de medição do vocabulário. O problema com a técnica de Honoré estava no fato de não se distinguir entre itens gramaticais (muito frequentes) e lexicais. Assim, Winter e Woolls (1996) solucionaram o problema excluindo as palavras gramaticas da medição. Resultados sobre estudos realizados com essas medidas podem ser verificados em Coulthard e Johnson (2007, p. 165).

Mais recentemente, Kredens (2002a) testou o potencial discriminatório de marcadores discursivos em textos orais, comparando entrevistas de dois músicos britânicos, Robert Smith e Steven Morrissey. Seus resultados indicaram 3 marcadores discursivos como significativos (like, I mean, kind of/sort off) para distinguir os seus idioletos.

Chaski (2001, 2005) propõe que a pontuação, mais precisamente a função sintática da pontuação, seja um marcador relevante. Seu método conta e classifica os sinais de pontuação como sendo internos às palavras, sintagmas, orações, ou separando apostos.

Uma incorporação recente à lista de medidas textuais são os n-gramas, que são sequências de caracteres contíguos (GRIEVE, 2005, p. 49). Um estudo relevante que estuda essa medida e sua capacidade de distinguir autores é o de Keselj et al. (2003 apud29 GRIEVE, 2005). Os autores destacam que uma das vantagens de se usar n-gramas está no fato de que eles existem em qualquer idioma. Segundo Grieve (2005, p. 50, tradução nossa), "Keselj et al. testaram seu método usando uma variedade de tamanhos de ngramas (de um a dez caracteres - ou 'gramas') e obtiveram sucesso em distinguir entre

\footnotetext{
${ }^{29} \mathrm{Keselj}$, V. et al. N-gram-based author profiles for authorship attribution. PACIFIC ASSOCIATION FOR COMPUTATIONAL LINGUISTICS. [S.l.: s.n.], 2003.
} 
conjuntos de autores ingleses, gregos e chineses" 30 . Outros estudos baseados em ngramas incluem Bennett (1976) ${ }^{31}$, Clement e Sharp (2003) ${ }^{32}$ e Peng et al. (2003) 33 (apud GRIEVE, 2007, p. 254).

Saindo da vertente estilométrica, diversos trabalhos têm persistido em apontar não apenas um elemento linguístico como distintivo, mas uma combinação deles na busca por um modo eficaz de se determinar a autoria de um texto num "contexto" comparativo (e.g. TURELL, 2010; McMENAMIN, 2002).

Descrever as "constelações" de variáveis e variantes empregadas por um determinado autor é a proposta de McMenamin (2002; 2010), chamada por ele de "Estilística Forense". McMenamin parte da Sociolinguística Variacionista, cujo pressuposto é o de que os usos linguísticos são inerentemente variáveis. De acordo com Labov (1966[2006], p. 3), “a variabilidade é parte integrante do sistema linguístico”. Ela é um fato observável tanto no uso linguístico de pessoas diferentes, dentro de uma mesma comunidade, quanto nos usos que os mesmos indivíduos fazem da língua nas diferentes situações comunicativas. Uma variável é um conjunto de duas ou mais formas linguísticas de se dizer "a mesma coisa" (LABOV, 1972). Para McMenamin, o conjunto de variáveis e variantes recorrentes podem indicar a autoria. Ele separa os tipos de variantes como "variantes dentro de uma mesma norma" e "variantes fora de uma norma".

Sobre a abordagem conhecida como Forensic Discourse Analysis, sua principal tarefa é identificar usos linguísticos que estejam "fora de lugar" (GRANT, 2004, p. 43). Por exemplo, ao analisar o registro escrito de um depoimento, pode-se ter uma "dica" de que ele foi forjado quando se encontram marcas do discurso policial no que deveria ser apenas a transcrição da fala de um "cidadão comum". O caso inaugural dessa abordagem

\footnotetext{
30 Texto original: "Keselj et al. tested their method using a range of n-gram sizes (one to ten-grams) and achieved success distinguishing between sets of English, Greek and Chinese authors" (GRIEVE, 2005, p.50).

31 BENNETT, W. R. Scientific and engineering problem-solving with the computer. Englewood Cliffs, NJ: Prentice Hall, 1976.

32 CLEMENT, R. e SHARP, D. Ngram and Bayesian classification of documents. Literary and Linguistic Computing, 18, p. 423-447, 2003.

${ }_{33}$ PENG, F et al. Language independent authorship attribution using character level language models. TENTH CONFERENCE OF THE EUROPEAN CHAPTER OF THE ASSOCIATION FOR COMPUTATIONAL LINGUISTICS. Budapest, Hungary, 2003.
} 
é o do pedido de perdão póstumo a Derek Bentley, por sua família - em que trabalhou o linguista Malcolm Coulthard. Em 1952, Derek Bentley e Chris Craig, respectivamente com 19 e 16 anos, foram vistos subindo no telhado de um depósito em Londres. A polícia cercou o prédio e policiais os seguiram no telhado para efetuar a prisão. Bentley se rendeu, mas Craig começou a atirar, ferindo um policial e matando outro. Bentley também foi acusado do assassinato. Os dois foram declarados culpados, sendo que Craig foi condenado à prisão perpétua por ser menor de idade e Bentley foi condenado à morte e executado. Parte da evidência usada contra Bentley no julgamento foi de cunho linguístico: o seu depoimento, em que era possível mostrar como ele realmente tinha culpa no assassinato, pois admitiu ter instigado Craig a atirar. Em 1998, 46 anos mais tarde, a família de Bentley entrou com uma ação contestando a condenação. A dúvida estava em se Bentley havia realmente sido o autor do depoimento, ou seja, se o depoimento escrito continha exatamente o que ele havia dito. A análise empreendida por Coulthard demonstrou que o documento continha várias características linguísticas que indicavam que ele não era uma transcrição "verbatim" do que foi dito. Dentre as características, foram encontradas algumas que eram peculiares do registro linguístico policial e que, ao contrário, não eram comuns para garotos com o perfil sociolinguístico de Bentley. No fim, a justiça retificou a sentença e concedeu a Bentley o perdão póstumo (Cf. COULTHARD, 2006, 2005, 1994).

Em português, embora em menor quantidade, também se encontram trabalhos sobre autoria ${ }^{34}$. Silva (2008, p. 95) verifica a "utilidade e aplicabilidade" da elevada frequência de palavras e expressões como marcador. Em tal estudo, Silva analisou a frequência dos tetragramas (combinação de quatro palavras) utilizados uma única vez (hapax legomena) e "a frequência de expressões que ocorrem mais vezes nos textos do mesmo autor (bapax dislegomena)" (SILVA, 2008, p. 95). Silva et al. (2011) analisam mensagens do twitter, considerando características como interjeições, o uso de emoticons, pontuação e abreviações.

\footnotetext{
34 Observa-se, porém, que muitos desses trabalhos têm tido como objeto textos literários ou jornalísticos e não são voltados especificamente para o contexto forense.
} 
Brandão (2006) é mais um exemplo de trabalho em atribuição de autoria em português. O autor propôs a utilização de um método que tem como principal característica a contagem dos itens funcionais presentes nos textos. Em seu trabalho de 2006, analisaram-se as Cartas Chilenas - um conjunto de quatorze poemas do século XVIII, atribuídos a Tomás Antônio Gonzaga, porém assinadas com o pseudônimo "Critilo". Varela et al. (2011) apostam em categorias gramaticais como marcadores de estilo e aliam este marcador a um modelo computacional de classificação de documentos.

Turell (2010) também utiliza como característica linguística a sequência de categorias (classes) linguísticas, os erros ortográficos e a utilização de construções que não estejam de acordo com a norma padrão (TURELL, 2010). Sobre a sequência de categorias gramaticais como distintivas de um autor, Turell (2010, p. 232) cita ainda uma série de estudos que também se basearam nessa característica.

Uma relação das características normalmente examinadas nos trabalhos aqui citados pode ser vista a seguir, no Quadro 2:

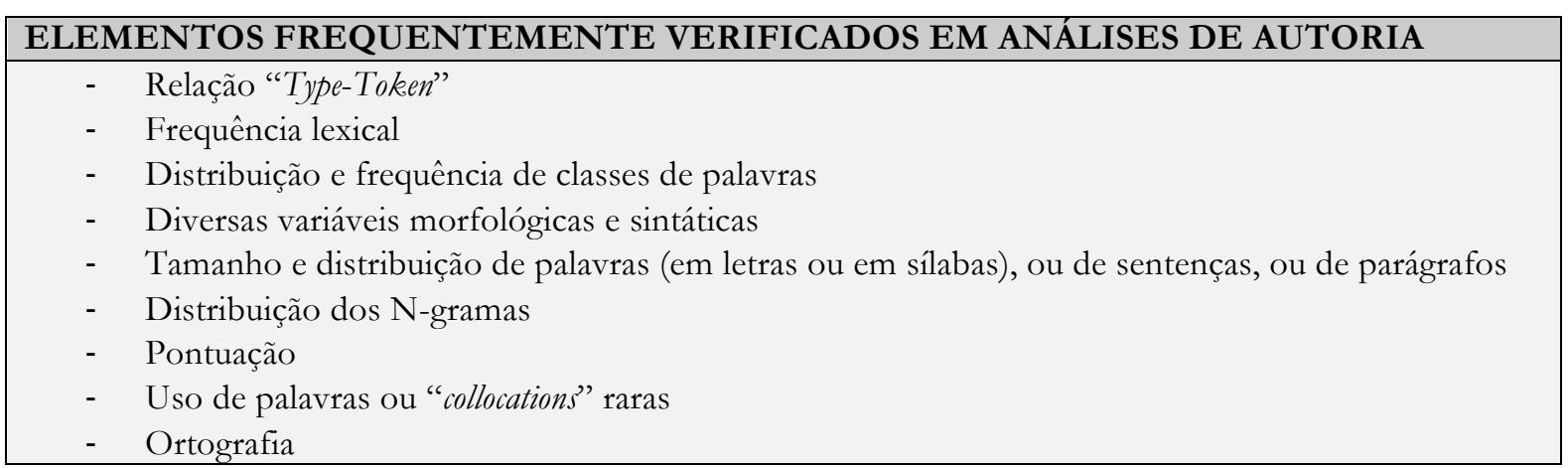

Quadro 2- Elementos frequentemente verificados em análises de autoria.

Qualquer que seja a metodologia de análise, os métodos para imputação de autoria, apesar de voltarem-se para características linguísticas diferentes, têm em comum o fato de sempre tentar identificar elementos que sejam ou não próprios de um autor. Tais elementos podem ser encontrados nos diferentes níveis linguísticos dos textos, ou seja, podem estar tanto no léxico quanto no nível ortográfico, ou morfológico, ou sintático, conforme vem relatando esta seção. 
Em se tratando de que elementos analisar, Grant (2004, p. 47) afirma que é importante distinguir entre "marcadores" e "idiossincrasia". Segundo ele, a definição tradicional de um marcador é um elemento linguístico que é característico ou não de um autor, num determinado registro. Entretanto, há especificidades ao se considerar quando se pretende diferenciar um marcador de um elemento idiossincrático. Para explicar essa diferença, Grant lança mão de uma analogia com a identificação de pessoas. Para tal identificação, existe uma série de características, tais como altura ou cor dos olhos, que podem ser úteis porque são aplicáveis a qualquer pessoa, no sentindo de que todas as pessoas vão ter uma altura e quase todas vão ter olhos. Altura e olhos seriam, então, “marcadores". Pode haver também características únicas que distinguem algumas pessoas, como uma cicatriz ou uma marca de nascença. Segundo Grant (2004, p. 48, tradução nossa):

Essas características distintivas são idiossincráticas porque não faz sentido verificar cada indivíduo para ver se ele possui 'uma cicatriz na mão' ou 'uma marca de nascença no rosto’. É bastante provável que muitos indivíduos apresentarão alguma característica distintiva, mas não há como saber de antemão qual será ela ${ }^{35}$.

A diferença enfatizada por Grant é importante para atribuição de autoria em termos de desenvolvimento de métodos de identificação.

De volta ao panorama histórico, destaca-se que Grant (2004) testa alguns marcadores linguísticos e idiossincrasias verificando sua adequação em termos de validade e confiabilidade, enquanto Grieve $(2005,2007)$ compara as medidas mais usualmente utilizadas em estudos quantitativos de atribuição de autoria em termos de seus resultados quando aplicadas ao mesmo corpus.

Alguns trabalhos (e.g. COULTHARD, 1994; TURELL, 2010, p. 215) propõem que os elementos linguísticos julgados relevantes para análise de autoria, principalmente os idiossincráticos, sejam comparados com um corpus de referência para que assim se possa atestar sua raridade. Os corpora de referência também são de grande interesse para os tipos de análise de autoria que compreendem a criação de perfis sociolinguísticos.

35 Texto original: "these distinguishing features are idiosyncratic because it makes no sense to check every individual for a 'scar on hand' or 'birthmark on face'. It is likely that most or many individuals will have some feature which is distinguishing, but there is no telling, in advance, what it might be” (GRANT, 2004, p.48). 


\subsubsection{Breve percurso histórico: perfis sociolinguísticos}

$\mathrm{Na}$ Linguística Forense, associar elementos linguísticos ao pertencimento de um indivíduo a certos grupos sociais tem sido chamado de author profiling (GRIEVE, 2014; NINI, 2013; GIBBONS, 2003), ou linguistic profiling (TURELL; GAVALDÀ, 2012; CHASKI, 2012), ou authorship profiling (OLSSON, 2008b; ARGAMON; KOPPEL, 2013) ou ainda sociolinguistic profiling (GRANT, 2008; NINI, 2013) - termos que podem ser traduzidos, respectivamente, por depreensão do perfil do autor, perfil linguístico, perfil de autoria, e perfil sociolinguístico. De acordo com Gibbons (2003, p. 307, tradução nossa, grifo nosso),

frequentemente pode não ser possível, e algumas vezes pode nem ser necessário, identificar linguisticamente um indivíduo. Entretanto, outra tarefa forense que os linguistas são capazes de realizar é depreender um perfil [sociolinguístico] do falante ou do escritor ${ }^{36}$.

Em muitos casos, é impossível determinar o provável autor de um escrito, mas a proposta é que seja possível definir, ao menos, um grupo, um conjunto no qual provavelmente ele esteja inserido, por meio da apreensão desses perfis, que poderão ser usados pela polícia para o estreitamento da busca por um suspeito. Ademais, tais perfis podem ser usados em investigações em que policiais precisem escrever - na Internet, por exemplo - a um interlocutor fazendo-se passar por outra pessoa, com um perfil diferente do seu (Cf. GRANT; MacLEOD, 2013).

Segundo Grant (2008, p. 223, tradução nossa, grifo nosso) “Os linguistas podem ser capazes de responder à pergunta ‘Que tipo de pessoa linguística escreveu este texto?’ e isso pode ser chamado de elaboração de um perfil sociolinguístico" ${ }^{37}$. Essa é a técnica utilizada, via de regra, em casos em que não há textos para comparar com aquele cuja

\footnotetext{
36 Texto original: "it may often not be possible, and in some cases it may not be necessary, to provide language based identification of a particular person. However, another forensic service that linguists may be able to provide is a profile of the speaker or writer" (Gibbons, 2003, p. 307).

37 Texto original: "Linguists may be able to answer the question What kind of linguistic person(s) wrote this text? and this might be referred to as socio-linguistic profiling" (GRANT, 2008, p. 223).
} 
autoria é questionada, configurando o que o autor chama de "problema do texto único"38 (GRANT, 2008, p. 222). De acordo com Shuy (2014, p. 76-77, tradução nossa):

Um perfil linguístico não tem a pretensão de identificar autores específicos. Ao contrário, ele descreve como a língua de um suspeito corresponde a informações sociais, econômicas, educacionais e outras que pesquisas sociolinguísticas prévias identificaram como sendo características de grupos sociais específicos ${ }^{39}$.

Quando se trata de língua oral, estudos semelhantes têm sido realizados com variáveis fonético-fonológicas, e aplicados com certa frequência. De acordo com Foulkes e French (2001, p.330, tradução nossa ${ }^{40}$ ):

A combinação da análise fonética e sociolinguística de uma voz pode ajudar a depreender informações sobre o 'background' do falante. O estabelecimento de um perfil do falante é regularmente solicitado em fases iniciais de sequestros em que uma gravação da voz do sequestrador pode ser a única pista para sua identidade. Podem ser recolhidas informações sobre o sexo, a idade, a origem regional e a posição social do falante, e idiossincrasias, tais como distúrbios da fala (...). Estabelecer um perfil do falante ajuda a definir uma população "alvo" e, assim, estreitar a busca pelo culpado .

Embora ainda não sejam muito consistentemente utilizados em casos que envolvam textos escritos (sendo que o caso devil strip, citado anteriormente, é recorrentemente utilizado como exemplo), os perfis sociolinguísticos que se podem extrair desses textos têm despertado interesse de pesquisadores e praticantes em Linguística Forense (SHUY, 2001, 2014; OLSSON, 2008b; GIBBONS, 2003; GRANT, 2008; ALMEIDA, 2012a, 2012b, 2013; TURELL; GAVALDÀ, 2012; NINI, 2013; GRANT; MacLEOD, 2013; GRIEVE, 2014). Segundo Shuy (2014, p. 74, tradução

\footnotetext{
${ }^{38}$ Em inglês, “single text problem". Ver também Olsson (2004, p. 71) e Coulthard, Grant e Kredens (2010, p. 526). Os últimos ressaltam que pode não haver textos para comparar ou pode acontecer da investigação ainda não ter estreitado a lista de suspeitos.

39 Texto original: "A linguistic profile does not claim to identify specific authors. Instead, it describes how the suspect's language matches social, economic, education level, and other information that previous sociolinguistics research has identified to be characteristic of specific societal groups" (SHUY, 2014, p. 76-77).

40 Texto original: "A combination of phonetic and sociolinguistic analysis of a voice can aid in establishing information about the speaker's background. Speaker profiling is regularly requested in the early stages of kidnappings, where a recording of the kidnapper's voice may be the only clue to his or her identity. Information can be gleaned about the speaker's sex, age, regional and social background, and idiosyncrasies such as speech disorders. The strength of conclusions varies and is highly dependent on the length and quality of material, the degree of any disguise involved, and the extent of descriptive dialectological and sociolinguistic information available. Establishing a speaker profile helps in defining a 'target' population and thereby narrowing the search for the culprit" (FOULKES; FRENCH, 2001, p.330).
} 
nossa $\left.a^{41}\right)$ : "perfis linguísticos tornaram-se uma forma útil de ajudar a polícia a estreitar listas de suspeitos e, em alguns casos, até mesmo usá-los para confrontar suspeitos que podem, através do confronto, admitir seus crimes".

Não são comuns métodos que sistematicamente permitam estabelecer perfis de autores, mas os pesquisadores nisso interessados concordam que informações sociolinguísticas sobre a língua em questão devem ser utilizadas. Faltam, porém, sugestões de como essas informações poderiam ser armazenadas e prontamente obtidas, embora algumas iniciativas procedentes de pesquisadores da Ciência da Computação, como as de Argamon et al. (2003) ${ }^{42}$ e Koppel et al. (2009) ${ }^{43}$ tenham obtido sucesso, ao fazer uso de complexos modelos estatísticos e computacionais (e.g. aprendizado de máquinas) que levam em conta um grande número de variáveis linguísticas. (COULTHARD; GRANT; KREDENS, 2010).

\subsubsection{Alguns casos}

Ainda pouco difundida no Brasil, a análise de autoria com propósitos forenses já é bastante utilizada em outros países, principalmente no Reino Unido e nos Estados Unidos. De fato, já houve até mesmo alguns casos “de peso" solucionados com a sua ajuda, tal como o caso Ramsey (descrito brevemente na seção 1) e aquele que ficou conhecido como The Unabombert4. Entre 1978 e 1995, nos Estados Unidos, várias bombas foram enviadas pelo correio a diferentes indivíduos. Com o passar do tempo, o FBI notou que as pessoas que recebiam as bombas eram todas funcionárias de universidades ou companhias aéreas (daí o nome Unabomber. Un, de "University" e A, de "Airlines"). Em 1995, alguns jornais de circulação nacional receberam um manuscrito intitulado Industrial Society and its Future, de alguém que alegava ser o Unabomber. O manuscrito foi publicado

\footnotetext{
41 Texto original: "Linguistic profiling has become a useful way to help law enforcement narrow down lists of suspects and, in some cases, even use it to confront suspects with these linguistic profiles as a way of convincing them to admit their crimes" (SHUY, 2014, p. 74).

42 Sobre a classificação dos textos por sexo/gênero.

43 Para classificação por idade e língua nativa (Inglês ou outras).

${ }^{44}$ Cf. e.g. Coulthard; Johnson (2007, p. 162); Solan; Tiersma (2005, kindle edition); FBI (2008); Shuy (2014, p. 75).
} 
pelo jornal Washington Post, e alguns meses depois o FBI foi contatado por um homem dizendo que o manuscrito soava como sendo de seu irmão, um ex-professor universitário de matemática. O caso estava sendo analisado pelo agente do FBI Jim Fitzgerald, que estava lendo atentamente o manifesto em busca de pistas que pudessem levar ao seu autor. Após a denúncia, Fitzgerald comparou o manifesto com textos que o suspeito enviara para a sua família no decorrer dos anos, encontrando ali padrões recorrentes, o que serviu de base para a expedição de um mandado de busca. Como resultado, o FBI localizou e prendeu Ted Kaczynski. Para corroborar a análise de Fitzgerald, o FBI contratou Donald Foster (que havia tido sucesso em alguns casos de autoria), e a sua análise mostrou que os textos encontrados e o manifesto compartilhavam várias escolhas linguísticas, tanto lexicais quanto gramaticais, e haviam sido escritos pela mesma pessoa. Segundo Grant (2004, p. 12, tradução nossa), “a identificação do Unabomber por meio da análise e seu Manifesto é talvez o maior sucesso da atribuição de autoria forense" 45 .

Outro caso bastante presente na literatura é o do desaparecimento de Danielle Jones, em Junho de 2001 (GRANT, 2010, p.508). Horas depois do seu desparecimento, duas mensagens foram enviadas de seu celular, como sendo dela. Entretanto, a polícia tinha evidências para suspeitar que as mensagens tinham sido enviadas pelo seu tio Stuart Campbell. O linguista Malcolm Coulthard atuou no caso e sua análise indicou que era improvável que essas mensagens tivessem sido escritas pela garota. Um caso semelhante é o de Jenny Nicholl, que desapareceu em Junho de 2005 (GRANT, 2010, p.508). Mais uma vez, mensagens de celular atribuídas à vítima tiveram sua autoria questionada pela polícia e, também neste caso, Coulthard apresentou uma análise linguística que indicava pouca probabilidade de Jenny tê-las escrito.

Um caso relativamente recente é o de Paul Ceglia versus Mark Zuckerberg (fundador do Facebook). Em 2011, Ceglia entrou com uma ação contra o criador da rede social, alegando que este lhe havia prometido metade da fortuna proveniente da rede social e que poderia provar isso por meio de e-mails que eles haviam trocado no passado. Zuckerberg negou ter escrito os e-mails apresentados. Para ajudar a resolver o caso, o linguista Gerald McMenamin foi contratado e realizou análises linguísticas com o objetivo

\footnotetext{
45 Texto original: "The identification of the Unabomber through the analysis of his Manifesto is perhaps the greatest success for forensic authorship attribution to date" (GRANT, 2004, p.12).
} 
de verificar se era possível que o fundador do site tivesse escrito os e-mails ${ }^{46}$. A conclusão de McMenamin, fundamentada em uma análise em que comparou variáveis/variantes linguísticas usadas pelo autor dos textos conhecidos com aquelas usadas pelo autor do texto questionado, foi que Zuckerberg não compôs os e-mails.

Grant (2013) também noticia um caso que ficou bastante conhecido na impressa britânica ${ }^{47}$. Trata-se do assassinato de Amanda Birks. Do mesmo modo que no caso Nicholl, a polícia tinha razões para suspeitar que certas mensagens do celular de Amanda haviam sido enviadas por outra pessoa que se fez passar por ela. As mensagens do celular de Amanda e do seu marido - o principal suspeito - foram entregues à promotoria, que contratou Grant para conduzir uma análise estilística, que mostrou que certas mensagens que diziam que Amanda estava bem haviam, na verdade, enviadas pelo marido.

Chaski (1997) expõe o caso da morte de Michael Hunter, em 1992. Hunter morreu por causa de uma injeção que combinava alguns medicamentos. Joseph Mannino, seu colega de quarto, foi quem avisou a polícia e lhe entregou disquetes que continham uma suposta carta de suicídio escrita por Hunter. A polícia entrou em contato com Chaski e forneceu a ela documentos de Hunter, de Mannino, e de um terceiro colega de quarto, com os quais ela deveria comparar a carta questionada. A análise linguística realizada, que focalizou sintaxe e pontuação, mostrou que a carta provavelmente não tinha sido escrita por Hunter, mas por Mannino. Algum tempo depois, Mannino admitiu ter escrito a carta de suicídio falsa.

Casos em que se procedeu à elaboração de perfis sociolinguísticos são mais raros. Como já se mencionou, o caso "devil strip" é repetidamente citado na literatura sobre o tema. Alguns pesquisadores, como por exemplo aqueles do Centro de Linguística Forense

\footnotetext{
46 Disponível em:

$<$ http://www.vocabulary.com/articles/wordroutes/does-e-mail-have-fingerprints/>;

$<$ http://www.nytimes.com/2011/07/24/opinion/sunday/24gray.html>;

$<$ http://pt.scribd.com/doc/56976903/W-D-N-Y-1960merged-linguist>;

$<$ http://online.wsj.com/public/resources/documents/cegliaamendedcomplaint041211.pdf>.

Acesso em 10/12/2012.

${ }^{47}$ E.g. In: "Businessman admits murdering wife and setting fire to her home". The Telegraph. Nov, 2009. Disponível em <http://www.telegraph.co.uk/news/uknews/crime/6488982/Businessman-admits-murdering-wife-and-settingfire-to-her-home.html>. Acesso em 20/02/2014.
} 
da Universidade de Aston ${ }^{48}$, têm trabalhado em casos assim, mas muitos deles não podem ser divulgados (Informação oral) ${ }^{49}$.

Dentre os casos de que se tem notícia, está o da carta anônima que foi endereçada ao Primeiro Ministro britânico ${ }^{50}$. Segundo Coulthard, Grant e Kredens (2010, p. 527) há itens lexicais na carta que são características dialetais. Dentre eles, está o uso de bad-minded people 51 , item característico do inglês jamaicano. Os autores alertam, porém, que é necessário ter cautela quando se trata de chegar a alguma conclusão com base nesse tipo de informação e, assim uma cocorrência desse tipo não pode ser considerada como evidência de que o escritor é jamaicano, mas apenas que provavelmente ele foi exposto a variedades jamaicanas do inglês ${ }^{52}$ (COULTHARD, GRANT, KREDENS, 2010).

Outro caso diz respeito às cartas anônimas de conteúdo racista que foram enviadas a diversos indivíduos no Reino Unido. Durante as investigações, o linguista Tim Grant trabalhou no caso. Ele trabalhou com a hipótese de que, com base na análise linguística, o autor das cartas era provavelmente mulher ${ }^{53}$ e provavelmente mais velha ${ }^{54}$. Quando a autoria das cartas foi finalmente revelada, viu-se que se tratava realmente de uma mulher - Margaret Walker - na casa dos $70 \operatorname{anos}^{55}$.

Esses foram apenas alguns exemplos de casos em que o uso de evidência linguística concernente à autoria textual teve um papel relevante.

\footnotetext{
${ }^{48}$ http://www.forensiclinguistics.net/; http://www.aston.ac.uk/research/case-studies/forensic-lingusitics/.

49 Informação oral obtida em conversas com esses pesquisadores, por ocasião de Congressos ou Cursos.

${ }^{50}$ Não fica claro no texto em que esse caso é citado qual era o propósito da carta.

51 Trecho da carta referente à morte da Princesa Diana, extraída de Coulthard, Grant e Kredens (2010, p. 527): "She was an innocent girl who tried to do her best in a world governed by old cruel farts. [...] Sir, the whole system stinks. Sometimes, I am ashamed to be white by the things others are allowed to say and do. Why did many stand by and allow Diana to be killed? Surely, this cannot be right? Many in this force are gutted by the things we have come to know and are told to keep quiet about. Sir, it is time to bring these shameful things out into the open. Please. Do'nt let our country go down the pan just to protect the interests of a few bad- minded people".

52 No fim, descobriu-se que o autor era um homem britânico de ascendência jamaicana.

${ }^{53}$ Cf. Tappenden, 2009. Disponível em < http://news.bbc.co.uk/2/hi/uk_news/england/8282817.stm>. Acesso em $16 / 06 / 2014$.

${ }^{54}$ Há também menção do caso na entrevista do autor para o programa de TV CrimeWatch, da BBC.

${ }^{55}$ Cf. Semke [201-]. Disponível em <http://www.portsmouth.co.uk/news/local/racist-gran-barred-from-sendingoffensive-letters-1-4299547>. Acesso em 12/06/2014.
} 


\subsection{Validade e confiabilidade}

Como se apontou na seção anterior, muitos são os marcadores de autoria sugeridos ao longo do anos, com mais ou menos sucesso para os textos - comumente curtos - que são examinados num contexto forense. Definir o que seria um "bom" marcador de autoria significa determinar a sua validade e confiabilidade.

Validade tem a ver com saber se uma determinada medida é realmente capaz de indicar o que acreditamos que ela mede (GRANT; BAKER, 2001). Olsson (2008, p. 41, tradução nossa, grifo nosso) segue nessa direção ao afirmar que "não é suficiente simplesmente encontrar semelhanças e diferenças entre dois estilos textuais. Precisamos entender qual a natureza desses pontos de semelhança e diferença e os níveis linguísticos em que eles ocorrem" 56 . Em outras palavras, a validade de um marcador está relacionada, de uma lado, à construção teórica que o envolve e, de outro, ao fato de que ele esteja medindo realmente o que se propõe a medir.

A confiabilidade, por sua vez, está relacionada à possibilidade de um método poder ser replicado por outros estudiosos (GRANT, 2004; GRANT; BAKER, 2001; GIBBONS, 2011). Dessa forma, pode haver métodos replicáveis, isto é, confiáveis, que mesmo assim não sejam válidos (GRANT, 2004), porque lhes falta fundamentação teórica.

Validade e confiabilidade, se observadas, podem conferir a uma análise de autoria uma base mais científica. Segundo Grant (2004, p. 51, tradução nossa): "São esses conceitos metodológicos de confiabilidade e validade que podem fornecer uma base científica para qualquer pretensão de atribuição de autoria" 57 . No entanto, o autor ressalta que "ainda assim, demonstrações de confiabilidade ou validade dos marcadores usados em casos de atribuição de autoria são raros na literatura"58.

\footnotetext{
56 Texto original: "It is not sufficient simply to find a set of similarities or differences between two text styles. We need to understand the nature of those points of similarity and difference and the linguistic levels at which they can occur" (OLSSON, 2008, p. 41).

57 Texto original: "It is these methodological concepts of reliability and validity that can provide a scientific basis to any claims of authorship attribution" (GRANT, 2004, p. 51).

58 Texto original: "yet demonstrations of the reliability or validity of markers used in authorship attribution cases, are rare in the literature" (GRANT, 2004, p. 51).
} 
Em análises de autoria, normalmente se justifica a validade de um marcador simplesmente com o argumento de que existem hábitos de falar ou escrever. Existem pressupostos linguísticos e cognitivos (por exemplo, os scripts linguísticos de Schank e Abelson, 197759; e o princípio idiomático de Sinclair, 199160) que apoiam tal afirmação (GRANT, 2004). Isso leva à conclusão de que todos os marcadores já hipotetizados são válidos, já que sempre podem ser explicados por essa noção de hábito. Contudo, Grant e Baker (2001) e Grant (2004) defendem que apenas dizer que uma determinada característica é fruto de um hábito linguístico não é suficiente e que, para passar em um teste de validade, um marcador linguístico de autoria deveria também passar pelo crivo do entendimento teórico. Segundo eles,

\begin{abstract}
Demonstrar a validade deve passar pelo desenvolvimento de um entendimento teórico das razões pelas quais um determinado marcador pode prever a autoria textual com sucesso. Tal construto teórico deve envolver mais do que a mera descrição de padrões linguísticos: deve explicar porque pode haver constância no uso linguístico de um mesmo autor e variação no uso linguístico entre autores" (GRANT; BAKER, 2001, p. 77, tradução nossa) ${ }^{61}$.
\end{abstract}

Outro aspecto importante acerca da validade e da confiabilidade é que elas costumam ser mais prontamente relacionadas a análises quantitativas (GIBBONS, 2011). Todavia, uma análise quantitativa pode falhar em atender esses requisitos, enquanto uma análise qualitativa, por outro lado, pode perfeitamente ser tanto válida quanto confiável. Validade e confiabilidade não deveriam, então, a princípio, ser atreladas apenas a métodos quantitativos (GIBBONS, 2011) ${ }^{62}$.

\footnotetext{
${ }^{59}$ SCHANK, R. C.; ABELSON, R. P. Scripts, plans, goals and understanding. Hillsdale, NJ, USA: Lawrence Erlbaum Associates, 1977.

${ }^{60}$ SINCLAIR, J. M. Corpus concordance collocation. Oxford: Oxford University Press, 1991.

61 Texto original: "Demonstrating validity must involve developing a theoretical understanding of why a proposed marker might successfully predict authorship. Such a theoretical construct must involve more than a description of linguistic structures or patterns. It must explain why there might be constancy within any author and variation between authors" (GRANT; BAKER, 2001, p.77).

62 Segundo Gibbons (2011, p. 246), "It would clearly be to the detriment of the justice system if reliable and valuable qualitative evidence such as that presented in Eagleson (1994) were not admitted. Indeed, there are occasions where a quantitative analysis may be inappropriate - for instance in one case in which I was involved, I was asked only to describe to the court the effect of an umlaut in German. This is a comparatively straightforward descriptive task, where I consulted reference books, but mainly used my subjective knowledge. Similarly Shuy's (2008) evidence on meaning is almost all qualitative. It is in attribution cases that both qualitative and quantitative methods are needed to provide evidence that will convince a court".
} 
Com relação à proposta desta tese, as análises que seguem nos capítulos de 3 a 6 procuram atender ao requisito de validade, na medida em que se baseiam em modelos teóricos já amplamente estudados (validade teórica) e procuram demonstrar, qualitativa e quantitativamente, que a recorrência dos elementos linguísticos-discursivos propostos como marcadores de estilos individuaius ou de grupo podem realmente distinguir autores ou indicar grupos aos quais eles pertençam (ou seja, os instrumentos empregado "medem" realmente aquilo que ser quer medir). Quanto à confiabilidade, os métodos aqui utilizados são apresentados de modo a permitir que sejam empregados por outros pesquisadores ${ }^{63}$.

\subsection{Processamento de linguagem, consciência metalinguística e tentativas de disfarce}

Parte da validade de qualquer marcador de autoria textual pode ser dada porque se confia na premissa de que usos linguísticos se tornam hábitos. Segundo essa premissa ${ }^{64}$, o processamento da linguagem é automático ou inconsciente. Para Cobley (2005, p. 223, tradução nossa ${ }^{65}$ ), "dentre os comportamentos sociais, nenhum é tão dependente de mecanismos inconscientes quanto a língua". Por causa desse automatismo, combinam-se as unidades linguísticas sem que se pense nelas, enquanto o foco da atenção está direcionado ao conteúdo da mensagem que se quer transmitir. Dessa forma, espera-se que a produção linguística seja difícil de controlar em alguns aspectos (CHASKI, 1997).

Especificamente com relação à escrita, Coulmas (2003, p. 218) afirma que, uma vez internalizados, os processos de escrita tornam-se mais inconscientes. McMenamin (2010, p.488) observa que o estilo linguístico reflete as respostas do escritor aos requerimentos de um gênero textual, por exemplo, o que seria mais consciente, e também

\footnotetext{
${ }^{63}$ Mais sobre os conceitos de validade e confiabilidade neste trabalho é mencionado adiante (capítulo 1, item 1.5; capítulo 5, item 5.2; capítulo 6, item 6.1).

${ }^{64}$ Trata-se de pressupostos e hipóteses, já que, segundo Coulmas (2003, p.217) “o que se passa quando as pessoas deitam a caneta sobre o papel é difícil de descobrir". Texto original: "what happens when people, literally, put pen to paper is difficult to discover".

${ }^{65}$ Texto original: "Among all social behaviors none is as dependent upon unconscious mechanisms as language" (COBLEY, 2005, p. 223).
} 
seus hábitos "adquiridos através de uma experiência de longo prazo com a escrita" (tradução nossa $\left.{ }^{66}\right)$.

Apesar da crença de que os comportamentos linguísticos sejam, pelo menos em parte, inconscientes, existe também o que se chama de "consciência metalinguística", que, segundo Chaski (1997, p. 19) é a habilidade de pensar conscientemente e falar sobre a língua. A importância desse conceito para a atribuição de autoria é que a sua possibilidade faz emergir dúvida sobre eventuais disfarces linguísticos:

Suponha que alguém seja tão sensível à linguagem, tão metalinguisticamente consciente, que possa vencer a automatização do processamento linguístico e realmente mudar seus padrões naturais de tal modo que consiga imitar os padrões idioletais de outro indivíduo e suprimir os seus próprios. (CHASKI, 1997, p. 19, tradução nossa ${ }^{67}$ ).

Chaski informa, ainda, que diferentes adultos podem ter habilidades metalinguísticas diferentes e que, por isso, deve ser mantido o ponto de vista de que, sim, o disfarce é possível, dependendo do nível de consciência metalinguística do autor.

Ehrhardt (2007, p. 387, tradução nossa) é clara ao confirmar que dissimulações linguísticas de fato existem no âmbito forense. Segundo ela, "o disfarce é uma característica comum em textos criminosos, embora os autores contem com apenas um número limitado de estratégias de manipulação [do estilo]" (EHRHARDT, 2007, p. 87) ${ }^{68}$.

Em análises forenses de autoria (com exceção do plágio, não contemplado nesta pesquisa), observa-se que, via de regra, os textos são escritos por pessoas “comuns" e não profissionais da escrita e, por isso, espera-se que as tentativas de disfarce, se ocorrerem, não tenham sucesso, já que faltaria ao "escritor comum" a experiência em reconhecer um estilo e alterar o seu próprio. Essas questões justificam, por exemplo, a coleta dos textos utilizados nesta pesquisa (o CGAA), provenientes de informantes que sejam "naüve-writers". Além disso, os textos que ordinariamente são coletados para um corpus a fim de

\footnotetext{
${ }^{66}$ Texto original: "acquired through the long-term experiential process of writing” (McMENAMIN, 2010, p. 488).

${ }^{67}$ Texto original: "Suppose someone is so sensitive to language, so metalinguistically aware, that such a person can overcome the automatization of language processing and actually change natural patterns to such a degree as to imitate the idiolectal patterns of another speaker and suppress one's own idiolectal patterns" (CHASKI, 1997, p. 19).

${ }^{68}$ Texto original: "Disguise is a common feature among incriminating texts, although authors have only a limited number of manipulation strategies at hand" (EHRHARDT, 2007, p. 87).
} 
comparação - mensagens de celular, posts em redes sociais, e-mails, cartas, textos de blogs, diários, entre outros - são exemplos de escritos cotidianos, em que, segundo McMenamin (2002), de maneira análoga à fala espontânea e num contexto informal ${ }^{69}$, pouca ou nenhuma atenção é direcionada ao processo de escrita. O autor afirma que quanto menos atenção se presta à produção linguística, mais regularmente estruturada a variação linguística será.

Mesmo assim, se tentativas de disfarce ocorrem, elas podem ser apreendidas pelo analista na medida em que os imitadores não são aptos a reproduzir o tipo ou a frequência das variáveis linguísticas peculiares de um outro escritor (McMENAMIN, 2002). De acordo com Ehrhardt (2007, p. 387, tradução nossa ${ }^{70}$ ),

manipulações [de estilo] propositais podem ser detectadas considerando-se aspectos como, por exemplo, a incompatibilidade entre erros e seus equivalentes corretos em um texto e a combinação de uma linguagem com muitos erros, mas com perfeita coerência no que diz respeito ao conteúdo (Dern 2006a $\left.{ }^{71}\right)$.

De qualquer forma, testar em que grau tentativas de disfarce podem ter sucesso poderia ser o tema de um estudo mais sistemático.

\subsection{O texto como prova: aspectos jurídicos}

Se a Linguística Forense é a disciplina que se ocupa do fornecimento de evidências linguísticas no âmbito policial ou judicial, pode-se dizer que ela trata do texto enquanto prova $^{72}$. Assim, cabem algumas considerações sobre as provas para o Direito. Antes de

\footnotetext{
${ }^{69}$ Tal proposta de McMenamin baseia-se na ideia laboviana de que há graus de atenção que o falante aplica à própria fala.

${ }^{70}$ Texto original: "Intentional manipulations can be detected by considering aspects like, among other things, the incompatibility of errors and their correct equivalents within a text and the combination of an extremely faulty language with a perfect understanding of the text content (Dern 2006)" (EHRHARDT, 2007, p. 387).

${ }^{71}$ DERN, C. Bewertung inkriminierter Schreiben: zur problem der verwischung von spuren durch verstellung. Kriminalistik, 5, p. 323-327, 2006.

${ }^{72}$ A Linguística Forense não sugere que a análise textual deva constituir prova inquestionável de autoria ou não autoria de um delito, mas que possa ser considerada junto com outros elementos normalmente tomados como evidência.
} 
mais nada, vale ressaltar que, enquanto os resultados de análises para atribuição de autoria têm um valor mais "processual" e "evidencial", os perfis sociolinguísticos têm mais valor investigativo, isto é, eles são mais passíveis de utilização no curso de investigações ${ }^{73}$ do que no tribunal (Cf. GRANT, 2008, p. 224; GIBBONS, 2003, p.307).

\subsubsection{Prova e prova pericial}

Havendo a incerteza sobre circunstâncias ou alegações que sejam pertinentes para o esclarecimento de um caso, entram em cena atividades probatórias (CAPEZ, 2012, p. 360). "Do latim probatio, [prova] é o conjunto de atos praticados pelas partes [...], pelo juiz e por terceiros (p. ex., peritos), destinados a levar o magistrado à convicção acerca da existência ou inexistência de um fato, da falsidade ou veracidade de uma afirmação" (CAPEZ, 2012, p. 360). O Art. 332 do Cap. VI do Código de Processo Civil apresenta a seguinte redação: “Todos os meios legais, bem como os moralmente legítimos, ainda que não especificados neste Código, são hábeis para provar a verdade dos fatos, em que se funda a ação ou a defesa” (CPC, Cap.VI, Art.332) ${ }^{74}$.

A definição de Capez diz respeito à prova enquanto "atividade probatória", o ato de provar. Manzano (2011) observa que, no Direito, a palavra prova é usada de diversas maneiras, já que se pode falar em "elemento de prova", "meios de prova", "meio de obtenção da prova", "fonte de prova", etc.

Ao analisar textos em busca de sua autoria em um processo judicial, o linguista deve atuar, muitas vezes, como "perito"75, examinando-os e oferecendo a sua opinião ${ }^{76}$. Segundo Capez (2012, p. 405), a perícia ${ }^{77}$ :

\footnotetext{
${ }^{73}$ Coulthard, Grant e Kredens (2010) ressaltam o trabalho do linguista forense em âmbito investigativo. Eles afirmam que, sim, muito do trabalho desse profissional é direcionado para o fornecimento de provas em processos judiciais, mas há também uma quantidade substancial de trabalho que consiste em dar opiniões - prestar uma consultoria - em casos de investigação ou em casos que ainda não são parte de um processo judicial e podem ou não vir a sê-lo.

${ }^{74}$ Disponível em <http://www.planalto.gov.br/ccivil_03/leis/15869.htm>. Acesso em 01/10/2012.

75 A perícia pode ser oficial ou não oficial. No primeiro caso, o perito é indicado por uma autoridade e é contratado pelo Estado. No segundo, peritos são indicados livremente pelas partes (MANZANO, 2011, p. 76).
} 
consiste em um exame elaborado por pessoa, em regra profissional, dotada de formação e conhecimentos técnicos específicos acerca dos fatos necessários ao deslinde da causa [...]. Trata-se de um juízo exercido por especialista, com o propósito de prestar auxílio ao magistrado em questões fora da sua área de conhecimento profissional.

Em outras palavras, a perícia está: “destinada a esclarecer o juiz sobre circunstâncias relativas aos fatos conflituosos, que envolvem conhecimentos técnicos ou científicos" (WAMBIER; TALAMINI, 2011, p. 555). Durante a perícia, chamada de "prova técnica" ou "científica", o perito elabora o "laudo pericial", definido como "toda peça escrita na qual os peritos lançam o resultado do exame efetivado, mencionando o que observaram e consignando suas conclusões" (CAPEZ, 2012, p. 409). O Código de Processo Penal78 (CPP) dá exemplos de várias situações em que é necessário o exame pericial. No entanto, quanto à atribuição de autoria, infelizmente, tal Código (Cap. II, Art. 174) faz menção apenas aos casos em que há necessidade de se fazer um exame grafotécnico, de comparação da caligrafia dos suspeitos. Essa menção explícita a tais casos, contudo, não exclui a necessidade de análises linguísticas de autoria, já que a quantidade de documentos produzidos por meio digital aumenta a cada dia.

A opinião do perito, expressa em um laudo, é chamada, pelo Direito, de "elemento de prova" ou simplesmente "prova" (Cf. MANZANO, 2011, p.3). Os meios através dos quais se extraem as evidências são chamados de "meios de prova". Didier Jr., Braga e Oliveira (2009, p. 42, grifo do autor), por sua vez, acrescentam mais uma acepção ao termo prova, como utilizado pelo Direito, que é “o resultado dos atos ou dos meios de prova que foram produzidos no intuito de buscar o convencimento judicial". Fala-se também em "fonte de prova", isto é, as pessoas ou coisas das quais se pode conseguir a prova (MANZANO, 2011, p.5); e, ainda, em “objeto de prova”, ou seja, "os fatos cuja demonstração interessa ao deslinde da causa” (MANZANO, 2011, p. 5).

A partir dessas definições, no contexto de autoria textual questionada em âmbito forense, tem-se:

\footnotetext{
${ }^{76}$ Ainda sobre o papel dos peritos, existe a figura do perito enquanto testemunha (em inglês, expert witness). Entretanto, no Brasil, o perito não pode ser testemunha (MANZANO, 2011, p. 13).

${ }^{77}$ Capez (2012, p. 405) informa que a perícia é também chamada de "prova crítica".

${ }^{78}$ Disponível em < http://www.planalto.gov.br/ccivil_03/decreto-lei/del3689.htm>. Acesso em 30/09/2012.
} 
- os textos de autoria questionada como fontes de prova;

- as análises produzidas para determinar a autoria textual como meios de prova;

- a opinião do perito sobre autoria linguística, explicitada em um laudo, como elemento de prova;

- a hipótese sobre a autoria dos textos em questão como objeto de prova ${ }^{79}$

Existe ainda o "resultado da prova", que é a conclusão que se extrai a partir do exame dos vários elementos de prova existentes (por exemplo, a decisão do júri ou do juiz).

Nos casos de autoria textual questionada, pode-se dizer que a análise do texto é uma prova indiciária ou não plena (CAPEZ, 2012, p.360-361), isto é, não constitui, sozinha, prova convincente da autoria de um delito; deve ser considerada em conjunto com outros elementos, outras evidências.

Em um processo, a prova deve ser admitida e assuntada, procedimento conhecido como “procedimento probatório". A esse respeito, Manzano (2011, p. 7, grifo do autor) explica:

Fase de admissão é aquela em que o juiz, de ofício ou mediante requerimento da parte, provê a decisão sobre a admissibilidade da fonte ou meio de prova. Em caso de deliberação positiva, prossegue-se à fase de assunção, que consiste na operação da concreta imissão do elemento de prova no processo, como dado utilizável pela sentença, a partir da fonte e por intermédio do meio de prova.

Assim, a perícia "sujeita-se às fases de admissão e assunção, que compõem o chamado procedimento probatório" (MANZANO, 2011, p. 8). Especificidades sobre a admissibilidade de provas são tratadas a seguir, na seção 1.5.1.1.

Manzano (2011, p. 15) observa que

a característica fundamental da perícia como prova científica, e que a distingue dos demais meios de prova, é que ela se vale de um princípio científico aplicado por meio de técnica adequada, cujo conhecimento escapa, via de regra, ao domínio dos aplicadores do direito, mas que é essencial ao acertamento do fato e o deslinde da causa.

${ }^{79}$ Manzano (2011, p. 5, grifo do autor) ressalta que "objeto da prova não é o fato, mas sim a afirmação sobre um fato". 
Nesse sentido, um problema em torno de aceitar a análise linguística como uma análise especializada é o fato de que todos se acham conhecedores da língua, na medida em que a utilizam. Segundo Coulthard, Grant e Kredens (2010, p. 530, tradução nossa)

\begin{abstract}
Em alguns países, os tribunais têm tendido a não admitir tal evidência [linguística] apoiando-se na premissa de que juízes e jurados, enquanto usuários competentes da língua, têm a capacidade de entender e interpretar os problemas linguísticos que emergem" 80 .
\end{abstract}

Ora, nem todos que dirigem um automóvel, ou seja, que são capazes de utilizá-lo conhecem os seus mecanismos internos, o seu funcionamento. Assim, apenas um especialista é apto a prover uma opinião aprofundada sobre ele.

Existem alguns procedimentos probatórios que são disciplinados em lei. Exemplos seriam a autópsia e a exumação. Com relação a textos escritos, a legislação trata do exame grafotécnico, que é "o exame para o reconhecimento de escritos, por comparação de letra" (MANZANO, 2011, p. 54). A análise linguística, todavia, não está descrita em lei e, assim, perícias desse tipo constituem "prova inominada". A "prova nominada" é a que tem nome previsto em lei e a inominada, aquela que não o tem. Quaisquer desses tipos podem ter ou não seu rito probatório descrito por lei. Quando tal rito não é pré-determinado pela legislação, tem-se uma "prova atípica". A perícia realizada em textos com o objetivo de elucidar sua autoria é, portanto, prova atípica. A atipicidade da prova pericial é natural, uma vez que, tratando-se de empreitada técnica e científica, os métodos empregados na perícia estão sujeitos a mudanças que não poderiam ser acompanhadas pela legislação com a mesma velocidade. A ausência de regulamentação de todas as perícias possíveis existe, pois não há como prevê-la, uma vez que inovações técnicas, baseadas em novas tecnologias, ocorrem repetidamente.

Sobre a tipicidade ou atipicidade no Brasil, "mesmo quanto às perícias nominadas, o Código e as leis nada dispõem sobre o procedimento técnico envolvido no rito

\footnotetext{
${ }^{80}$ Texto original: "In some countries courts are often disinclined to admit such evidence on the assumption that judges and jurors, as competent language users, have the capacity to understand and interpret the linguistic matter in question" (COULTHARD; GRANT; KREDENS, 2010, p. 530).
} 
probatório, isto é, quanto à confiabilidade do princípio científico subjacente e a técnica ou o método de aplicação adequado” (MANZANO, 2011, p. 57). Manzano ressalta que o CPP brasileiro não faz nenhuma restrição quanto à inserção da prova atípica no processo (MANZANO, 2011, p. 66), embora existam limites para sua obtenção e produção, haja vista princípios constitucionais que devem ser observados.

Laudos periciais, como outras provas, são ponderados pelo juiz e este pode aceitálos ou negá-los no todo ou em parte. No entanto, é de costume que o juiz somente rechace a conclusão de um perito em episódios de dolo ou erro (MANZANO, 2011, p. 106).

\subsubsection{Da admissibilidade da prova}

Em razão do fato de que a previsão legislativa acerca das perícias é escassa, a apreciação das provas periciais, com relação à sua confiabilidade, fica a cargo do juiz. Se todas as provas periciais fossem típicas, isto é, com técnicas previstas por lei, não existiria empecilhos no que diz respeito à sua admissibilidade. Como a tipicidade da prova não é uma constante, é imperativo que o juiz se muna de critérios para admitir as provas num processo (MANZANO, 2011).

Esses critérios estão relacionados a dois requisitos: o de relevância e o de confiabilidade. Segundo Manzano (2011, p. 188), a relevância tem a ver com saber se a teoria científica utilizada para a produção do elemento de prova está realmente apta a explicar/comprovar o fato em questão (nesse sentido, é um conceito análogo ao de validade, discutido anteriormente). A confiabilidade está relacionada ao conhecimento, pelo juiz ou pela comunidade científica em questão, dos métodos e procedimentos empregados. 
No Direito estadunidense, a questão da admissibilidade da prova científica sobreveio a partir do caso Frye81, em 1923 e passou por modificações com o que ficou conhecido como a trilogia da admissibilidade: os casos Daubert ${ }^{82}$, Joiner ${ }^{83}$ e Kumbo Tire Co ${ }^{84}$ (MANZANO, 2011). Para entender a importância desses casos para a admissibilidade das provas, é preciso saber que os EUA - assim como outros países de origem anglo-saxã, como o Reino Unido e a Austrália - funcionam juridicamente sob o regime conhecido como Common Law, em que as decisões sobre casos jurídicos se baseia principalmente na Jurisprudência, isto é, no casos e nas decisões anteriores. No Brasil, a estrutura jurídica adotada oficialmente é a Civil Law, o que significa que as leis são a fonte fundamental para o Direito. Dessa forma, os casos supracitados são importantes para admissibilidade de provas científicas, na medida em que eles são casos emblemáticos na jurisprudência americana e que servem até hoje de base para outras decisões acerca da admissibilidade das provas.

A partir de Frye, estabeleceu-se o critério da aceitação geral, segundo o qual poderiam ser aceitas apenas provas fundamentadas em teorias científicas devidamente avaliadas e reconhecidas pela comunidade científica relevante. Contudo, a partir do início da trilogia, com Daubert, em 1993, outros critérios passaram a ser ponderados para a admissibilidade das evidências, seguindo padrões apontados pelas FRE (Federal Rules of Evidence) ${ }^{85}$. Os novos critérios - que começaram a vigorar com Daubert e foram reelaborados posteriormente a partir dos casos Joiner e Kumho - não são exaustivos nem indispensáveis e respondem às seguintes perguntas:

a) O método e as técnicas foram testados e podem ser replicados?

\footnotetext{
${ }^{81}$ Frye v. United States, 293 F. 213 (D.C. Cir. 1923). Caso em que a promotoria dos Estados Unidos queria introduzir o teste de polígrafo como evidência.

${ }^{82}$ Daubert v. Merrell Dow Pharm., Inc., 509 U.S. 579 (1993). Caso em que um grupo de mães alegava que a sua ingestão do remédio Benedictin, tinha feito com que seus filhos nascessem com defeitos.

${ }^{83}$ Gen. Elec. Co. v. Joiner, 522 U.S. 136, 139 (1997). Caso em que Robert Joiner processou a General Eletrics, empresa em que trabalhava como eletricista, alegando que um acidente ocorrido em seu trabalho, envolvendo uma substância tóxica, havia causado seu câncer de pulmão.

${ }^{84}$ Kumho tire CO., LTD., et al. v. Carmichael et al. In the supreme court of the united states (1999). Caso em que Patrick Carmichael processou a fabricante de pneus Kumbo sob a alegação de que o pneu que estourou do carro que dirigia estava defeituoso e que tal defeito foi a causa do acidente que levou à morte de um dos passageiros.

${ }^{85}$ As "Regras Federais da Prova" são aplicadas aos processos civis e penais federais nos EUA, mas também são modelo para muitos dos estados norte-americanos (MANZANO, 2011).
} 
b) O método passou por uma revisão por outros estudiosos da área e foi publicado em veículos relevantes (peer review)?

c) Existe um percentual de erro conhecido ou potencial para o método em questão?

d) Há aceitação geral da teoria usada como fundamento no meio científico relevante 86 ?

e) O desenvolvimento do método e das técnicas foi feito a priori e não exclusivamente para o contexto judicial e caso em questão?

Verifica-se, portanto, que os critérios ${ }^{87}$ estabelecidos pelas FRE e corroborados pela trilogia da admissibilidade objetivam afastar das cortes elementos de prova que tenham sido construídos a partir do que se pode chamar de "junk science"88. Embora sejam nascidos e mantidos no Direito estadunidense, os fatores acima também têm sido empregados em outros locais. Também há casos em que os critérios não são exatamente os mesmos, mas de qualquer forma há um ou mais critérios que se avaliam. Como já vimos, diferentemente do que ocorre nos Estados Unidos, no Reino Unido confia-se mais na experiência do perito do que no método em si (COULTHARD, 2012; MANZANO, 2011). No Canadá, os critérios observados são: relevância, necessidade, ausência de uma regra de exclusão e, a exemplo do Reino Unido, a qualificação do perito (MANZANO, 2011, p. 220). Na Austrália, o assunto passou a ser regulamentado a partir de 1995, com a diferença de que lá os critérios não são observados com objetivo de se aceitar ou não as evidências num processo, mas sim no momento da sentença. Outros países como Itália, Alemanha, Portugal e Brasil "mantêm disposições acerca dos peritos e assistentes, dos laudos e de exames em espécie", mas "nada dispõem sobre critérios ou fatores de admissibilidade da prova técnica ou científica” (MANZANO, 2011, p. 222).

\footnotetext{
${ }^{86}$ Este critério é o mesmo que já existia desde Frye.

${ }^{87}$ Críticas podem ser direcionadas a cada um desses critérios. Manzano (2011) arrola algumas delas.

${ }^{88}$ Em português, algo como "ciência fajuta" ou "pseudociência".
} 


\subsubsection{Busca e apreensão da fonte de prova pericial}

A busca e apreensão está regulamentada nos arts. 240 a 250 do CPP. Ela pode incidir sobre o domicílio ou sobre a pessoa e tem vários objetivos que se relacionam às fontes de prova pertinentes a este trabalho, dentre eles:

- "descobrir objetos necessários à prova de infração ou à defesa do réu”; e

- “apreender cartas, abertas ou não, destinadas ao acusado ou em seu poder, quando haja suspeita de que o conhecimento de seu conteúdo possa ser útil à elucidação do fato" (CPP, Art. 240).

\subsubsection{Textos enquanto "documentos"}

Alguns textos de autoria questionada podem se enquadrar na categoria de prova documental, uma vez que se considera "documento" "qualquer escrito que possa servir como meio de prova, quer tenha sido previamente elaborado com essa finalidade, quer tenha sido feito originalmente com outro fim" (CAPEZ, 2012, p. 402, grifo nosso). É considerado autor de um documento, segundo o Art. 371 do Código de Processo Civil:

I- aquele que o fez e o assinou; II- aquele por conta de quem foi feito, estando assinado; III- aquele que, mandando compô-lo, não o firmou, porque, conforme a experiência comum, não se costuma assinar [...]

Alguns autores, como, por exemplo, Wambier e Talamini (2011, p. 534) e Didier Jr, Braga e Oliveira (2009, p. 147), classificam os autores de um documento, no âmbito jurídico, em dois tipos: autor material versus autor intelectual ${ }^{89}$. Para Wambier e Talamini (2011, p. 534):

Materialmente, é autor aquele que cria o documento, independentemente de ser responsável pelo seu conteúdo, ou seja, é quem elabora o suporte, nele lançando ideias que não são suas. Autor intelectual é quem transmite o

${ }^{89}$ Se o autor material e o intelectual são a mesma pessoa, diz-se que o document é autógrafo; se os autores forem distintos, diz-se que o documento é heterógrafo (DIDIER JR.; BRAGA; OLIVEIRA, 2009, p. 147). 
pensamento que se tornará o conteúdo do documento, ainda que venha a ser materialmente elaborado por outrem.

Tal distinção é relevante em muitas situações. Tome-se como exemplo um caso em que um indivíduo é coagido por outro a escrever um texto que lhe foi ditado. Quem "portou a pena" é o autor material, mas quem “ditou as palavras" é o autor intelectual. É o segundo tipo de autor que interessa nos casos de atribuição de autoria objeto deste estudo.

Se uma das partes lançar dúvidas sobre a autoria de um documento, há a necessidade de atividade probatória. Didier Jr., Braga e Oliveira (2009) dizem que o meio mais comum de se provar a autoria de um documento é a sua subscrição (assinatura). Eles dizem que o reconhecimento da assinatura não é o único meio de reconhecimento de autoria, mas, ao citar outros, não aludem à análise linguística (conforme se mencionou anteriormente, a linguística forense é ainda incipiente no Brasil, o que se reflete em seus manuais de Direito). Contudo, o que fazer quando os documentos não são assinados ou são produzidos inteiramente de modo digital? A presente pesquisa procura preencher essa lacuna.

Nem todo documento precisa ser inserido num processo como prova documental. “Às vezes, o documento é fonte de prova, mas o fato nele representado chega à mente do juiz por outra via, distinta da prova documental” (DIDIER JR.; BRAGA; OLIVEIRA, 2009, p. 141). Documentos podem ingressar no processo depois de terem sido objeto de análise numa inspeção judicial ou numa perícia.

\subsubsection{Exemplos brasileiros da aplicabilidade da análise de autoria forense}

No Brasil, encontram-se casos em que a autoria de textos foi questionada sem que houvesse uma análise linguística capaz de ajudar na decisão sobre quem foi realmente o seu autor intelectual. Seguem alguns exemplos: 
a) Ação Penal no. 50/2006 - 5a Vara Judicial da Comarca de Jaú.

Este caso está relacionado a uma ameaça feita em uma carta anônima, por meio da qual se pretendia extorquir dinheiro. Consta dos autos:

A acusada, visando à obtenção de vantagem econômica naquele montante, redigiu e endereçou uma carta anônima à vítima, afirmando que fazia parte de uma quadrilha envolvida com o tráfico ilícito de entorpecentes, que o irmão da vítima também integrava o bando e que necessitava da referida quantia 'para girar' o negócio, consignando que entregasse o dinheiro sob pena de sua família pagar com a vida. (Apelação no 9113750-80.2007.8.26.0000-Jaú, p. 3, grifo nosso)

A única prova pericial realizada com relação ao documento foi um exame grafotécnico ${ }^{90}$, que determinou que a carta havia realmente sido escrita pela acusada. Ora, o exame grafotécnico prova a autoria material do documento, mas não a sua autoria intelectual. Sua análise linguística traria mais acuracidade à atribuição de autoria.

\section{b) Agravo de Execução Penal no 0471160-74.2010.8.26.0000 - Comarca de Marília}

Neste caso, nem mesmo um exame grafotécnico foi realizado para se tentar identificar o autor de uma carta de autoria questionada. Trata-se de uma carta interceptada em um presídio, em que um dos presos tentava se comunicar com membros da facção criminosa PCC para o possível batismo de novos membros, com instruções para que as normas disciplinares do presídio não fossem seguidas. O preso suspeito de tê-la escrito negou o fato, conforme consta dos autos (p.4).

\section{c) Apelação Criminal, No. 01162901.3/8-0000-000 - Comarca de Cardoso}

Refere-se a um caso de furto em que foi encontrado um bilhete incriminador. Foi realizado exame grafotécnico que comprovou a autoria do bilhete, mas a Apelação foi

\footnotetext{
${ }^{90}$ Consta da Apelação: "No curdo da investigação policial, colheu-se material gráfico da acusada (fl. 12/14), realizouse exame grafotécnico, apurando-se que a carta fora elaborada pela acusada" (p. 4).
} 
realizada pois a defesa acredita que o exame não foi suficiente para determinar a autoria do escrito:

o laudo realizado no bilhete encontrado no local do furto afirmou não haver afinidades suficientes em quantidade e qualidade para imputar-lhe a autoria dos escritos. Ressalta que na última avaliação gráfica houve, ainda, abuso na coleta de material, dada a variação nas grafias, denotando ter sido induzido a escrever "nas mais diversas características" (p.2).

Diante de tal apelação e desconfiança quanto à validade do exame grafotécnico, uma análise linguística de autoria teria sido, mais uma vez, de grande valia para o deslinde do caso.

d) Apelação Criminal Com Revisão n 993.03.,065599-1 - Comarca de São Paulo

A Apelação refere-se a um caso de assassinato em que figuraram várias cartas de autoria questionada, que continham ameaças (p. 4):

Carta anônima endereçada a Normeni anuncia "uma pá de tiro" se o irmão e "Aldinho" não deixassem São Paulo (fl. 20). Em outra missiva, supostamente escrita por Sandra, cunhada do réu, aponta-se como motivo do crime o furto de dinheiro e arma de "Tonho" (fl. 21). Em seu depoimento, Normeni apresentou ainda outra carta, também atribuída a Sandra, com referência a "tarefas do Tonho e do Ladinho" e à posição de que "patrão Boliviano" até considera justo a irmã da vítima "correr atrás do Tonho" (fl. 191).

Apesar da dúvida sobre quem realmente escreveu as cartas, nenhum exame foi realizado.

e) Ananias dos Santos: assassinato em Cunba/SP

Em 2011, Ananias dos Santos foi acusado de matar suas duas irmãs em Cunha/SP. Em julho de 2011, cartas em seu nome, confessando o crime, foram enviadas à Promotoria. Em 2012, ele negou ter escrito as cartas. Segundo a reportagem do site G1, 
ele afirma ter ditado a carta para outro detento que escreveu frases que não correspondem à realidade ${ }^{91}$.

Os exemplos acima apoiam a aplicabilidade da Linguística - mais precisamente das análises linguísticas de autoria - a situações forenses.

Embora raros, encontram-se exemplos brasileiros em que laudos periciais envolvendo análise de autoria textual foram realizados. Um deles é o laudo elaborado por Harkot-de-la-Taille (resumidamente relatado em HARKOT-DE-LA-TAILLE, 2008), em que se analisam uma carta com ameaça de morte, de autoria questionada, e uma entrevista televisiva de autoria conhecida, do indivíduo suspeito de ter escrito a carta. O episódio envolve a ex-primeira-dama de São Paulo, Niceia Pitta, que havia acusado o empresário Jorge Ynes de tê-la ameaçado de morte. A análise de Harkot-de-la-Taille comparou a carta de ameaça com um diálogo (uma entrevista dada à TV Record, no programa Fala que eu te escuto) entre o suspeito e um apresentador e mostrou que os enunciadores dos dois textos eram distintos. Outros casos chegaram ao nosso conhecimento apenas como informação oral, não havendo trabalhos ou documentos públicos oficiais que os descrevam.

\footnotetext{
${ }^{91}$ Disponível em <http://g1.globo.com/sao-paulo/noticia/2012/03/acusado-de-matar-irmas-em-cunha-sp-mudaversao-sobre-crime.html>. Acesso em 26/03/2012.
} 


\section{Estilo e AUTORIA}

He took a letter from his pocket and tossed it onto the table. 'This purports to be from an old friend of mine, Lady Constance

Culmington. I have not seen her for some years. She went to the East. It is exactly the

kind of vague incoherent letter she would write, urging me to join her here and referring

to her host and hostess in the vaguest of terms. The same technique, you will observe'.

(Agatha Christie. And then there were none.)

The language left by a speaker in a recorded message or by a writer in an anonymous letter can likewise be associated with the language known to be used by groups or individuals.

(Gerald McMenamin. Forensic Linguistics: advances in forensic stylistics.) 


\subsection{Idioleto e Estilo}

Como já se mencionou, a ideia de que é possível saber se alguém é o autor de um texto ou um conjunto de textos baseia-se no pressuposto de que o uso linguístico torna-se, ao longo do tempo, um hábito, assim como se tornam habituais outros comportamentos humanos. Segundo Tomblin (2012, p. 177), existem evidências da Psicolinguística, da Sociolinguística, da Linguística de Corpus e dos estudos de Aquisição de Linguagem que mostram que a comunicação é baseada em padrões e em "maneiras preferidas" de expressar as ideias.

Os "hábitos linguísticos" dos indivíduos resultam em seus "idioletos", ou seja, dois ou mais indivíduos diferentes empregam versões diferentes da língua na sua fala ou redação. De acordo com Sapir (1927, p. 900, tradução nossa1), "Nós todos temos nossos estilos individuais [...]. Sempre há um método individual de combinar as palavras em grupos e esses grupos em unidades maiores". Em outro momento, o autor afirma:

Todos sabem que a língua é variável. Dois indivíduos da mesma geração e residentes no mesmo local, falando precisamente o mesmo dialeto e participando dos mesmos círculos sociais, nunca apresentam absolutamente os mesmos hábitos linguísticos (SAPIR, 1949, p. 147, tradução nossa²).

Mais especificamente no campo da Linguística Forense, Coulthard e Johnson (2007, p. 161) afirmam que o linguista aborda o problema de autoria questionada justamente a partir desse ponto de vista teórico. A ideia de que cada indivíduo tenha um modo particular de usar a língua vigora desde quando se apresentou a noção de ethos, na Arte Retórica, de Aristóteles. Na Linguística, o interesse por essa noção pode ser rastreado até Hermann Paul (no final do século XIX) e Sapir (1927) (Cf. COULTHARD; GRANT; KREDENS, 2010), embora o termo “idioleto" só tenha sido cunhado em 1948 por Bloch (KREDENS, 2002b; TURELL, 2010; COULTHARD; JOHNSON, 2007, p. 161).

\footnotetext{
${ }^{1}$ Texto original: "We all have our individual styles [...]. There is always an individual method (...) of arranging words into groups and of working these up into larger units" (SAPIR, 1927, p. 900).

${ }^{2}$ Texto original: "Everyone knows that language is variable. Two individuals of the same generation and locality, speaking precisely the same dialect and moving in the same social circles, are never absolutely at one in their speech habits" (SAPIR, 1949, p. 147).
} 
Pode-se fazer uma correspondência entre os conceitos de idioleto e estilo, na medida em que tanto um quanto o outro dizem respeito ao conjunto de elementos linguísticos que caracterizam um indivíduo. Talvez uma diferença crucial entre eles esteja na abrangência do segundo, conforme preveem estudos mais recentes da Sociolinguística Variacionista, que entendem o estilo tanto como caracterizador de um indivíduo quanto como indicador de uma afiliação social (IRVINE, 2001; ECKERT; RICKFORD, 2001; COUPLAND, 2007). Tal ideia encontra respaldo em Sapir (1927, p. 900, grifo nosso, tradução nossa), para quem o estilo linguístico é “(...) uma faceta cotidiana da fala que caracteriza tanto o grupo social quanto o indivíduo" ${ }^{3}$. Assim, nota-se que Sapir já teorizava acerca do estilo como individual ou social.

Se a definição de idioleto de Bloch é observada mais de perto, nota-se que, já desde o início, o conceito estava relacionado a uma dimensão social da língua, uma vez que é definido como "a totalidade das possíveis elocuções de um falante em um determinado momento enquanto usa a língua para interagir com outro falante"4 (BLOCH, 1948, p. 7, tradução nossa). Vê-se então que, já com Bloch, o idioleto não é tido como simplesmente "a língua de um indivíduo", mas sim compreendido como a relação que essa língua "individual” contrai com a língua "social”. Nessa esteira segue Labov, nos anos 1960, que propõe: “a língua dos indivíduos não pode ser entendida sem conhecimento da comunidade da qual eles fazem parte"5 (LABOV, 2006 [1966], p. 5). Mais especificamente no âmbito da Linguística Forense, Turell (2010) e McMenamin (2002; 2010) têm posições semelhantes. Turell (2010) cunha o termo "estilo idioletal" como não propriamente o "sistema linguístico de um indivíduo", mas sim a forma como um sistema linguístico compartilhado por um grupo é usado de modo distintivo por um indivíduo. Para McMenamin (2010, p. 488, tradução nossa), “o estilo linguístico é o

\footnotetext{
${ }^{3}$ Texto original: "an everyday facet of speech that characterizes both the social group and the individual" (SAPIR, 1927, p. 900).

${ }^{4}$ Texto original: "The totality of the possible utterances of one speaker at one time in using a language to interact with one other speaker" (BLOCH, 1948, p. 7).

${ }^{5}$ Texto original: "the language of individuals cannot be understood without knowledge of the community of which they are members" (LABOV, 2006 [1966], p. 5).
} 
resultado do que um indivíduo seleciona para seu uso do conjunto de ferramentas linguísticas disponíveis para o grupo ao qual pertence"'.

Em termos de filiação teórica, vê-se que as duas principais noções da análise de autoria - idioleto e estilo (este último, individual ou social) - bebem da fonte dos estudos sociolinguísticos iniciados por Labov (1966 [2006]), na medida em que, assim como a Sociolinguística, preocupam-se com a relação entre a variação intrafalante e interfalante, ou seja, entre a variação presente na fala de um mesmo indivíduo e de um grupo de indivíduos.

McMenamin (2002, p.115, tradução nossa) resume a relação entre a variação tanto no nível individual quanto no grupo - e a análise de estilo na língua escrita:

O estilo é o reflexo da variação individual ou dentro de um grupo, na língua escrita. A variação individual é uma consequência das escolhas do escritor dentre o conjunto de todas as formas disponíveis (...). A estilística linguística é a análise científica de marcadores de estilo individuais, observados e descritos no idioleto de um único escritor, bem como os marcadores de estilo de uma classe, identificados na língua ou dialeto de grupos de escritores?

Para as análises forenses de autoria textual, interessam as duas espécies de estilo: individual e social. A primeira vem ao caso quando se quer levantar características que indiquem um indivíduo dentro de uma pequena lista de suspeitos (com seus respectivos textos para cotejo); a segunda quando não se trata de determinar o autor de um escrito, mas sim de identificar perfis, estreitando uma lista de suspeitos.

\subsection{Estilo como distinção, cosseleção e recorrência}

No senso comum, seja em termos linguísticos ou considerando-se qualquer outra manifestação (por exemplo, vestuário, decoração), impera uma oposição entre “ter” ou

\footnotetext{
${ }^{6}$ Texto original: "linguistic style is the result of what an individual selects to use from the array of linguistic tools available to his or her own group" (McMENAMIN, 2010, p. 488).

7 Texto original: "Style is the reflection of group or individual variation in written language. Individual variation is a result of the writer's choices of one form out of the array of all available forms (...). Linguistics stylistics is the scientific analysis of an individual style-markers as observed and described in the idiolect of a single writer, as well as class style-markers as identified in the language or dialect of groups of writers".
} 
"não ter" estilo. O indivíduo "estiloso" é aquele que faz uso de algum recurso que se destaca; aquele cujas escolhas diferem sobremaneira das escolhas da maioria. Essa maneira de pensar o estilo vai ao encontro de duas reconhecidas concepções:

a) o estilo como expressividade: noção proveniente de uma Estilística Linguística, filiada a Bally (1941; 1952 apud FIORIN, 2008, p. 93); e

b) o estilo como desvio: noção advinda de uma Estilística Literária filiada a Spitzer e Damaso Alonso (FIORIN, 2008, p. 95).

Ainda no senso comum, outra ideia sobre o estilo é aquela ligada a um conjunto de características (por exemplo, tendências, gostos, comportamentos, modos de falar) que podem ser associadas tanto a um indivíduo quanto a um grupo.

Essas duas concepções têm em comum o fato de considerar o estilo como algo distintivo. Na língua, ou em outros sistemas semióticos, estilo tem a ver com distinção, conforme observa Irvine (2001, p. 22, tradução nossa $\left.{ }^{8}\right)$ :

O que quer que 'estilos' sejam, em linguagem ou em qualquer outra coisa, eles são parte de um sistema de distinção em que um estilo contrasta com outros estilos possíveis e o sentido social que estes estilos veiculam também contrastam entre si.

Mesmo que as duas grandes vertentes sobre o estilo mencionadas aqui tenham como base a mesma ideia de distinção, para fins de atribuição de autoria, a ideia de estilo como expressividade e a oposição entre "com estilo" e "sem estilo" é ignorada e prevalece a ideia de que todo autor tem um estilo9. Prevalece, ainda, a ideia de que fatos de estilo ocorrem em qualquer tipo de texto e não apenas nos literários - como pode dar a entender uma noção de estilo mais aliada a objetivos estéticos ${ }^{10}$. Isso é importante principalmente em se tratando do contexto forense, no qual, como já se mencionou

\footnotetext{
8 Texto original: "Whatever 'styles' are, in language or elsewhere, they are part of a system of distinction, in which a style contrast with possible styles, and the social meaning signified by the style contrasts with other social meanings" (IRVINE, 2001, p. 22).

9 Tal noção alinha-se à de Discini (2009, p. 8): "Importa desconsiderar a oposição estilo vs. ausência de estilo. Tudo tem estilo, para uma estilística discursiva".

10 “[...] não há razão para considerar o texto literário como locus privilegiado dos fatos estilísticos. Ao contrário, o estilo é um fato discursivo, que se apresenta em qualquer discurso, seja ele verbal ou não verbal" (FIORIN, 2008, p. 106).
} 
anteriormente, figuram textos que muitas vezes não foram elaborados por profissionais da escrita, ou seja, trata-se de textos mais cotidianos.

Se o sentido que permeia as várias definições de estilo está relacionado a distinção ou diferença e se todo autor tem um estilo, seu estudo é fundamental quando se trata de identificar a autoria de um texto ou grupo de textos, ou de excluir suspeitos da lista de possíveis autores. A possibilidade de determinar perfis sociolinguísticos de autores também parte da premissa de que existem estilos enquanto distinção.

A ideia de estilo ou "estilo idioletal" presente na literatura sobre atribuição de autoria forense é a de "cosseleção" ou "combinação" de características linguísticas. McMenamin (2002, p.51) afirma que o estilo linguístico é dado pela recorrência de uma combinação de traços linguísticos, uma "constelação de variáveis", e não pelo estabelecimento de um único traço isoladamente e isso se deve ao fato de que formas linguísticas únicas, singulares, são raras. Love (2002, p. 101), sugere que não é apenas através de uma ou outra característica que se pode reconhecer um estilo, mas pela repetição, pela consistência de uma combinação de características. Na mesma linha, segue Coulthard (2006, p. 1, tradução nossa, grifo nosso) ao afirmar: "embora a princípio qualquer falante ou escritor possa usar qualquer palavra a qualquer momento, eles tendem a usar tipicamente a mesma cosseleção de palavras"11. Rudman (1998, p. 360) afirma que propriedades linguísticas comumente indicadas como potenciais marcadores de estilo (tamanho de palavras, tamanho de sentenças, relação "type/token", etc.) não podem ser tomadas isoladamente, mas se tornam importantes se consideradas em conjunto com outros aspectos. Tais posições vão ao encontro do que afirma Johnstone (2000, p. 417, tradução nossa ${ }^{12}$ ): “os indivíduos criam vozes únicas através da seleção e combinação dos recursos linguísticos que estão disponíveis para eles".

Assim, a identificação de autores ou a elaboração de perfis sociolinguísticos nunca será feita com base em apenas uma característica linguística, mas na combinação de várias delas. Tais características podem aparecer também isoladamente em outros autores, mas é

\footnotetext{
11 Texto original: "whereas in principle any speaker/writer can use any word at any time, in fact they tend to make typical and individuating co-selections of preferred words" (COULTHARD, 2006, p. 1).

12 Texto original: “[...] individuals create unique voices by selecting and combining the linguistic resources available to them" (JOHNSTONE, 2000, p. 417).
} 
improvável que o mesmo conjunto de elementos apareça igualmente em outro autor (McMENAMIN, 2002, p. 172). Fiorin (2008, p. 97) afirma que “o que determina um estilo é o conjunto de traços reiterados e não uma característica isolada". Dizer que os traços devem ser reiterados, é falar em recorrência. Se o estilo é uma combinação de elementos com poder distintivo, tal distinção só pode ser reconhecida se houver recorrência.

\subsection{Estilo como variação intrafalante}

O pressuposto da Sociolinguística variacionista é o de que os usos linguísticos são inerentemente variáveis. De acordo com Labov (2006 [1966], p.3), “A variabilidade é parte integrante do sistema linguístico". Ela é um fato observável tanto no uso linguístico feito por pessoas diferentes, dentro de uma mesma comunidade, quanto nos usos que os mesmos indivíduos fazem da língua nas diferentes situações comunicativas. Conforme Labov, "Tanto quanto podemos ver, não existe falante de estilo único [...], todo falante que encontramos exibe alternância de algumas variáveis linguísticas à medida que mudam o contexto social e o tópico" (LABOV, 2008, p. 243).

Embora a variação linguística seja um consenso e de ter sempre sido observada por estudiosos da linguagem, a sua natureza é controversa. Era comum o pressuposto - e para alguns programas de investigação ainda é - de que a variação é de ordem acidental. Isso porque os dois principais programas de investigação da Linguística Moderna introduziram uma diferença conceitual entre o que seria homogêneo, sistêmico e o que seria heterogêneo, regido pelo uso: o estruturalismo, herdeiro das ideias de Ferdinand de Saussure, trabalhou com a dicotomia Langue/Parole (Língua/Fala), e o gerativismo, cujo precursor foi Noam Chomsky, com Competence/Performance (Competência/Perfórmance). Pode-se dizer que ambos rejeitaram a heterogeneidade como objeto de estudo, concentrando seus esforços na investigação da Langue e da Competence. Assim, para muitos programas de investigação, a variação se encontra apenas na perfórmance, sendo fortuita e aleatória. Foi a partir dos anos 1960, com a Sociolinguística variacionista , que a variação passou a ser encarada como algo sistemático, não aleatório, condicionado por fatores 
linguísticos e extralinguísticos. Weinreich, Labov e Herzog (2006 [1968]) sustentam que a língua não precisa ser livre de variação, homogênea, para ser ordenada, estruturada, regular.

Assim, "no centro da empreitada sociolinguística está a busca por uma explicação do motivo pelo qual os falantes escolhem uma forma linguística e não outra”, diz Kiesling (2009, p. 171, tradução nossa $\left.{ }^{13}\right)$. Uma dessas explicações se concentra na variação que um mesmo falante apresenta, a depender do contexto ou situação (de modo amplo) de comunicação. Quando se considera o estilo no domínio da Sociolinguística, observa-se que os dois primeiros momentos da sua investigação enfocam justamente a variação intrafalante (chamada também de variação estilística).

Labov $(1966,1972)$ estava interessado em mostrar que em diferentes "contextos" ou com propósitos diferentes, o mesmo falante se expressaria de modo distinto, durante uma mesma entrevista sociolinguística, ou seja, ele faria uso de diferentes variantes linguísticas, ou de uma mesma variante com frequências maiores ou menores, nos diferentes momentos da entrevista. A explicação por trás dessa alternância estava ligada à atenção que as pessoas prestam à sua própria fala, sendo que uma maior atenção corresponde a contextos mais formais de comunicação, enquanto contextos mais casuais, com menos formalidade, tendem a ser acompanhados de menos atenção, o que resulta em usos linguísticos distintos.

Num segundo momento, uma nova abordagem para tratar da alternância entre estilos foi sugerida. O modelo foi chamado de Audience Design (BELL, 1984) e sustenta que a alternância entre estilos se dá em resposta aos interlocutores e não apenas à atenção à situação, como no modelo anterior. A base para esse modelo foi a Teoria da Acomodação (Speech Accomodation Theory: GILES, 1973; GILES; POWESLAND, 1975) que é, segundo Schilling-Estes (2001, p.383, tradução nossa) ${ }^{14}$, "um modelo social e psicológico que sustenta que os falantes tendem a ajustar o seu modo de falar de acordo

\footnotetext{
13 Texto original: "At the heart of the sociolinguistic enterprise is the search to explain why speakers choose one linguistic form over another" (KIESLING, 2009, p. 171).

14 Texto original: "a social psychological model which holds that speakers tend to adjust their speech toward that of their addressees, in order to win their approval” (SCHILLING-ESTES, 2001, p.383).
} 
com os seus enunciatários, para obter sua aprovação"15. Um ganho desse modelo com relação ao anterior é a sua abrangência, uma vez que "ele não se limita ao estilos de fala que podem ocorrer na entrevista sociolinguística, mas sim foi pensado para ser aplicável a dados mais naturais, tais como interações conversacionais entre amigos e colegas de trabalho” (SCHILLING-ESTES, 2001, p.383, tradução nossa'6).

A noção de variação intrafalante ou estilística é fundamental na análise de autoria, que se calca da ideia de que a variação interfalante é maior do que a variação intrafalante. A observação da existência de variação intrafalante leva a pensar de que modo se pode determinar um único estilo ao longo de textos de tipos diferentes, sobre diferentes assuntos e com propósitos comunicativos diferentes. Aborda-se mais densamente essa questão no item 2.6 deste capítulo.

\subsection{Estilo como identidade}

Apenas num terceiro momento dos estudos sociolinguísticos sobre o estilo, ele passa a ser considerado também numa dimensão social e visto em termos de identidade. Estudos mais recentes sobre o tema (e.g. ECKERT, 2000, 2001; COUPLAND, 2001, 2007; PODESVA et al. 2001; KIESLING, 1996, 1998), afirmam que ele é um recurso para a criação e apresentação de uma identidade, e não primariamente uma resposta ao contexto comunicacional como nas duas fases anteriores.

Antes de traçar as principais diferenças entre esses estudos de estilo, cabe distinguir os dois principais rumos que as pesquisas sociolinguísticas tomaram e traçar um breve panorama das três principais “ondas" pelas quais a Sociolinguística Variacionista passou desde sua instauração. A Sociolinguística vem se desenvolvendo desde os anos 60 e os fenômenos estudados e os modos de estudá-los têm variado de acordo com os objetivos perseguidos e os pesquisadores envolvidos (DURANTI, 2001, p. 5), já que as

\footnotetext{
${ }^{15}$ Não se pode deixar de reconhecer a influência da Retórica em tal proposição.

16 Texto original: "it is not limited to speech styles in the sociolinguistic interview but is intended to be applicable to more naturalistic data such as conversational interaction with peers and co-workers". (SCHILLING-ESTES, 2001, p.383).
} 
investigações sociolinguísticas transitam entre dois polos: um com tendências mais antropológicas (representado, principalmente, pelos estudos que se iniciaram seguindo as investigações de John Gumperz) e etnográficas (na esteira de Dell Hymes), com pesquisas de cunho qualitativo, e outro de natureza mais linguística propriamente (seguindo as pesquisas de William Labov), cuja metodologia é, em geral, quantitativa. A Sociolinguística Variacionista está relacionada a este segundo polo e, assim, é comum que ela seja associada apenas aos estudos quantitativos da variação. No entanto, ao longo dos anos, a metodologia quantitativa deixou de ser a única dentre os estudos variacionistas e passou a ser mais um modo de examinar a variação, conforme explica Penelope Eckert (2012) que distingue os estudos variacionistas em três "ondas" - vertentes que não se substituem, mas que se complementam, já que tratam do mesmo fenômeno (a variação) sob diferentes pontos de vista e com uma prática metodológica distinta.

Segundo Eckert [20--?], a "primeira onda" é a dos estudos que se voltam para categorias sociais mais “macro”, iniciados por Labov (1966 [2006]), em que o foco está na revelação de correlações entre uma variável dependente e variáveis independentes sociais e linguísticas. Ela resume esse primeiro modo de análise da seguinte maneira (tradução nossa ${ }^{17}$ ): “Os estudos nessa tradição fazem uso de métodos quantitativos para examinar a relação entre a variação linguística e as principais categorias demográficas (classe, idade, sexo, etnia)". Os trabalhos da primeira onda revelaram padrões regulares de estratificação socioeconômica das formas linguísticas (ECKERT, 2012, p. 88). Outra característica importante é que as categorias selecionadas como variáveis independentes são "impostas" aos dados pelo pesquisador, ou seja, são definidas a priori e não etnograficamente definidas.

Sobre a segunda onda das abordagens variacionistas, Eckert afirma que elas: "empregam métodos etnográficos buscando relacionar a variação a categorias mais locais, projetadas pelos participantes” (ECKERT, [20--?], tradução nossa) ${ }^{18}$. Assim, as macro

\footnotetext{
17 Texto original: "The studies in this tradition use survey and quantitative methods to examine the relation between linguistic variability and major demographic categories (class, age, sex class, ethnicity)” (ECKERT, [20--?]). Disponível em < http://www.stanford.edu/ eckert/thirdwave.html>. Acesso em 19/10/2010.

18 Texto original: "The second wave of variation studies employs ethnographic methods to seek out the relation between variation and local, participant-designed categories and configurations. These commonly give local meaning to the more abstract demographic categories outlined in the first wave" (ECKERT, [20--?]. Disponível em < http://www.stanford.edu/ eckert/thirdwave.html>. Acesso em 19/10/2010).
} 
categorias demográfico-sociais dão lugar às "comunidades de práticas" e "redes sociais". Por serem mais etnográficos, os estudos da segunda onda proporcionaram visões mais "locais" dos fenômenos sob estudo. Todavia, assim como os estudos da primeira onda, os da segunda lidam com categorias de certa forma estáticas, ou seja, não recriadas ou reproduzidas pelos falantes em cada ato (ECKERT, 2012, p. 93).

Um trabalho importante considerado de segunda onda é o de Eckert (1989) em que ela enfoca dois grupos sociais antagônicos, em uma escola de ensino médio: os jocks e os burnouts ${ }^{19}$. Eckert mostra que variantes linguísticas co-variam com outras condutas e recursos semióticos na criação e manutenção desses dois grupos.

$\mathrm{Na}$ terceira onda, a perspectiva se inverte, na medida em que enquanto a primeira e a segunda onda enxergam a variação como um reflexo de identidades sociais e categorias, a terceira a vê como uma prática utilizada pelos falantes para criar essas identidades sociais no momento mesmo da enunciação. Nessa perspectiva, o sentido social não é apenas veiculado pela linguagem, mas criado por ela.

Para os autores mais associados à chamada terceira onda, o estilo é um conjunto de variáveis que estão associadas com a "persona" 20 do falante e que também indexam uma afiliação social; ele pode caracterizar um indivíduo ou indicar uma formação social (IRVINE, 2001). Da mesma forma, Schilling-Estes (2001) observa que padrões de variação estilística podem categorizar uma pessoa ou um grupo de pessoas.

No entanto, essas identidades não são estáticas, nem pré-definidas, mas construídas e colocadas em discurso pelos próprios participantes. Assim, uma diferença fundamental entre esse enfoque sobre o estilo e o anterior está pautada pelos vários sentidos sociais que podem ser veiculados. Nas palavras de Rezende (2009, p. 122, grifo nosso) “em Coupland, a 'atenção à fala' do sujeito não é um processo de monitoramento que considere o eixo prestígio versus estigma, mas um recurso elaborativo e criativo, que pode apontar para uma vasta gama de sentidos sociais possíveis". Irvine (2001, p. 23, tradução nossa) sugere que os estilos "são as maneiras pelas quais os falantes, enquanto

\footnotetext{
19 Poderia ser traduzido por algo como "caretas" e "descolados".

20 Pode se associar essa vertente aos estudos de Goffman (1959 [2002]) sobre a representação do "eu”.
} 
agentes no espaço social (e sociolinguístico), negociam as suas posições a objetivos dentro de um sistema de distinções e possibilidades"21.

Um exemplo é o trablho de Coupland (1980), em que se observa a fala de um radialista em Cardiff, no Reino Unido. Tal estudo mostrou que um determinado conjunto de variáveis fonológicas tinha o propósito de projetar uma imagem de competência ou incompetência desse radialista, para efeitos de humor; enquanto outro conjunto projetava graus de pertencimento à comunidade.

Mais uma diferença entre os dois primeiros momentos do estudo sociolinguístico do estilo (mais "responsivos") e o terceiro (mais "agentivo") é a questão da seleção das variáveis. Primeiramente, as variáveis elegidas para observação eram, geralmente, aquelas que tinham alguma relevância para o estudo da estrutura e da mudança linguística frequentemente, variáveis fonológicas e morfossintáticas - ao passo que as abordagens que defendem a agentividade selecionam variáveis que tenham algum significado social, incluindo aí também elementos lexicais, pragmáticos e discursivos (SCHILLING-ESTES, 2001). Além disso, as pesquisas que seguem as primeiras abordagens centram-se na observação de uma única ou muito poucas variáveis em diferentes contextos, enquanto aquelas que se alinham à última abordagem enfatizam o estilo como um conjunto de variáveis que co-ocorrem (ECKERT, 2001). Ainda quanto ao conjunto de variáveis, Eckert afirma que o estilo linguístico é um agrupamento de recursos linguísticos e uma associação deste agrupamento a um significado social. Conforme vimos na seção 2.2, a ideia de cosseleção ou combinação de elementos é justamente a que está na base da estilística forense.

Se o estilo provém da recorrência, da repetição de elementos linguísticos, ele pode ser atrelado à noção de "hábito" e nisso repousa a ideia de que se pode de algum modo identificar um autor ou um grupo ao qual ele pertence. A visão de hábito linguístico encontra respaldo em Bourdieu (1980) e o conceito de habitus. Bourdieu acreditava que os usos linguísticos eram babitus, na medida em que eles estavam sempre relacionados a significados históricos, políticos e sociais. Ou seja, pode-se dizer que ao tomar a palavra,

\footnotetext{
${ }^{21}$ Texto original: I take it that styles in speaking involve the ways speakers, as agents in social (and sociolinguistic) space, negotiate their positions and goals within a system of distinctions and possibilities" (IRVINE, 2001, p. 23).
} 
um enunciador acaba por refletir uma ideologia que indica, por sua vez, o seu pertencimento a um determinado grupo. A visão de uso linguístico enquanto habitus põe em cheque a ideia de que um indivíduo seleciona livremente as formas que vai utilizar. Conforme Coupland (2007, p. 90, tradução nossa)

O conceito de habitus implica que não podemos facilmente (se é que se pode de alguma maneira) afastar as associações ideológicas de nossa maneira arraigada de falar, porque elas resultam de um processo lento de socialização em formas normativas e aceitáveis de falar para os nossos grupos sociais ${ }^{22}$.

A noção de habitus é essencial para a validade da aplicação da analise estilística no contexto forense, principalmente no que diz respeito à determinar um grupo social ao qual o autor pertence, com base em sua ideologia, revelada no texto ${ }^{23}$. Quanto mais habitual o comportamento, mais ele se torna automático e mais difícil é conseguir disfarçá-lo, conforme se comenta no capítulo 1.

As diferenças sociais que os estilos veiculam não são "naturais", mas produto de um conjunto de crenças e valores, de uma ideologia. Ao se instaurar enquanto sujeito discursivo, um indivíduo emprega formas linguísticas que o distinguem ${ }^{24}$ dos grupos sociais dos quais ele não faz parte, aproximando-se, ao mesmo tempo, daquele grupo com o qual se identifica.

Estilos são expressões de identidades. Segundo Groebner ${ }^{25}$ (2004 apud EDWARDS, 2009, p. 16), “identidade” se refere tanto a uma subjetividade, a uma apresentação do "eu", quanto a marcas de pertencimento a certos grupos. Segundo Edwards (2009, p. 19, tradução nossa) ${ }^{26}$ a "essência da identidade é a similaridade". Quando se trata de estilo social, pensa-se o estilo enquanto diferenças entre um grupo e outro, mas essas diferenças devem ser recorrentes dentro de cada grupo, ou seja, deve

\footnotetext{
22 Texto original: "The concept of habitus implies that we cannot easily (if at all) shake off the ideological associations of our own ingrained ways of speaking, because they result from a slow process of being socialised into normative and acceptable ways of speaking for our social groups" (COUPLAND, 2007, p. 90).

23 Proposta melhor desenvolvida mais adiante.

${ }^{24}$ Lembrando que, como diz Irvine (2001), estilo é distinção.

${ }^{25}$ GROEBNER, V. Der Schein der Person: Steckbrief, Ausweis und Kontrolle im Europa des Mittelalters. Munich: Beck, 2004.

${ }^{26}$ Texto original: "The essence of identity is similarity" (EDWARDS, 2009, p. 19).
} 
haver similaridades que indivíduos de um mesmo grupo compartilham. Assim, pode-se dizer que a identidade está relacionada ao estilo social. Segundo Kiesling (2009, p. 175, tradução nossa),

Identidade em uma corrente variacionista está relaciona-se às maneiras como os indivíduos são parecidos ou diferentes de outros indivíduos em um determinado grupo social - daí o seu agrupamento de acordo com características tais como gênero e idade. Desde Labov (196327), tem sido demonstrado que tais tipos de identidade afetam os padrões de variação dos falantes ${ }^{28}$.

Determinar identidades é útil em contextos forenses. Antes de tratar desses contextos mais especificamente, apresenta-se um episódio bíblico que serve de exemplo de como uma característica linguística é associada a uma identidade social:

Jefté reuniu então todos os homens de Gileade e lutou contra Efraim. Os gileaditas feriram os efraimitas porque estes tinham dito: "Vocês, gileaditas, são desertores de Efraim e de Manassés". Os gileaditas tomaram as passagens do Jordão que conduziam a Efraim. Sempre que um fugitivo de Efraim dizia: "Deixem-me atravessar", os homens de Gileade perguntavam: "Você é efraimita?" Se respondesse que não, diziam: "Então diga: Chibolete". Se ele dissesse: "Sibolete", sem conseguir pronunciar corretamente a palavra, prendiam-no e matavam-no no lugar de passagem do Jordão. Quarenta e dois mil efraimitas foram mortos naquela ocasião. (Juízes 12:4-6) ${ }^{29}$

Nessa passagem, os gileaditas derrotaram mais de 40 mil efraimitas e em seguida ocuparam o Rio Jordão. Após o término da batalha, alguns soldados efraimitas remanescentes se disfarçaram de gileaditas e pediram permissão para cruzar o rio. A pronúncia de "Chibolete" versus "Sibolete" era usada como teste para determinar se o indivíduo era ou não proveniente de Efraim. Embora esse seja um exemplo de língua oral, a escrita também revela elementos capazes de relacionar um indivíduo a um grupo social. Nas palavras de Turell (2010, p. 212, tradução nossa),

Os linguistas forenses trabalham com a premissa de que a língua, oral e escrita, provê diversos tipos de informação. A produção linguística de falantes ou

\footnotetext{
${ }^{27} \mathrm{LABOV}, \mathrm{W}$. The social motivation of a sound change. Word, n. 18, p. 1-42, 1963.

28 Texto original: "identity in one current of variationist work has to do with the ways in which individuals are similar to or different from other individuals in a particular social group - hence their grouping on characteristics such as gender and age. These kinds of identities have been shown since Labov (1963) to affect speakers' variation patterns" (KIESLING, 2009, p. 175).

${ }^{29}$ Bíblia online. Disponível em <https://www.bibliaonline.com.br/nvi/jz/12>. Acesso em 15/06/2014.
} 
escritores pode revelar algumas vezes informações sobre a sua idade, gênero, profissão, educação, religião e visão política. Pode também fornecer pistas para a determinação da origem geográfica, etnia ou raça ${ }^{30}$.

Verifica-se que tanto a passagem bíblica aqui citada quanto o caso "devil strip" basearam-se em apenas uma característica linguística, o que, atualmente, não é o que ocorre quando se quer depreender um perfil, conforme explica Shuy (2014, p.73). Tal ideia vai ao encontro da noção de estilo apresentada na seção 2.2: o estilo é dado pela recorrência de uma combinação de elementos.

Análises estilísticas que correlacionam usos linguísticos a grupos sociais têm sido foco de pesquisas Sociolinguísticas (e.g. LABOV, 1966 e 1972; TRUDGILL, 1974; ECKERT, 1989 e 2000). Conforme Edwards (2009, p. 21, tradução nossa),

\begin{abstract}
A importância da língua como uma marca de identidade no nível de grupo é (...) evidente (...): todos estão acostumados a sotaques, dialetos e variações linguísticas que revelam o pertencimento de falantes a determinadas comunidades de fala, classes sociais, grupos étnicos e nacionais; além disso, associam-se falantes quanto ao gênero, ou idade, ou ocupação, ou por seu pertencimento a gangues e clubes, ou afiliação política, ou religiosa, entre outros $^{31}$.
\end{abstract}

Percebe-se, então, que tal perspectiva relaciona-se sobremaneira a este trabalho, uma vez que o exame de um texto com o objetivo de obter informações sobre um autor leva a indagações acerca da identidade desse autor e do modo como ela é construída e indexada por meio do texto.

\footnotetext{
${ }^{30}$ Texto original: "Forensic linguists work with the assumption that oral and written language provides information of several kinds. The linguistic production of individual speakers and writers can sometimes reveal information about an individual's age, gender, occupation, education, religion and political background. It can also provide clues to the determination of an individual's geographical origin, ethnicity or race" (TURELL, 2010, p. 212).

31 Texto original; "the importance of language as an identity marker at a group level is (...) evident (...): everyone is used to accent, dialect and language variations that reveal speakers' memberships in particular speech communities, social classes, ethnic and national groups. As well, such variations are obvious when the groupings are based upon gender, or age, or occupation, or club or gang membership, or political affiliation, or religious confession, and so on" (EDWARDS, 2009, p. 21).
} 


\subsection{Estilo, Semiótica e plano do conteúdo}

Um dos objetivos deste trabalho é integrar o plano do conteúdo, segundo o modelo da Semiótica Discursiva, às análises forenses do estilo textual. Essa vertente da Semiótica, fundada por Algirdas Julien Greimas, é também chamada de Semiótica "francesa" ou "greimasiana" 32.

Herdeira da linguística saussuriana, a Semiótica francesa é uma teoria da significação que busca desvendar os mecanismos de construção do sentido nos diversos tipos de texto, postulando que os discursos são redes de relações e que a partir destas o sentido é gerado. Em outras palavras, o sentido está, não no signo a priori, mas nas relações que um signo estabelece com o outro dentro de cada texto. Além de ser uma teoria da significação, a semiótica é também uma metodologia de análise de textos (ALMEIDA, 2009, p. 11).

Na esteira de Hjelmslev (2003 [1943], p. 53), a semiótica baseia-se na ideia de que um texto é um signo e que esse, por sua vez, é "um todo formado por uma expressão e um conteúdo”. Um conteúdo é, sempre, manifestado por uma expressão. Como vimos na Introdução, o plano do conteúdo é abordado pelos semioticistas sob a forma de um "percurso gerativo do sentido" (GREIMAS; COURTÉS, 2008 [1979]), um simulacro metodológico de uma estrutura analisável, uma "gramática" que está presente em todos os textos. Desde o nível mais profundo do percurso gerativo até a manifestação textual (Figura 6), passa-se de estruturas mais simples e abstratas (pressupostas) para mais complexas e concretas (pressuponentes). A análise semiótica vai para além da manifestação do texto e para além da aparência, buscando os sentidos imanentes dos textos.

\footnotetext{
32 Tal esclarecimento é necessário, uma vez que existem várias linhas de pesquisa que também se chamam "Semiótica". Dentre elas, citamos a Semiótica "peirciana" - cujo fundador foi o americano Charles Sanders Peirce e a Semiótica "russa" - desenvolvida por Yuri Lotman (ALMEIDA, 2007, p. 4).
} 


\begin{tabular}{|ll|}
\hline Plano da & Grafia \\
\cline { 2 - 2 } & Morfossintaxe \\
\cline { 2 - 2 } & Léxico \\
\cline { 2 - 2 } $\begin{array}{l}\text { Plano do } \\
\text { Conteúdo }\end{array}$ & Nível Discursivo \\
\cline { 2 - 2 } & Nível Narrativo \\
\cline { 2 - 2 } & Nível Fundamental \\
\cline { 2 - 2 } & Tensividade \\
\hline
\end{tabular}

Figura 6 - Semiótica Discursiva: plano da expressão e plano do conteúdo na linguagem verbal escrita

São três as etapas do percurso gerativo do sentido, resumidas a seguir ${ }^{33}$.

1) Nivel fundamental: nível mais abstrato que apresenta uma oposição semântica mínima que permeará todo o texto e estará na base de sua construção. Em desenvolvimentos mais recentes, no âmbito da Semiótica Tensiva (TATIT, 2001; ZILBERBERG, 2006a e 2006c), o nível fundamental tem sido visto como um nível em que há oposições ainda mais abstratas do que "categorias semânticas", da ordem, por exemplo, de continuidades e descontinuidades, ou relaxamento e tensão. Fala-se, então, em um "nível tensivo".

2) Nivel narrativo: organização narrativa que está "por trás" de todos os textos; costuma ser formulada em termos de transformações, envolvendo o ponto de vista de um "sujeito" que está em busca de um "objeto". Um sujeito pode estar em conjunção ou disjunção com um objeto; assim, a transformação é a mudança desse estado conjunto ou disjunto.

\footnotetext{
33 Os níveis do plano do conteúdo aqui resumidos serão brevemente explicados no momento da análise que se propõe no capítulo 4. Para uma revisão exaustiva do campo da Semiótica Discursiva, ver Barros (2001; 2003), Fiorin (2005; 2008), Greimas e Courtés (1979 [2008] ), Greimas e Fontanille (1993), Zilberberg (2006a; 2006b; 2006c) e Tatit (2001).
} 
3) Nivel discursivo: o revestimento concreto dos níveis anteriores mais abstratos, levando-se em conta os graus de figuratividade dos conteúdos propostos, bem como as múltiplas estratégias de que se vale o enunciador para engendrar efeitos de proximidade ou distância enunciativa.

Considerando-se a importância do plano do conteúdo para a análise semiótica de textos, é de se esperar que o estudo do estilo nessa teoria considere também esse plano. Greimas e Courtés (2008 [1979], p. 182, grifo nosso) definem como estilísticos aqueles "fatos estruturais pertencentes tanto à forma do conteúdo de um discurso quanto aqueles pertencentes à forma da expressão". Para Fiorin (2008, p. 97, grifo nosso), estilo é "um conjunto global de traços recorrentes do plano do conteúdo (formas discursivas) e do plano da expressão (formas textuais), que produzem um efeito de sentido de identidade. Configuram um ethos discursivo, ou seja, uma imagem do enunciador". Estilo é, então, recorrência e distintividade (ou diferenciação), tanto no plano da expressão quanto do conteúdo (FIORIN, 2008; DISCINI, 2009, 2013).

Percebe-se que a definição semiótica de estilo vai ao encontro do que é o estilo no âmbito da Linguística Forense, conforme descrito na seção 2.2. Fiorin (2008, pp. 96-102, grifo nosso) explica:

Estilo é o conjunto de traços particulares (...). É o conjunto de características que determina a singularidade de alguma coisa (...). O termo estilo alude, então, a um fato diferencial: diferença de um autor em relação a outro, de um pintor relativamente a outro, de uma época em relação a outra, etc. (...). Diferença e repetição são dois momentos no processo dinâmico de produção estilística. $O$ estilo aparece como diferença e, em seguida, fixa-se em esquemas (...).

Discini (2013, p. 79, grifo nosso) observa que "o estilo, como modo de presença de um sujeito dado no ato de enunciar pressuposto a uma totalidade de enunciados, remete a um sujeito discursivo, que deixa rastros de sua identidade naquilo que diz".

A Semiótica postula que as escolhas de um enunciador se dão em todos os níveis, mesmo os mais abstratos. O enunciador seleciona "os valores praticados em todos os estratos gerativos, das estruturas profundas, às de superfície” (TATIT, 2001, p. 19). Sendo assim, o estilo é controlado pela instância da enunciação e, portanto, aparece tanto no 
plano da expressão quanto no plano do conteúdo. Ainda segundo Discini (2009, p. 26. grifo nosso), o estilo:

deverá despontar de um eixo sintático-semântico comum, que se deve apresentar em todos os níveis do percurso gerativo do sentido [...]. Falando em conteúdo e expressão, bem como na relação de pressuposição mútua entre eles, não mais deverá interessar a manifestação textual em si mesma.

A semioticista propõe, ainda, que estilos podem ser depreendidos a partir da comparação de uma totalidade de discursos: “O fato de estilo deverá ser considerado uma unidade formal do discurso, que se depreende pela comparação de vários textos de uma mesma totalidade de discursos” (DISCINI, 2009, p. 26). Segundo ela (2009, p. 28), "cumpre ao analista de estilo (re)construir o ator da enunciação de uma totalidade de discursos".

$\mathrm{Na}$ atribuição de autoria forense, esse ator da enunciação será relacionado a um indivíduo “de carne e osso". Conforme explica Harkot-de-La-Taille (2008, p. 2),

A figura dos laudos periciais acerca da autoria de determinado texto pressupõe a possibilidade de, por meio de uma dada produção textual, estabelecerem-se, com base em marcas linguístico-discursivas, relações de identidade entre o sujeito do discurso - "de papel" - e um cidadão - sujeito "de carne e osso".

Silva (2012) vale-se da Semiótica Discursiva para comparar os estilos de alguns “autores espirituais", psicografados pelo médium brasileiro Francisco Xavier. Em busca do estilo e do ethos desses autores, sua análise baseia-se em uma "observação dos procedimentos, na construção do discurso, das recorrências no modo de utilizar figuras e temas, e das relações axiológicas entre temas e figuras, na constituição de um sistema de atrações e repulsões" (SILVA, 2012, p. 88), ou seja, em elementos que estão em níveis mais profundos dos textos e não na superfície.

Para Greimas e Courtés (2008 [1979] pp. 180, 253), como característica pessoal de um escritor, o estilo está próximo da noção de idioleto, que por sua vez está ligado à variação (indivíduos diferentes usam a língua de forma diferente), e o estilo significa que essa variação estará recorrentemente presente na língua de um indivíduo. 
Discini (2009, p. 31$)^{34}$ resume o que a semiótica considera acerca do estilo:

a) o estilo é apreensível numa totalidade; b) o estilo é um fato diferencial; c) o efeito de individualidade permite a construção do ator da enunciação; d) o ator da enunciação manifesta-se por um ethos (um caráter, que pressupõe um corpo e uma voz ${ }^{35}$ ); e) o estilo é um modo recorrente de refencialização da enunciação no enunciado; f) o estilo constrói-se sobre outro estilo" (DISCINI, 2009, p. 31).

\subsection{Implicações e propostas para análises de autoria}

Um exame da noção de estilo nos quadro teóricos que fundamentam esta tese (Sociolinguística e Semiótica), põe em evidência algumas limitações para uma análise de autoria textual no contexto forense que seja apropriada. Tais limitações referem-se tanto ao estilo individual, conceito fundamental para atribuição de autoria, quanto ao estilo social, fundamental para a elaboração de perfis sociolinguísticos. Nesta seção, almeja-se retomar esses problemas, que se relataram brevemente na Introdução e, em seguida, descrevem-se as propostas para sua solução.

\subsubsection{Plano do conteúdo na atribuição de autoria}

Até aqui, viu-se que a atribuição de autoria fundamenta-se na ideia de que cada indivíduo faz um uso particular da língua e que este uso o distingue de outros indivíduos ${ }^{36}$. No entanto, as pesquisas sociolinguísticas têm evidenciado que um único indivíduo utiliza a língua de modo diferente, dependendo de vários fatores, tais como tema, destinatário, registro, gênero textual, "meio" de comunicação. Dessa forma, o "mundo ideal” para uma análise de autoria é a existência de textos para comparação que tenham sido escritos com o mesmo propósito, o mesmo registro, o mesmo gênero do texto questionado e a

\footnotetext{
${ }^{34}$ Essas características do estilo são relevantes tanto quando se trata de depreender o estilo de um indivíduo quanto de um grupo.

35 O estilo enquanto “corpo" é objeto de trabalho recente de Discini (2013), no âmbito da Semiótica Discursiva. Os desdobramentos dessa ideia, no entanto, ainda não são levados em conta por este trabalho.

${ }^{36}$ Conforme Introdução, seção 2.
} 
destinatários semelhantes, eliminando-se, assim, a questão da variação intrafalante. De fato, é essa a situação que permeia os casos de atribuição de autoria não-forenses, ou seja, quando se deseja revelar a autoria de textos literários ou religiosos, por exemplo. A esse respeito, Grieve (2007, p. 255, tradução nossa ${ }^{37}$ ) adverte:

Ao se determinar a autoria de um texto anônimo [ou questionado], é desnecessário e pouco seguro compilar um corpus de textos dos autores suspeitos que tente representar toda a variedade de textos que aquele autor pode produzir: o texto questionado é produto de uma situação única e então cada corpus deveria ser constituído de textos produzidos no registro mais similar possível, para uma audiência o mais parecida possível [...]. De outro modo, o investigador pode obter falsos negativos [...]. É melhor coletar um corpus que represente o menor grau de variação na língua daquele autor.

Essa situação ideal, no entanto, não é a regra em casos na esfera forense, em que, conforme se elaborou na Introdução, os escritos cotejados são habitualmente distintos com relação às suas situações de produção. Por exemplo, o texto de autoria questionada pode ser um bilhete de resgate e os textos colhidos para o confronto - por vezes os únicos que a polícia conseguiu obter - podem ser diferentes em muitos aspectos (já que podem surgir aí textos como mensagens de celular, posts em redes sociais, e-mails, cartas, textos de blogs, diários - todos mais ou menos formais - entre outros). Em outras palavras, não se pode garantir - e é até mesmo improvável - que se consigam textos que tenham sido escritos obedecendo-se a todos os fatores que compõem a situação de produção do bilhete de resgate. Muito menos provável é que se obtenham dos autores suspeitos outros desses bilhetes.

Para resolver esse problema, é preciso encontrar elementos que não variem (ou que, pelo menos, variem menos) em textos muito diferentes de um mesmo autor. Assim, esta pesquisa testa a hipótese de que tais características podem ser encontradas no plano do conteúdo. Não se fala do conteúdo enquanto sinônimo de tema, mas sim, enquanto

\footnotetext{
37 Texto original: "When attributing an anonymous text, it is unnecessary and unsound to compile an author-based corpus that attempts to represent the variety that encompasses all that author's written utterances: the anonymous text is the product of a single situation and so each author-based corpus should be composed of texts produced in the most similar register, for the most similar audience, and around the same point in time as the anonymous text. Otherwise, the investigator might get false negatives: when the anonymous text is compared to the writings of its author they may not match because of variation that is the product of differences in audience or register or time. Rather, it is best to compile author-based corpora that represent the narrowest variety of language possible" GRANT (2007, p. 255).
} 
organização sintática do discurso, um conjunto de categorias, uma gramática que subjaz todos os textos, conforme propõe a semiótica greimasiana.

Como mencionou-se na Introdução, vale lembrar que a semiótica funda-se na pensamento hjelmsleviano segundo o qual a língua é expressão e conteúdo - um desenvolvimento da dicotomia saussuriana entre significante e significado (SAUSSURE, 2002 [1916], p. 79). Partindo dessa noção de língua, observa-se que os diversos métodos que medem o estilo (ver capítulo 1, seção 1.2) consideram elementos que estão na superfície textual, ou seja, no plano da expressão. São dois os problemas em se considerar apenas esses elementos, em detrimento das categorias do plano do conteúdo. O primeiro reside no fato de que os discursos são textualizados em níveis que vão do mais abstrato ao mais concreto. Sendo assim, o nível da manifestação (o plano da expressão) é o mais concreto e, por consequência, o mais "numeroso". Isso significa dizer que uma ou poucas categorias de um nível mais profundo podem ser manifestadas por um leque muito grande de opções. Quanto mais opções um indivíduo tem, maior a possibilidade de variação. A variação intrafalante é, pois, abundante no plano da expressão. O segundo problema está no fato de que as características textuais do nível da manifestação podem indicar um estilo se aparecerem recorrentemente. Os textos forenses, porém, são relativamente curtos o que impede que isso aconteça.

Partindo dessas dificuldades, aventaram-se as seguintes hipóteses:

1) A variação intrafalante tende a ser menor na medida em que se "desce" para os níveis mais "profundos" do plano do conteúdo. Isso deve ocorrer porque, quanto mais abstrato/simples o nível no plano do conteúdo, menos alternativas há para os indivíduos, o que leva a chances maiores de sempre repetir "as mesmas coisas", isto é, organizar os textos segundo as mesmas categorias. Se com essa grande chance de realizar sempre as mesmas escolhas, dois indivíduos distintos escolhem recorrentemente as mesmas opções, mas diferentemente um do outro, isso significa que a opção de cada um tem grande poder discriminatório.

2) Uma vez que a organização do plano do conteúdo, principalmente no que diz respeito aos seus níveis mais profundos (fundamental/tensivo e narrativo) sempre existe, mesmo que de modo pressuposto, em todo e qualquer tipo de texto, independentemente 
de seu tamanho, um método de análise de autoria que incorpore essas categorias se tornaria mais independente do tamanho dos textos e, por isso, mais favorável ao contexto forense.

Os capítulos 4 e 5 apresentam análises com a finalidade de testar essas hipóteses, examinando, dessa forma, a adequação da incorporação do plano do conteúdo às análises forenses de autoria textual.

Outras duas vantagens da análise semiótica do plano do conteúdo na esfera forense são:

a) Se o estilo não se dá por uma ou outra característica textual isoladamente, mas por uma combinação de características, quanto mais delas puderem ser examinadas, maior a acuracidade da análise, já que, quanto mais elementos puderem ser agregados, mais se vão estreitando as probabilidades de que exatamente os mesmos elementos ocorram em outros autores.

b) Por se tratar de características discursivas subjacentes tanto a textos orais quanto escritos, podem ser analisados comparativamente textos provenientes dessas duas modalidades linguísticas, a exemplo do trabalho de Harkot-de-la-Taille (2008), em que se comparou uma carta de ameaça (texto escrito) com uma entrevista televisiva (texto oral).

\subsubsection{Estilos sociais e perfis sociolinguísticos: os universos discursivos}

A Introdução mencionou que outro problema que se coloca com relação à depreensão de perfis sociolinguísticos de autores - e que também é uma questão para a sociolinguística em termos gerais - é definir o que se toma como grupo social. Vimos que os estudos mais "tradicionais" em Sociolinguística buscam as correlações entre os usos linguísticos e as categorias socio-demográficas (por exemplo sexo, escolaridade, idade, classe social, etnia). De fato, apreender essas categorias é importante no contexto forense e o capítulo 3 desenvolve uma análise em torno de uma delas - sexo/gênero. No entanto, como muitos dos textos que aparecem em casos forenses são comumente breves 
e as variáveis linguísticas que poderiam indexar essas categorias socio-demográficas são escassas, torna-se quase impossível a tarefa de depreender um perfil socio-demográfico. Nesses casos, pode entrar em cena a outra gama de estudos sociolinguísticos, que retomam a preocupação com outros significados sociais da variação. Podem existir usos linguísticos relacionados a outros tipos de agrupamentos sociais que não necessariamente as categorias demográficas.

Alguns desses grupos são as chamadas "comunidades de práticas", definidas como "um grupo de pessoas que se engajam mutuamente em torno de uma empreitada" (ECKERT; McCONNELL-GINET, 1992, p.46, tradução nossa) ${ }^{38}$ e que "precisam estar juntas para que realizem as suas práticas comuns" (MEYERHOFF, 2001, p.527, grifo nosso, tradução nossa ${ }^{39}$ ), como, por exemplo, frequentadores de um clube, de um bar, membros de uma associação, trabalhadores de uma mesma empresa, etc. O trabalho de Silva e Dias (2014) acerca das identidades reveladas por crianças que trabalham com o tráfico de drogas, na cidade de Vitória da Conquista-BA, em seus depoimentos à polícia, é um exemplo interessante na academia brasileira, ligado à Linguística Forense. Trata-se de identificar os marcadores linguísticos desse grupo.

Contudo, práticas e crenças que se depreendem recorrentemente em textos de um autor podem ser associadas a grupos que não sejam necessariamente comunidades de práticas, ou seja, grupos cujos membros não precisem estar juntos. Seus integrantes seriam membros de um mesmo "universo discursivo" ou da mesma "comunidade virtual" e não da mesma "comunidade de práticas". São casos em que mesmo que se adotasse uma perspectiva mais local e "micro" do que se considera grupo social (como por exemplo, as comunidades de práticas) para a elaboração dos perfis sociolinguísticos, isso não daria conta dos textos que revelam pertencimento do autor a outros tipos de grupos que não sejam necessariamente essas comunidades.

A seção 3.2 do capítulo 3 apresenta uma análise que corrobora essa ideia, mostrando, ainda, que não são só "variáveis linguísticas" que indexam pertencimento a

\footnotetext{
38 Texto original: "an aggregate of people who come together around some enterprise" (ECKERT; McCONNELLGINET, 1992, p.46).

39 Texto original: "need to get together in order to engage in their shared practices" (MEYERHOFF, 2001, p.527).
} 
esses grupos, mas também outros elementos, o que vai ao encontro do que diz Eckert (2001) ao afirmar que o estilo é um agrupamento de recursos linguísticos e uma associação deste agrupamento a um significado social. A autora fala em "recursos linguísticos" e não apenas em "variáveis linguísticas". Segundo ela (ECKERT, [20--?], tradução nossa), a terceira onda "enxerga estilos, mais do que variáveis, como diretamente associados com categorias identitárias e explora a contribuição das variáveis para a criação dos estilos" ${ }^{40}$. Não são apenas as variáveis linguísticas, no sentido laboviano do termo ${ }^{41}$, que contribuem para a criação dos estilos. Outros elementos podem ter esse caráter e a recorrência semântica, foco da análise, é um deles.

Um exemplo pode ser dado com textos retirados do corpus CGAA. Uma das autoras contribuiu com 34 textos que eram posts ou mensagens privadas da rede social Facebook, além de algumas mensagens SMS. Em vários deles, existem palavras ou expressões que remetem ao "cuidado com o corpo" ou à manutenção de peso. Percebe-se a instauração de grupos opostos: os que cuidam do corpo versus os que não cuidam. $\mathrm{O}$ primeiro é valorizado positivamente; é aquele com o qual o enunciador se identifica. Criase a identidade de membro de um grupo com determinadas crenças e práticas, de membro de um certo universo discursivo. Vê-se que o grupo "pessoas que se preocupam com o corpo" é uma espécie de "comunidade imaginária 42 ", em que seus membros não necessariamente interagem de forma direta e, por vezes, nem se conhecem. Seguem trechos desses textos (grifo nosso):

1. Oieee! Tudo bem! Eu achei mto linda... O povo da academia ficou olhando hj!

2. Por isso que cortar o chocolate da dieta é um dos tratamentos recomendados a pessoas alérgicas.

3. Como está com a dieta?

\footnotetext{
40 Texto original: "it views styles, rather than variables, as directly associated with identity categories, and explores the contributions of variables to styles" (ECKERT, [20--?]). Disponível em <http://www.stanford.edu/ eckert/thirdwave.html>. Acesso em 19/10/2010.

${ }^{41}$ Uma variável é definida como duas ou mais maneiras de se dizer a mesma coisa.

42 O termo "imagined comunities" foi cunhado por Anderson (1983) para designar o tipo de relacionamento que membros de uma nação contraem entre si, já que eles possuem um sentimento de pertencimento a um grupo, embora não interajam face a face com todos os outros membros. Apesar de ter sido criado especificamente em relação à ideia de nacionalismo, o termo têm sido usado para designar também "comunidades de interesse" (BRIARD; CARTER, 2013). Disponível em < http://niagaraknowledgeexchange.com/wpcontent/uploads/2013/12/Communities-of-Practice-Interest_Nov2013.pdf>. Acesso em 28/07/2014.
} 
4. Ai, eu tô sem malhar faz 2 dias por causa do show do xxxx e eventos da xxxx essa semana, estou pra ficar louca! Fico mega ansiosa quando não vou...

5. Seu caso nao eh de cirurgia do estomago. A lipo esc. Ele tira da barriga e soc na bunda, por exemplk. Acho q ele pode sugerir pra vc uma abdominoplastia, puxa a pele e corta

6. Eu sei que tenho tendência a ser bulímica pq tenho vontade de vomitar depois que como, ou tomar laxante... rs Eu comprei diet shake, pq vc não tenta? Comprei um que tem sabor de vitamina, achei mor bom...

7. Nem fui malhar hj, tô com mta cólica...

8. Estou praticamente de dieta pq nao comi direito ontem, sabe quando vc se sente fraca?

9. Eu sou meio neurótica com barriga... Não tomo refrigerante e "tento" não comer nada mto calórico à noite. Antigamente eu era completamente bitolada, agora estou melhor. Mas o fato é que tenho medo de ficar com o corpo da minha irmã, que não se cuida e faz criação de celulite... rsrsr

10. meu médico se chama ACADEMIA!

11. Parei de encher a cara de pao, quer dizer, diminuí... Antes de almoçar e jantar eu como eu prato cheio de salada e depois uma carninha com pouco arroz. E tomo mto chá pq enche a pança.

12. Finalmente, depois de tanto assistir "The Walking Dead", tive meu primeiro sonho com zumbi! E vc estava nele, xxxx! Tb estava o He-Man e o gato guerreiro! eu tinha marcado de correr com vc e ia te encontrar numa rua aí (...).

Caso esses textos fossem parte de uma situação real de investigação, suspeitos poderiam ser eliminados ou incluídos pela polícia com base na diferença ou semelhança figurativa de seus textos.

A recorrência semântica é depreendida por meio da análise do nível discursivo dos textos, que é um dos níveis de análise do plano do conteúdo, segundo o modelo da Semiótica Discursiva. Tal nível é constituído pelos temas e as figuras que recobrem os valores dos níveis fundamental e tensivo e as transformações da estrutura narrativa. Nele “todas as formas abstratas do nível narrativo são revestidas de termos que lhe dão concretude" (FIORIN, 2005, p.41). Dentre os níveis do plano do conteúdo, o nível discursivo é, portanto, o mais concreto e também o mais variável. Por exemplo, o estado de um Sujeito em disjunção com um Objeto, próprio do nível narrativo, pode ser revestido de muitas formas no nível discursivo; pode aparecer como alguém que quer uma casa e não a tem, ou um animal que quer um dono e não o tem, ou uma princesa que quer se casar, etc. A semântica do nível discursivo é o locus da dimensão figurativa dos textos. Segundo Greimas (1981 [1976], p.44, grifo nosso), "podemos perguntar se não seria o caso de considerar a forma figurativa da comunicação como uma das 
características principais da dimensão semiótica da sociedade". Se admitimos que sim, então faz todo sentido que este seja o nível que revela o pertencimento a algum tipo de grupo social.

Especificamente sobre indivíduos como parte de grupos que se constituem linguístico-discursivamente, Greimas afirma que as pessoas podem participar

não de grupos sociais propriamente ditos, mas de 'comunidades de linguagem' restritas, de grupos semióticos caracterizados pela competência que possuem em comum os indivíduos que deles fazem parte para emitir e receber certo tipo de discurso (GREIMAS, 1981 [1976], p.42).

Assim, os grupos mencionados por Greimas se assemelham aos universos discursivos propostos neste trabalho. Um universo discursivo seria, então, um conjunto de práticas, valores e ideologias que formam uma espécie de grupo semiótico. A análise da seção 3.2 do capítulo 3 pretende exemplificar como isso se dá.

A ideia de um universo discursivo associa a língua a outros sistemas semióticos, o que vai ao encontro da definição de Irvine de estilo:

enquanto dialeto e registro, ao menos como sociolinguistas geralmente os definem, apontam apenas para fenômenos linguísticos, o estilo envolve princípios de distintividade que podem ir além do sistema linguístico para outros aspectos do comportamento que são organizados semioticamente (IRVINE, 2001, p. 32, tradução nossa ${ }^{43}$ ).

Isso, por sua vez, é semelhante ao conceito greimasiano de Sociossemiótica. Segundo Greimas e Courtés (2008 [1979]),

\footnotetext{
Enquanto se põem em relação classes sociais tradicionais (aristocracia, burguesia, povo) por um lado e registros de língua por outro, a aproximação é geralmente aceita como uma evidência. Mas os critérios utilizados para estabelecer a estratificação social de nossas sociedades industriais (tais como os "modos de vida": comportamentos vestimentares, culinários, de habitação, etc.) parecem estar ligados, para o semioticista, a práticas significantes que pertencem àquilo que ele considera como sendo o vasto domínio das semióticas chamadas não linguísticas.
}

\footnotetext{
${ }^{43}$ Texto original: "whereas dialect and register, at least as sociolinguists ordinarily identify them, point to linguistic phenomena only, style involves principles of distinctiveness that may extend beyond the linguistic system to other aspects of comportment that are semiotically organized" (IRVINE, 2001, p. 32).
} 
Nas palavras de Irvine (2001, p. 23, tradução nossa), o estilo é "uma semiose de distintividade social"44. A análise de Eckert (sobre jocks e burnouts) também vem ao encontro dessa ideia:

Com práticas e ideologias fortemente opostas, os jocks e os burnouts desenvolvem a sua oposição de um elaborado complexo estilístico que envolve vestimentas, maquiagem, estilos de cabelos, joias e acessórios, uso de substâncias, território, conduta, a relação com o corpo, etc. - e, claro, a língua (ECKERT, 2001, p. 124, tradução nossa ${ }^{45}$ ).

Quando se fala sobre estilo, se fala sobre um processo de combinação de elementos do comportamento com o significado social. Se uma garota começa a falar palavrões, isso por si só não constitui um estilo, mas se combina com uma série de outras coisas que ela faz para formar um estilo (...). O leitor pode parar para pensar de que maneira combinações de gramática, léxico, entonação, fonologia segmental, marcadores discursivos e tipos de atos de fala - por exemplo - poderiam ser combinados com o emprego dos palavrões para constituir diferentes personae (...). A diferença no uso das variáveis linguísticas por jocks e burnouts é apenas uma pequena parte do trabalho estilístico que se põe a criar diferenças entre duas categorias opostas. Jocks e burnouts têm territórios distintos (...). Eles se vestem de modo diferente (...). Eles usam diferentes penteados (...). As meninas usam maquiagem de modos diferentes (...). Os burnouts ostentam o uso de substâncias controladas (particularmente cigarros), aos passo que os jocks participam de atividades "anti-fumo" (...). Eles ouvem diferentes tipos de música, frequentam lugares diferentes, fazem coisas diferentes (ECKERT; McCONNELL-GINETT, 2013, p. 264, tradução $\left.\operatorname{nossa}^{46}\right)$.

Em termos linguísticos, Eckert estava preocupada em identificar variantes que indexassem essas diferenças. Uma vez que no contexto forense os textos são usualmente curtos e escassos, a tarefa de encontrar essas variantes é muito dificultada. Por isso, propõe-se que se olhe para outros elementos linguísticos (a recorrência semântica, no

\footnotetext{
44 Texto original: “a social semiosis of distinctiveness” (IRVINE, 2001, p. 23).

45 Texto original: "With strongly opposed practices and ideologies, the jocks and the burnouts develop their opposition through an elaborate stylistic complex that involves clothing, makeup, hair style, jewelry and other adornment, use and display of substances, territory, demeanor, body hexus, and so on and on - and, of course, language" (ECKERT, 2001, p. 124).

46 Texto original: "When we talk about style, we are talking about a process that connects combinations of elements of behavior with social meaning. If a girl takes up swearing, the swearing itself does not constitute a style, but it combines with all the other things she does to constitute a style(...). The reader might stop to think about how combinations of grammar, lexicon, intonation, voice quality, segmental phonology, discourse markers and speech act types - for example - would combine with swearing to constitute quite different personae (...). The difference in use of linguistic variables by jocks and burnouts, as discussed in chapter eight, is only a small part of the stylistic work that goes into the creation of difference between the two mutually opposed categories. Jocks and burnouts have distinct territories (...). They wear different clothing. (...). They had different hairstyles (...). The girls wore different makeup (...). The burnouts flaunted the use of controlled substances (particularly cigarettes) while the jocks participated in antismoking activities in the school (...). They listened to different music, went to different places, did different things" (ECKERT; McCONNELL-GINETT, 2013, p.264).
} 
caso deste trabalho) que sejam capazes de exercer este papel indexical. Buscar apenas variáveis fonético-fonológicas ou morfológicas, presentes na superfície dos textos, como usualmente se faz em pesquisas sociolinguísticas, deixaria de lado o plano do conteúdo, parte integrante da língua. Por consequência, outros recursos - como, por exemplo, a recorrência semântica - não seriam considerados.

Segundo Greimas e Courtés, (2008 [1979], p. 480), “as variações socioletais são encontradas tanto no nível da superfície lexical quanto no das organizações discursivas", ou seja, seria possível associar variações sociais não só a variações linguísticas propriamente ditas (do plano da expressão), mas "semiolinguísticas", do plano do conteúdo. Dessa forma, para uma sociolinguística interessada em entender como um falante/escritor exibe a sua afiliação a um grupo por meio de sua fala ou escrita, ir além do plano da expressão para o plano do conteúdo é imprescindível, o que nos leva a pensar que olhar exclusivamente para o que a Sociolinguística considera variáveis não é suficiente. Tal ideia vai ao encontro do que diz Eckert ([20--?], tradução nossa, grifo nosso) quando ela afirma que a "terceira onda da sociolinguística" está interessada em "qualquer material linguístico que sirva a um propósito social/estilístico" ${ }^{47}$. Analisar a recorrência semântica em um texto leva o linguista a apreender os seus temas e, nestes, pode haver pistas das práticas ou ideologias compartilhadas pelo autor com os grupos sociais aos quais pertence.

Pensa-se que outras categorias discursivas (do plano do conteúdo) também poderiam ser arroladas e associadas a grupos sociais. Por exemplo, pode-se perguntar se um determinado modo de instauração da categoria de pessoa nos textos (primeira ou terceira pessoas, conferindo maior ou menor subjetividade) pode ser relacionado a determinados grupos sociais. Pessoas de uma certa classe social, com um certo nível de escolaridade estariam mais propensas a escrever os seus textos de uma forma mais concisa ou mais prolixa? Haveria uma tendência a escreverem textos mais temáticos ou mais figurativos? Esses são alguns exemplos de "variáveis discursivas" que podem vir a ser consideradas.

${ }^{47}$ Texto original: "any linguistic material that serves a social/stylistic purpose" (ECKERT, [20--?]). 


\section{ANÁlises de Estillos} SOCIAIS PARA ELABORAR PERFIS

\section{SOCIOLINGUÍSTICOS}

He [Sherlock Holmes] threw over a sheet of thick, pink-tinted note-paper which had been lying open upon the table. "It came by the last post," said he. (...). The note was undated, and without either signature or address [...]. "The man who wrote the note is a German. Do you note the peculiar construction of the sentence

- 'This account of you we have from all quarters received.' A Frenchman or Russian could not have written that. It is the German who is so uncourteous to his verbs".

(Arthur Conan Doyle. A Scandal in Bohemia.)

The world is full of social styles.

(Nikolas Coupland. Style.) 
A epígrafe a este capítulo apresenta um trecho de $A$ Scandal in Bohemia em que o famigerado detetive Sherlock Holmes conversa com seu amigo, Dr. Watson, sobre um bilhete anônimo que recebera. Holmes estabelece uma relação entre a falta de cortesia "no uso do verbos" e a nacionalidade alemã. Chegar a tal conclusão de modo tão súbito pode não ser factível, mas o texto fictício apresenta um interesse real: o de tentar depreender um certo grupo social a partir de um texto, no decorrer de uma investigação, conforme discutiu-se anteriormente. Neste capítulo, apresentam-se dois exemplos de análise (deve-se, na verdade, enxergá-los como “análises-piloto”). O primeiro diz respeito a uma categoria demográfica e o segundo trata de um universo discursivo.

O objetivo desses dois exemplos, embora sejam estudos preliminares e que tenham levado em conta pouca quantidade de dados, é mostrar como a análise sociolinguística e discursiva pode ter um lugar na elaboração de "perfis sociolinguísticos".

\subsection{Sexo e gênero no Facebook}

O capítulo 2 relatou que estudos sociolinguísticos têm demonstrado correlações entre usos linguísticos e categorias sociais (ou "fatores externos"), tais como idade, classe social, escolaridade, sexo/gênero e etnia (e.g. LABOV, 1996, 1972 e 2001; CHAMBERS, 1995; CHAMBERS, TRUDGILL e SCHILLING-ESTES, 2001). Esta seção concentrase na categoria sexo/gênero e tem por objetivo apresentar a análise de um conjunto de textos escritos em português brasileiro, com destaque para as características linguísticas que podem ser associadas à redação por parte de homens ou mulheres, no contexto específico de comunicação escrita na rede social Facebook.

A motivação forense para tal estudo está no fato de que têm sido relatados casos de insultos e ameaças feitos através de falsos perfis em redes sociais online (Facebook, Twitter, etc.) ou via e-mails anônimos. Grant e MacLeod (2012, p. 210) afirmam que se tem notado o aumento do uso de comunicações online para a organização e a realização 
de uma variedade de crimes, e também para a disseminação de material criminoso. Segundo Marquilhas e Cardoso, (2012, p. 417),

com a divulgação de ficheiros pela internet (correio eletrônico, twitter, blogues, facebook), multiplicam-se os problemas criados pela fraude textual, a qual tem sobretudo três facetas: a dos textos apócrifos, a dos textos plagiados e a dos textos anônimos. Tornou-se extremamente fácil escrever fraudulentamente em nome de outros, usar fraudulentamente os textos de outros ou ocultar com máfé o próprio nome aquando da partilha de um enunciado escrito.

O estudo das práticas linguísticas nessas mídias torna-se, portanto, de grande relevância para a Linguística Forense. Também podem ser citados como exemplos de trabalhos direcionados a elas Silva et al (2011) e Herring e Paolillo (2006).

Segundo pesquisas sociolinguísticas, pessoas de sexos diferentes usam a língua de maneira diferente (e.g. LABOV, 1972; CHAMBERS, 1995; HOLMES e MEYERHOFF, 2003; CAMERON e KULICK, 2003). Isso leva à ideia de que investigar características linguísticas relacionadas aos sexos/gêneros nos textos é útil num contexto forense, uma vez que determinar o sexo de um autor é um passo para identificar quem estava ao teclado.

As características linguísticas que podem indicar o sexo/gênero podem variar de acordo com o gênero textual. Assim, o ideal em um estudo que pretenda identificar se um texto pertence a um homem ou uma mulher é partir de um corpus de referência específico do gênero ou tipo textual que se quer investigar, em vez de partir de "fora para dentro", a exemplo dos trabalhos de Herring e Paolillo (2006), que examinam weblogs e de Argamon et al (2003) e Koppel e at (2002), que se concentram em textos literários. O corpus utilizado aqui é composto por 200 textos extraídos da rede social Facebook (mensagens privadas, mensagens de status e comentários) ${ }^{1}$, de 20 autores diferentes: 10 homens e 10 mulheres $^{2}$ na faixa etária de 20 a 35 anos. Todos os textos foram coletados dentre autores que podem ser considerados, nos termos de Bayeen et al. (2002), "nä̈ve writers", ou seja, não são, de modo algum, profissionais da escrita. Produzidos, então, por indivíduos

\footnotetext{
${ }^{1}$ Um estudo mais completo poderia considerar, também, o interlocutor de cada um desses enunciadores. Ou seja, sexo/gênero do interlocutor entraria como um fator a influenciar a escolha do enunciador.

2 A referência a "homens" e "mulheres" aqui diz respeito ao sexo dos falantes. Vale ressaltar que conheço todos os informantes; dessa forma, não há como elementos linguísticos estarem sendo atribuídos erroneamento a cada um dos sexos. Outra preocupação foi limitar a amostra apenas a autores que se identificam como heterossexuais.
} 
“normais", esses textos são bastante próximos daqueles que via de regra aparecem em casos forenses reais: são curtos, escritos para uma audiência limitada, não muito planejados. Quando da coleta dos textos, os informantes/autores foram solicitados a nos enviar textos que já tivessem produzido a priori, coletados aleatoriamente de seu perfil na rede social. Como se mencionou na Introdução, as solicitações foram feitas a pessoas de meu convívio, tais como amigos, familiares e alunos.

Uma primeira análise, qualitativa, dos textos permitiu estabelecer algumas características linguísticas que parecem ser comuns ao gênero "mensagens em redes sociais", em português. Elas estão listadas no Quadro 3, a seguir:

\section{PONTUAÇÃO}

Ponto de exclamação

Repetição de ponto de exclamação ou de interrogação

Reticências

Reticências "estendidas"

"Erros" de pontuação

\section{GRAFIA/ORTOGRAFIA}

Uso de caixa alta

Erros de acentuação gráfica

Repetição de letras

"Erros" de ortografia

Uso de abreviações e siglas

\section{MORFOSSINTAXE}

Interjeições

Diminutivos

"Erro" com relação à gramática padrão ${ }^{3}$

\section{VOCABULÁRIO}

Linguagem ofensiva ou tabu (palavrões)

Gírias

Palavras estrangeiras

Marcadores discursivos (né?, né... tipo... assim... hein)

Onomatopeias

"Emoticons"

Quadro 3 - Características linguísticas apontadas como relevantes pela análise qualitativa

As subseções que seguem apresentam, respectivamente: uma discussão sobre a categoria social sexo/gênero; uma descrição das características que foram

\footnotetext{
${ }^{3}$ Por exemplo: concordância verbal e nominal não realizada, problemas de colocação pronominal, entre outros.
} 
quantitativamente selecionadas como típicas da linguagem de homens ou mulheres no Facebook; uma aplicação dessas características a um conjunto de textos, a fim de testar se elas são capazes de indicar o sexo de seu autor.

\subsubsection{Sexo e gênero}

De acordo com Cheshire (2004), sexo, idade, classe social e etnia são as categorias demográfico-sociais mais usadas nas ciências humanas e dividir as pessoas com bases em seu sexo/gênero (como "homens" e "mulheres") tem sido uma prática comum para as Ciências Sociais há bastante tempo. No entanto, as últimas décadas presenciaram muitas pesquisas dedicadas a diferenciar o conceito de sexo daquele de gênero. Em poucas palavras, pode-se dizer que enquanto "sexo" é um conceito biológico, "gênero" é um construto social e masculinidade e feminilidade estão associados aos papéis sociais que as pessoas ocupam. Neste contexto, emerge a pergunta "por que homens e mulheres usam a língua diferentemente?”. A resposta tem a ver com o sexo enquanto condição fisiológica ou está mais relacionada com o que significa ser homem ou mulher da perspectiva do gênero? Chambers (1995, p. 103), por exemplo, ressalta que o lado social e o biológico estão, algumas vezes, entrelaçados. Ele cita como exemplo o papel social de uma mãe que é tradicionalmente assumido pelas mulheres em virtude de suas condições biológicas de engravidar e amamentar os bebês. De modo geral, a Sociolinguística não apenas vem demonstrando uma correlação entre sexo/gênero e alguns usos linguísticos, mas também tem tentado explicar o motivo das diferenças no emprego de certas formas linguísticas por homens e mulheres (e.g. CHAMBERS, 1995; ROMAINE, 2003; CAMERON, 2010).

Para imputar um autor a um grupo, bastaria saber quais elementos linguísticos são marcas de sexo e gênero, ou seja, explicações sobre os motivos da variação não seriam necessárias. No entanto, entender as correlações que estão por trás do funcionamento de uma variável linguística é importante em termos de validade (conceito que se discutiu no capítulo 1). A análise linguística em um contexto forense ganha mais credibilidade se houver uma explicação que acompanha os fenômenos observados (GRANT, 2004, 2012). 
Um achado comum das pesquisas sociolinguísticas é o fato de que as mulheres tendem, mais do que os homens, a favorecer o uso de formas linguísticas consideradas padrão ou de prestígio. Romaine (2003, p. 103) enfatiza que é um tanto paradoxal as mulheres usarem mais as variantes de maior prestígio quando, na maioria das sociedades, são os homens que ocupam posições de maior status e poder. Uma hipótese que explica tal fato é que as mulheres estariam utilizando meios linguísticos para alcançar um status que lhes é negado através de outros canais. Tal hipótese leva a outra: o uso de formas mais ou menos prestigiadas estaria ligado mais às posições de poder ocupadas do que ao gênero por si só, como demonstraram O'Barr e Atkins (19804 apud ROMAINE, 2003) num estudo que revela que certas particularidades consideradas parte da linguagem feminina' também foram empregadas por homens em uma posição de poder subordinada.

Com isso, seria de se esperar que, em virtude do fato de que as mulheres vêm tendo, cada vez mais, um maior status na sociedade, e ocupando mais posições de poder e prestígio, a tendência de usarem as formas padrão mais do que os homens diminuiria e as diferenças linguísticas entre os gêneros também diminuiriam. Pesquisas como a de Nordberg e Sundgren ${ }^{5}$ (1998, 1999 apud ROMAINE, 2003) revelam, porém, que as diferenças de gênero para a maioria das variáveis linguísticas se mantêm e em alguns casos até mesmo aumentaram.

O debate em torno da questão não termina por aí e faz emergir, ainda, outras discussões. Por exemplo, Milroy et. al (1994) aventam que o fenômeno não se dá quando as mulheres escolhem as formas de prestígio, mas na direção oposta, ou seja, primeiro as mulheres passam a usar determinadas formas e daí elas se tornam prestigiadas. Um outro fator que influencia a construção de uma fala "feminina" ou "masculina" é a classe social. É comum mulheres de classes sociais mais baixas falarem de um modo que os outros percebam como mais masculino ao mesmo tempo em que homens de classes sociais mais

\footnotetext{
${ }^{4}$ O'BARR, W.; ATKINS, B. 'Women's Language' or 'powerless language'?. In: McConnell-Ginet et al. (eds.). Women and languages in literature and society. p. 93-110. New York: Praeger, 1980.

5

- NORDBERG, B.; SUNDGREN, E. On observing language change: a swedish case study. FUMS Rapport nr. 190. Institutionen för nordiska språk vid Uppsala Universitet, 1998.

- NORDBERG, B.; SUNDGREN, E. Från lokalspråk till standard i en mellansvensk stad: individuell eller generationell förändring? FUMS Rapport. Institutionen för nordiska språk vid Uppsala Universitet, 1999.
} 
altas têm seu falar percebido como mais feminino. Mais um fator relevante seria a mobilidade que homens e mulheres têm entre grupos, isto é, os contatos que eles mantêm e as redes sociais de que participam atuam como forças que os levam a usar estas ou aquelas variantes.

As hipóteses descritas sugerem que quaisquer que sejam as diferenças entre as falas de homens e mulheres, elas não podem ser atribuídas isoladamente ao gênero, mas sim analisadas pela combinação dessa variável com outros fatores, tais como classe social, escolaridade, mobilidade, contexto, etc.

Em termos do tratamento da correlação entre sexo/gênero e usos linguísticos e seu tratamento pela Sociolinguística, apesar da distinção entre sexo e gênero ser observada, as análises de cunho quantitativo frequentemente lidam "apenas" com homens e mulheres e raramente incluem outros gêneros - o que, de fato, pode oferecer bastante dificuldade. De qualquer forma, ainda na tentativa de explicar o motivo pelo qual, em alguns casos, mesmo quando as mulheres ocupam papéis sociais e posições de poder iguais aos dos homens e participam de tantas redes sociais quanto eles (por vezes, das mesmas redes sociais) atesta-se diferenciação nos seus usos linguísticos, alguns teóricos lançam mão da hipótese de que tais diferenças na linguagem de homens e mulheres têm, sim, uma parcela biológica. Chambers (1995, p. 132) afirma que evidências empíricas mostram que as mulheres são muito mais aptas do que os homens a terem uma boa performance linguística em variadas situações - o que se dá porque as mulheres teriam, como sugerem certos estudos psicológicos e neurológicos, uma habilidade verbal maior do que a dos homens e sua superioridade sociolinguística seria apenas uma extensão dessa habilidade verbal mais geral.

Nenhuma das explicações arroladas anteriormente é cabal, nem podem ser generalizadas. Talvez o que melhor explique a diferença entre a linguagem de homens e mulheres é uma combinação dessas hipóteses, dependendo da situação em questão. Um bom ponto de partida seria dar mais atenção aos papéis que homens e mulheres desempenham em suas comunidades de práticas (ECKERT; McCONNELL-GINET, 2013). Essa sugestão reside no fato de que o gênero não é um produto pronto e prédefinido, mas sim construído de formas diferentes a partir da participação em diferentes 
comunidades de prática. O que é ser masculino ou feminino no modo de falar depende sobremaneira da situação em que se fala. Isso vai ao encontro da ideia defendida por Butler (20046 apud CAMERON, 2010, p. 131) de que o gênero é performativo. Ou seja, masculino ou feminino não existem a priori, mas são criados e reafirmados a partir dos nossos atos, inclusive os de fala, em relação aos atos dos membros das comunidades da qual somos parte.

A ideia de que é possível depreender um significado social a partir de um uso linguístico repousa na noção de indexicalidade da língua, o que significa dizer que uma determinada forma linguística pode indicar um significado social. Acerca do gênero, é importante levar em conta que sua indexação pode ser indireta, de acordo com Ochs (1991):

a relação entre linguagem e gênero não é uma ligação entre uma forma linguística e o sentido social de gênero. Ao contrário, essa relação é constituida e medida pela relação da linguagem com posturas ${ }^{7}$, atos sociais, atividades sociais e outros construtos sociais. (OCHS, 1991, p. 336, tradução nossa ${ }^{8}$ ).

Assim, as formas linguísticas não seriam índices diretos de gênero, mas de outros significados sociais, que, por sua vez, têm relações estabelecidas com noções de gênero. A autora também afima que "poucos elementos linguísticos indexam direta e exclusimante o gênero" (OCHS, 1991, p. 340, grifo do autor, tradução nossa9 ). Por isso seria importante sempre levar em conta a relação entre os usos e os diferentes fatores sociais.

Apesar de se concentrar, num primeiro momento, apenas na variável sexo/gênero, este estudo não ignora a importância do desenvolvimento de um modelo de elaboração de perfis sociolinguísticos que dê conta dessa "multivariabilidade", ou seja, dos outros fatores sociais que estão envolvidos no uso de um ou outro elemento linguístico.

\footnotetext{
${ }^{6}$ BUTLER, J. Undoing gender. Nova York, Routledge, 2004.

7 Do inglês "stances"; "tomada de posição".

8 Texto original: "the relation between language and gender is not a simple straightforward mapping of linguistic form to social meaning of gender. Rather the relation of language to gender is constituted and mediated by the relation of language to stances, social acts, social activities, and other social constructs" (OCHS, 1991, p. 336).

9 Texto original: "few features of language directly and exclusively index gender" (OCHS, 1991, p. 340, grifo do autor).
} 


\subsubsection{Análise}

Um exame quantitativo mostrou que, dentre as características selecionadas qualitativamente, são relevantes para distinguir o estilo linguístico de homens e mulheres ${ }^{10}$ no Facebook aquelas presentes no Quadro 4, a seguir:

\section{HOMENS}

Linguagem ofensiva ou tabu (palavrões)

Gírias

Palavras estrangeiras

Uso de caixa alta

Erros de pontuação

Interjeições

Erros de acentuação

Onomatopeias

\section{MULHERES}

Repetição de letras

"Emoticons"

Diminutivos

Marcadores discursivos (né?, né, tipo, assim, hein)

Quadro 4-Características linguísticas de homens ou de mulheres

Para chegar a esses resultados, calculou-se a frequência desses elementos a cada mil palavras e, em seguida, calculou-se se o conjunto de pessoas (homens ou mulheres) que fez mais uso de determinado elemento o fez em mais de 50\% das vezes. Ou seja, foram consideradas relevantes os elementos utilizados pelo menos 1,5 vezes a mais por um conjunto de pessoas do que pelo outro. As tabelas 1 e 2 a seguir mostram esses números. Observe-se que esses resultados não significam que, por exemplo, todos os homens necessariamente utilizam esses elementos em suas mensagens, mas, ao contrário, que quando esses recursos linguísticos são utilizados, o autor provavelmente é homem.

10 Vale a pena lembrar que "homens" e "mulheres" sempre se referem, aqui, ao sexo dos falantes. 
Tabela 1 - Frequência dos elementos índices de sexo/gênero feminino

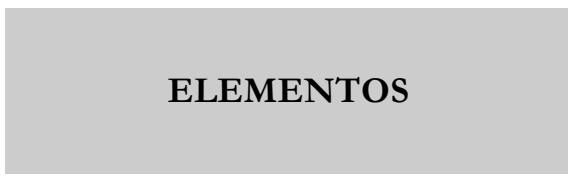

Diminutivos

\begin{tabular}{|c|}
\hline Repetição de letras \\
Marcadores discursivos \\
"Emoticons"
\end{tabular}

*Frequência a cada 1000 palavras

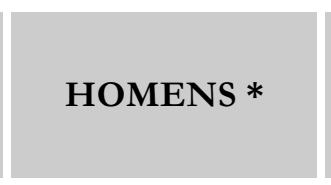

1,2

\begin{tabular}{|l|}
\hline 2,0 \\
\hline 1,2 \\
\hline 2,8 \\
\hline
\end{tabular}

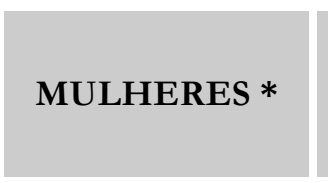

12,3

\begin{tabular}{|l|}
\hline 5,9 \\
\hline 2,3 \\
\hline 4,6 \\
\hline
\end{tabular}

Quantas vezes as mulheres usam esses elementos mais do que os homens

10

3

2

Tabela 2 - Frequência dos elementos índices de sexo/gênero masculino

\begin{tabular}{|c|c|c|c|}
\hline ELEMENTOS & HOMENS * & MULHERES * & $\begin{array}{c}\text { Quantas vezes os } \\
\text { homens usam esses } \\
\text { elementos mais do que } \\
\text { as mulheres }\end{array}$ \\
\hline Linguagem ofensiva & 15,7 & 0,68 & 23 \\
\hline Caixa alta & 35,3 & 1,82 & 19 \\
\hline Gírias & 14,5 & 1,37 & 11 \\
\hline Palavras estrangeiras & 4,8 & 1,82 & 3 \\
\hline Interjeições & 8 & 3,64 & 2 \\
\hline Erros de acentuação gráfica & 28,5 & 15,48 & 2 \\
\hline Onomatopeias & 11,6 & 6,6 & 2 \\
\hline Erros de pontuação & 29,3 & 19,58 & 1,5 \\
\hline
\end{tabular}

*Frequência a cada 1000 palavras

Esses resultados são comentados a seguir. Resslta-se que, mais adiante, esses elementos linguísticos são aplicados a um conjunto de mensagens a fim de testar sua eficácia para identificar o sexo/gênero de um autor. 
De acordo com a Tabela 1, as mulheres "repetem letras" 3 vezes mais do que os homens. Os exemplos a seguir são excertos do corpus $^{11}$ :

1. Gentemmmmm que povo é esse na campanha do Russomano?! "A cara de SP"

2. Bom diaaa.... hj é dia de buscar o vestidooooooo!!!! :) :)

3. Domingo, me faça um favor chegue logo, de novooooooooo! Agradeço desde já.

4. Já conversamos, sei que hj está animadeeenha, mas eu tinha que postar meus votos benevolentes por aqui.

5. Eis que o umidificador de ar apita mostrando que o filtro está sujo! Ok.... Apita sem paraaaaar!

Normalmente, a letra repetida representa algum fonema que teria sido alongado na fala. Smith et al. (200912 apud GRANT; MaCLEOD, 2012, p. 215) chamam esses caracteres repetidos de "Prosodic emphasisers".

Quanto aos "Emoticons", as mulheres os usam 2 vezes mais do que os homens. Vejamos alguns exemplos:

6. Depois de uma noite curtindo insônia ... início do ano letivo, chuva e trânsito. Bom dia!!! ;)

7. Adote um animal: a felicidade está por aí...! : o )

8. E amanhã... casamento no civil!!! :)

9. Hoje foi um daqueles dias, em que eu me arrependi da profissão que escolhi... muiiiito triste $:($

10. Não apenas mãe, mais sim uma irmã, uma conselheira, e com certeza minha melhor amiga $*_{-} *$

Marcadores discursivos também são empregados 2 vezes mais pelas mulheres do que pelos homens. Seguem exemplos:

11. Gentemmmmm que povo é esse na campanha do Russomano?! "A cara de SP" Tamos mal hein, gte feiaaaa hahhaa

12. Mãe, Minha eterna Rainha né *_*

\footnotetext{
${ }^{11}$ Nomes de pessoas e locais que pudessem de alguma forma identificar os autores desses textos foram substituídos em todo o corpus por "Xxxxxx".

12 SMITH, D.J., SPENCER, S.; GRANT, T. Authorship analysis for counter terrorism. Unpublished Research Report, QinetiQ/Aston University, 2009.
} 
13. Ela dormiu até que bem... Acordou bastante por causa da fome, né...

14. Tipo uma mulher de calcinha e sutiã numa escola significa o amor entre os povos asiáticos.

Esses dois elementos relacionados à linguagem feminina podem ter algo a ver com o fato de que as mulheres, ao menos na maioria das sociedades, ocupam menos posição de poder e são menos livres para se expressarem, precisando envolver o interlocutor e criar um ambiente amigável (e.g. LAKOFF, 1975; FISHMAN, 1980; TANNEN, 1990).

Por fim, o fato linguístico que mais se destacou dentre aqueles que podem ser considerados índice da fala feminina é o emprego de diminutivos, que ocorrem, neste corpus, 10 vezes mais nos textos escritos por mulheres do que naqueles escritos por homens. As sentenças a seguir trazem alguns exemplos:

15. Ai, tomara que o Xxxxxx esteja bem e seja só uma tossinha.

16. Eu era tontinha, acreditava em todo mundo.... E continuo sendo !!!

17. Cachorro sem nome, bem peludinho, aproximadamente 1 ano, macho, já vacinado e muito carinhoso.

18. Ai ai ai vcs duas!!!! Sim Xxxxxx vc é a minha flor da Bahia, sem brigas meninas, tem chefinha para todos!!!

19. Incrivel como o sistema de declaracao de imposto de renda é maravilhoso no Brasil. $\mathrm{Na}$ hora de receber os bonitinhos sao competentes, neh?

Essa é uma característica cuja relação com sexo/gênero foi estudada no português brasileiro (particularmente na variedade paulistana). Mendes (2012) analisa um corpus oral de entrevistas sociolinguísticas e seus resultados revelam um uso mais frequente do diminuitivo entre as mulheres (elas o empregam praticamente duas vezes mais que os homens). Segundo o autor, "as análises dos usos de diminutivos apresentadas parecem confirmar a hipótese de que eles podem funcionar como marcadores de sexo/gênero" (MENDES, 2012, p. 123).

Quanto aos marcadores da "linguagem masculina", nota-se que o uso de linguagem ofensiva e "palavrões" é, neste corpus, muito mais frequente nos textos escritos usado por homens do que por mulheres (23 vezes mais): 
20. Voce que joga lixo na rua pela janela do carro, igual a uma imbecil que acabei de ver fazendo isso, va pro inferno! Fico indigui com essa porra

21. E ai Xxxxxx, aqui esta nublado e +- a mesma temperatura dai de sampa!!! Hehehhe fala para o Xxxxxx que eu darei um abraço por trás nele

22. mas acredito que a maioria dos donos dos templos dao risada todo final de mes enquanto eu me fodo em pagar 800 reais de IPTU em $50 \mathrm{~m} 2$. E assim continua a vida!

23. Transito fodido...!!! Zerando SF zero 3 no psp kkkkk carro automatico salva haahuahaPor que tem varias pessoas que só colocam indireta nessa porra de face?

A segunda característica que mais se destaca é o uso de caixa alta, ou seja, a digitação em letras maiúsculas em toda a palavra. Os homens lançaram mão desse recurso 19 vezes mais do que as mulheres no corpus sob análise:

\section{GRAÇAS A DEUS, AQUELAS MALDITAS MUSICAS QUE OUVIAMOS DE MANEIRA INDESEJADA ACABARAM}

25. Ave maria!!! Que stress é esse meu deus? Que correria é essa? HELP MEEEE!!!

26. Você percebe quando a pessoa é caipira quando ela pede CARDÁPIO para comer no Habibs kkkkkkkk

27. uma cozinha baseada em PIMENTA, BACON e TEQUILA é a melhor do mundo.....

28. Objetivo alcançado! Sai da frente que agora EU SOU DO PELOTÃO QUÉNIA!!!

O terceiro tipo de elemento mais empregado pelos homens foram as gírias: 11 vezes mais empregadas por homens do que por mulheres. Alguns exemplos são:

29. kkkkkkkkk lembrei de tu geral mano

30. Não ligo muito pra esse lance de Papa, chamar um cara de sua santidade na

31. Nossa piro nessa musica, ainda mais quando toco ela

32. para toda mina gata escrevendo QUALQUER BOBAGEM no facebook, tem sempre 17 imbecis pronto para curtir o que ela fala incondicionalmente

33. Com certeza velho... Porra velho... Quase me fez chorar aqui mano

Note-se que muitas as características observadas no estilo masculino de escrever, (e evitadas pelas mulheres), são associadas a noções de "mau uso" da língua. Mesmo se considera o "uso de caixa alta", que é um fato eminentemente de codificação escrita, 
pode-se considerar que regras da "boa" escrita estão sendo quebradas"13. Isso vai ao encontro de muitos estudos sociolinguísticos que associam a linguagem masculina a formas linguísticas de menor prestígio (ROMAINE, 2003; CHAMBERS, 1995). Os resultados aqui encontrados também vão ao encontro de Herring e Paolillo (2006), para quem, em "Discurso mediado por computadores" (Computer-mediated discourse), os homens tendem a insultar, desafiar o enunciatário e expressar sarcasmo mais do que as mulheres.

Em síntese, de modo geral, as características depreendidas como índice de um ou outro sexo no Facebook vão ao encontro dos resultados de pesquisas sociolinguísticas prévias e/ou reafirmam estereótipos sobre linguagem e sexo.

Como no contexto forense tem-se, via de regra, acesso a pouca quantidade de dados, pode surgir a dúvida sobre se os elementos depreendidos de um certo texto ou grupo de textos são de fato suficientes para alguma indicação de autoria. No entanto, tal dúvida é amenizada quando se lembra de que a ideia de estilo ou presente na literatura sobre análise de autoria forense é a de "cosseleção" ou "combinação" de características. A identificação de um autor ou de um "grupo" ou "categoria" social não será feita com base em apenas uma característica ou elemento linguístico, mas considerando-se uma combinação de vários deles.

Além dos elementos que se exploraram até aqui, outro aspecto que chama a atenção quando se trata do uso diferente que homens e mulheres fazem da linguagem é a recorrência semântica em cada um dos conjuntos de textos. Em torno de 40\% das mensagens escritas por mulheres apresentam o tema do "carinho" ou "cuidado". Entre aquelas escritas por homens, mais de 50\% tratam de entretenimento (esportes, música, etc.). A depreensão dos temas se dá por meio da observação das recorrências semânticas no plano do conteúdo, no nível que a Semiótica chama de "discursivo", conforme se explicou no capítulo 2, item 2.6.1.

A predominância do entretenimento nas "conversas" online masculinas (bem como o uso mais frequente de palavras ofensivas ou palavrões conforme se observou

\footnotetext{
${ }^{13}$ Em comunicação mediada por computadores, o uso de Caixa Alta indica, na maioria das vezes, não apenas ênfase, mas também que o enunciador está "gritando".
} 
anteriormente) equipara-se ao que relata Cameron (2010, p. 130, grifo nosso), segundo quem, entre outras coisas, o estereótipo da fala masculina "evidencia gêneros conversacionais como piadas, trocas de insultos e resultados de jogos".

O quadro 5 a seguir traz exemplos de mensagens com os temas supramencionados:

TEXTOS MASCULINOS
"Entretenimento/Diversão"
(+ de 50\% das mensagens)
"Anderson bateu física e moralmente no imbecil do
Sonnen" (MMA/UFC)
"Acabei de ganhar da minha preta o manto sagrado
do glorioso alvi-negro praiano" (Futebol)
"eu estou bem... Algumas lesões leves no braço
direito... o que prejudica minha performance no
Starcraft" (vídeo games)
"Nossa, qta musica kkk vale a pena comprar
msm" "Cu
"Então gente, conforme combinado, vamos nesta
sexta-feira comemorar?!?"
"Lua de mel fechada!!! Parque da Costeira Natal-
RN que nos espere!!!"
puta mano, soh rolo um churras na casa dela, mais
nem teve mais nada
vou levar Curaçau Blue pra botarmos fogo em
tudo... kkk. Vamos fazer fase 1, 2, 3, ... 10...
(referindo-se a uma festa)

\section{TEXTOS FEMININOS \\ "Cuidado/ carinho" \\ (em torno de $40 \%$ das mensagens)}

"Dou sempre um jeitinho de falar com as pessoas queridas"

"Ai, tomara que o $\operatorname{xxxxx}$ esteja bem e seja só uma tossinha"

"Tenho certeza de que ele vai ser muito bem cuidado" (falando sobre um filhote de cachorro)

"Que deliiiicia! Feirinha gastronomica com os $2 \mathrm{Ma}$ do meu coracao!"

"Se precisar, estou na loucura, mas conte mesmo comigo! Tenho aí horarios flexiveis no trampo. Qquer coisa me liga, tá?"

"Ai ai ai vcs duas!!!! Sim xxxxx vc é a minha flor daBahia, sem brigas meninas, tem chefinha para todos!!!"

"q lindo!! amigo eu te amo mto! Vc faz parte da nossa história"

"Aaaah! Que fofa!!!! Nao fica aih mto tempo, não. Vai para a casa!!! Hmmm...sorvete!!! que delicia! eu querooooo!!! sauddes!!! bju"

Quadro 5 - Temas em mensagens de homens e mulheres

Esses resultados vão ao encontro da afirmação de Herring e Paolillo (2006), para quem, em "Discurso mediado por computadores", as mulheres tendem a ser mais educadas (polite), solidárias, e a se expressar de maneira mais emocional do que os homens.

O estudo de temas e figuras não se enquadra no estudo de "variáveis linguísticas" nos moldes daquelas comumente estudadas pela Sociolinguística, uma vez que uma variável linguística nesse campo teórico é uma ou mais maneira de se dizer "a mesma 
coisa". Entretanto, a partir do momento em que se consegue identificar temas preferidos por determinados grupos sociais, tem-se uma "dica" sobre as ideologias que os integrantes desses grupos compartilham e esse pode ser mais um fator importante ao se construir um perfil sociolinguístico (neste caso, baseado no sexo/gênero).

\subsubsection{Exemplo de aplicação}

Esta seção mostra o resultado de um exercício destinado a testar se os elementos linguísticos anteriormente arrolados, incluindo a recorrência temática, permitiriam identificar corretamente o sexo do autor de um grupo de mensagens do Facebook. Pedimos a um autor que não estava entre os 20 selecionados anteriormente que nos enviasse 10 textos oriundos da rede social (seguindo o mesmo procedimento realizado para a coleta dos demais textos).

Analisando-se como o autor dos textos questionados empregou cada uma das as características, percebe-se que ele se aproxima mais do padrão masculino do que do feminino. Ressalte-se novamente que não é o uso de um ou outro elemento isolado que funciona como índice de sexo/gênero, mas sim uma combinação de elementos. Assim, quanto mais deles aparecerem em um grupo de textos de autoria questionada, maior a probabilidade de o autor ser homem ou mulher. A Tabela 3 a seguir apresenta uma comparação das frequências dos elementos linguísticos em textos escritos por homens, mulheres e pelo autor desconhecido. 
Tabela 3 - Frequência dos elementos linguísticos em textos escritos por Homens, Mulheres e pelo Autor desconhecido

\begin{tabular}{|c|c|c|c|}
\hline & \multicolumn{3}{|c|}{ FREQUENCIA } \\
\hline CARACTERÍSTICAS & MULHERES & HOMENS & $\begin{array}{c}\text { AUTOR } \\
\text { DESCONHECIDO }\end{array}$ \\
\hline Linguagem Ofensiva & 0,6 & 15,7 & 18 \\
\hline Caixa Alta & 1,82 & 35,3 & 48 \\
\hline Gírias & 1,37 & 14,5 & 18 \\
\hline Palavras Estrangeiras & 1,82 & 4,8 & 10 \\
\hline Diminutivos & 12,3 & 1,2 & 3 \\
\hline Repetição de Letras & 5,9 & 2 & 5 \\
\hline Marcadores Discursivos & 2,3 & 1,2 & 0 \\
\hline Emoticons & 4,6 & 2,8 & 5 \\
\hline
\end{tabular}

A Figura 7 a seguir ajuda a visualizar os números apresentados. Assim, se em 7 de 9 elementos (considerando-se também o tema), o autor "desconhecido" se aproxima do perfil masculino, ou seja, se ele compartilha com o perfil masculino de $78 \%$ das características, pode-se dizer que há grandes chances de que ele seja homem.

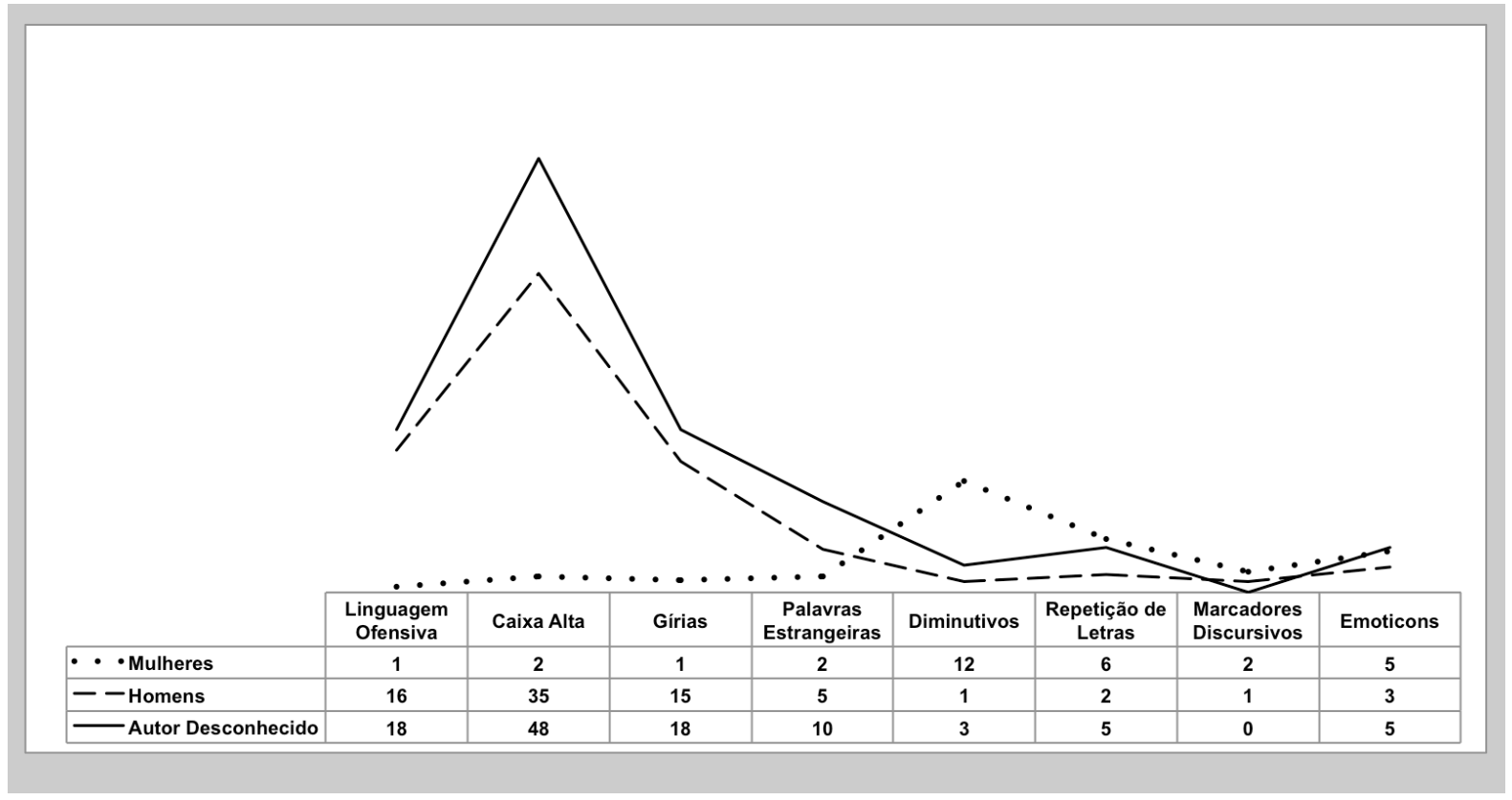

Figura 7 - Comparação entre homens, mulheres e autor desconhecido 
De fato, este autor é um homem, com idade por volta dos 30 anos. O gráfico mostra como o "autor desconhecido" se assemelha muito mais à "curva" do perfil masculino do que àquela do feminino.

Este breve estudo dá pistas de quais poderiam ser os índices de sexo/gênero nas mensagens escritas na rede social Facebook. A elaboração de um perfil sociolinguístico deve ponderar sobre vários fatores sociais aos quais formas linguísticas possam estar correlacionadas. Esta pesquisa está alinhada a tal premissa e investiga unicamente essa categoria neste momento apenas para atender aos requisitos de um método analítico. Futuramente, é desejável que se empreguem os resultados aqui expostos na criação de perfis sociolinguísticos em casos de atribuição de autoria, adicionando-se os resultados obtidos a partir do exame das correlações de usos linguísticos com outros fatores sociais em textos escritos em português brasileiro.

Segue um quadro-resumo com as características linguísticas que podem ser índices de sexo/gênero em mensagens do Facebook (e talvez de outras redes sociais), de acordo com este estudo:

\begin{tabular}{l|l}
\multicolumn{1}{c}{ HOMENS } & \multicolumn{1}{c}{ MULHERES } \\
\hline Linguagem ofensiva ou tabu (palavrões) & Repetição de letras \\
\hline Gírias & "Emoticons" \\
\hline Palavras estrangeiras & Diminutivos \\
\hline Uso de caixa alta & Marcadores discursivos (né?, né, tipo, assim, hein) \\
\hline $\begin{array}{l}\text { Erros de pontuação } \\
\text { Interjeições }\end{array}$ & \\
\hline Erros de acentuação & \\
\hline Onomatopeias & \\
\hline
\end{tabular}

Quadro 6 - Índices de gênero em mensagens do Facebook

Trabalhos futuros poderão ser realizados para atingir os seguintes objetivos:

- Coletar uma maior quantidade de textos/informantes, para verificar se as características aqui depreendidas permanecem; e aplicar esta parte do perfil 
sociolinguístico, relativa ao sexo/gênero, a esses outros textos, expandindo os testes que verificariam sua eficácia.

- Verificar que medidas estatísticas poderiam ser úteis para determinar a relevância das características depreendidas.

- Realizar estudos com outras variáveis demográficas.

- Verificar qual o melhor modo de construir e manter uma "base de dados de correlações".

\subsection{O Universo discursivo em cartas do "Massacre de Realengo"}

Conforme discutiu-se no capítulo 2, para alguns textos com os quais esta pesquisa se deparou, as noções correntes de grupo social para a Sociolinguística (inclusive a de comunidades de práticas) não seriam úteis no sentido de depreender um grupo ao qual o autor pertenceria. Apesar disso, é possível depreender uma espécie de "grupo", revelado através dos textos, e talvez criado por eles (essa abordagem mais construcionista estaria de acordo com estudos do estilo na chamada "terceira onda" da Sociolinguística, que se apresentou no capítulo 2, item 2.4).

Este trabalho propõe que esses tipos distintos de grupos, correspondentes ao que chamamos de "universos discursivos" (seção 2.6.2), podem ser acessados por meio da recorrência semântica presente nos textos, que funciona ora como um marcador de um estilo individual, ora como marcador de um estilo de um grupo social. Analisá-la pode levar o linguista a apreender percursos figurativos que revelem práticas ou ideologias compartilhadas pelo autor com os grupos sociais aos quais pertence.

Pode ser útil ao leitor retomar, neste momento, a discussão acerca da constituição de universos discursivos que se deu na seção 2.6.2 desta tese. 


\subsubsection{O caso e o corpus}

Em abril de 2011, Wellington Menezes de Oliveira matou 12 crianças entre 12 e 14 anos numa escola pública do Rio de Janeiro - fato que ficou conhecido como o "Massacre de Realengo". Interceptado por policiais, Wellington cometeu suicídio. Junto a seu corpo, foi encontrada uma espécie de carta de despedida, uma nota de suicídio. Durante a investigação, a polícia encontrou outras cartas na casa de Wellington e um vídeo no qual ele lê uma delas. São esses textos que formam o corpus neste exercício de análise, cujo objetivo é determinar se as cartas encontradas na casa do atirador e a carta de suicídio revelam pertencimento do seu enunciador a um mesmo universo discursivo (noção que se apresentou no capítulo 2, item 2.6.2).

Este estudo examina como a recorrência semântica cria categorias semânticas fundamentais que perpassam os textos e acabam por estabelecer uma categoria principal que representa dois grupos, cada um compartilhando a sua "rede discursiva" de práticas, valores e ideologias.

Uma leitura atenta da carta de suicídio nos permite reconhecer algumas palavras e expressões que estão conectadas por seu significado, formando certas isotopias, algumas das quais ${ }^{14}$ constituem, por sua vez, certas oposições semânticas. As isotopias e as oposições descritas a seguir também podem ser vistas nos textos encontrados na casa do atirador. Antes de prosseguir, cabe introduzir a transcrição da carta-testamento ${ }^{15}$.

\footnotetext{
Primeiramente deverão saber que os impuros não poderão me tocar sem luvas, somente os castos ou os que perderam suas castidades após o casamento e não se envolveram em adultério poderão me tocar sem luvas, ou seja, nenhum fornicador ou adultero poderá ter contato direto comigo, nem nada que seja impuro poderá tocar em meu sangue, nenhum impuro pode ter contato direto com um virgem sem sua permissão, os que cuidarem de meu sepultamento deverão retirar toda minha vestimenta, me banhar, me secar e me envolver totalmente despido em um lençol branco que esta nesse prédio, em uma bolsa que deixei na primeira sala do primeiro andar, após me envolverem nesse lençol poderão me colocar em meu caixão. Se possível, quero ser sepultado ao lado da sepultura onde minha mãe dorme, minha mãe se chama Dicéa Menezes de Oliveira e esta sepultada no cemitério Murundu. Preciso da visita de um fiel
}

\footnotetext{
${ }^{14} \mathrm{O}$ conceito de isotopia, em Semiótica, corresponde à "iteratividade em uma cadeia sintagmática" (GREIMAS; COURTÉS, 1979), ou seja, à recorrência. No nível discursivo, a isotopia é o resultado da recorrência semântica.

15 Os demais textos encontram-se no fim deste volume, no Anexo B.
} 
seguidor de Deus em minha sepultura pelo menos uma vez, preciso que ele ore diante de minha sepultura pedindo o perdão de Deus pelo o que eu fiz rogando para que na sua vinda Jesus me desperte do sono da morte para a vida eterna.

Eu deixei uma casa em Sepetiba da qual nenhum familiar precisa, existem instituições pobres, financiadas por pessoas generosas que cuidam de animais abandonados, eu quero que esse espaço onde eu passei meus últimos meses seja doado à uma dessas instituições, pois os animais são seres muito desprezados e precisam muito mais de proteção e carinho do que os seres humanos que possuem a vantagem de poder se comunicar, trabalhar para se sustentar, os animais não podem pedir comida ou trabalhar para se alimentarem, por isso, os que se apropriarem de minha casa, eu peço por favor que tenham bom senso e cumpram o meu pedido, pois cumprindo o meu pedido, automaticamente estarão cumprindo a vontade dos pais que desejavam passar esse imóvel para meu nome e todos sabem disso, senão cumprirem meu pedido, automaticamente estarão desrespeitando a vontade dos pais, o que prova que vocês não tem nenhuma consideração pelos nossos pais que já dormem, eu acredito que todos vocês tenham alguma consideração pelos nossos pais, provem isso fazendo o que eu pedi. ${ }^{16}$

\subsubsection{Oposições semânticas e o estabelecimento do universo discursivo}

A análise da figuratividade dos textos leva a oposições que revelam, manifestam ideologias. Esta seção descreve essa figuratividade.

A primeira oposição que se encontra, formada por recorrência semântica, é "Proteção" versus "Humilhação" dos mais fracos; uma outra é dada pelo "Eterno" versus o "Efêmero"; e uma terceira é a oposição "Pureza" versus "Impureza". Os quadros a seguir apresentam essas três oposições e trazem exemplos que remetem a elas, extraídos dos textos. Vale ressaltar que os excertos presentes nos quadros são tanto da "cartatestamento" quanto dos demais escritos.

${ }^{16}$ Essa é a transcrição na íntegra. Uma cópia da carta original encontra-se no Anexo B. 


\section{PROTEÇÃO}

- "mas estou tranquilo pq sei que Deus esta do meu lado"

- "não poderia viver bem sabendo que vocês sofrem todos dias nas mãos dos infiéis por isso resolvi fazer algo para balançar esse cenário cruel morri pelos que são incapazes de se defender"

- "morri para inspirar vocês irmãos a se defenderem e se fortalecerem"

- "meu desejo é que estabeleça uma união entre vocês e os irmãos mais fortes e corajosos fiquem atentos para proteger os irmãos mais fracos juntos serão muito mais fortes"

- "zelando pela proteção dos irmãos mais fracos"

- "quero parabenizar o irmão casey heynes ${ }^{17}$ pela sua escelênte atitude que ajudou no combate aos maus"

- "quero lembrar os irmãos, cho hui ${ }^{18}$ e edmar aparecido freitas 19 , embora já estejam dormindo"

- "morri pelos que são incapazes de se defender"

- "existem instituições pobres, financiadas por pessoas generosas que cuidam de animais abandonados"

- "os animais são seres muito desprezados e precisam muito mais de proteção e carinho do que os seres humanos"

\section{HUMILHAÇÃO}

•"Eles [os colegas] eram violentos comigo"

- "Tipo se ele é pobre, direto pra cadeia"

- "Na maioria das vezes condenando inocentes"

- "cada vez que verem alguém sendo humilhado e agredido injustamente"

- "cada vez que verem alguém sofrendo preconceito ou sendo discriminado"

- “cada vez que verem alguém se aproveitando da bondade ou da inoscência de um ser"

- "ou agridem ou debocham dos agredidos"

- "se divertiam com as humilhações que eu sofria sem se importar com meus sentimentos"

- "gostam de se aproveitar dos fracos e indefesos"

- "gostam de tirar vantagens dos inocentes"

- "não poderia viver bem sabendo que vocês sofrem todos dias nas mãos dos infiéis por isso resolvi fazer algo para balançar esse cenário cruel"

- "que são ridicularizados agredidos humilhados os que sofrem na mão de pessoas cruéis covardes que se aproveitam da ingenuidade e fraqueza deles morri para inspirar vocês irmãos a se defenderem e se fortalecerem"

• "os animais são seres muito desprezados"

Quadro 7 - "Proteção" versus "Humilhação"

\footnotetext{
${ }^{17}$ Casey Heynes é um garoto australiano que sofria bullying por ser obeso e um dia se revoltou contra seus agressores agredindo-os. Disponível em <https://www.youtube.com/watch?v=EHkhUKYhcko>. Acesso em 27/08/2012>.

${ }^{18}$ Cho Hui foi um universitário sul-coreano, na Virgínia, EUA. "Em 16 de abril de 2007, ele invadiu a universidade praticando assassinatos em massa, matando 32 pessoas, e deixando mais de quinze pessoas feridas e em seguida suicidando-se, no Massacre de Virginia Tech". Disponível em <http://pt.wikipedia.org/wiki/Cho_Seung-hui>. Acesso em 27/08/2012.

${ }^{19}$ Edmar Aparecido Freitas era um estudante brasileiro que sofria bullying desde os 7 anos de idade. Em 2003, aos 18 anos, foi armado ao colégio em que estudava e matou vários estudantes, suicidando-se em seguida. Disponível em <http://stopbullyingschool.blogspot.com/2011/04/sao-paulo-2003-edmar-aparecido-freitas.html>. Acesso em $27 / 08 / 2012$
} 


\section{PUREZA}

- "o que importa é ser reconhecido por Deus e não por certos humanos imperfeitos"

- "limpeza da casa"

- "quando digo fiel me refiro aos que seguem as leis de deus e se preservam se mantendo longe de tudo que mancharia sua dignidade"

- "somente os castos"

- "nenhum impuro pode ter contato direto com um virgem"

- "retirar toda minha vestimenta, me banhar"

- "me envolver totalmente despido em um lençol branco"

\section{IMPUREZA}

- "qual a diferença entre uma pessoa q aproveitou a vida c impurificando"

- "o phillip usou meu pc para ver pornografia"

- "tava falando coisas obcenas e xingando"

"os injustos mentirosos ladrões corruptos são sempre vistos como leais"

- "os impuros não poderão me tocar sem luvas"

• "nenhum fornicador ou adultero"

- nada que seja impuro poderá tocar em meu sangue

- nenhum impuro pode ter contato direto com um virgem

Quadro 8 - "Pureza" versus "Impureza"

\section{ETERNO}

- "sabem q após suas mortes td q eles fizeram em favor de deus será recompensado"

- "pois isso sim obterá resultados favoráveis no fim"

- “mas deus não acaba deus sempre estará lá no céu"

- "pq isso tudo acaba mas deus é eterno"

- "não será com pessoas limitadas desse mundo $q$ viverei eternamente e sim com Deus"

- "pq será ao lado d deus q viverei toda a eternidade e não nesse mundo passageiro"

- "se deus achar que sou merecedor no grande dia em que jesus retornar deus irá me restaurar e colocar uma porção de seu espírito em mim para que eu reviva e finalmente tenha vida eterna"

- "quem sabe serei transformado de mero ser carnal para um ser espiritual para a vida eterna"

- "me desperte do sono da morte para a vida eterna" (o autor pede para ser enterrado de uma determinada maneira, porque ele acredita na vida eterna).

\section{EFÊMERO}

- "uma das coisas que mais me irrita é a vaidade as pessoas c dedicando a cuidar do corpo como (xxx) banquete ou louvor a vermes da terra"

- "pessoas assim não reconhece q td acaba"

- "eles só visualizam o presente"

- "sem a conciênssia d q esta vida acabará um dia"

- "e por isso eu tenho essa convicção q o importante não é obtermos riquezas mesmo q honestamente pq isso tudo acaba"

- "prazeres passageiros que este mundo oferece"

- "os prazeres e o reconhecimento deste mundo são coisas passageiras"

- "não procuro dividir para usufruir dos prazeres passageiros do mundo". 
Encontra-se presente também uma recorrência de palavras e expressões que remetem à religiosidade. O quadro a seguir mostra exemplos:

\section{RELIGIOSIDADE}

- "Preciso da visita de um fiel seguidor de Deus em minha sepultura".

- "preciso que ele ore diante de minha sepultura pedindo o perdão de Deus".

- "rogando para que na sua vinda Jesus me desperte"

- Descrição do ritual de como quer ser enterrado

- "são pessoas sem deus no coração meus pais tem fé em jeová mas deixam d cumprir com as exigências da congregação e os demais cometem tais atos por carência d deus no coração e sei q um deles quer c juntar a mim para aparecer para o mundo e não por fé"

- "pq sei q deus esta do meu lado"

• "não seguirem a religião com devoção"

• "mas eu mudei com o alcorão"

- "seus servos q deixam isso td de lado para c dedicar ao máximo a deus"

- "td q eles fizeram em favor de deus será recompensado e deus olhará (...)"

• “não possuem deus em seus corações”

- "acredito q mtos justos c tornaram injustos por perceberem q assim é um jeito lucrativo de ser reconhecido pela sociedade como justos por carência d deus em seus corações"

- "cada segundo d nossas vidas para servir a ele [Deus]"

- "para quando chegar a hora ele [Deus ]nos receber com mto intusiasmo"

- "a menina q me convido a ir a igreja dela"

• "só disse pra ficar realmente $100 \%$ com vc e com Deus"

- “o q importa é ser reconhecido por Deus pq não será com pessoas limitadas desse mundo q viverei eternamente e sim com Deus por isso eu dedico cada segundo da minha vida a Deus não procuro dividir para usufruir dos prazeres passageiros do mundo eu estou fora do grupo mas faço todos os dias minha oração do meio dia q é a d reconhecimento a Deus e as outras 5 que são de dedicação a Deus e umas $4 \mathrm{~h}$ do dia passo lendo o Alcorão"

- "ir a igreja dos tij20"

- "e sei que deus olhara para meu sacrifício e minhas ações neste mundo"

- "ridicularizam os fiéis, quando digo fiel eu não me refiro a frequentadores de religioes"

- "quando digo fiel me refiro aos que seguem as leis de deus e se preservam se mantendo longe de tudo que mancharia sua dignidade"

- "uma rede de combate aos infiéis entre os irmãos obviamente tendo muito cuidado pois

- provavelmente existirão muitos infiéis que tentarão se infiltrar"

- "que os maus sejam extintos que deus vos abençôe"

\section{Quadro 10 - Religiosidade}

20 Testemunhas de Jeová. 
As três oposições encontradas, mais a questão da religiosidade perpassam os textos e acabam por criar dois grupos nos quais o autor divide os indivíduos, a humanidade: os fiéis - com quem ele se identifica - e o infiéis (termos que aparecem frequentemente nos textos) que ele repudia. A Pureza, o Eterno e a Proteção das mais fracos são valores euforizados, estimados pelos textos, ao passo que seus opostos a Impureza, o Efêmero e a Humilhação são negados. Juntas, essas oposições, criadas a partir de recorrências semânticas, mais a isotopia da religiosidade instauram uma oposição mais geral que perpassa todos os textos e define grupos sociais: Fiéis versus Infiéis.

Interessante observar que neste conjunto de textos os grupos opostos que afloram a partir da análise dos textos estão relacionados à religiosidade, importante fator de agregação ou desagregação de indivíduos em grupos.

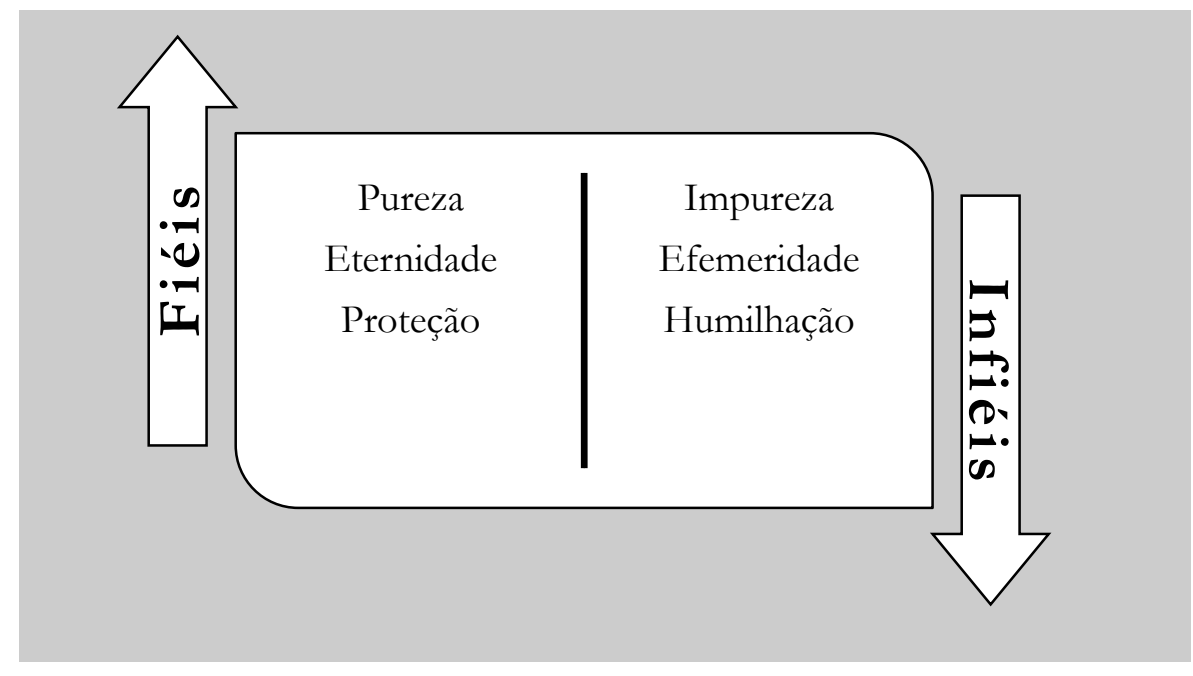

Figura 8 - Oposições semânticas que remetem a um universo discursivo

Mesmo que não se possa concluir que o autor dos textos é a mesma pessoa, podese deduzir que os autores fazem parte, pelo menos, do mesmo grupo social, o dos "fiéis", tomado aqui como já explicado, como um "universo discursivo".

Além de sua utilidade para o contexto forense, essa noção também contribui para os estudos de Sociolinguística interessados em revelar significados sociais e identidades, já que considera um tipo de agrupamento social diferente daqueles comumente empregados (comunidades de fala ou de práticas). Ademais, depreender o pertencimento de um sujeito 
a um grupo social através da recorrência semântica em seus textos amplia o escopo do que pode ser considerado como indicativo de um grupo, para além das características linguísticas normalmente consideradas como "variáveis" pela Sociolinguística, dando a essa disciplina ferramentas adicionais para identificar estilos de grupo. 
4 ESTILOS INDIVIDUAIS

E ATRIBUIÇÃo DE

AUTORIA: ANÁLISE

QUALITATIVA 


\subsection{Objetivos e Corpus}

Um dos objetivos desta tese, conforme estabeleceu-se anteriormente, é verificar a aplicabilidade da análise do plano do conteúdo, nos moldes da Semiótica Francesa, a casos de atribuição de autoria. Esse objetivo encontra motivação principalmente no fato de que a língua é constituída pela interrelação entre plano da expressão e plano do conteúdo e os métodos existentes para atribuição de autoria concentram-se em elementos do primeiro.

O capítulo 2 apresentou a noção de plano de conteúdo e o modelo do "percurso gerativo do sentido”. Neste e nos próximos capítulos, o objetivo é desenvolver estudos a fim de averiguar se as categorias de análise semiótica servem como marcadores de estilo.

A primeira análise, neste capítulo, é qualitativa e procura demonstrar como os textos podem ser analisados semioticamente. Para isso, explicam-se brevemente alguns elementos ${ }^{1}$ do plano do conteúdo na medida em que se analisa o conjunto de textos em questão. A análise se concentra em determinar elementos do plano do conteúdo que sejam recorrentes ao longo do conjunto de textos examinado, de modo que possam ser indicativos de um estilo. Os resultados sugerem que há elementos do plano do conteúdo suficientemente recorrentes para distinguir um autor.

Para a realização dessa análise, selecionou-se aleatoriamente um subconjunto de textos que compõem um corpus maior - o chamado Corpus Geral para Análise de Autoria (CGAA) - que vem sendo coletado conforme descreveu-se na Introdução. Este subconjunto contém 21 textos de um mesmo autor (adulto, com idade entre 26 e 40 anos, do sexo feminino e com nível superior de escolaridade), dentre os quais um foi selecionado aleatoriamente ${ }^{2}$ a fim de simular $^{3}$ um texto questionado ${ }^{4}$ Esses 21 textos podem ser vistos na íntegra no Anexo A.

\footnotetext{
${ }^{1}$ Conforme sugerido no capítulo 2, para uma revisão exaustiva modos de análise empregados pela Semiótica Discursiva, consultem-se Barros (2001; 2003), Fiorin (2005; 2008) e Greimas e Courtés (1979 [2008]).

2 Utilizou-se a função "RANDBETWEEN" do Microsoft Excel ${ }^{\mathbf{T M}}$.

3 "Simular" no sentido de que, devido ao método utilizado para coletar os textos, sabe-se de antemão que todos os textos são do mesmo autor. No capítulo 5, apresentamos um "teste cego", ou seja, um experimento em que não se sabe previamente se a autoria do texto questionado é ou não a mesma de um conjunto de textos conhecidos.
} 
Assim, existe 1 texto simuladamente questionado e 20 textos de autoria conhecida. A pergunta que se coloca é: "É possível que o texto questionado tenha sido escrito pelo mesmo autor dos textos de autoria conhecida?".

Os textos coletados desse autor compreendem e-mails profissionais, pessoais, um texto de um blog e, em sua maior parte, posts na rede social Facebook. A Tabela 4 apresenta algumas de suas características:

Tabela 4- Lista de textos deste estudo

\begin{tabular}{|c|c|c|c|}
\hline TEXTO & TIPO DO TEXTO & $\begin{array}{c}\text { NÚ MERO DE } \\
\text { PALAVRAS }\end{array}$ & $\begin{array}{c}\text { NÚMERO DE } \\
\text { CARACTERES }\end{array}$ \\
\hline $\mathbf{1}$ & Post no Facebook & 76 & 354 \\
\hline $\mathbf{2}$ & Post no Facebook & 35 & 206 \\
\hline $\mathbf{3}$ & E-mail profissional & 254 & 1234 \\
\hline $\mathbf{4}$ & Post no Facebook & 126 & 693 \\
\hline $\mathbf{5}$ & Texto de Blog & 439 & 2194 \\
\hline $\mathbf{6}$ & E-mail profissional & 3597 \\
\hline $\mathbf{7}$ & E-mail entre amigos & 715 & 1650 \\
\hline $\mathbf{8}$ & Introdução para TCC & 353 & 1814 \\
\hline $\mathbf{9}$ & Post no Facebook & 322 & 622 \\
\hline $\mathbf{1 0}$ & Post no Facebook & 143 & 1062 \\
\hline $\mathbf{1 1}$ & Post no Facebook & 219 & 269 \\
\hline $\mathbf{1 2}$ & Post no Facebook & 56 & 287 \\
\hline $\mathbf{1 3}$ & Post no Facebook & 64 & 955 \\
\hline $\mathbf{1 4}$ & Post no Facebook & 196 & 362 \\
\hline $\mathbf{1 5}$ & Resposta a um post no Facebook & 88 & 768 \\
\hline $\mathbf{1 6}$ & Comentário de vídeo no Facebook & 139 & $\mathbf{1 6 0 4 0}$ \\
\hline $\mathbf{1 7}$ & Post no Facebook & 49 & 246 \\
\hline $\mathbf{1 8}$ & Post no Facebook & 60 & 242 \\
\hline $\mathbf{1 9}$ & Post no Facebook & 68 & 328 \\
\hline $\mathbf{2 0}$ & Post no Facebook & 54 & 247 \\
\hline $\mathbf{2 1}$ & Comentário de foto no Facebook & 55 & 245 \\
\hline & & 74 & 315 \\
\hline
\end{tabular}

Embora esses textos sejam, em sua maioria, muito diferentes quanto ao tema e, algumas vezes, provenientes de diferentes situações de comunicação, a análise do seu

\footnotetext{
${ }^{4}$ Vale lembrar que todos esses textos são "reais", isto é, não foram escritos "sob demanda", já haviam sido produzidos a priori no momento da sua coleta.
} 
plano do conteúdo, de acordo com o modelo da Semiótica Discursiva, indica que há recorrências que remetem a um mesmo $e^{2} h^{5} s^{5}$. Essas recorrências foram percebidas em diferentes instâncias de organização do plano do conteúdo, isto é, em categorias pertencentes a diferentes níveis do percurso gerativo do sentido.

\subsection{Análise Semiótica}

Esta seção organiza-se em torno dos níveis de análise semiótica, conforme o percurso gerativo do sentido e faz também algumas considerações acerca da tensividade. A cada subitem, existe uma breve explicação dos conceitos teóricos utilizados na análise dos textos aqui considerados, seguida de um quadro com a análise propriamente dita e com excertos. Os quadros não apresentam todos os textos, mas somente aqueles que contribuem para a constituição de um ethos, apontando para um único autor.

\subsubsection{Nível narrativo}

Para a Semiótica, todo texto apresenta uma narratividade, um nível narrativo, subjacente. Assim, neste programa de pesquisa, a narratividade não está ligada, conforme se costuma pensar, apenas aos textos que estão organizados narrativamente em sua superfície e relatam ações ou eventos (como, por exemplo, os romances, os contos, as fábulas, etc.); diferentemente, a todo texto subjaz uma relação (que pode ser juntiva ou disjuntiva) entre um "sujeito" e um “objeto", relação esta em que podem ocorrer transformações; são essas relações e transformações que constituem a narratividade de um texto. Quando um sujeito está em disjunção com um objeto, é essa "falta" que faz "andar" o texto. Tais transformações são organizadas em três etapas, que a semiótica francesa convencionou chamar de "esquema narrativo canônico" (BARROS, 2003):

\footnotetext{
${ }^{5}$ Conforme se mencionou no capítulo 2, item 2.5, o ethos é uma "imagem" do enunciador.
} 
- manipulação: fase em que um destinador tenta convencer um destinatário a fazer ou crer em algo; nela:

um sujeito transmite a outro um querer e/ou um dever. Essa fase pode ser concretizada como um pedido, uma súplica, uma ordem, etc. Temos, por exemplo, uma manipulação por provocação, quando o manipulador diz ao manipulado que ele é incapaz de realizar uma ação, esperando que, como reação, ele a execute com vistas a provar que é perfeitamente capaz de fazê-la (FIORIN, [20--?], p. 169).

- ação: fase em que o sujeito age para mudar o seu estado juntivo; a ação pressupõe que o sujeito é competente 6 , ou seja, que ele pode e/ou sabe fazer o que se propõe. Fiorin [20--?] exemplifica a competência e a ação (ou performance):

Quando, num conto maravilhoso, uma fada dá a um príncipe um objeto mágico, que lhe permitirá realizar uma ação extraordinária, está dando-lhe um poder fazer, figurativizado pelo referido objeto mágico [fase da competência]. [Na fase da ação ou performance], ocorre a transformação principal da narrativa. Num conto de fadas em que a princesa foi raptada pelo dragão, a performance será a libertação da princesa (FIORIN, [20--?], p. 169).

- sanção: fase em que um destinador julgador avalia as ações e comportamentos dos sujeitos; os sujeitos podem também ser premiados ou castigados nesta fase.

Nem todas as etapas previstas precisam estar sempre explícitas em um texto, mas elas estão sempre logicamente pressupostas. Se existe uma sanção, é porque alguma ação existiu e, se esta existe, é porque houve uma manipulação. Há textos que se concentram na etapa da ação; outros, como alguns textos publicitários, por exemplo, podem apresentar só a manipulação. Além disso, essas etapas podem ser organizadas de modos diferentes, não sendo necessária a sua aparição em ordem lógica (FIORIN, 2005, p. 34).

Os textos podem ainda se desenrolar a partir de um "acontecimento" ou de uma "rotina" (ZILBERBERG, 2007). O acontecimento é algo que se dá de repente, um fato raro que ocorre sem que o sujeito o espere e que o tire de sua rotina. Ele pode ser responsável por iniciar uma ação por parte do sujeito (fazer emissivo ou continuativo) ou

\footnotetext{
${ }^{6}$ É comum que alguns autores considerem a competência como uma fase separada dentro do esquema narrativo canônico, a exemplo de FIORIN ([20--?]).
} 
por arrebatá-lo, privando-o do agir (fazer remissivo). Quando um texto é da ordem da rotina, nada de novo acontece, há espaço para trivialidades. Acontecimento e Rotina estão ainda relacionados a outro nível de significação: o nível tensivo (ZILBERBERG, 2006a; 2006b; 2006c), que se descreve mais adiante, no item 4.2.4.

Quando o que se vê é apenas um estado juntivo entre um sujeito e um objeto (ou seja, apenas se identifica a situação do sujeito com relação ao objeto - conjunção ou disjunção), diz-se que existe um enunciado de estado; quando ocorre uma transformação nesse estado, existe um enunciado de fazer. Quando um enunciado de fazer muda um enunciado de estado, ou seja, algo ocorre e isso altera a situação do sujeito com relação a um objeto, existe um programa narrativo ${ }^{7}$. Um texto pode apresentar apenas um programa narrativo ou vários, e esses programas podem ser classificados segundo vários critérios $^{8}$. Os programas narrativos $(\mathrm{PN})$ ocorrem dentro das diferentes etapas do "esquema narrativo (EN) canônico" (manipulação, ação, julgamento). O Quadro 11, a seguir, mostra esse esquema:

\begin{tabular}{|c|c|c|c|c|c|c|c|c|c|}
\hline \multicolumn{10}{|c|}{ ESQUEMA NARRATIVO CANÔNICO } \\
\hline \multirow{2}{*}{\multicolumn{4}{|c|}{$\begin{array}{c}\text { MANIPULAÇÃO } \\
\text { percurso do destinador } \\
\text { manipulador }\end{array}$}} & \multirow{2}{*}{\multicolumn{4}{|c|}{$\begin{array}{r}\text { COMPETÊNCIA/AÇ } \\
\text { percurso do sujeito }\end{array}$}} & \multicolumn{2}{|c|}{ SANÇÃO } \\
\hline & & & & & & & & $\begin{array}{r}\text { percurso d } \\
\text { jul }\end{array}$ & $\begin{array}{l}\text { destinador } \\
\text { ador }\end{array}$ \\
\hline \multicolumn{2}{|c|}{$\begin{array}{l}\text { PN de doação } \\
\text { de } \\
\text { competência } \\
\text { semântica }\end{array}$} & \multicolumn{2}{|c|}{$\begin{array}{l}\text { PN de doação } \\
\text { de } \\
\text { competência } \\
\text { modal }\end{array}$} & \multicolumn{2}{|c|}{$\begin{array}{c}\text { PN de } \\
\text { competência }\end{array}$} & \multicolumn{2}{|c|}{$\begin{array}{c}\text { PN de } \\
\text { perfórmance }\end{array}$} & $\begin{array}{c}\text { PN de } \\
\text { interpretação }\end{array}$ & $\begin{array}{l}\mathrm{PN} \text { de } \\
\text { retribuição }\end{array}$ \\
\hline $\begin{array}{c}\text { EN } \\
\text { do } \\
\text { fazer } \\
\text { S1 } \neq\end{array}$ & $\begin{array}{c}\text { EN } \\
\text { de } \\
\text { estad } \\
\text { o } \\
\text { S2 }\end{array}$ & $\begin{array}{c}\text { EN } \\
\text { do } \\
\text { fazer } \\
\text { S1 } \neq\end{array}$ & $\begin{array}{c}\text { EN } \\
\text { de } \\
\text { estad } \\
{ }^{\circ} \\
\text { S2 }\end{array}$ & $\begin{array}{l}\mathrm{EN} \\
\text { do } \\
\text { fazer } \\
\mathrm{S} 1 \neq\end{array}$ & $\begin{array}{c}\text { EN } \\
\text { de } \\
\text { estad } \\
{ }^{\circ} \\
\mathrm{S}^{2}\end{array}$ & $\begin{array}{c}\text { EN } \\
\text { do } \\
\text { fazer } \\
\text { S1 }\end{array}$ & $\begin{array}{c}\text { EN } \\
\text { de } \\
\text { estad } \\
\text { o } \\
\text { S2 }\end{array}$ & $\begin{array}{l}\text { EN do fazer } \\
\qquad \mathrm{S} 1 \neq\end{array}$ & $\begin{array}{l}\text { EN de estado } \\
\text { S2 }\end{array}$ \\
\hline
\end{tabular}

Quadro 11 - Esquema narrativo canônico.

$\mathrm{PN}=$ percurso narrativo; $\mathrm{EN}=$ enunciado.

Fonte: Barros (2003).

O esquema narrativo canônico é uma constante, mas o modo como suas etapas se articulam é variável. Segundo Barros (2003, p. 43), o esquema narrativo “oferece muitas

\footnotetext{
7 Segundo Barros (2003, p. 20), um programa narrativo é "um enunciado de fazer que rege um enunciado de estado".

${ }^{8}$ Barros (2003, pp. 21-26) explica tais critérios e apresenta diversos exemplos.
} 
oportunidades de variações e combinações que dão caráter único e específico às narrativas-ocorrências". Ora, se as combinações, como diz Barros, dão caráter único às narrativas-ocorrências, supõem-se que recorrências de tais combinações ao longo de diferentes textos de um mesmo autor podem ser uma marca de autoria, de um estilo.

Quanto aos textos ora analisados, sua maioria não apresenta o esquema narrativo canônico completo, mas concentra-se apenas na fase da sanção, em que o sujeito (destinador-julgador) avalia a ação de outros sujeitos. A fase da manipulação também ocorre em muitos dos textos desse subconjunto, mas escolheu-se aqui como característica mais marcante a sanção, que é mais frequente. Em muitos desses textos, observa-se também que a sanção é a fase principal em torno da qual se organiza o texto. O Quadro 12, a seguir, apresenta trechos dos textos que corroboram essa análise. Observa-se que o enunciador julga, avalia ações e comportamentos dos sujeitos.

\begin{tabular}{|c|c|c|}
\hline TEXTO & COMENTÁRIO & EXCERTOS 9 \\
\hline 1 & $\begin{array}{l}\text { Ao procurar saber se vão ou não poder } \\
\text { usar um certo cupom para jogar } \\
\text { boliche, o enunciador ocupa uma } \\
\text { posição de julgador, já que avalia o } \\
\text { comportamento e o estado dos amigos } \\
\text { que se tornaram pais recentemente. }\end{array}$ & $\begin{array}{l}\text { - Afinal, quero saber: agora que você já é mãe e o Jonas } \\
\text { já é pai, já devem saber a resposta. } \\
\text { - Eu acho que o groupon dos pais está perdido.... Nao } \\
\text { largarão da pequena!!! hibibi }\end{array}$ \\
\hline 2 & $\begin{array}{l}\text { A fase da sanção pode ser percebida } \\
\text { imediatamente, já que o enunciador faz } \\
\text { uma avaliação negativa do gosto do } \\
\text { enunciatário. }\end{array}$ & $\begin{array}{l}\text { - não gostei nada nada do filme... } \\
\text {-Xinguei-te mentalmente algumas vezes } \\
\text {-aqueles que ve emprestou eu gostei!!!”" } \\
\text {-nao gostei do chapeuzinho vermelho sexy }\end{array}$ \\
\hline 3 & $\begin{array}{l}\text { Avalia-se a conduta de outro sujeito. } \\
\text { Pede-se ao enunciatário que cobre de } \\
\text { uma determinada empresa os } \\
\text { pagamentos em atraso referentes a um } \\
\text { acordo judicial e, ao fazê-lo, avalia o } \\
\text { comportamento da empresa } \\
\text { negativamente. }\end{array}$ & $\begin{array}{l}\text { (o que pode ser pressuposto por meio de "jä" e "por duas } \\
\text { vezes"): } \\
\text {-"por duas vezes, em novembro e dezembro, a } \\
\text { Reclamada já havia depositado o valor do acordo com } \\
\text { atraso" }\end{array}$ \\
\hline 4 & $\begin{array}{l}\text { O sujeito avalia negativamente a ação } \\
\text { de deputados que votaram a favor de } \\
\text { emenda constitucional com a qual não } \\
\text { concorda. Há também uma avaliação } \\
\text { negativa do país. }\end{array}$ & $\begin{array}{l}\text { - Massssssssss "se liga" na nossa querida CAMARA } \\
\text { DOS DEPUTADOS (uso irônico do adjetivo } \\
\text { 'querida'). } \\
\text { ABSURDOOOOOOO (sobre a emenda) } \\
\text { - Comonosso Brazilsão é^\%@^\$\%\&*®@^(*\# }\end{array}$ \\
\hline 5 & $\begin{array}{l}\text { O enunciador avalia os } \\
\text { comportamentos daqueles que se } \\
\text { divorciam. }\end{array}$ & $\begin{array}{l}\text {-Alguns entram ali apenas para conversar e contar os } \\
\text { problemas -Outros ali } \\
\text { ingressam com muita paz e harmonia }\end{array}$ \\
\hline 8 & $\begin{array}{l}\text { Sujeito avalia situação do meio } \\
\text { ambiente, bem como a ação da } \\
\text { "humanidade", despreocupada com }\end{array}$ & $\begin{array}{l}\text { - Este tema foi escolbido devido aos reflexos da conduta } \\
\text { bumana no meio ambiente, que tem gerado a longo prazo, } \\
\text { grandes estragos ambientais, comprometendo assim, a }\end{array}$ \\
\hline
\end{tabular}

9 Todos os excertos, de todos os quadros, estão digitados conforme se apresentam nos originais. 


\begin{tabular}{|l|l|} 
TEXTO & COMENTÁRIO \\
\hline & este. \\
& \\
\end{tabular}

9

O sujeito avalia negativamente a opinião das pessoas que gostam do frio.

A contar que alguém jogara filhotinhos
de gato dentro de sua casa, o sujeito
avalia negativamente quem cometeu
essa ação. Avalia também a ação da
gatinha-mãe, que enfrentara o cão
bravo.

11 Ao saber que a criança está doente, avalia-se que isto pode ter se dado porque ela quer alguma coisa.

12

Assim como nos outros textos, aparece um momento em que o enunciador faz uma avaliação, ocupando a posição de destinador-jogador, na fase da sanção.

O sujeito avalia negativamente a OABSP

15

$$
\text { O sujeito avalia seu próprio }
$$
conhecimento.

Há implicitamente uma avaliação

16 negativa dos organizadores de um concurso, que mudaram as regras "no meio do jogo".

17

O pilar do texto é a surpresa pela descoberta do "verdadeiro" café, em contraposição ao café do supermercado. Há claramente uma avaliação dos tipos de café.

Uma avaliação é evidente, uma vez que, mesmo ao se colocar à disposição para

18 receber tais gatos como doação, o enunciador não deixa de avaliar negativamente as pessoas que compram gatos de raça.

Há uma avaliação negativa dos serviços que encerram suas atividades às $16 \mathrm{ou}$ $17 \mathrm{~h}$.
Neste texto, mesmo ao tentar convencer o enunciatário a fazer um

\section{EXCERTOS 9}

sadia qualidade de vida (...) a bumanidade parece não se preocupar imediatamente com este problema, haja vista que seus reflexos surgem ao longo de anos.

- (pergunta) "precisa passar frio ou congelar????????"

- (afirmação jocosa) "Este frio só para a menopausa mesmo!"

- O que o gênio não sabia é que eu tinha um cachorro extremamente violento, que estava solto no quintal - a teimosa e valente mini-gatinha resolveu enfrenta-lo, ficando em duas patinhas

- Sú... as vezes as crianças ficam doentes quando querem alguma coisa... Será que não significa que a Sonia quer um dalmata ou um gatinho malhadinho?? : o )

- Lembrei da viagem pro $\times x \times x \times x \times$ pro casamento dos gaúchos Fulana e Beltrano (que foi lindo!)

- A colônia que a OABSP tem, é lá no fim do mundo virando a esquerda, né?

- Caso você não saiba, se você tentar cancelar sua

O ABSP em Jaaneiro, ve deve pagar o ano

INTEIRINHO, mesmo sem utilizar.

- (em um momento, descreve várias qualidades da $O A B$ -

$M G$, o que desqualifica a $O A B-S P$ )

- acho que a de SP está precisando de um bom chacoalhão, hein?

- meu inglês está enferrujadaaaaço.

- Esse é o video de dança da minha amiga. Eles estão competindo no dancetube. Eram primeiro lugar, mas o concurso foi prorrogado e faltando 5 dias estao quase perdendo o primeiro lugar (que já era deles se tivesse encerrado na data prometida)

- Houve uma época em que eu achava que aquilo que vendiam no mercado em embalagem de café, era café!!! Hoje sei: aquilo é palha!

- Café é só o da Tia Ivone, em que ela mesma planta, torra e mói!

\section{- Acho sem-vergonbice comprar gato de raça, com tantos SRD's por aí}

-Não dá pra resolver tudo em 3 dias, ainda que fique até tarde (pois a maioria dos rolos são em cartórios, bancos, etc, que fecham as 16 ou 17b! E ainda, pdem 5 dias uteis para emitir certidoes)

-V ai dar um pequeno trabalbinho 


\begin{tabular}{|c|c|c|}
\hline TEXTO & COMENTÁRIO & EXCERTOS 9 \\
\hline & $\begin{array}{l}\text { procedimento, o sujeito admite que este } \\
\text { é trabalhoso. }\end{array}$ & \\
\hline 21 & $\begin{array}{l}\text { Sobre um bolo que um amigo fez, num } \\
\text { primeiro momento, o sujeito o avalia } \\
\text { positivamente; depois, julga que ele } \\
\text { deveria ter sido feito de outra forma. }\end{array}$ & $\begin{array}{l}\text { - Está lindo } \\
\text { - Mas vai uma dica: pega um pedaço de linha, apoia a } \\
\text { mão na metade do bolo e corta o bolinho em dois, porém, } \\
\text { mantendo o formato redondo. Corta na altura e nao na } \\
\text { metade dele!!! Rssss }\end{array}$ \\
\hline
\end{tabular}

Quadro 12 - Nível narrativo - fase da sanção.

Observamos anteriormente que os textos podem ainda se desenrolar a partir de um "acontecimento" ou de uma "rotina". A maioria dos textos analisados é da ordem do acontecimento (e não da rotina), o que desencadeia um fazer emissivo por parte do sujeito. Veja o Quadro 13 para exemplos extraídos dos textos e explanações.

\section{TEXTO COMENTÁRIO GERAL/EXEMPLOS}

\begin{tabular}{|c|c|}
\hline 1 & $\begin{array}{l}\text { Os amigos tornaram-se pais e isso suscita uma dúvida quanto a poderem ou não ir jogar } \\
\text { boliche num futuro próximo. Essa dúvida surge a partir do momento em que os amigos } \\
\text { tornam-se pais: "Afinal, quero saber: agora que você já é mãe e o Jonas já é pai, já devem saber a } \\
\text { resposta. É possivel deixar a pequena por algumas horinhas para jogar boliche daqui uns meses ou isso é } \\
\text { muito ilusório?!? Rsssss". Este fato raro, é um "acontecimento" nos termos de Zilberberg } \\
\text { (2007) e vem impedir o sujeito de continuar o seu programa (jogar boliche com os } \\
\text { amigos). Pode-se dizer que o acontecimento causou uma ruptura, uma quebra na } \\
\text { continuidade. }\end{array}$ \\
\hline 2 & $\begin{array}{l}\text { O fato de o enunciatário ter gostado do filme pega o enunciador de surpresa (de novo, } \\
\text { acontecimento), expressada por "Nossa" em "Nossa Jane...". }\end{array}$ \\
\hline 3 & $\begin{array}{l}\text { O enunciador deixa claro sua surpresa em constatar que a Reclamada mais uma vez } \\
\text { atrasou o pagamento, pois ela já tinha sido avisada: "Contudo, mesmo após sua orientação, a } \\
\text { empresa novamente deixa de depositar na data acordada". Assim, mais uma vez o texto é da } \\
\text { ordem do acontecimento, já que instaura uma ruptura na rotina do sujeito, que tem que } \\
\text { tomar a ação de escrever o e-mail de cobrança. }\end{array}$ \\
\hline 6 & $\begin{array}{l}\text { O texto se inicia com a constatação, por parte do enunciador, de que faltam dados num } \\
\text { processo de inventário em que trabalha. Essa falta é o que cria uma ruptura, já que o } \\
\text { sujeito não pode continuar o seu trabalho. Para suprimir a falta, ele escreve ao } \\
\text { enunciatário. "Boa tarde, Mário! Tudo bom? Precisamos de alguns dados faltantes para a conclusão do } \\
\text { inventário". }\end{array}$ \\
\hline 8 & $\begin{array}{l}\text { A ruptura que faz com que o sujeito componha o texto é a percepção de que (grifo nosso) } \\
\text { "Atualmente estes reflexos da degradação ambiental tem se demonstrado de maneira mais clarividente". }\end{array}$ \\
\hline 9 & $\begin{array}{l}\text { O sujeito não esperava o frio intenso e é afetado por ele, ficando surpreso, como pode ser } \\
\text { visto em: "menina do céu (...). Eu ganbei umas tulipas... Li que ve tinha que guardar o bulbo no } \\
\text { congelador para simular a situação real dela na natureza. Se eu soubesse que ia esfriar desse jeito, tinha } \\
\text { deixado na varanda mesmo!!!" }\end{array}$ \\
\hline 11 & O que motiva a escritura do enunciado é a doença da filha da amiga (acontecimento). \\
\hline 13 & $\begin{array}{l}\text { O acontecimento é a notícia da construção de uma colônia de férias da OAB: "Outro dia eu } \\
\text { vi uma reportagem que a } \mathrm{O} A B \text { ganhou EM 2006, um terreno pra construir uma colônia de férias em } \\
\text { Campos de Jordão". }\end{array}$ \\
\hline
\end{tabular}




\section{TEXTO COMENTÁRIO GERAL/EXEMPLOS}

Neste texto vê-se um sujeito que é tirado de seu dia a dia ao assumir uma nova ocupação: a de professora de inglês. Trata-se de uma surpresa, já que não se esperava a proposta para o cargo, como se vê em "Obrigada!!! Especialmente a Tá, que surgiu com esta possibilidade" (grifo nosso).

Algo totalmente inesperado aconteceu: a prorrogação de um concurso (fato não muito comum) o que tirou a liderança da amiga.

17 O pilar do texto é a surpresa pela descoberta do "verdadeiro" café: "Houve uma época em que eu achava que aquilo que vendiam no mercado em embalagem de café, era café!!!! Hoje sei: aquilo épalha?"

Bolo feito por um amigo, de quem não ela não esperava tal ação. $O$ texto ressalta explicitamente que se está surpreso com o que foi feito pelo sujeito "Julio": "Meu.... me amarrota que eu to passadd!"

Quadro 13 - Acontecimento/Fazer emissivo

\subsubsection{Modalidades e paixões}

A Semiótica vê as paixões como efeitos de sentido resultantes das combinações, dos arranjos entre as modalidades (querer, dever, poder, saber) que incidem sobre o "ser". Por exemplo, a curiosidade é um querer-saber. Além disso, elas se distinguem de acordo com tipo de objeto da junção, com a temporalidade e com a aspectualidade. As paixões são o "sentir" do sujeito; mesmo que "nada aconteça" em termos de ações, o sujeito pode sentir. Trata-se da dimensão afetiva do discurso.

Em Semiótica das Paixões, Greimas e Fontanille estabelecem que (1993, p. 50):

as paixões concernem, na organização do conjunto da teoria, ao 'ser' do sujeito e não a seu 'fazer', o que não significa, é claro, que as paixões não tenham nada que ver com o fazer e o sujeito do fazer, nem que seja porque também este último comporta um 'ser' que é a sua competência. O sujeito afetado pela paixão será, portanto, sempre, em última análise, sujeito modalizado segundo o 'ser', isto é, sujeito considerado como sujeito de estado, ainda que, por outro lado, ele seja responsável por um fazer [...].

O esquema narrativo canônico que se apresentou na seção anterior diz respeito à sintaxe narrativa; já a modalização e as paixões, ainda no nível narrativo, dizem respeito à semântica narrativa. 
$\mathrm{Na}$ esfera passional, pode-se dizer que, na maioria dos textos do autor analisado, vê-se um sujeito do inconformismo que é ou aquele que não quer crer ou aquele que não se resigna. Inconformado com o acontecimento, o sujeito não se resigna, não "deixa para lá”. Ao contrário: ele escreve sobre aquilo e demonstra por vezes a sua indignação.

Observe-se como isso vai ao encontro da definição do dicionário Houaiss para o verbete inconformismo:

1 tendência, atitude ou procedimento de inconformado, de quem não aceita condições ou situações incômodas ou desfavoráveis;

2 tendência ou atitude de não se acatar passivamente o modo de agir e de pensar da maioria do grupo em que se vive.

Veja-se ainda a definição de inconformidade:

1 ausência de conformidade;

1.1 falta de acordo, de entendimento; divergência, desacordo;

1.2 falta de resignação, de submissão; rebeldia, resistência

O inconformismo (ou a indignação) é quase sempre a motivação para a composição do texto; é o que faz o enunciador escrever e está presente na maioria dos textos ora analisados. O Quadro 14 traz trechos do corpus que corroboram o inconformismo, algumas vezes elevado a uma indignação, que é o resultado de uma sequência que compreende um acontecimento e uma sanção negativa, percebidos por um sujeito tenso.

\begin{tabular}{c|c|} 
TEXTO & \multicolumn{1}{c}{ COMENTÁRIO } \\
& $\begin{array}{l}\text { Sujeito inconformado, que não espera, não } \\
\text { aceita passivamente os acontecimentos, o } \\
\text { que o motiva a escrever o enunciado para } \\
\text { tentar suprimir a situação de ignorância em } \\
\text { que vive. Ele não aceita não saber o que vai } \\
\text { acontecer com o cupom. Quer saber o } \\
\text { quanto antes para poder tomar uma decisão. } \\
\text { Evidente pela cobrança que faz aos amigos. }\end{array}$ \\
& $\begin{array}{l}\text { O sujeito não se conforma com o fato da } \\
\text { amiga ter gostado de um certo filme (não } \\
\text { quer crer no gosto dela). Alia-se ao }\end{array}$ \\
\hline 2
\end{tabular}

\section{EXCERTOS}

- Afinal, quero saber: agora que você já é mãe e o Jonas já é pai, já devem saber a resposta. É possivel deixar a pequena por algumas horinhas para jogar boliche daqui uns meses ou isso é muito ilusório?!? Rsssss

-Precisamos saber para gastarmos o groupon: 0 boliche rola ou não rola até antes de 28/08?!?

- Nossa Jane... não gostei nada nada do filme... Xinguei-te mentalmente algumas vezues, tá? 


\begin{tabular}{|l|l|}
\hline TEXTO & \multicolumn{1}{c}{ COMENTÁRIO } \\
\hline 3 & $\begin{array}{l}\text { inconformismo certa indignação pelo gosto } \\
\text { do outro (evidenciada por "xinguei-te } \\
\text { mentalmente"). }\end{array}$ \\
\hline \multirow{2}{*}{$\begin{array}{l}\text { O sujeito não se conforma com a } \\
\text { persistência no atraso. Escreve ao } \\
\text { enunciatário cobrando. }\end{array}$} \\
\\
4 \\
$\begin{array}{l}\text { Inconformismo/Indignação com relação à } \\
\text { tentativa de aprovação de uma Emenda } \\
\text { Constitucional }\end{array}$ \\
\end{tabular}

O texto é a Introdução de um Trabalho de Conclusão de Curso, cujo tema é a proteção ao direito dos animais. O sujeito inconformado e que avalia negativamente as ações humanas sobre o meio ambiente fica evidente pelos exemplos da coluna ao lado.

O enunciador não quer acreditar que existem pessoas gostam do frio.

Ao contar que alguém jogara filhotinhos de gato dentro de sua casa, diz "O que o gênio não sabia é que eu tinha um cachorro extremamente violento, que estava solto no quintal', ou seja, não se conforma com a ingenuidade do praticante da ação. Percebe-se também que justamente a ação avaliada positivamente pelo sujeito é a ação de um sujeito da não conformidade: a gatinha não se resigna diante do perigo: ao contrário, parte para a ação.

Mesmo após ter sido picado por insetos e estar com as pernas inchadas, o enunciador,

Contudo, mesmo após a sua orientação, a empresa novamente deixa de depositar na data acordada. - por duas vezes, em novembro e dezembro, a Reclamada já havia depositado o valor do acordo com atraso.

- conjunção "Mas" (ainda reforçada pelo fato de ter sido escrita com duplicação de letras); uso irônico do adjetivo "querida"; uso de caixa alta para escrever todas as palavras da frase em que conta o que está para acontecer (caixa alta é associado, na Internet, a uma ênfase ou a um modo de indicar que se está "gritando"): "Massssssssss "se liga" na nossa querida CAMARA DOS DEPUTADOS:" - uso de "absurdo"; explicitação da concordância com os partidos que votaram contra a emenda: "ABSURDOOOOOOO (...). Únicos que votaram contra: PPS, PV e PSOL!!!!!!!! (Ganharam meu voto!!)"

- Este tema foi escolhido devido aos reflexos da conduta humana no meio ambiente, que tem gerado a longo prazo, grandes estragos ambientais, comprometendo assim, a sadia qualidade de vida (...) - Estes reflexos da degradação ambiental tem se demonstrado de maneira mais clarividente. Contudo, a humanidade parece não se preocupar imediatamente com este problema, haja vista que seus reflexos surgem ao longo de anos.

- Eu nunca entendi essa ideia de 'curtir o frio' precisa passar frio ou congelar???????? que não se conforma, não se rende, vai à aula de dança.

- O que o gênio não sabia é que eu tinha um cachorro extremamente violento, que estava solto no quintal $-a$ teimosa e valente mini-gatinha resolveu enfrenta-lo, ficando em duas patinhas

- Meu pé voltou parecendo um pãozinho depois da picada... Mas deu pra dançar numa perna só!! : o 


\begin{tabular}{|c|c|c|}
\hline TEXTO & COMENTÁRIO & EXCERTOS \\
\hline 13 & $\begin{array}{l}\text { Sujeito não se conforma com certas "regras" } \\
\text { da OAB-SP. }\end{array}$ & $\begin{array}{l}\text { - A colônia que a OABSP tem, é lá no fim do } \\
\text { mundo virando a esquerda, né? } \\
\text { Mas nunca mais vi nada a respeito. } \\
\text {-Depois de conbecer outras } O A B \text { 's, acho que a de } \\
\text { SP está precisando de um bom chacoalhão, hein? }\end{array}$ \\
\hline 15 & $\begin{array}{l}\text { A paixão do inconformismo aparece } \\
\text { novamente, não aliada a uma indignação } \\
\text { mas como sentido do sujeito inconformado } \\
\text { como aquele que não se resigna. Mesmo } \\
\text { com o inglês "enferrujadaaaaço", vai "se jogar" } \\
\text { na nova atividade". }\end{array}$ & $\begin{array}{l}\text { - Deu um friozinho na barriga de assistir as aulas } \\
\text { com as crianças que não param quietas (rss) mas } \\
\text { vamos se jogar!!!!bihihi } \\
\text { Pq meu inglês está enferrujadaaaaço..! }\end{array}$ \\
\hline 16 & $\begin{array}{l}\text { O inconformismo é claro com as regras do } \\
\text { concurso que mudaram. }\end{array}$ & $\begin{array}{l}\text { - estão quase perdendo o primeiro lugar (que já era } \\
\text { deles se tivesse encerrado na data prometida) }\end{array}$ \\
\hline 17 & $\begin{array}{l}\text { O sujeito inconformado aparece novamente, } \\
\text { com um tom de indignação, por exemplo, } \\
\text { em "Fui enganada a vida toda!!!?. E ele não se } \\
\text { conforma, não aceitando o café que lhe foi } \\
\text { apresentado a vida toda e se rende ao } \\
\text { "verdadeiro" café: "Agora sim eu posso dizer } \\
\text { que gosto de café - mas do café-café! Não do pseudo- } \\
\text { café?" }\end{array}$ & - Fui enganada a vida toda!!! \\
\hline 18 & $\begin{array}{l}\text { Considerando que uma das acepções de } \\
\text { inconformismo é "tendência ou atitude de } \\
\text { não se acatar passivamente o modo de agir e } \\
\text { de pensar da maioria do grupo em que se } \\
\text { vive" (Dicionário Houaiss), verifica-se que o } \\
\text { sujeito não se conforma com o fato de } \\
\text { algumas pessoas pagarem para ter gatos. }\end{array}$ & $\begin{array}{l}\text {-Acho sem-vergonbice comprar gato de raça, com } \\
\text { tantos SRD's por aí }\end{array}$ \\
\hline
\end{tabular}

Quadro 14 - Paixão do inconformismo.

Já que essa paixão é recorrente, ela pode ser uma marca do estilo desse autor.

\subsubsection{Nível fundamental}

Para a Semiótica Discursiva, os objetos que os sujeitos buscam no nível narrativo estão investidos de valores correspondentes a termos de uma categoria semântica que se instaura num nível mais profundo, que se chama de "nível fundamental". Por exemplo, um preso que foge tem na fuga um objeto investido do valor de "Liberdade" oposto à “Opressão”, sendo essa oposição uma categoria semântica básica que vai permear todo o texto. Essa categoria se articula em termos de negação ou afirmação de seus polos. As 
relações entre os dois polos são dadas por um modelo lógico que representa as relações de contradição, contrariedade e complementaridade entre os termos: o quadrado semiótico (Figura 9). Outros exemplos de categorias semânticas básicas frequentemente analisadas quando se utiliza a Semiótica como referencial teórico são "vida e morte", "natureza e cultura", "identidade e alteridade".

Cada um dos termos de uma categoria semântica básica é um valor positivo ou negativo, dentro de cada texto. Nas palavras de Fiorin ([20--?], p. 168), os elementos em oposição são sobremodalizados "com um traço de positividade ou negatividade, ou em termos mais precisos, com os traços / euforia/ e /disforia/. Dois textos podem, por exemplo, trabalhar com a mesma categoria semântica, mas axiologizá-la diferententemente e isso vai produzir discursos completamente distintos”. Segundo o autor "essa categoria semântica do nível fundamental é, então, o elemento mais simples e abstrato de ordenamento dos múltiplos conteúdos do texto. O discurso ecologista [por exemplo] articula-se em torno da oposição semântica /civilização/ vs. / natureza/" (FIORIN, [20--?], p.168).
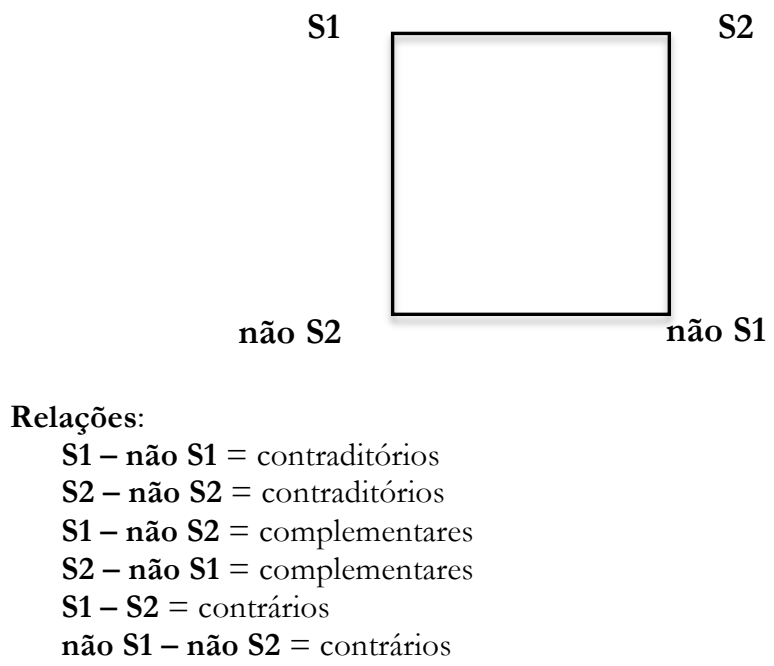

Figura 9 - Quadrado semiótico 
Nos textos em questão, existe a recorrência da categoria semântica fundamental do “errado" versus “certo". O Quadro $15^{10}$, a seguir, apresenta algumas passagens encontradas no corpus que exemplificam que, ao julgar negativamente certas ações "dos outros", o enunciador cria a oposição mencionada, valorizando o "certo" e identificandoo como aquilo que ele faz, e desvalorizando o errado, que é sempre a atitude ou o comportamento alheio. Assim, cria também mais uma oposição semântica: "alteridade" versus "identidade", com a valorização do "eu" e a desvalorização do "outro". O quadrado semiótico, na Figura 10 apresenta essas relações.

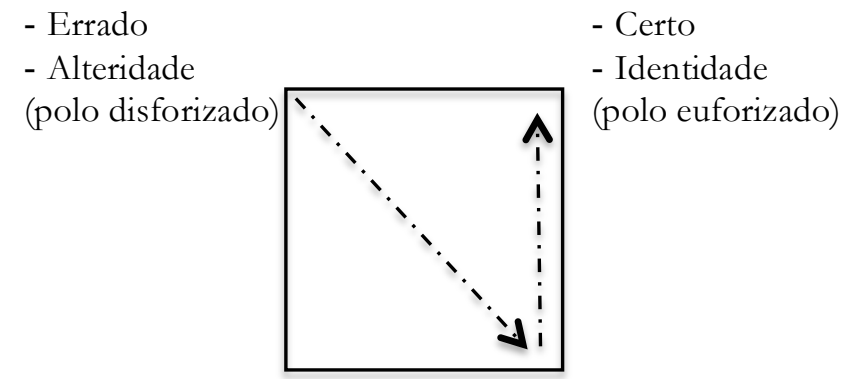

Figura 10 - Quadrado semiótico: “certo vs. errado" / "identidade vs. alteridade”.

\begin{tabular}{|c|c|}
\hline TEXTO & EXEMPLOS \\
\hline$\underline{2}$ & $\begin{array}{l}\text { - Nossa Jane... não gostei nada nada do filme... Xinguei-te mentalmente algumas vezes, tá? } \\
\text { (hauhaubuaha). }\end{array}$ \\
\hline 3 & $\begin{array}{l}\text { - por duas vezes, em novembro e dezembro, a Reclamada já havia depositado o valor do acordo com atraso. } \\
\text { - Solicitei ao Dr. que orientasse a Empresa para que não mais houvesse atraso, bavendo de minha parte } \\
\text { certa tolerância quanto aos atrasos. }\end{array}$ \\
\hline 4 & $\begin{array}{l}\text { - Como nosso Brazilsäo é^\%@^\$\%@*@^^(*\#, até hoje existem "donos de cartório" por "berança de } \\
\text { família", sem concurso público. } \\
\text { ELES QUEREM APROVAR UMA EMENDA CONSTITUCIONAL OUMA "LEI", } \\
\text { PARA OS LEIGOS) PROPONDO QUE, QUEM ESTA LA SEM CONCURSO, } \\
\text { TENHA O DIREITO DE FICAR!!!! ABSURDOOOOOOO. }\end{array}$ \\
\hline 5 & $\begin{array}{l}\text { - Discute-se cada armário comprado - e neste momento você percebe a mesquinharia em que vivem alguns } \\
\text { casais, que costumam guardar notas fiscais de anos atrás, já pensando em uma futura separação. } \\
\text { Buscam partilhar aquilo que não é seu de direito - apenas pelo objetivo de uma "falsa vingança". Os filhos } \\
\text { viram simples moeda de troca. Enquanto a mãe, que geralmente detem a guarda, busca o direito de pensão } \\
\text { alimentícia, o pai, apenas para tirar-lhe a paz, ingressa com pedido de visitas, mesmo sabendo que irá }\end{array}$ \\
\hline
\end{tabular}

10 Os grifos são nossos e visam a identificar os trechos que se relacionam mais diretamente às categorias mencionadas. 


\begin{tabular}{|c|c|}
\hline TEXTO & EXEMPLOS \\
\hline & $\begin{array}{l}\text { retirar a criança e deixa-la com a avó, sem manter qualquer contato. } \\
\text { E a situação perdura. Perdura de forma indeterminada. Conselho e consulta gratuita da Dra.: não estão } \\
\text { felizes? Façam sim o divórcio. Todos tem direito à felicidade. }\end{array}$ \\
\hline 8 & $\begin{array}{l}\text { - Neste mesmo capitulo, veremos as manifestações populares que configurariam o delito em estudo, como a } \\
\text { vivissecção, rodeios, circos e a farra- do-boi. } \\
\text { - Este tema foi escolbido devido aos reflexos da conduta humana no meio ambiente, que tem gerado a longo } \\
\text { prazo, grandes estragos ambientais, } \\
\text { - Atualmente estes reflexos da degradação ambiental tem se demonstrado de maneira mais clarividente. } \\
\text { Contudo, a humanidade parece não se preocupar imediatamente com este problema. }\end{array}$ \\
\hline$\underline{9}$ & $\begin{array}{l}\text { - Eu nunca entendi esta ideia de "curtir o frio". Ficar debaixo do cobertor ou sair na rua parecendo um } \\
\text { boneco de neve é curtir o frio?? Eu hein!!! (...). Este frio só para a menopausa mesmo! Se você tiver esta } \\
\text { alegria por "curtir o frio" (e eu sei que vc é destas), ve vai amar aqui!!! }\end{array}$ \\
\hline 10 & $\begin{array}{l}\text { - Quando eu tinha } 08 \text { anos, alguém jogou dentro da minha casa três filhotinhos de gatos... todos cheios de } \\
\text { pulga! O que o gênio não sabia é que eu tinha um cachorro extremamente violento, que estava solto no } \\
\text { quintal. } \\
\text { - Adote um animal: a felicidade está por aí...! : o ) (o enunciador conta a história de como } \\
\text { conseguiu sua gata de estimação, valorizando como é bom ter um animalzinho). }\end{array}$ \\
\hline & - Se precisar, estou na loucura, mas conte mesmo comigo! (Texto 11) \\
\hline 13 & $\begin{array}{l}\text { - A OABMG dá uma "remuneração" para advogada em licença-maternidade, isenção da anuidade no ano } \\
\text { do nascimento do bebê, máquina de suco e café expresso nas salinhas e, ao cancelar sua anuidade, vc paga } \\
\text { proporcional ao mês de cancelamento. Caso você não saiba, se você tentar cancelar sua OABSP em Janeiro, } \\
\text { ve deve pagar o ano INTEIRINHO, mesmo sem utilizar. } \\
\text { - Enfim. Logo, logo teremos eleiçôes OABSP. Depois de conhecer outras } O A B \text { 's, acho que a de SP estáá } \\
\text { precisando de um bom chacoalhão, hein? }\end{array}$ \\
\hline 16 & $\begin{array}{l}\text { - Eram primeiro lugar, mas o concurso foi prorrogado e faltando } 5 \text { dias estao quase perdendo o primeiro } \\
\text { lugar (que já era deles se tivesse encerrado na data prometida). }\end{array}$ \\
\hline 17 & $\begin{array}{l}\text { - Fui enganada a vida toda!!! Agora sim eu posso dizer que gosto de café - mas do café-café! Não do } \\
\text { pseudo-café!! }\end{array}$ \\
\hline$\underline{18}$ & $\begin{array}{l}\text { - Acho sem-vergonbice comprar gato de raça, com tantos SRD's por aí. Mas, por outro lado, sempre quis } \\
\text { um desses. Então, vai que alguém vai pro exterior e precise deixar o gato com alguém que goste destes } \\
\underline{\text { bichinhos... estou por aí!! }={ }^{\wedge} .{ }^{\wedge}=}\end{array}$ \\
\hline 19 & $\begin{array}{l}\text { - (pois a maioria dos rolos são em cartórios, bancos, etc, que fecham as } 16 \text { ou } 17 \mathrm{~h} ! \text { E ainda, pdem } 5 \text { dias } \\
\text { uteis para emitir certidoes). }\end{array}$ \\
\hline$\underline{20}$ & - Ab vai.... eu sempre ajudo quando pedem! V amos ajuda-lo!! \\
\hline 21 & $\begin{array}{l}\text { - Mas vai uma dica: pega um pedaço de linha, apoia a mão na metade do bolo e corta o bolinho em dois, } \\
\text { porém, mantendo o formato redondo. Corta na altura e nao na metade dele!!! Rssss }\end{array}$ \\
\hline
\end{tabular}

Quadro 15 - Exemplos de passagens do corpus que remetem às oposições "certo vs. errado" / "identidade vs. alteridade".

\subsubsection{Nível discursivo}

O nível discursivo é aquele em que estão os temas e as figuras que recobrem os valores dos níveis fundamental e tensivo e as transformações da estrutura narrativa. Neste nível, "todas as formas abstratas do nível narrativo são revestidas de termos que lhe dão concretude" (FIORIN, 2005, p. 41). Dentre os níveis do plano do conteúdo, o nível 
discursivo é, portanto, o mais concreto e também o mais variável. Por exemplo, o estado de um Sujeito em disjunção com um Objeto, próprio do nível narrativo, pode ser revestido de muitas formas no nível discursivo; pode aparecer como alguém que quer uma casa e não a tem, ou um animal que quer um dono e não o tem, ou uma princesa que quer se casar, etc. O seguinte exemplo, que ilustra essa concretização das formas mais abstratas, é dado por Fiorin ([20--?]):

Um sujeito $A$, que estava em conjunção com objeto vida, entra em disjunção com ele. Essa estrutura poderia ser concretizada como assassinato, se o sujeito operador da disjunção for concretizado como um ser humano diferente de A; como suicídio, se o sujeito operador da disjunção e A forem concretizados como a mesma personagem; como morte por acidente, se o sujeito operador for concretizado como um desastre ou uma catástrofe natural, etc. Esse é um primeiro nível de concretização. Depois, essa concretização primeira é suscetível de uma nova concretização. $\mathrm{O}$ assassinato pode ter sido um tiro dado por ladrões durante um roubo ou espancamento realizado por policiais numa Delegacia (FIORIN, [20--?], p. 171).

A tematização e a figurativização dizem respeito à semântica discursiva. Entretanto, o nível discursivo também conta com uma sintaxe: depreendem-se as projeções da enunciação no enunciado - através das categorias de pessoa, tempo e espaço - e os métodos que o enunciador emprega para convencer o enunciatário a aceitar o seu discurso.

A Semiótica observa que o discursivo é o mais variável dos níveis no que diz respeito à semântica, pois as categorias semio-narrativas e tensivas, mais abstratas, podem ser revestidas por numerosas figuras diferentes que lhe dão concretude (esse é o nível mais próximo da manifestação). Um mesmo enunciador pode utilizar as mesmas estruturas semio-narrativas ou tensivas para tratar de assuntos tão diferentes quanto um problema de trabalho ou animais que ele viu no parque, por exemplo. Esta análise qualitativa não depreendeu elementos recorrentes neste nível que possam ser marcas de um estilo. 


\subsubsection{Tensividade}

No nível tensivo, articulam-se as categorias mais abstratas dos textos, tais como continuidade versus descontinuidade ou relaxamento versus tensão. Este nível pode ser considerado o mais abstrato na imanência de um texto. Os temas e figuras do nível discursivo, as transformações do nível narrativo, as paixões, o aspecto pressupõem a articulação do sentido em categorias mais gerais, tais como "relaxamento" e "tensão", ou "continuidade" e "descontinuidade".

Outra noção importante a considerar no que diz respeito à tensividade é a de extensidade versus intensidade. Zilberberg (2006a, p. 169-170) propõe que a tensividade é a união dessas grandezas; a primeira une a temporalidade e a espacialidade, e a última, o andamento e a tonicidade. A intensidade diz respeito ao sensível, aos estados de alma, e a extensidade, ao inteligível, aos estados de coisas.

Também os universos de valores são regidos no espaço tensivo pelas valências de intensidade e extensidade. $\mathrm{Na}$ extensidade, são dois os grandes tipos de valores: os de universo (ou universal) e os de absoluto. Os primeiros levam à valorização da participação, da expansão, do numeroso - regidos pelas operações de mistura e abertura; já os últimos, relacionam-se à valorização do raro, do exclusivo, do puro, do pouco - regidos pelas operações de triagem e fechamento (FONTANILLE; ZILBERBERG, 2001).

Vê-se que, em termos de intensidade, a maioria dos textos opera em uma tonicidade forte, já que existe um sujeito inconformado (ver seção 4.2.2), que está sempre avaliando (na maior parte das vezes, negativamente) as ações dos outros (conforme visto na seção 3.2) e cuja motivação para compor os enunciados é um acontecimento (conforme seção 4.2.1, ou seja, algo que o tira de seu dia a dia, compõe textos calcados na tensão). Se um acontecimento é o que está na base dos enunciados, esses textos são também da ordem da descontinuidade. No entanto, em muitos dos textos, verifica-se que o enunciador procura de algum modo "amenizar" tal tensão, o que pode ser conferido com alguns exemplos extraídos do corpus, no Quadro 16. 


\begin{tabular}{c|c} 
TEXTO & \multicolumn{1}{c}{ COMENTÁRIO GERAL } \\
& $\begin{array}{l}\text { O fato de os amigos terem se tornado pais é } \\
\text { uma quebra na continuidade. o sujeito } \\
\text { percebe o descompasso que há entre o seu } \\
\text { andamento (acelerado) e o do mundo (dos } \\
\text { outros, dos enunciatários). Daí a cobrança } \\
\text { ("rola ou não rola (...) ?!??; “É possivel deixar a } \\
\text { pequena (...) ou isso é muito ilusório?!?’). Essa } \\
\text { cobrança eleva a tonicidade do enunciado. }\end{array}$ \\
& $\begin{array}{l}\text { Assim como no texto 1, uma tensão se } \\
\text { instaura, já que pode ser criada uma } \\
\text { polêmica a respeito da qualidade do filme, } \\
\text { principalmente por se tratar de uma } \\
\text { avaliação do gosto de amigos. }\end{array}$ \\
&
\end{tabular}

3

5

8

10 relaxamento pela doença da filha da amiga; descontinuidade.

O ocorrido tira o sujeito de seu estado de relaxamento, há uma quebra na continuidade. Ele deve fazer uma cobrança, o que instaura uma tensão no texto.

O divórcio, tema deste texto, é um acontecimento, que tira os envolvidos de estado relaxamento e os coloca em um estado tenso, sobre o qual o enunciador discorre: "O desgaste emocional que gera um divórcio é imensurável".

A ruptura que faz com que o sujeito componha o texto é a percepção de que (grifo nosso) “Atualmente estes reflexos da degradação ambiental tem se demonstrado de maneira mais clarividente". Este estado do meio ambiente tira o sujeito de seu relaxamento.

O fato de ter colocado os gatinhos pulguentos sobre a cama é inesperado e estabelece uma tensão, uma descontinuidade.

Ocorreu um acontecimento (picada de insetos) que instaura descontinuidade.
ATENUAÇÃO DA TENSÃO (OU TENSÃO AMENIZADA)

\begin{abstract}
A tensão é amenizada pelas indicações constantes de riso ("rssssss", "bihihi”).
\end{abstract}

Aqui também o sujeito vai atenuar essa tensão utilizando alguns marcadores como risos ("haubaubuaha", "bihi"), o "tá?" e um diminutivo ("Bjinhos").

Tentativa de amenizar a tensão, porém, pelo fato de o texto ser mais formal, utilizam-se estratégias diferentes das vistas até o momento, como o uso de "peço a gentileza".

A tensão devida ao tema delicado é amenizada também neste texto, por meio do tom mais informal do fim do texto, principalmente pelo início do último parágrafo: "Conselho e consulta gratuita da Dra" e pela expressão "sacudam a poeira", bastante coloquial.

Tensão se ameniza já que o sujeito estudará o meio ambiente, tão importante: "Sendo assim, iremos abranger neste trabalho este bem jurídico tão importante, de uso comum do povo: o meio ambiente".

Tensão suavizada pelo riso (“hihi”). Além disso, o cachorro é citado, logo no início do texto, criando-se uma tensão que é em seguida amenizada por "Um anjo nos fez. perceber isso (...)".

O fato motivador do enunciado é algo um tanto grave - a doença da criança -, mas há também aqui a atenuação da tensão, por meio pergunta em tom de brincadeira envolvendo as figuras dos animais de estimação e uso do diminutivo: "Será que não significa que a Sonia quer um dalmata on um gatinho malhadinho??”.

Novamente, vê-se a tensão do enunciado e a gravidade da situação sendo amenizadas pelo tom de brincadeira de algumas expressões, como: "inchaço das perninhas!!!?", "Meu pé voltou parecendo um pãozinho depois da picada... Mas deu pra dançar numa perna só!! : o" 


\begin{tabular}{|c|c|}
\hline TEXTO & COMENTÁRIO GERAL \\
\hline 13 & $\begin{array}{l}\text { Ocorre descontinuidade e tensão ao receber } \\
\text { resposta da OAB-SP e constatar diferenças } \\
\text { com relação à OAB-MG. }\end{array}$ \\
\hline 16 & $\begin{array}{l}\text { O pedido para que outros assistam ao vídeo } \\
\text { acaba por ser quase uma ordem, ao se usar o } \\
\text { imperativo, ainda reforçado pela exclamação } \\
\text { "assistam!". }\end{array}$ \\
\hline 19 & $\begin{array}{l}\text { A tensão é instaurada pela constatação de } \\
\text { que não se conseguirá resolver todas as } \\
\text { atividades. }\end{array}$ \\
\hline 20 & $\begin{array}{l}\text { Sujeito faz um pedido. A tensão/urgência } \\
\text { pode ser depreendida logo no início: } \\
\text { "Gente!!!!". }\end{array}$ \\
\hline 21 & $\begin{array}{l}\text { O texto ressalta explicitamente que se está } \\
\text { surpreso (descontinuidade) com o que foi } \\
\text { feito pelo sujeito "Julio": "Meu... me amarrota } \\
\text { que eu to passada?". }\end{array}$ \\
\hline
\end{tabular}

\section{ATENUAÇÃO DA TENSÃO (OU TENSÃO AMENIZADA)}

O texto começa tenso com um tom formal "Colegas advogados paulistas" e termina relaxado com "Beijinhos".

Novamente se vê uma atenuação da tensão com o uso do diminutivo

"rapidinho".

Tensão amenizada pelo riso e tom jocoso ("Pelo visto vou resolver parcialmente tudo e resolver integralmente nada! rssss $A$ advocacia ainda me pira".).

Tensão amenizada ao se usar o diminutivo duas vezes para explicar que a tarefa que o enunciatário terá que executar não é trabalhosa: "V ai dar um pequeno trabalhinho".

Julga que o bolo deveria ter sido feito de outra forma. Avaliação negativa (crítica) que instaura tensão, que, por sua vez, é amenizada pelos risos ("rsssss").

Quadro 16 - Tonicidade forte/descontinuidade; atenuação da tensão.

Em resumo, as características do plano do conteúdo que se mostraram relevantes, devido a sua recorrência, como marcadores do estilo do autor figuram no Quadro 17, a seguir:

\section{MARCADORES DE ESTILO DO AUTOR ANALISADO (PLANO DO CONTEÚDO)}

Sanção - percurso de interpretação

\section{Acontecimento}

Inconformismo

"Certo" x "Errado"

Tonicidade forte/Descontinuidade ; Atenuação da Tensão

Quadro 17 - Marcadores de estilo do autor analisado (plano do conteúdo)

O fato de que um mesmo conjunto de características do plano do conteúdo é encontrado ao longo da maior parte dos textos do mesmo autor corrobora a hipótese inicial de que elementos que organizam o plano do conteúdo podem funcionar como marcadores de estilo autoral. 


\subsubsection{O texto questionado}

Conforme a proposta que se estabeleceu no início deste capítulo, finalizar este estudo requer também a análise do texto cuja autoria se simula como questionada, no sentido de verificar se nele estão presentes os elementos identificados no conjunto de 20 textos do "autor conhecido". O Quadro 18 esquematiza o resultado da análise.

\begin{tabular}{|c|c|c|}
\hline CARACTERÍSTICA & COMENTÁRIO & EXCERTOS \\
\hline Sanção & $\begin{array}{l}\text { Avalia o comportamento da } \\
\text { amiga, sua reação e as atitudes } \\
\text { com relação à celebração de seu } \\
\text { casamento. }\end{array}$ & $\begin{array}{l}\text { - "nunca vi um casamento tão detalhado como o seu"; } \\
\text { - "não é comum cada detalhe que ve pensou!!" } \\
\text { - "Desde pequena gosta de organizar cada detalhe, } \\
\text { como faziamos nos trabalhos de maquetes e musicas. } \\
\text { Para alguns isso é 'nóia'. Para nós sempre foi 'o } \\
\text { trabalho bem feito'. } \\
\text {-"muito pelo contrario, ve está bem calma (...) será o } \\
\text { casamento da princesa, pq ves pensaram em tudo } \\
\text { para ser o casamento do sonho" } \\
\text {-"Bom.... acho que vc já ficou brava" }\end{array}$ \\
\hline Acontecimento & $\begin{array}{l}\text { O sujeito constata o } \\
\text { planejamento de um casamento } \\
\text { detalhado como nunca visto; } \\
\text { - Há uma má reação da amiga } \\
\text { frente à brincadeira realizada. }\end{array}$ & $\begin{array}{l}\text {-"Nao entenda mal a brincadeira." } \\
\text { "Mas acredite se quiser, não é comum cada detalbe } \\
\text { que vc pensou!!" } \\
\text { "Bom.... acho que vc já ficou brava" }\end{array}$ \\
\hline Inconformismo & $\begin{array}{l}\text { Não se conforma com todos os } \\
\text { preparativos para o casamento. }\end{array}$ & $\begin{array}{l}\text { - "não é comum cada detalhe que ve pensou!!" } \\
\text {-" Mas sendo sincera, não é comum! Eu, pelo menos, } \\
\text { nunca vi." } \\
\text { - "São trocentos mil detalhes que vc pensa!! Eu acho } \\
\text { que ve não dorme!!!!" } \\
\text {-"resolvi falar para nao ficar mal explicado" }\end{array}$ \\
\hline $\begin{array}{l}\text { Tonicidade forte / } \\
\text { Descontinuidade; } \\
\text { Atenuação da Tensão }\end{array}$ & $\begin{array}{l}\text { A tensão é instaurada pelas } \\
\text { críticas que faz à amiga. } \\
\text { Indicações de riso ao longo do } \\
\text { texto tentam amenizar a } \\
\text { situação, mais a despedida } \\
\text { carinhosa (ver ao lado). }\end{array}$ & $\begin{array}{l}\text { - "rsss" } \\
\text {-"Beijos" } \\
\text {-"amo vcs" }\end{array}$ \\
\hline
\end{tabular}

Quadro 18 - Características do texto questionado

A repetição da mesma combinação de elementos indica que é muito provável que o autor do texto questionado seja o mesmo dos textos conhecidos (de fato, neste exemplo, sabe-se que é). O estilo se dá pela recorrência de um conjunto, de uma cosseleção de características (no plano da expressão ou do conteúdo); nunca por uma ou outra característica tomada isoladamente. Assim, é claro que uma ou outra dessas características 
podem aparecer em textos de outros autores, mas é muito improvável que exatamente a mesma combinação de todos esses elementos esteja presente. 


\section{ESTILOS INDIVIDUAIS E ATRIBUiÇÃo DE AUTORIA: ANÁLISE QUANTITATIVA}

Jamie Starbuck, 36, admitted murdering his wife Debbie and was ordered to serve a minimum of 30 years by the judge at Nottingham Crown Court.

Starbuck, from Nottingham, used his wife's money to travel the world.

He tried to cover up the crime by sending emails in Mrs Starbuck's name for nearly three years, pretending they were travelling together

(BBC News, 2013)1 


\subsection{Medindo semelhanças e diferenças entre textos a partir do plano do conteúdo}

A análise qualitativa do capítulo anterior sugere que características do plano do conteúdo podem funcionar como marcadores de estilo quando recorrentes. O estudo no presente capítulo, por sua vez, objetiva testar se tal hipótese se sustenta estatisticamente. É necessário verificar se as características depreendidas numa análise semiótica de elementos do plano do conteúdo têm realmente o potencial de distinguir autores. Para tanto, desenvolveu-se um experimento que se descreve nas seções a seguir.

\subsection{Metodologia}

\subsubsection{Corpus, software e extração dos dados}

Separaram-se textos de 4 autores do CGAA. O primeiro autor, selecionado aleatoriamente, é o mesmo da análise qualitativa da seção anterior; a partir dele, os próximos três autores do mesmo perfil sociolinguístico ${ }^{2}$ foram selecionados. A escolha por autores de perfis sociolinguísticos semelhantes deu-se uma vez que, conforme explica Chaski (2001, p. 4, tradução nossa) ${ }^{3}$, "se a técnica testada pode diferenciar os autores de documentos que tenham as mesmas características dialetais, então ela pode certamente funcionar com documentos que não as compartilham”. Com isso, garante-se que as características depreendidas distinguem realmente indivíduos e não grupos sociais.

Selecionaram-se 20 textos de cada autor e posteriormente cada um desses conjuntos de 20 foi dividido em dois subconjuntos de 10 (A e B), conforme o Quadro 19:

\footnotetext{
${ }^{2}$ São 4 mulheres, com idade entre 26 e 40 anos e nível superior de escolaridade.

3 Texto original: "If the tested technique can differentiate the authors of documents which share dialectal features, then it can certainly work on documents which do not share dialectal features" (CHASKI, 2001, p. 4).
} 


\begin{tabular}{|c|c|c|c|c|c|c|}
\hline Autor 1 & \multicolumn{2}{|c|}{ Autor 2} & \multicolumn{2}{|c|}{ Autor 3} & \multicolumn{2}{|c|}{ Autor 4} \\
\hline $1 \mathrm{~A}$ & $2 \mathrm{~A}$ & $2 \mathrm{~B}$ & $3 \mathrm{~A}$ & $3 B$ & $4 \mathrm{~A}$ & $4 B$ \\
\hline
\end{tabular}

Quadro 19 - Quatro autores e subamostras de textos

A suposição é que a "distância" entre os grupos A e B de cada autor é menor do que aquela entre os diferentes autores. Por exemplo, 1A é mais semelhante a 1B do que a todos os outros grupos $(2 \mathrm{~A}, 2 \mathrm{~B}, 3 \mathrm{~A}, 3 \mathrm{~B}, 4 \mathrm{~A}, 4 \mathrm{~B})$. Em outras palavras, a variação interfalante (ou interautor) é maior do que a variação intrafalante (ou intra-autor). Isso vai ao encontro de duas premissas de qualquer análise comparativa de autoria, segundo Grant (2012): a) o estilo dos textos de um mesmo autor é suficientemente consistente; e b) essa consistência é distintiva o suficiente para distinguir autores.

O desafio foi, então, o de medir a semelhança e diferença (a "distância" ou a "proximidade") entre os textos. Numa análise quantitativa de elementos do plano da expressão, recursos computacionais podem ser prontamente utilizados para extração dos dados na maioria dos casos. Trata-se de uma análise automática, já que se dá uma instrução ao computador do que procurar, por exemplo, as ocorrências de "voce", "ce", "cê", "você", "vc" num texto em português. Ao contrário, por mais estruturado que seja o plano do conteúdo, não se pode automaticamente analisá-lo (pelo menos não até o momento, para a maior parte de suas categorias de análise). Isso não quer dizer, entretanto, que ele não seja passível de medição. Gibbons (2011, p. 252, tradução nossa ${ }^{4}$, grifo do autor) afirma que "o Discurso, já que sua manifestação é algumas vezes menos concreta, não tem sido passível de análises quantitativas”. Ora, o discurso pode não ter sido ainda objeto de análises quantitativas, mas ele pode, sim, ser submetido a elas; não se pode analisar o discurso automaticamente, mas uma vez que ele se organiza em categorias de análises, elas podem ser quantificadas.

Uma opção para a quantificação de categorias do plano do conteúdo seria utilizar um recurso comum à Linguística de Corpus: o de "etiquetar" ("codificar", "anotar") o

\footnotetext{
${ }^{4}$ Texto original: "Discourse, because its surface manifestations are sometimes less concrete, has not been easily amenable to quantitative analysis” (GIBBONS, 2011, p. 252).
} 
texto. A primeira ideia que surgiu neste trabalho foi criar uma lista com essas etiquetas, correspondentes a cada uma das características do plano do conteúdo. Uma vez que um texto estivesse em formato digital que permitisse sua edição (*.txt, *.doc, etc), poder-se-ia inserir manualmente uma certa característica semiótica no momento da análise. Por exemplo, se num texto aparecesse a fase do julgamento (presente no nível narrativo do percurso gerativo do sentido), tal fase poderia ser marcada no arquivo por meio de uma etiqueta previamente definida, tal como $<$ JULGAM $>$. Assim, todas as vezes em que o analista identificasse essa fase, em todos os textos, deveria anotar <JULGAM $>$ no arquivo. Isso teria que ocorrer para todos os níveis de análise. De acordo com a semiótica tensiva, por exemplo, um texto poderia ser da ordem da concessão ou da implicação. Assim, seria o caso de incluir alguma anotação como <CONCES $>$ ou $<$ IMPLIC $>$ no arquivo, conforme o caso. Ao fim da análise, um programa computacional simples conseguiria extrair essas marcações.

Tal tarefa - bastante trabalhosa, ao mesmo tempo que bastante simples apresentou, porém, alguns problemas, a ver:

1. o fato de o analista ter que acessar diretamente o arquivo poderia suscitar alterações não desejadas que poderiam prejudicar algum outro tipo de análise que se desejasse fazer posteriormente.

2. há risco de ocorrência de erros na hora da etiquetação; mesmo "copiando" e "colando" a etiqueta, seria muito possível algo dar errado e um ou outro caractere da etiqueta sobrar ou faltar.

3. há também risco do analista "pular", ainda que não intencionalmente, algum passo da análise e deixar de fora do estudo um ou outro elemento semiótico, num ou noutro texto.

Assim, uma saída para minimizar esses problemas foi fazer uso de um software durante a análise: o Corpus Tool (UAM Corpus Tool, v. 3.1.12: O’DONNELL, 2007). Este 
programa permite que o analista insira "sistemas" ou "esquemas" de análise ${ }^{5}$. Permite, ainda, que textos sejam incluídos, para serem analisados de acordo com esses esquemas. A "etiquetação" é manual, já que cabe ao analista - e não ao computador, de modo automático - selecionar trecho por trecho a analisar e atribuir a ele uma das etiquetas previamente cadastradas no sistema. Contudo, as etiquetas permanecem armazenadas no sistema e podem ser extraídas para arquivos *.txt ou *.xml, para que sejam contadas.

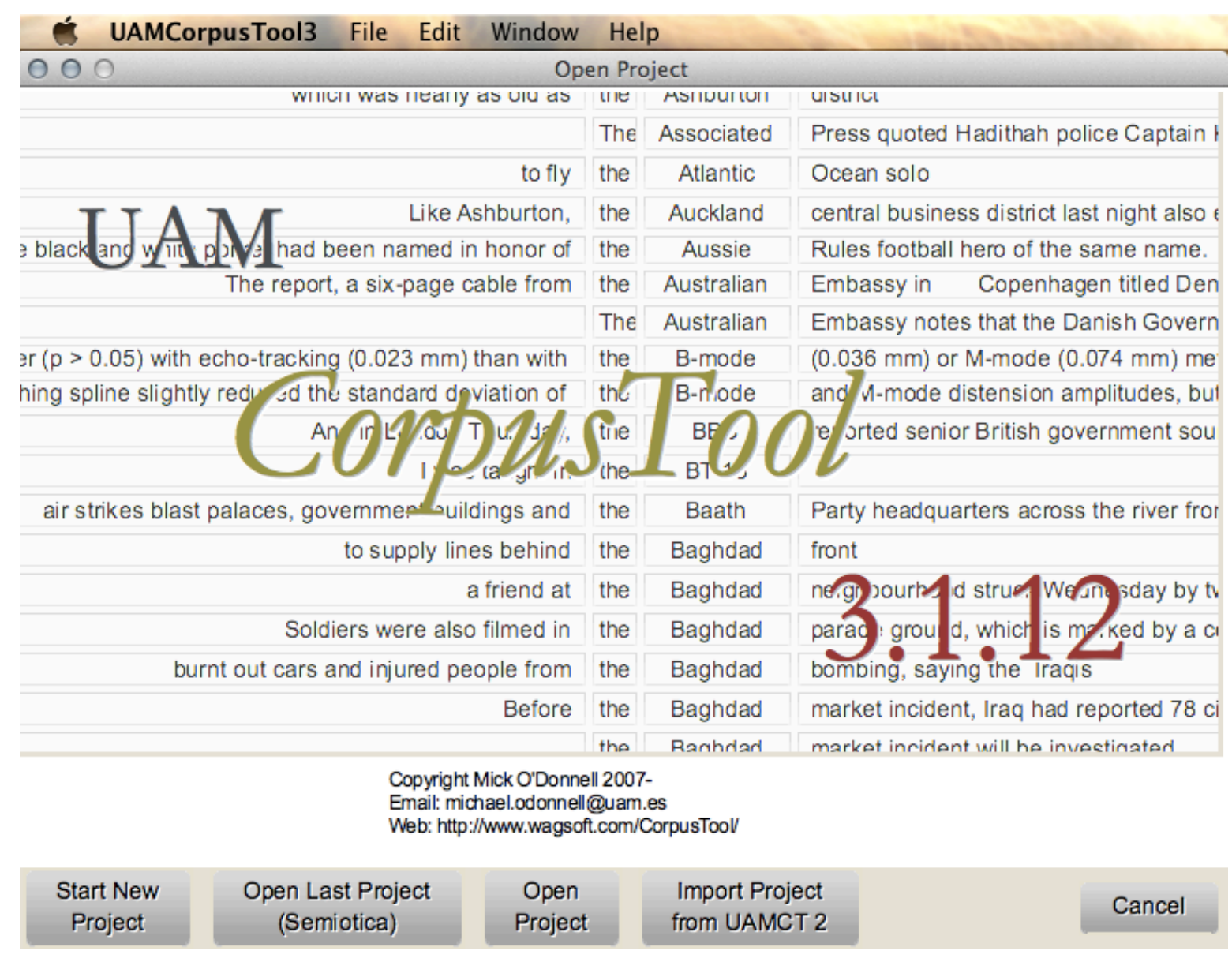

Figura 11 - Tela inicial do Corpus Tool, versão 3.1.12

\footnotetext{
${ }^{5} \mathrm{O}$ pesquisador pode inserir qualquer "esquema" de análise no sistema, como por exemplo os níveis de análise da Linguística Sistêmico-Funcional (GRANT; NINI, 2014). Para esta pesquisa, obviamente, inseriram-se categorias do modelo de análise da Semiótica Discursiva. O design desses esquemas de análise no Corpus Tool é apresentado no Apêndice A.
} 
Este trabalho procurou introduzir em tais esquemas de análise as principais ${ }^{6}$ características que emergem de análises semióticas, separadas em seus diversos níveis, conforme o percurso gerativo do sentido (Figura 12 a seguir).

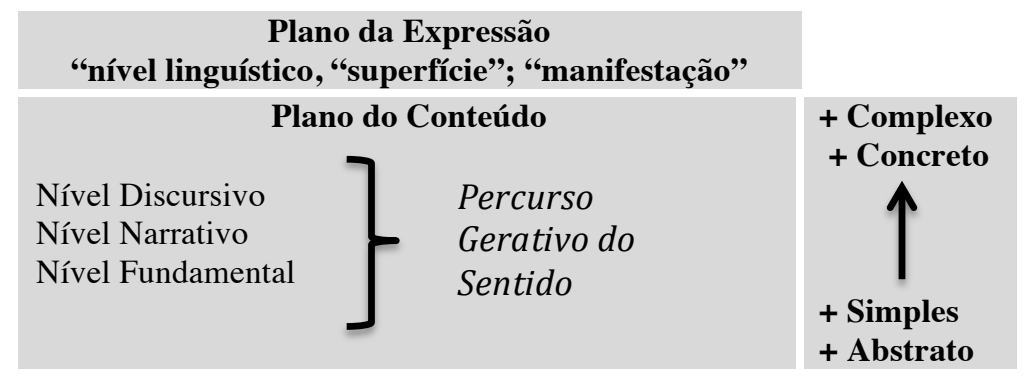

Figura 12 - Semiótica Discursiva: plano da expressão e plano do conteúdo com o percurso gerativo do sentido

A título de exemplo, reproduzem-se, a seguir, as telas do sistema Corpus Tool, para que se compreenda de que modo a análise foi realizada no programa.

Os esquemas de análise são incluídos no programa em "camadas" (layers). No caso deste trabalho, incluíram-se as seguintes: sintaxe narrativa, semântica narrativa, sintaxe discursiva, semântica discursiva, nível fundamental e tensividade. Depois que todos os textos desejados são importados para o programa, a tela inicial conterá cada uma das camadas, seguidas do nome do arquivo, como na Figura 13, a seguir:

\footnotetext{
${ }^{6}$ Vale ressaltar que foram incluídas as características julgadas mais importantes ou que se percebem com mais frequência em análises semióticas. Com isso, uma ou outra característica pode ter ficado de fora, mas o Corpus Tool permite que elas sejam facilmente inseridas em futuras análises caso seja necessário.
} 


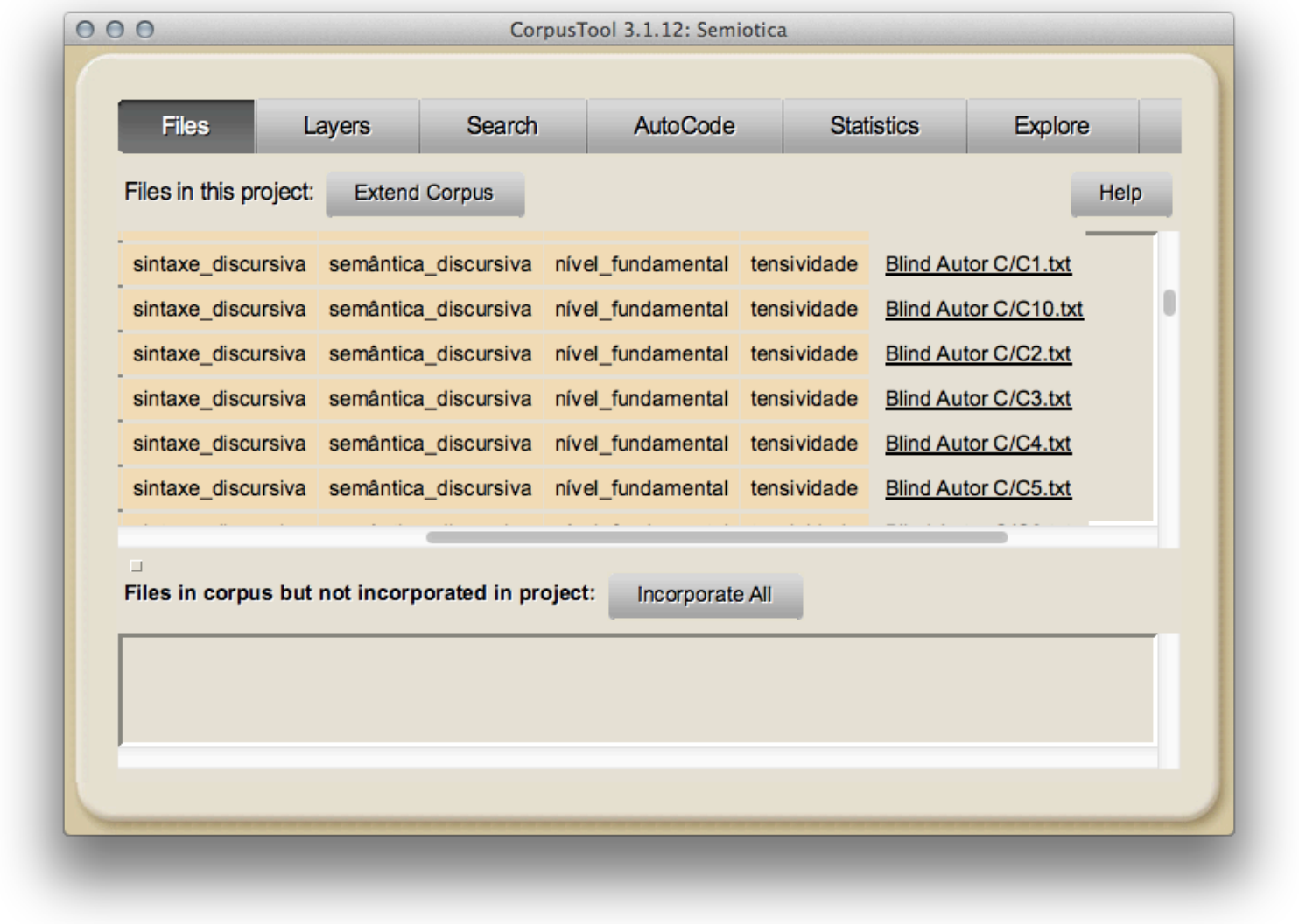

Figura 13 - Corpus Tool: "Layers" e arquivos importados

Para iniciar o procedimento, basta clicar no título da "camada" que se quer analisar, da mesma linha do arquivo que se quer analisar. Suponhamos que se queira analisar a "sintaxe narrativa" do arquivo "Blind Author C/C1.txt". Ao clicar na camada, a seguinte tela surgiria, mostrando o texto e os passos de análise. 


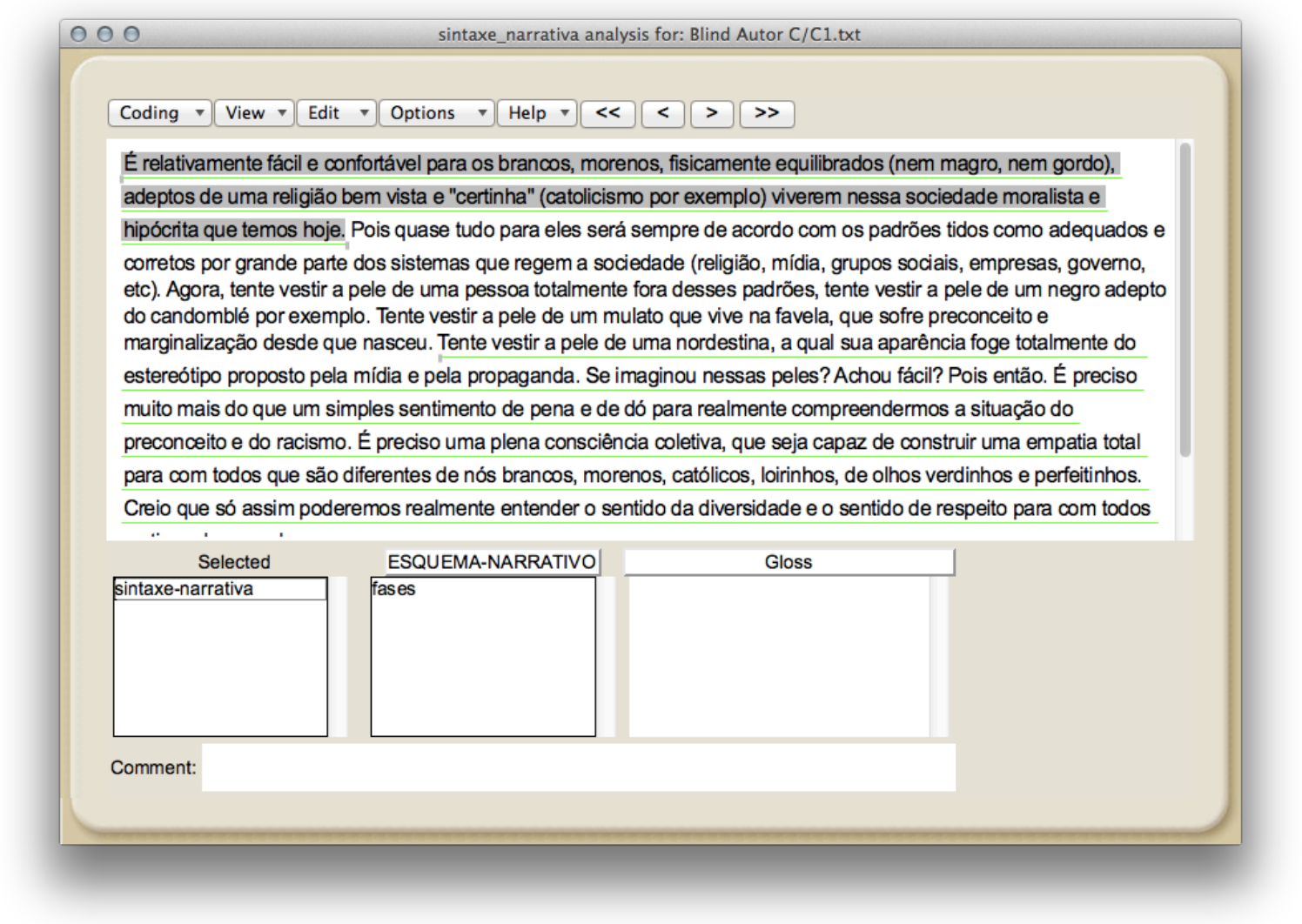

Figura 14 - Corpus Tool: tela de análise

Supondo que quiséssemos informar que o texto acima apresenta explicitamente a fase da manipulação e que existe uma manipulação por provocação, indicar isso seria possível ao se clicar nesta opção assim que ela aparecesse na tela, nos quadros que estão no canto inferior esquerdo da Figura 14. As Figuras 15 e 16 mostram como essa opção apareceria, assim que se clicasse em "fases":

\begin{tabular}{|l|c|}
\hline \multicolumn{1}{|c|}{ Selected } & MANIPULACAO \\
\hline $\begin{array}{l}\text { sintaxe-narrativa } \\
\text { fases }\end{array}$ & tipos-de-manipulacao \\
\hline & \\
& \\
\hline
\end{tabular}

Figura 15 - Corpus Tool: escolhendo uma "etiqueta" 


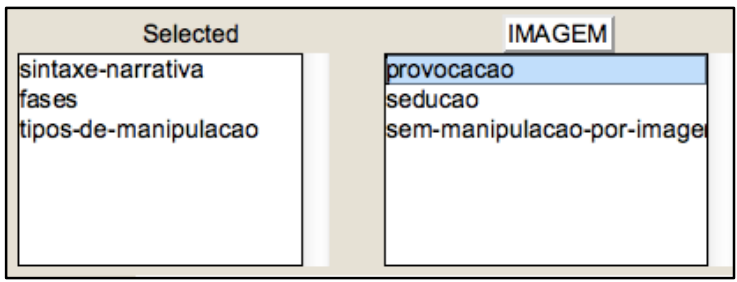

Figura 16 - Corpus Tool: escolhendo uma "etiqueta"

Depois que a "etiqueta" denominada "provocação" fosse escolhida, o sistema prosseguiria oferecendo ao analista as outras possibilidades de tipos de manipulação cadastrados no sistema, conforme se vê na Figura 17:

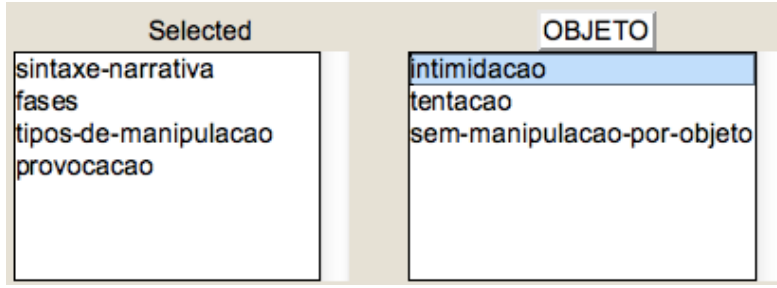

Figura 17 - Corpus Tool: escolhendo uma "etiqueta"

O analista seria, assim, "obrigado" a passar por todas as opções, ou seja, por todas as categorias cadastradas no sistema, não sendo possível ignorá-las. O sistema não garante que a categoria correta seja escolhida pelo analista, mas garante, ao menos, que ele não deixe de fora nenhuma categoria (por esquecimento, por exemplo).

Quando se seleciona uma etiqueta, ela é salva no sistema, atrelada ao texto que se estava examinando e pode, como já se mencionou, ser quantificada. Observa-se que com o uso do Corpus Tool, os problemas 1 e 2 acima descritos seriam eliminados e o 3 bastante diminuído, já que o software força o usuário a passar por todas as fases cadastradas.

Para o exercício que ora se apresenta, os 80 exemplares de textos dos 4 autores foram inseridos no programa e um a um analisados semioticamente, seguindo-se um por um todos os níveis e categorias de análise que foram incluídas no sistema. Após a análise, os textos foram exportados em um arquivo *.txt no seguinte modelo, em que na coluna 
"features" estão as etiquetas a serem extraídas (após o sinal de “;”) para serem contabilizadas como características de um autor:

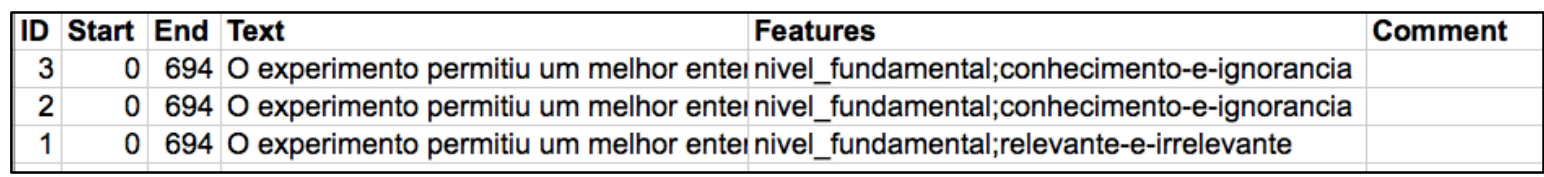

Figura 18 - Modelo de arquivo *.txt exportado do Corpus Tool

Os dados (as etiquetas que se descreveram acima) foram então extraídos por meio de scripts ${ }^{7}$ desenvolvidos em linguagem de programação $P E R L^{8}$ e em Shell script. Para a extração, levou-se em conta o fato de uma determinada característica estar presente ou ausente em cada um dos textos de cada subcorpus. Assim, a frequência de cada característica dentro de cada conjunto A ou B para cada autor (1, 2, 3 ou 4) variou de 0 a 10 (já que cada um desses subcorpus contou com 10 textos). Se uma característica aparece em um texto, ainda que repetidas vezes, ela foi contada apenas uma vez ${ }^{9}$.

\subsubsection{Medição da distância entre os subcorpora}

Com os dados extraídos, a análise quantitativa foi realizada, primeiramente, através do Coeficiente de Jaccard $^{10}$ (uma medida estatística utilizada para calcular a similaridade entre conjuntos). Em tal coeficiente, cada característica de um conjunto é contada como presente ou ausente e, a partir de tal quantificação, pode-se verificar qual é a "distância" entre dois conjuntos. A fórmula do Coeficiente de Jaccard é:

\footnotetext{
${ }^{7}$ Os scripts foram desenvolvidos por Ricardo Piantola, doutorando em Engenharia da Computação na Escola Politécnica da Universidade de São Paulo. Eles estão disponíveis no Anexo D.

8 THE PERL PROGRAMMING LANGUAGE. Disponível em < http://www.perl.org/>.

${ }^{9} \mathrm{O}$ motivo para essa frequência ter sido contada apenas em termos de presença ou ausência está relacionado às medidas estatísticas escolhidas, que serão expostas mais adiante.

10 Também conhecido como "Índice de Jaccard", ou "Índice de Similaridade de Jaccard". Em Linguística Forense, tal medida aparece principalmente nos trabalhos de Tim Grant (GRANT, 2010; MACLEOD e GRANT, 2012; GRANT, 2012).
} 


$$
J(A, B)=\frac{|A \cap B|}{|A \cup B|}
$$

Ou seja, dados dois conjuntos A e B, a similaridade entre eles é medida pelo "tamanho" de sua intersecção dividido pelo "tamanho" de sua união. Os resultados vão de 0 a 1 , em que 0 indica total dessemelhança entre os dois conjuntos e 1 indica identidade entre eles ${ }^{11}$.

Antes de aplicar a fórmula do Coeficiente de Jaccard, algumas decisões foram tomadas:

- Excluíram-se todas as características cuja frequência era 0 para todos os textos e também aquelas presentes em todos os textos, já que tais características não seriam distintivas.

- Uma vez que um estilo está relacionado à consistência, ou seja, a uma recorrência de elementos, foram consideradas apenas características que apareceram pelo menos 5 vezes em pelo menos um dos conjuntos. Isto é, apenas as características que apareceram em pelo menos metade dos textos de um conjunto foram consideradas recorrentes.

A Tabela 5 disponibiliza a frequência dessas características:

Tabela 5 - Frequência das características recorrentes

\begin{tabular}{|l|c|c|c|c|c|c|c|c|}
\hline & \multicolumn{2}{|c|}{ AUTOR 1 } & \multicolumn{2}{c|}{ AUTOR 2 } & \multicolumn{3}{c|}{ AUTOR 3 } & \multicolumn{2}{c|}{ AUTOR 4 } \\
\hline CARACTERÍSTICAS & $\mathbf{1 A}$ & $\mathbf{1 B}$ & $\mathbf{2 A}$ & $\mathbf{2 B}$ & $\mathbf{3 A}$ & $\mathbf{3 B}$ & $\mathbf{4 A}$ & 4B \\
\hline tentação & 0 & 0 & 0 & 0 & 5 & 5 & 0 & 0 \\
\hline fazer-emissivo & 0 & 0 & 6 & 0 & 5 & 5 & 0 & 0 \\
\hline avalia-positivamente & 0 & 0 & 6 & 5 & 5 & 0 & 0 & 0 \\
\hline avalia-negativamente & 8 & 10 & 7 & 6 & 0 & 0 & 9 & 7 \\
\hline mentira-ou-segredo & 5 & 5 & 0 & 0 & 0 & 0 & 0 & 0 \\
\hline transitiva-doação & 5 & 0 & 0 & 0 & 0 & 0 & 0 & 0 \\
\hline programa-de-uso & 5 & 0 & 0 & 0 & 0 & 0 & 0 & 0 \\
\hline
\end{tabular}

\footnotetext{
11 Outra expressão para o coeficiente de Jaccard é $(c /(a+b+c)$, em que:

$\mathrm{a}=\mathrm{a}$ quantidade de características que um conjunto possui.

$\mathrm{b}=\mathrm{a}$ quantidade de caracaterísticas que o outro conjunto possui.

$\mathrm{c}=$ a quantidade de características que está presente em ambos os conjuntos.
} 


\begin{tabular}{|c|c|c|c|c|c|c|c|c|}
\hline quer-fazer & 0 & 0 & 0 & 5 & 0 & 0 & 0 & 0 \\
\hline não-poder-fazer-impotência & 5 & 0 & 0 & 0 & 0 & 0 & 0 & 0 \\
\hline querer-ser & 0 & 0 & 5 & 6 & 0 & 0 & 0 & 0 \\
\hline saber-não-ser & 9 & 0 & 5 & 5 & 6 & 0 & 0 & 0 \\
\hline fazer-fazer-intervenção & 6 & 5 & 0 & 0 & 0 & 0 & 9 & 5 \\
\hline querer-saber-curiosidade & 5 & 0 & 0 & 0 & 5 & 0 & 0 & 0 \\
\hline fazer-saber-comunicar & 6 & 0 & 5 & 0 & 8 & 8 & 6 & 5 \\
\hline repulsa & 0 & 0 & 6 & 0 & 0 & 0 & 0 & 0 \\
\hline decepção & 6 & 9 & 0 & 0 & 0 & 0 & 0 & 0 \\
\hline orgulho & 0 & 0 & 5 & 0 & 6 & 0 & 0 & 0 \\
\hline inconformismo & 0 & 6 & 0 & 0 & 0 & 0 & 9 & 7 \\
\hline insatisfação & 5 & 6 & 5 & 5 & 0 & 0 & 0 & 0 \\
\hline desprezo & 5 & 8 & 0 & 0 & 0 & 0 & 5 & 0 \\
\hline empatia & 0 & 0 & 5 & 5 & 0 & 0 & 0 & 0 \\
\hline enuncivo-espaco-1 & 0 & 0 & 6 & 5 & 0 & 0 & 0 & 0 \\
\hline ilustração-exemplos & 0 & 0 & 5 & 6 & 6 & 5 & 5 & 6 \\
\hline hipérbole & 0 & 0 & 6 & 5 & 0 & 0 & 0 & 0 \\
\hline clichês & 0 & 0 & 0 & 0 & 5 & 5 & 0 & 0 \\
\hline antítese & 6 & 5 & 0 & 0 & 0 & 0 & 0 & 0 \\
\hline digressão & 0 & 0 & 0 & 0 & 6 & 0 & 0 & 0 \\
\hline indignado & 5 & 5 & 0 & 0 & 0 & 0 & 0 & 0 \\
\hline seriedade & 6 & 0 & 0 & 0 & 0 & 0 & 0 & 0 \\
\hline sarcasmo & 5 & 8 & 0 & 0 & 0 & 0 & 0 & 0 \\
\hline detentor-do-saber & 0 & 0 & 0 & 0 & 8 & 5 & 0 & 0 \\
\hline errado-e-certo & 0 & 0 & 0 & 0 & 0 & 0 & 9 & 5 \\
\hline descaso-e-colaboração & 0 & 5 & 0 & 0 & 0 & 0 & 0 & 0 \\
\hline compromisso-e-isenção & 5 & 5 & 0 & 0 & 0 & 0 & 0 & 0 \\
\hline conhecimento-e-ignorância & 0 & 0 & 0 & 0 & 5 & 7 & 0 & 0 \\
\hline concentrado & 0 & 0 & 0 & 0 & 0 & 0 & 6 & 0 \\
\hline +persistência & 6 & 5 & 0 & 0 & 0 & 0 & 6 & 0 \\
\hline abreviamento & 7 & 5 & 0 & 0 & 5 & 5 & 6 & 0 \\
\hline demora & 5 & 5 & 0 & 0 & 0 & 0 & 0 & 0 \\
\hline tensionado & 7 & 8 & 5 & 0 & 0 & 0 & 0 & 0 \\
\hline relaxado & 0 & 0 & 0 & 0 & 5 & 6 & 0 & 0 \\
\hline atenuação-da-tensão & 0 & 0 & 5 & 0 & 5 & 0 & 8 & 10 \\
\hline rotina-estado & 0 & 0 & 0 & 5 & 9 & 8 & 0 & 0 \\
\hline acontecimento & 10 & 10 & 7 & 6 & 0 & 0 & 9 & 9 \\
\hline
\end{tabular}

Em seguida, os dados da Tabela 5 foram convertidos em valores binários para permitir o cálculo do coeficiente de Jaccard. O valor " 0 " foi atribuído à ausência de uma característica e "1" à presença. A Tabela 6 apresenta tais valores. 
Tabela 6-Características por subamostraa: valores binários

\begin{tabular}{|c|c|c|c|c|c|c|c|c|}
\hline \multirow[t]{2}{*}{ CARACTERÍSTICAS } & \multicolumn{8}{|c|}{ VALORES BINÁRIOS } \\
\hline & $1 \mathrm{~A}$ & $1 \mathrm{~B}$ & $2 \mathrm{~A}$ & $2 \mathrm{~B}$ & $3 \mathrm{~A}$ & $3 \mathrm{~B}$ & $4 \mathrm{~A}$ & $4 \mathrm{~B}$ \\
\hline tentação & - & - & - & - & 1 & 1 & - & - \\
\hline fazer-emissivo & - & - & 1 & - & 1 & 1 & - & - \\
\hline avalia-positivamente & - & - & 1 & 1 & 1 & - & - & - \\
\hline avalia-negativamente & 1 & 1 & 1 & 1 & - & - & 1 & 1 \\
\hline mentira-ou-segredo & 1 & 1 & - & - & - & - & - & - \\
\hline transitiva-doação & 1 & - & - & - & - & - & - & - \\
\hline programa-de-uso & 1 & - & - & - & - & - & - & - \\
\hline quer-fazer & - & - & - & 1 & - & - & - & - \\
\hline não-poder-fazer-impotência & 1 & - & - & - & - & - & - & - \\
\hline querer-ser & - & - & 1 & 1 & - & - & - & - \\
\hline saber-não-ser & 1 & - & 1 & 1 & 1 & - & - & - \\
\hline fazer-fazer-intervenção & 1 & 1 & - & - & - & - & 1 & 1 \\
\hline querer-saber-curiosidade & 1 & - & - & - & 1 & - & - & - \\
\hline fazer-saber-comunicar & 1 & - & 1 & - & 1 & 1 & 1 & 1 \\
\hline repulsa & - & - & 1 & - & - & - & - & - \\
\hline decepção & 1 & 1 & - & - & - & - & - & - \\
\hline orgulho & - & - & 1 & - & 1 & - & - & - \\
\hline inconformismo & - & 1 & - & - & - & - & 1 & 1 \\
\hline insatisfação & 1 & 1 & 1 & 1 & - & - & - & - \\
\hline desprezo & 1 & 1 & - & - & - & - & 1 & - \\
\hline empatia & - & - & 1 & 1 & - & - & - & - \\
\hline enuncivo-espaco-1 & - & - & 1 & 1 & - & - & - & - \\
\hline ilustração-exemplos & - & - & 1 & 1 & 1 & 1 & 1 & 1 \\
\hline hipérbole & - & - & 1 & 1 & - & - & - & - \\
\hline clichês & - & - & - & - & 1 & 1 & - & - \\
\hline antítese & 1 & 1 & - & - & - & - & - & - \\
\hline digressão & - & - & - & - & 1 & - & - & - \\
\hline indignado & 1 & 1 & - & - & - & - & - & - \\
\hline seriedade & 1 & - & - & - & - & - & - & - \\
\hline sarcasmo & 1 & 1 & - & - & - & - & - & - \\
\hline detentor-do-saber & - & - & - & - & 1 & 1 & - & - \\
\hline errado-e-certo & - & - & - & - & - & - & 1 & 1 \\
\hline descaso-e-colaboração & - & 1 & - & - & - & - & - & - \\
\hline compromisso-e-isenção & 1 & 1 & - & - & - & - & - & - \\
\hline conhecimento-e-ignorância & - & - & - & - & 1 & 1 & - & - \\
\hline concentrado & - & - & - & - & - & - & 1 & - \\
\hline +persistência & 1 & 1 & - & - & - & - & 1 & - \\
\hline abreviamento & 1 & 1 & - & - & 1 & 1 & 1 & - \\
\hline demora & 1 & 1 & - & - & - & - & - & - \\
\hline tensionado & 1 & 1 & 1 & - & - & - & - & - \\
\hline relaxado & - & - & - & - & 1 & 1 & - & - \\
\hline atenuação-da-tensão & - & - & 1 & - & 1 & - & 1 & 1 \\
\hline rotina-estado & - & - & - & 1 & 1 & 1 & - & - \\
\hline acontecimento & 1 & 1 & 1 & 1 & - & - & 1 & 1 \\
\hline
\end{tabular}


O Coeficiente de Jaccard foi então calculado para todos os pares possíveis entre os subconjuntos, conforme apresenta o Quadro 20, a seguir:

\begin{tabular}{|l|l|l|l|}
\hline PARES & & & \\
\hline $1 \mathrm{~A} \times 1 \mathrm{~B}$ & $1 \mathrm{~B} \times 2 \mathrm{~A}$ & $2 \mathrm{~A} \times 3 \mathrm{~A}$ & $2 \mathrm{~B} \times 4 \mathrm{~B}$ \\
\hline $1 \mathrm{~A} \times 2 \mathrm{~A}$ & $1 \mathrm{~B} \times 2 \mathrm{~B}$ & $2 \mathrm{~A} \times 3 \mathrm{~B}$ & $3 \mathrm{~A} \times 3 \mathrm{~B}$ \\
\hline $1 \mathrm{~A} \times 2 \mathrm{~B}$ & $1 \mathrm{~B} \times 3 \mathrm{~A}$ & $2 \mathrm{~A} \times 4 \mathrm{~A}$ & $3 \mathrm{~A} \times 4 \mathrm{~A}$ \\
\hline $1 \mathrm{~A} \times 3 \mathrm{~A}$ & $1 \mathrm{~B} \times 3 \mathrm{~B}$ & $2 \mathrm{~A} \times 4 \mathrm{~B}$ & $3 \mathrm{~A} \times 4 \mathrm{~B}$ \\
\hline $1 \mathrm{~A} \times 3 \mathrm{~B}$ & $1 \mathrm{~B} \times 4 \mathrm{~A}$ & $2 \mathrm{~B} \times 3 \mathrm{~A}$ & $3 \mathrm{~B} \times 4 \mathrm{~A}$ \\
\hline $1 \mathrm{~A} \times 4 \mathrm{~A}$ & $1 \mathrm{~B} \times 4 \mathrm{~B}$ & $2 \mathrm{~B} \times 3 \mathrm{~B}$ & $3 \mathrm{~B} \times 4 \mathrm{~B}$ \\
\hline $1 \mathrm{~A} \times 4 \mathrm{~B}$ & $2 \mathrm{~A} \times 2 \mathrm{~B}$ & $2 \mathrm{~B} \times 4 \mathrm{~A}$ & $4 \mathrm{~A} \times 4 \mathrm{~B}$ \\
\hline
\end{tabular}

Quadro 20 - Comparações possíveis entre os subcorpora para aplicação do Coeficiente de Jaccard

Num segundo momento, mediu-se a proximidade entre as subamostras por meio do Coeficiente de Yule ${ }^{1}$, que mede a correlação entre duas variáveis binárias. Dessa forma, cada um dos subgrupos, que já contavam com valores binários, foi considerado uma variável e a pergunta que se colocou foi: essas variáveis se correlacionam? A fórmula para o coeficiente de Yule é:

$$
q=\frac{a d-b c}{a d+b c}
$$

em que:

- $\quad \mathrm{a}=$ o número de vezes em que as duas variáveis tinham valor "1";

- $\quad \mathrm{b}=$ o número de vezes em que o valor "1" não ocorreu para a primeira variável, mas ocorreu para a segunda;

- $\quad \mathrm{c}=\mathrm{o}$ número de vezes em que o valor "1" ocorreu para a primeira variável, mas não ocorreu para a segunda;

- $\mathrm{d}=\mathrm{o}$ número de vezes em que o valor “1” não ocorreu em nenhuma das duas variáveis.

\footnotetext{
${ }^{1}$ Pode ser verificado em <http://www.ime.unicamp.br/ lramos/dachs/capitulo2-4.htm>.
} 
O resultado vai de -1 a 1 , sendo que 0 indica que não há correlação alguma, -1 indica que existe uma correlação negativa entre as variáveis e 1 indica que há uma correlação positiva. Assim, quanto mais próximo de 1 for valor de "q", mais fortemente correlacionadas estão as duas variáveis medidas. No caso dessa pesquisa, quanto maior a correlação entre dois subgrupos (os subgrupos são, aqui, as variáveis), maior a chance de os textos que os compõem pertencerem a um mesmo autor.

Se essas duas medidas - Coeficiente de Jaccard e Yule - medem as mesmas coisas e apontam para os mesmos resultados (e.g. os textos de um mesmo autor são mais próximos entre si do que quando comparados com outros autores) pode-se dizer que o método proposto (utilizar as categorias semióticas como marcadores de estilo) ganha em termos de confiabilidade ${ }^{2}$, comparativamente ao uso de apenas uma das medidas.

\section{Resultados}

A aplicação do coeficiente de Jaccard confirmou a hipótese de que as categorias semióticas são profícuas na distinção de autores. Em outras palavras, indicou que a similaridade entre subconjuntos de textos de um mesmo autor é maior do que a aquela entre subconjuntos de autores diferentes. Isto é, 1A é mais próximo de $1 \mathrm{~B}$ do que o é de 2A, 2B, 3A, 3B, 4A ou 4B; 2A é mais próximo de 2B do que o é de 1A, 1B, 3A, 3B, 4A ou $4 \mathrm{~B}$, e assim por diante.

As Tabelas de 7 a 10 apresentam esses resultados e os gráficos nas figuras de 19 a 22 a seguir ajudam a visualizar essas relações. Os Quadros de 21 a 24 apresentam as características recorrentes por autor, bem como comentários acerca da análise e trechos dos textos que a exemplificam.

\footnotetext{
${ }^{2}$ Medir algo com dois instrumentos diferentes, atingindo-se os mesmos resultados dá mostras de confiabilidade. Outros modos de se atestar a confiabilidade do método seriam: 1) repetir o experimento para outros conjuntos de textos; 2) repetir a análise e o experimento para os mesmos textos dentro de um certo intervalo de tempo, e 3) repetir a análise dos mesmos textos, mas dessa vez sob o ponto de vista de um outro analista. Devido a restrições de tempo, este trabalho não pôde se ocupar de todos esses testes de confiabilidade. Entretanto, tais estudos podem ser conduzidos futuramente.
} 

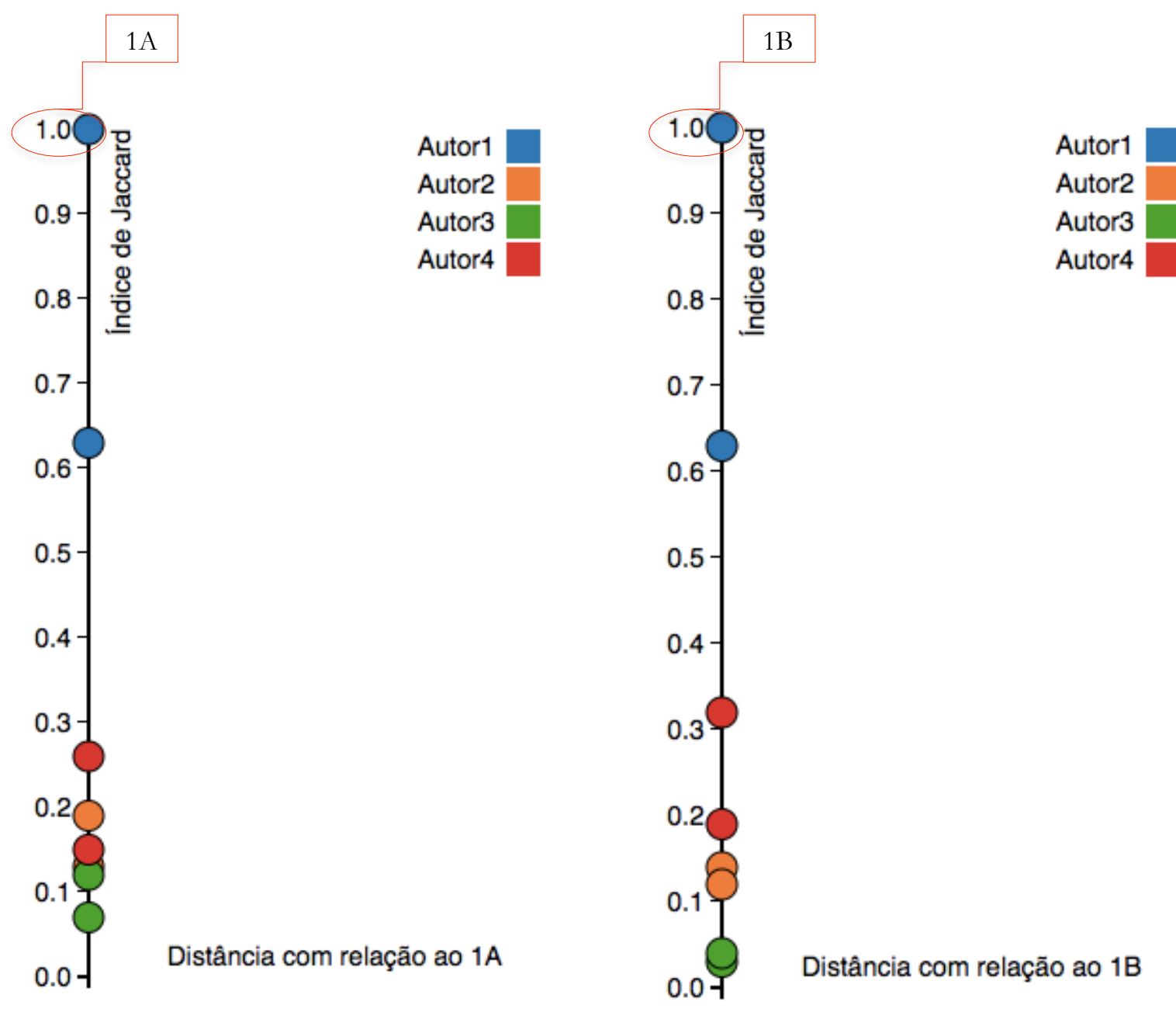

Figura 19 - Índice de Jaccard: distâncias com relação aos "subcorpora" 1A e 1B

Tabela 7 - Índice de Jaccard com relação ao Autor 1

\begin{tabular}{|c|c|c|}
\hline \multicolumn{2}{|c|}{ Autor 1} & \multirow{2}{*}{$\begin{array}{l}\text { Índice } \\
\qquad 0,63\end{array}$} \\
\hline $1 \mathrm{~A}$ & $1 B$ & \\
\hline $1 \mathrm{~A}$ & $2 \mathrm{~A}$ & 0,19 \\
\hline $1 \mathrm{~A}$ & $2 \mathrm{~B}$ & 0,13 \\
\hline $1 \mathrm{~A}$ & $3 \mathrm{~A}$ & 0,12 \\
\hline $1 \mathrm{~A}$ & $3 \mathrm{~B}$ & 0,07 \\
\hline $1 \mathrm{~A}$ & $4 \mathrm{~A}$ & 0,26 \\
\hline $1 \mathrm{~A}$ & $4 \mathrm{~B}$ & 0,15 \\
\hline $1 \mathrm{~B}$ & $2 \mathrm{~A}$ & 0,14 \\
\hline $1 \mathrm{~B}$ & $2 \mathrm{~B}$ & 0,12 \\
\hline $1 \mathrm{~B}$ & $3 \mathrm{~A}$ & 0,03 \\
\hline $1 \mathrm{~B}$ & $3 B$ & 0,04 \\
\hline $1 \mathrm{~B}$ & $4 \mathrm{~A}$ & 0,32 \\
\hline $1 \mathrm{~B}$ & $4 \mathrm{~B}$ & 0,19 \\
\hline
\end{tabular}



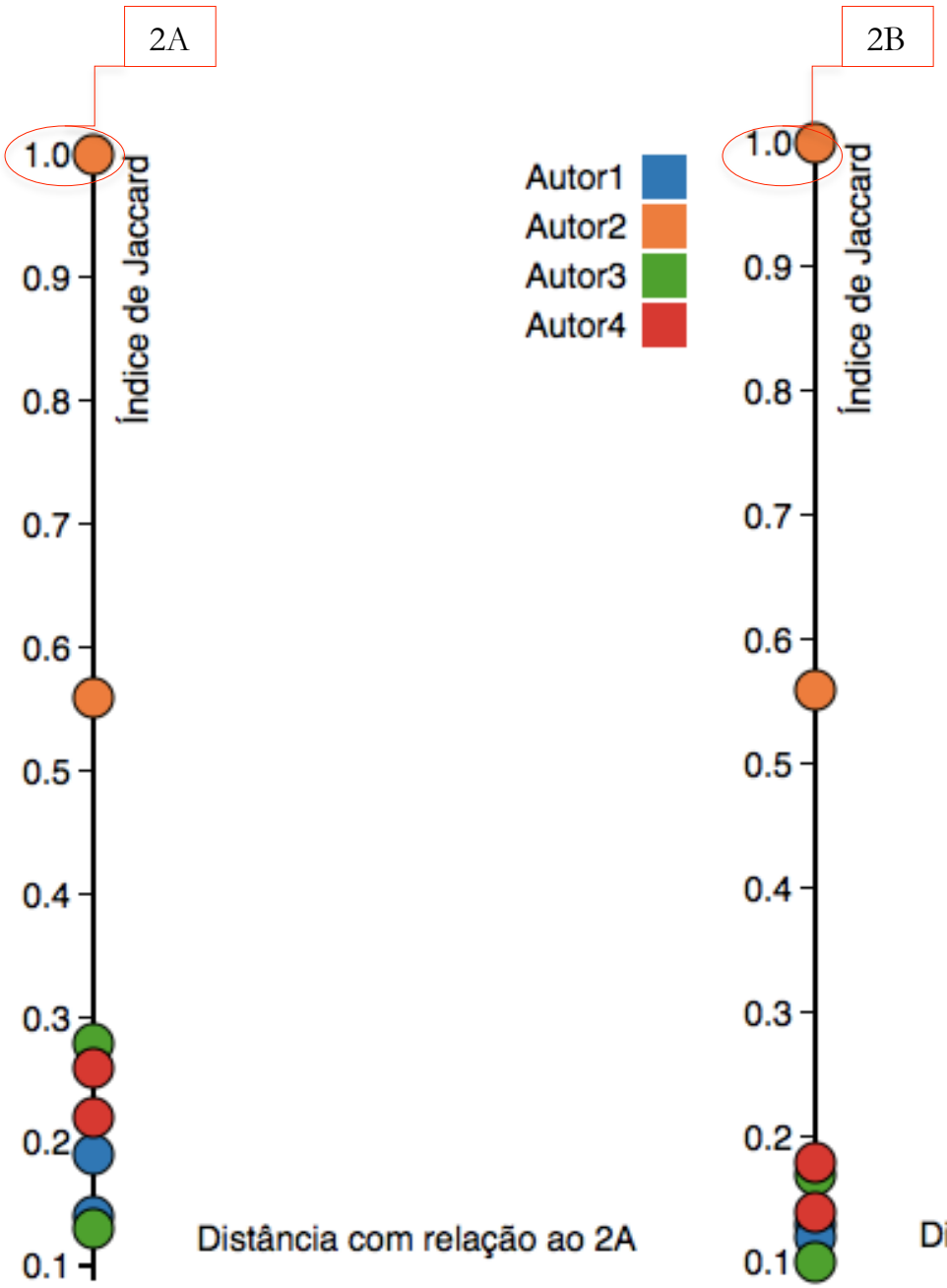

Autor1

Autor2

Autor3

Autor4

Figura 20 - Índice de Jaccard: distâncias com relação aos "subcorpora" 2A e 2B

Tabela 8 - Índice de Jaccard com relação ao Autor 2

\begin{tabular}{|c|c|c|}
\hline \multicolumn{2}{|c|}{ Autor 2} & \multirow{2}{*}{$\begin{array}{l}\text { Índice } \\
\qquad 0,56\end{array}$} \\
\hline $2 \mathrm{~A}$ & $2 B$ & \\
\hline $2 \mathrm{~A}$ & $1 \mathrm{~A}$ & 0,19 \\
\hline $2 \mathrm{~A}$ & $1 \mathrm{~B}$ & 0,14 \\
\hline $2 \mathrm{~A}$ & $3 \mathrm{~A}$ & 0,28 \\
\hline $2 \mathrm{~A}$ & $3 B$ & 0,13 \\
\hline $2 \mathrm{~A}$ & $4 \mathrm{~A}$ & 0,22 \\
\hline $2 \mathrm{~A}$ & $4 B$ & 0,26 \\
\hline $2 B$ & $1 \mathrm{~A}$ & 0,13 \\
\hline $2 \mathrm{~B}$ & $1 \mathrm{~B}$ & 0,12 \\
\hline $2 B$ & $3 \mathrm{~A}$ & 0,17 \\
\hline $2 \mathrm{~B}$ & $3 B$ & 0,10 \\
\hline $2 B$ & $4 \mathrm{~A}$ & 0,14 \\
\hline $2 \mathrm{~B}$ & $4 B$ & 0,18 \\
\hline
\end{tabular}



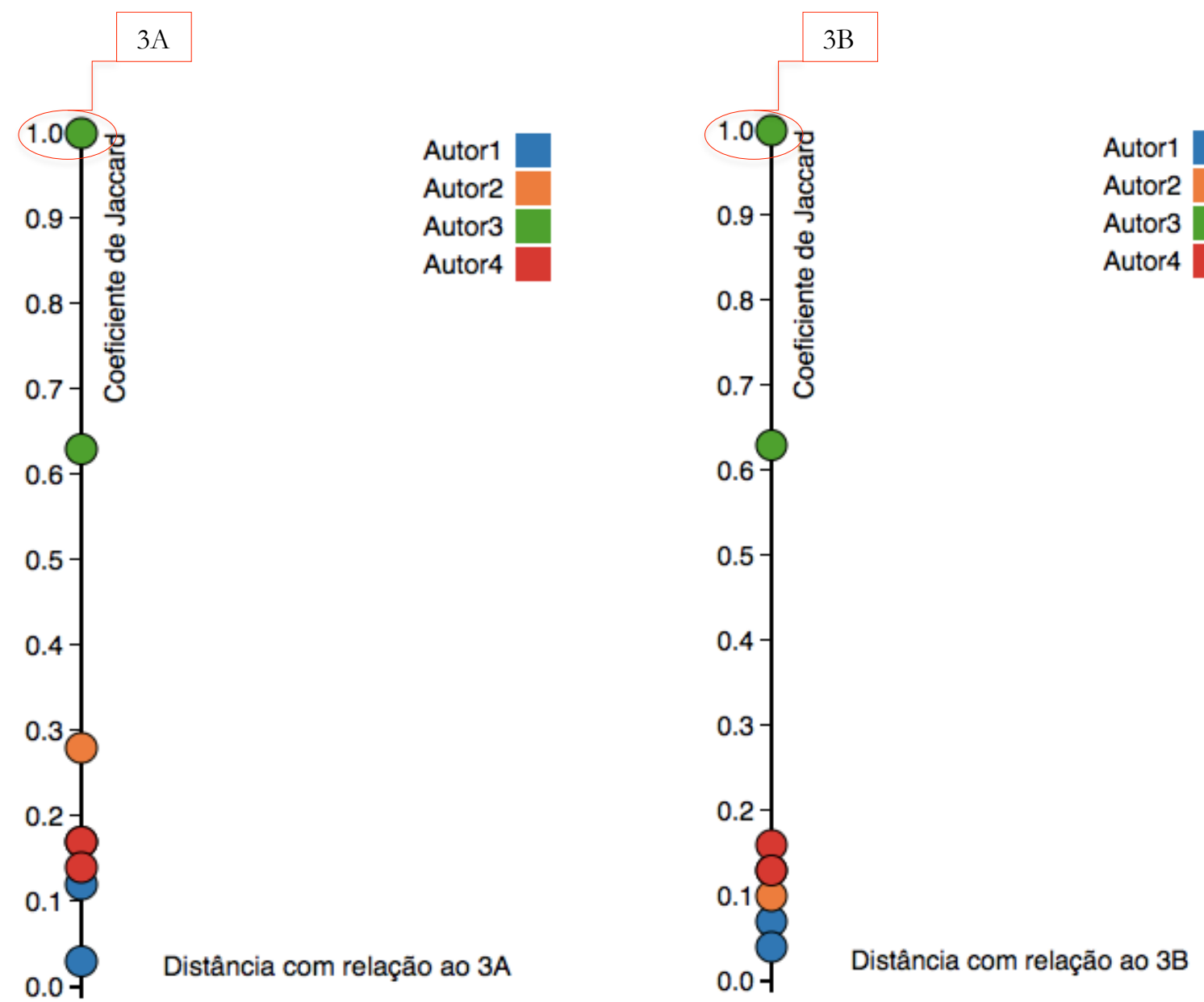

Figura 21 - Índice de Jaccard: distâncias com relação aos "subcorpora" 3A e 3B

Tabela 9 - Índice de Jaccard com relação ao Autor 3

\begin{tabular}{|c|c|c|}
\hline \multicolumn{2}{|c|}{ Autor 3} & Índice \\
\hline $3 A$ & $3 B$ & 0,63 \\
\hline $3 \mathrm{~A}$ & $1 \mathrm{~A}$ & 0,12 \\
\hline $3 \mathrm{~A}$ & $1 \mathrm{~B}$ & 0,03 \\
\hline $3 \mathrm{~A}$ & $2 \mathrm{~A}$ & 0,28 \\
\hline $3 \mathrm{~A}$ & $2 \mathrm{~B}$ & 0,17 \\
\hline $3 \mathrm{~A}$ & $4 \mathrm{~A}$ & 0,17 \\
\hline $3 \mathrm{~A}$ & $4 \mathrm{~B}$ & 0,14 \\
\hline $3 \mathrm{~B}$ & $1 \mathrm{~A}$ & 0,07 \\
\hline $3 \mathrm{~B}$ & $1 \mathrm{~B}$ & 0,04 \\
\hline $3 B$ & $2 \mathrm{~A}$ & 0,13 \\
\hline $3 B$ & $2 \mathrm{~B}$ & 0,10 \\
\hline $3 \mathrm{~B}$ & $4 \mathrm{~A}$ & 0,16 \\
\hline $3 \mathrm{~B}$ & $4 B$ & 0,13 \\
\hline
\end{tabular}



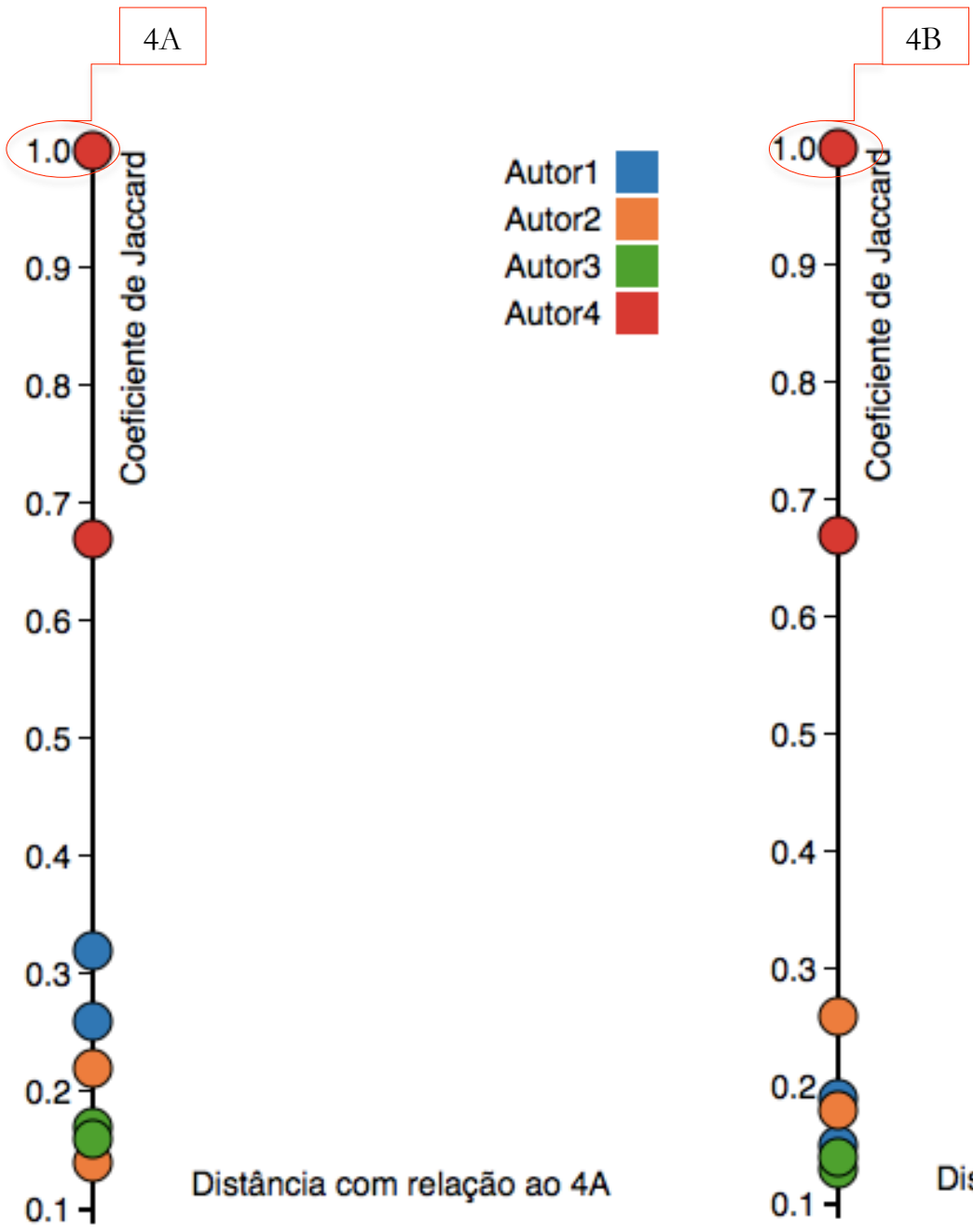

Autor1

Autor2

Autor3

Autor4

Figura 22 - Índice de Jaccard: distâncias com relação aos "subcorpora" 3A e 3B

Tabela 10 - Índice de Jaccard com relação ao Autor 4

\begin{tabular}{|c|c|c|}
\hline \multicolumn{2}{|c|}{ Autor 4} & \multirow{2}{*}{$\begin{array}{l}\text { Índice } \\
\qquad 0,67\end{array}$} \\
\hline $4 \mathrm{~A}$ & $4 B$ & \\
\hline $4 \mathrm{~A}$ & $1 \mathrm{~A}$ & 0,26 \\
\hline $4 \mathrm{~A}$ & $1 \mathrm{~B}$ & 0,32 \\
\hline $4 \mathrm{~A}$ & $2 \mathrm{~A}$ & 0,22 \\
\hline $4 \mathrm{~A}$ & $2 \mathrm{~B}$ & 0,14 \\
\hline $4 \mathrm{~A}$ & $3 \mathrm{~A}$ & 0,17 \\
\hline $4 \mathrm{~A}$ & $3 B$ & 0,16 \\
\hline $4 B$ & $1 \mathrm{~A}$ & 0,15 \\
\hline $4 B$ & $1 \mathrm{~B}$ & 0,19 \\
\hline $4 B$ & $2 \mathrm{~A}$ & 0,26 \\
\hline $4 \mathrm{~B}$ & $2 \mathrm{~B}$ & 0,18 \\
\hline $4 \mathrm{~B}$ & $3 \mathrm{~A}$ & 0,14 \\
\hline 4B & $3 B$ & 0,13 \\
\hline
\end{tabular}


Abaixo encontram-se os quadros referidos anteriormente, em que as características recorrentes de cada autor são exibidas. Observa-sa que há características que se repetem entre os autores, mas nunca se reproduz exatamente o mesmo grupo de características, o que ratifica o que se afirmou nos capítulos 2 e 4: o estilo é a recorrência de uma cosseleção de características e não de uma característica isolada; essa cosseleção pode distinguir autores, já que apesar de uma ou outra característica poder estar presente em textos de diversos autores, é muito improvável que precisamente a mesma combinação de de todas elas aconteça.

\begin{tabular}{|c|c|c|c|}
\hline \multicolumn{4}{|c|}{ Autor 1} \\
\hline Característica & Nível & Comentário & Excertos $^{3}$ \\
\hline $\begin{array}{c}\text { avalia- } \\
\text { negativamente }\end{array}$ & Narrativo & $\begin{array}{l}\text { Considerando o "esquema } \\
\text { narrativo canônico" } \\
\text { proposto pela semiótica } \\
\text { greimasiana (manipulação - } \\
\text { ação - sanção), é recorrente } \\
\text { nos textos do Autor } 1 \text { a fase } \\
\text { da sanção, em que uma } \\
\text { avaliação das ações de } \\
\text { outros sujeitos é feita, de } \\
\text { modo negativo. } \\
\text { Uma consideração } \\
\text { importante, no entanto, é } \\
\text { que avaliações negativas } \\
\text { aparecem em } 3 \text { dos } 4 \text { autores } \\
\text { analisados, levando à dúvida } \\
\text { de se elas realmente podem } \\
\text { ser distintivas ou se estão } \\
\text { atreladas aos gêneros } \\
\text { textuais que mais se } \\
\text { apresentam no corpus } \\
\text { (comentários de redes } \\
\text { sociais ou e-mails). }\end{array}$ & $\begin{array}{l}\text { - Internet grátis para analfabetos. Geniais } \\
\text { os planos de governo. } \\
\text { - Uma linha tênue entre a pertubação e a } \\
\text { falta de caráter é uma constante nos dias de } \\
\text { hoje. Será que todo mundo está com } \\
\text { depressão, tem síndrome do pânico, } \\
\text { bipolaridade ou isso já está sendo desculpa } \\
\text { para as pessoas agirem sem princípios? } \\
\text { - Quando estiver se sentindo um imbecil, } \\
\text { lembre-se que tem adolescentes brincando de } \\
\text { prender a respiração até desmaiar. }\end{array}$ \\
\hline $\begin{array}{c}\text { mentira-ou- } \\
\text { segredo }\end{array}$ & Narrativo & $\begin{array}{l}\text { Na fase da sanção, podem } \\
\text { entrar em cena as relações } \\
\text { entre o "ser" e o "parecer" } \\
\text { (modalidades veridictórias)4. }\end{array}$ & $\begin{array}{l}\text { - Fiz. uma compra (forno elétrico) no site } \\
\text { do Ponto Frio dia 09/10 em que o prazo } \\
\text { para entrega era de até } 13 \text { dias úteis. O } \\
\text { prazo passou e o produto não chegou. }\end{array}$ \\
\hline
\end{tabular}

\footnotetext{
${ }^{3} \mathrm{Em}$ todos os quadros de 21 a 24, os excertos foram selecionados aleatoriamente de alguns textos de cada autor; as transcrições correspondem exatamente aos originais. Os grifos destacam as palavras ou expressões que ajudam a determinar a ocorrência da característica sob exame.
}

${ }^{4}$ A figura a seguir representa as relações das modalidades veridictórias num quadrado semiótico. 


\begin{tabular}{|c|c|c|c|}
\hline \multicolumn{4}{|c|}{ Autor 1} \\
\hline Característica & Nível & Comentário & Excertos 3 \\
\hline & & $\begin{array}{l}\text { Recorrentemente, o Autor } 1 \\
\text { reconhece na ação de um } \\
\text { outro sujeito um segredo ou } \\
\text { uma mentira (algo que é, } \\
\text { mas não parece ou que } \\
\text { parece, mas não é). }\end{array}$ & $\begin{array}{l}\text { - Será que todo mundo está com depressão, } \\
\text { tem síndrome do pânico, bipolaridade ou } \\
\text { isso já está sendo desculpa para as pessoas } \\
\text { agirem sem princípios? } \\
\text { Não que eu esteja generalizando, muito } \\
\text { pelo contrário, acredito e respeito muito a } \\
\text { fragilidade dessas pessoas, mas tem muita } \\
\text { gente por ai com atitudes sem valores (...). }\end{array}$ \\
\hline $\begin{array}{l}\text { fazer-fazer- } \\
\text { intervenção }\end{array}$ & Narrativo & $\begin{array}{l}\text { Autor } 1 \text { assume } \\
\text { recorrentemente a posição } \\
\text { de um Destinador que "faz- } \\
\text { fazer", intervém para que } \\
\text { algo ocorra. }\end{array}$ & $\begin{array}{l}\text { - Mediante esta situação resolvi escrever, } \\
\text { pela última vez, tentando resolver isso. } \\
\text { Espero a sua resposta, o quanto antes e se } \\
\text { até o final da semana que vem você não nos } \\
\text { posicionar, estaremos procurando nosso } \\
\text { advogado para reclamar (...). } \\
\text { - Temos outros móveis planejados para } \\
\text { fazer, mas o descaso do pós-venda fará com } \\
\text { que procuremos outra loja. } \\
\text { - @,atualcard IA MANDEI } 1000 \\
\text { MENSAGENS NO SITE, NO } \\
\text { FACEBOOK, AQUI!!!!!!!! VOCESS } \\
\text { SÓ PODEM ESTAR BRINCANDO } \\
\text { COMIGO }\end{array}$ \\
\hline insatisfação & Narrativo & $\begin{array}{l}\text { O estado passional do } \\
\text { sujeito é o da insatisfação. } \\
\text { Em termos de combinação } \\
\text { de modalidades, ele quer-ser, } \\
\text { não-crê-ser e sabe-não- } \\
\text { poder-ser em conjunção } \\
\text { com o objeto. }\end{array}$ & $\begin{array}{l}\text { - Oi Xxxxx, } \\
\text { Entendo que dependa dele, mas não faz } 7 \\
\text { dias, faz } 7 \text { meses (...).Creio que sejam } \\
\text { alguns motivos para estar insatisfeita e } \\
\text { triste. } \\
\text { - Cheguei a uma conclusão: não é casar que } \\
\text { é um saco, ser pobre que é um saco!Porque } \\
\text { se eu fosse rica todos os problemas do } \\
\text { casamento seriam facilmente resolvidos (...). } \\
\text { Mas como dinheiro é algo que, infelizmente, } \\
\text { não faz parte da minha realidade atual e } \\
\text { anterior a esta data (quem sabe um dia } \\
\text { fará, amém), no lugar de esperar pelo sonbo } \\
\text { eu quero logo que este pesadelo acabe! }\end{array}$ \\
\hline desprezo & Narrativo & $\begin{array}{l}\text { Paixão do desprezo. } \\
\text { Segundo Aristóteles }{ }^{5} \text { "o }\end{array}$ & $\begin{array}{l}\text { - Internet grátis para analfabetos. Geniais } \\
\text { os planos de governo. }\end{array}$ \\
\hline
\end{tabular}

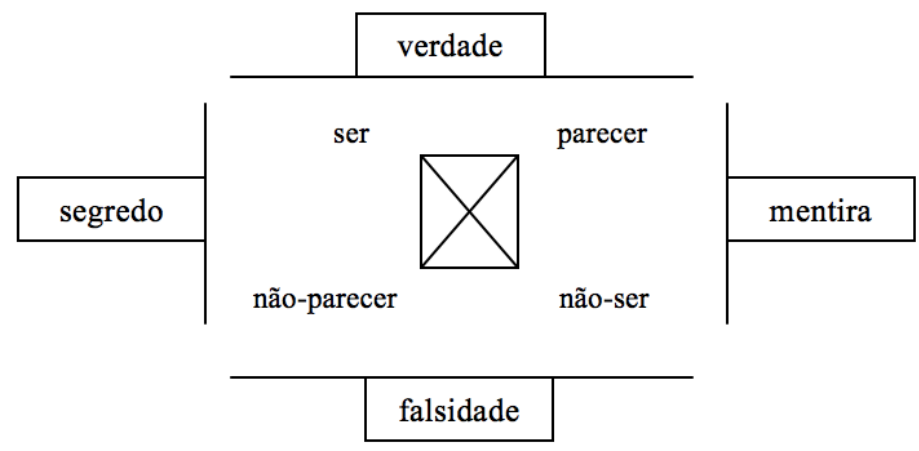

${ }^{5}$ In: Retórica das Paixões. 


\begin{tabular}{|c|c|c|c|}
\hline \multicolumn{4}{|c|}{ Autor 1} \\
\hline Característica & Nível & Comentário & Excertos 3 \\
\hline & & $\begin{array}{l}\text { desprezo é a "atualização de } \\
\text { uma opinião acerca do que } \\
\text { não parece digno de } \\
\text { consideração" e } \\
\text { "desdenhamos tudo o que } \\
\text { julgamos ser desprovido de } \\
\text { valor" (ARISTÓTELES, } \\
\text { 2000, p. 7). }\end{array}$ & $\begin{array}{l}\text { - Quando estiver se sentindo um imbecil, } \\
\text { lembre-se que tem adolescentes brincando de } \\
\text { prender a respiracão até desmaiar. } \\
\text { - Essa dieta de proteina tem as fases e o } \\
\text { cara so n colocon a ultima fase no livro que } \\
\text { a br q vc engorda de nv }\end{array}$ \\
\hline sarcasmo & Discursivo & Ethos sarcástico. & $\begin{array}{l}\text { - Internet grátis para analfabetos. Geniais } \\
\text { os planos de governo. } \\
\text { - Só nessa novela uma empregada sai mais } \\
\text { que os donos da casa e quando volta ainda } \\
\text { dá tempo de matar um boi, assar no papel } \\
\text { aluminio, com farofa, sobremesa e biscoitos } \\
\text { caseiros pro café. } \\
\text { - A Fifa não exclui ninguém! N tem } \\
\text { dinbeiro p/ ver a copa de perto?! Seja um } \\
\text { voluntário, trabalbe de graca e participe }\end{array}$ \\
\hline $\begin{array}{l}\text { compromisso- } \\
\text { e-isenção }\end{array}$ & Fundamental & $\begin{array}{l}\text { A categoria fundamental } \\
\text { mais recorrente nos textos } \\
\text { do Autor } 1 \text { é "compromisso } \\
\text { versus isenção". O } \\
\text { enunciador ora cobra } \\
\text { sujeitos que estejam } \\
\text { "devendo" algo, ora } \\
\text { desaprova as ações daqueles } \\
\text { que não cumpriram com o } \\
\text { seus compromissos. O } \\
\text { compromisso é a valorizado } \\
\text { e o a isenção, negada. }\end{array}$ & $\begin{array}{l}\text { - Não compramos no depósito, compramos } \\
\text { numa loja, o mínimo que deveriam fazer } \\
\text { era se preocupar com a minha entrega e não } \\
\text { jogar a bomba na minha mão. } \\
\text { - Fiz uma compra (forno elétrico) no site do } \\
\text { Ponto Frio dia 09/10/11 em que o prazo } \\
\text { para entrega era de até } 13 \text { dias úteis. } \\
\text { O prazo passou e o produto não chegou. } \\
\text { - A Engenheira é a pessoa ais enrolada do } \\
\text { mundo. Estrapolou TODOS OS } \\
\text { PRAZOS ESTIPUADOS } \\
\text { NUNCA chegou em nenbuma reunião no } \\
\text { horário marcado I Ao contrário do que dir } \\
\text { no site dela ELA NUNCA } \\
\text { ENTREGOU PLANTA DE } \\
\text { NADA EM } 3 D, \text { apresentou algumas } \\
\text { imagens apenas, que nunca foram } \\
\text { aprovadas e apenas da sala/ cozinha. (...) }\end{array}$ \\
\hline +persistência & Tensividade & $\begin{array}{l}\text { Tonicidade +; } \\
\text { Temportalidade + }\end{array}$ & $\mathrm{N} / \mathrm{A}$ \\
\hline $\begin{array}{l}\text { abreviamento } \\
\mathrm{x} \text { demora }\end{array}$ & Tensividade & $\begin{array}{l}\text { Oposição entre } \\
\text { "Abreviamento" e } \\
\text { "Demora". Andamento + } \\
\text { rápido = Duração } \\
\text { Abreviada. Se o andamento } \\
\text { é menor = demora. Sujeito } \\
\text { que realiza a ação esperada } \\
\text { "funciona" sob o regime da } \\
\text { demora. O enunciador que o } \\
\text { cobra, por sua vez, "quer" o } \\
\text { abreviamento. }\end{array}$ & $\begin{array}{l}\text { - Como todo bom banco demoraram um } \\
\text { pouco para liberar o financiamento. :( } \\
\text { Quando a gente ligava lá pra saber o } \\
\text { andamento do processo (....) } \\
\text { - @atualcard JA MANDEI } 1000 \\
\text { MENSAGENS NO SITE, NO } \\
\text { FACEBOOK, AQUI!!!!!!!! VOCES } \\
\text { SÓ PODEM ESTAR BRINCANDO } \\
\text { COMIGO } \\
\text { - Olá Xxxxx, boa tarde. Há meses } \\
\text { estamos tentando falar com você para } \\
\text { resolver nosso problema da melhor maneira } \\
\text { possivel, amigavelmente, contudo, não } \\
\text { estamos tendo a sua atenção da forma que } \\
\text { precisamos. Mediante esta situação resolvi }\end{array}$ \\
\hline
\end{tabular}




\begin{tabular}{|c|c|c|c|}
\hline \multicolumn{4}{|c|}{ Autor 1} \\
\hline Característica & Nível & Comentário & Excertos 3 \\
\hline & & & escrever, pela última vez.....). \\
\hline tensionado & Tensividade & $\mathrm{N} / \mathrm{A}$ & $\mathrm{N} / \mathrm{A}$ \\
\hline acontecimento & Tensividade & $\begin{array}{l}\text { Conforme explicou-se no } \\
\text { capítulo 4, "Os textos podem } \\
\text { ainda se desenrolar a partir de } \\
\text { um 'acontecimento' ou de uma } \\
\text { 'rotina'" (ZILBERBERG, } \\
\text { 2007). O acontecimento é algo } \\
\text { que se dá de repente, um fato raro } \\
\text { que ocorre sem que o sujeito o } \\
\text { espere e que o tire de sua rotina. } \\
\text { Ele pode ser responsável por } \\
\text { iniciar uma ação por parte do } \\
\text { sujeito (fazer emissivo ou } \\
\text { continuativo) ou por arrebatá-lo, } \\
\text { privando-o do agir (fazer } \\
\text { remissivo). Quando um texto é da } \\
\text { ordem da rotina, nada de novo } \\
\text { acontece, há espaço para } \\
\text { trivialidades". }\end{array}$ & $\begin{array}{l}\text { - Após agendamento a entrega não } \\
\text { aconteceu no horário previsto e ficamos aqui } \\
\text { por horas apenas esperando e não } \\
\text { conseguiram terminar a montagem no } \\
\text { mesmo dia. } \\
\text { - qdo eu te respondi vo n disse mais } \\
\text { nada... só agr este e-mail, até com um certo } \\
\text { tom de agressividade a cerca de um assunto } \\
\text { que eu nunca fui agressiva c ve (...). } \\
\text { - O pior de TUDO, é que além de todos } \\
\text { esses pontos eu tinha que aguentar o cara } \\
\text { que me desrespeitava e achava que a casa } \\
\text { era dele. Não terminamos a obra com eles } \\
\text { porque chegou o ponto do meu pai intervir e } \\
\text { expulsar o cara daqui. }\end{array}$ \\
\hline
\end{tabular}

Quadro 21 - Conjunto de características distintivas do Autor 1

\begin{tabular}{|c|c|c|c|}
\hline \multicolumn{4}{|c|}{ Autor 2} \\
\hline Característica & Nível & Comentário & Excertos \\
\hline $\begin{array}{c}\text { avalia- } \\
\text { positivamente }\end{array}$ & Narrativo & $\begin{array}{l}\text { A fase da sanção está } \\
\text { bastante presente neste } \\
\text { autor, ora com avaliações } \\
\text { negativas e ora com } \\
\text { avaliações positivas. Apesar } \\
\text { de avaliações negativas } \\
\text { aparecerem também em } \\
\text { outros autores examinados, } \\
\text { as positivas são } \\
\text { exclusividade deste autor } \\
\text { (em termos de consistência, } \\
\text { ou seja, pode até ser que } \\
\text { outros autores também } \\
\text { fizeram julgamentos } \\
\text { positivos, mas estes não } \\
\text { foram recorrentes o } \\
\text { suficiente para serem um } \\
\text { marcador de estilo). }\end{array}$ & $\begin{array}{l}\text { - Eu adoro esse meu primo, ele disse que } \\
\text { quando eu casar ele vai pintar algo que eu } \\
\text { escolher pra me dar de presente, mas como } \\
\text { vou decidir??? Rs } \\
\text { - Balanço de Paris: muito mais linda do } \\
\text { que eu imaginava. Franceses absurdamente } \\
\text { prestativos e simpáticos e tratamento de } \\
\text { primeira em todos os restaurantes! } \\
\text { - Tenho uma amiga psico e ela é ótima. }\end{array}$ \\
\hline $\begin{array}{c}\text { avalia- } \\
\text { negativamente }\end{array}$ & Narrativo & Ver Quadro 21 & $\begin{array}{l}\text { - Fora a educação desse país que é uma } \\
\text { merda, o povo é desaculturado, não liga pra } \\
\text { arte, só valoriza peito e bunda. } \\
\text { - Acho extremamente irritante ter que ficar } \\
\text { lendo o povo falando de futebol, um } \\
\text { atacando o outro, um respondendo pro outro } \\
\text { (...). Essas pessoas não sabem o quanto são }\end{array}$ \\
\hline
\end{tabular}




\begin{tabular}{|c|c|c|c|}
\hline \multicolumn{4}{|c|}{ Autor 2} \\
\hline Característica & Nível & Comentário & Excertos \\
\hline & & & $\begin{array}{l}\text { chatas e desagradáveis. } \\
\text { - Total de homens em } 2010 \text { de acordo com } \\
\text { o IBGE: } 93.390 .532 \\
\text { Total de mulheres: } 97.342 .162 \\
\text { E ainda assim só nasce mulher } \\
\text { ultimamente! Se vc é homem, solteiro e não } \\
\text { consegue namorada, pode crer que é por } \\
\text { pura incompetência! klkkkkkkkek }\end{array}$ \\
\hline insatisfação & Narrativo & Ver Quadro 21 & $\begin{array}{l}\text { - Eu tô mto cansada de ser cobrada. } \\
\text { - Eu amo minha casa e meu bairro, tenho } \\
\text { a vida que pedi a Deus, mas morro de } \\
\text { desgosto de mtas coisas... } \\
\text { - Eu gosto da Xxxxx, gostava do outro } \\
\text { time que eu tava. Não é a paixão da } \\
\text { minha vida, mas não era ruim! Já nesse, é } \\
\text { péssimo! }\end{array}$ \\
\hline empatia & Narrativo & $\begin{array}{l}\text { Levar o outro em } \\
\text { consideração, importar-se } \\
\text { com o outro, colocar-se no } \\
\text { lugar do outro. }\end{array}$ & $\begin{array}{l}\text { - Queria te ajudar, se ve morasse perto, a } \\
\text { gente ia malhar, eu te arrastava. Eu sei o } \\
\text { quanto ve deve tá triste, eh o mesmo quando } \\
\text { zuavam do meu nariz na escola }=S \\
\text { - Eu tô igual vc, com fome TODA } \\
\text { HORA! } \\
\text { - Mas olha, se tiver ruim pra vc, marcamos } \\
\text { outro dia SEM PROBLEMAS!!!!!!! }\end{array}$ \\
\hline $\begin{array}{l}\text { enuncivo- } \\
\text { espaco-1 }\end{array}$ & Discursivo & $\begin{array}{l}\text { No nível discursivo se } \\
\text { projetam pessoa, tempo e } \\
\text { espaço. Nos textos } \\
\text { analisados, as projeções de } \\
\text { pessoa e tempo ocorrem } \\
\text { consistentemente em todos } \\
\text { os autores. O espaço } \\
\text { enuncivo, porém, só foi } \\
\text { observado nos textos do } \\
\text { Autor 2. }\end{array}$ & $\begin{array}{l}\text { - Balanço de Paris: muito mais linda do } \\
\text { que eu imaginava } \\
\text { - O Eldorado é na marginal pinheiros th, } \\
\text { né? Se ve quiser, posso ir no Eldorado sim! } \\
\text { - As vezes que viajei pros ena e Canada, } \\
\text { voltei quase chorando de tristęa! }\end{array}$ \\
\hline $\begin{array}{l}\text { ilustração- } \\
\text { exemplos }\end{array}$ & Discursivo & $\mathrm{N} / \mathrm{A}$ & $\begin{array}{l}\text { - Mas o fato é que tenho medo de ficar com } \\
\text { o corpo da minba irmã, que não se cuida e } \\
\text { faz criação de celulite... }\end{array}$ \\
\hline hipérbole & Discursivo & $\mathrm{N} / \mathrm{A}$ & $\begin{array}{l}\text { - Eu li um post seu dizendo que ve tinha } \\
100 \text { alunos! Aposto que parece uma } \\
\text { manada de búfalos! } \\
\text { - Domingo e segunda en fiz aeróbio na } \\
\text { academia... Mas meu joelho tá FODIDO, } \\
\text { tem hora que nem consigo subir a escada, } \\
\text { meu Deus, o que vou fazer se não puder } \\
\text { malhar? } \\
\text { - Mas o fato é que tenho medo de ficar com } \\
\text { o corpo da minha irmã, que não se cuida e } \\
\text { faz criação de celulite... }\end{array}$ \\
\hline acontecimento & Tensivo & Ver Quadro 21 & $\mathrm{~N} / \mathrm{A}$ \\
\hline
\end{tabular}

Quadro 22 - Conjunto de características distintivas do Autor 2 
Autor 3

\begin{tabular}{|c|c|c|c|}
\hline Característica & Nível & Comentário & Excertos \\
\hline tentação & Narrativo & $\begin{array}{l}\text { Recorrência da fase de } \\
\text { manipulação por tentação, } \\
\text { ou seja, oferece-se um } \\
\text { objeto de valor positivo, } \\
\text { uma recompensa. }\end{array}$ & $\begin{array}{l}\text { - Amor, Eu acho que seria bom } \\
\text { investirmos em algo ... seria interessante, } \\
\text { pois em janeiro de } 2013 \text { a gente decide se } \\
\text { vai mudar pra lá ou vender. } \\
\text { - (...) vou fazer brincadeiras sim, vou } \\
\text { dizer que ve tá surtada (que pra mim } \\
\text { significa que ve está doida atrás das } \\
\text { coisas do casório), vou dizer que o Márcio } \\
\text { (o noivo) não é tão importante quanto a } \\
\text { noiva ... SABE POR QUE ??? } \\
\text { Porque vocês são meus AMIGOS.... e } \\
\text { amizade assim hoje em dia é tão difícil !!!! } \\
\text { (...). Nunca falaria nada pra te magoar } \\
\text {... só achei que seria um momento pra } \\
\text { gente rir um pouco... } \\
\text { - Ser mãe é ter o poder de amar } \\
\text { incondicionalmente uma pessoinha que } \\
\text { você nem conhece, se dedicar } 100 \% \text { do } \\
\text { tempo, colocar as prioridades do seu filho } \\
\text { antes das suas... E se sentir a pessoa } \\
\text { mais sortuda e feliz do mundo! }\end{array}$ \\
\hline $\begin{array}{l}\text { fazer-saber- } \\
\text { comunicar }\end{array}$ & Narrativo & $\begin{array}{l}\text { Autor recorrentemente } \\
\text { comunica algo, faz saber. }\end{array}$ & $\begin{array}{l}\text { - SER MÄE É.... } \\
\text { Bom, vou traduzir o que é ser mãe, } \\
\text { contando como foi o dia em que a } \\
\text { Xxxxx nasceu... Pois esse dia resume } \\
\text { tudo o que será pro resto da sua vida. } \\
\text { - Faça o que ve gosta, fique com pessoas } \\
\text { que te façam sorrir de verdade, que se } \\
\text { importem com vc, que te abracem com o } \\
\text { coração e a alma.... \# fica a dica. } \\
\text { - Porém neste final de semana, estive } \\
\text { pensando no "depois" e me lembrei que } \\
\text { não será tão simples, pois a Xxxxxx } \\
\text { tem muitas particularidades em } \\
\text { seus lançamentos. Estou apresentando as } \\
\text { particularidades e dificuldades antes de } \\
\text { nos depararmos com elas, ai estão meus } 8 \\
\text { anos de experiência. }\end{array}$ \\
\hline clichês & Discursivo & $\begin{array}{l}\text { Apesar de "clichês" não ser } \\
\text { um elemento do modelo } \\
\text { semiótico, este trabalho } \\
\text { utiliza este termo para } \\
\text { identificar passagens no } \\
\text { texto deste autor que são } \\
\text { "banais', reproduzem-se } \\
\text { ideias do senso comum ou } \\
\text { frases prontas. }\end{array}$ & $\begin{array}{l}\text { - Espero que esses dois monstros paguem } \\
\text { pelo que fez... É muito fácil bater em um } \\
\text { cara caído... } \\
\text { - Eu sei que não quero comprar uma } \\
\text { casa e continuar com esse apartamento } \\
\text { para alugar. Pois uma hora vai começar } \\
\text { a cair os azulejos, pq a gente toma } \\
\text { cuidado, mas inquilino não, né !!! } \\
\text { - amizade assim hoje em dia é tão difícil } \\
\text { !!!! } \\
\text { - Agradeço a todos pela amizade, pois } \\
\text { aprendi que qualidade não está apenas } \\
\text { no trabalho e sim em cada coisa que } \\
\text { fazemos, das mais simples às mais }\end{array}$ \\
\hline
\end{tabular}




\begin{tabular}{|c|c|c|c|}
\hline \multicolumn{4}{|c|}{ Autor 3} \\
\hline Característica & Nível & Comentário & Excertos \\
\hline & & & complexas. \\
\hline $\begin{array}{l}\text { detentor-do- } \\
\text { saber }\end{array}$ & Discursivo & $\begin{array}{l}\text { Ethos de alguém que detém o } \\
\text { saber, que tem o } \\
\text { conhecimento sobre algo e o } \\
\text { transmite }\end{array}$ & $\begin{array}{l}\text { Idem "fazer-saber-comunicar", } \\
\text { acima. }\end{array}$ \\
\hline $\begin{array}{l}\text { conhecimento- } \\
\text { e-ignorância }\end{array}$ & Fundamental & $\begin{array}{l}\text { Os textos quase sempre } \\
\text { remetem à oposição } \\
\text { "conhecimento versus } \\
\text { ignorância"; "saber versus } \\
\text { não saber" são os valores } \\
\text { negados ou euforizados. }\end{array}$ & $\begin{array}{l}\text { Idem "fazer-saber-comunicar" } \\
\text { acima. }\end{array}$ \\
\hline relaxado & Tensividade & & \\
\hline rotina-estado & Tensividade & $\begin{array}{l}\text { Ver Quadro } 21 . \text { O fatos dos } \\
\text { textos serem } \\
\text { recorrentemente da ordem } \\
\text { da rotina parece ser uma } \\
\text { forte característica distintiva } \\
\text { desse autor com relação aos } \\
\text { outros aqui analisados, já } \\
\text { que estes últimos } \\
\text { apresentavam em sua } \\
\text { maioria textos da ordem do } \\
\text { acontecimento. }\end{array}$ & $\begin{array}{l}\text { - Limpei a casa, fiz arroz, feijão, só falta } \\
\text { fritar os bifes... } \\
\text { - SER MÄE É.... Bom, vou traduzir o } \\
\text { que é ser mãe, contando como foi o dia em } \\
\text { que a Xxxxx nasceu... Pois esse dia } \\
\text { resume tudo o que será pro resto da sua } \\
\text { vida. } \\
\text { - Agora que tomei banho e coloquei a } \\
\text { Xxxxx pra dormir... Vamos lá... }\end{array}$ \\
\hline
\end{tabular}

Quadro 23 - Conjunto de características distintivas do Autor 3

\begin{tabular}{|c|c|c|c|}
\hline \multicolumn{4}{|c|}{ Autor $4^{6}$} \\
\hline Característica & Nível & Comentário & Excertos \\
\hline $\begin{array}{c}\text { avalia- } \\
\text { negativamente }\end{array}$ & Narrativo & Ver Quadro 21 & $\begin{array}{l}\text { - não gostei nada nada do filme... } \\
\text { Xinguei-te mentalmente algumas vezes. } \\
\text { - o que o gênio não sabia é que eu tinha } \\
\text { um cachorro extremamente violento (...) } \\
\text { - Houve uma época em que eu achava } \\
\text { que aquilo que vendiam no mercado em } \\
\text { embalagem de café, era café!!!! Hoje sei: } \\
\text { aquilo é palha! }\end{array}$ \\
\hline $\begin{array}{l}\text { fazer-fazer- } \\
\text { intervenção }\end{array}$ & Narrativo & Ver Quadro 21 & $\begin{array}{l}\text { - Se puderem ajudar, assistam!É } \\
\text { rapidinho!! Obrigada! } \\
\text { - Peco a gentileza de que o Dr. } \\
\text { novamente oriente a empresa quanto aos } \\
\text { atrasos e, a parcela que deveria ser } \\
\text { depositada no dia } 30 / 12 / 2010 \text { seja } \\
\text { depositada hoje (...). Caso seja necessário } \\
\text { peticionar nos autos, lembra-se que a } \\
\text { multa será (...). }\end{array}$ \\
\hline $\begin{array}{l}\text { inconformis- } \\
\text { mo }\end{array}$ & Narrativo & Ver Quadro 14 & Ver Quadro 14 \\
\hline
\end{tabular}

${ }^{6}$ Este autor é o mesmo cujos textos foram objeto de análise do capítulo 4. 


\begin{tabular}{|c|c|c|c|}
\hline \multicolumn{4}{|c|}{ Autor $4^{6}$} \\
\hline Característica & Nível & Comentário & Excertos \\
\hline errado-e-certo & Fundamental & Ver Quadro 15 & Ver Quadro 15 \\
\hline $\begin{array}{l}\text { atenuação-da- } \\
\text { tensão }\end{array}$ & Tensividade & Ver Quadro 16 & Ver Quadro 16 \\
\hline acontecimento & Tensividade & Ver Quadro 13 & Ver Quadro 13 \\
\hline
\end{tabular}

Quadro 24 - Conjunto de características distintivas do Autor 4

Os resultados obtidos através da aplicação do coeficiente de Yule coincidem com aqueles obtidos com o coeficiente de Jaccard. A correlação entre as subamostras é sempre maior quando se trata do mesmo autor, ou seja, 1A é mais fortemente correlacionado a 1B do que a todos os outros subconjuntos; $2 \mathrm{~A}$ é mais fortemente correlacionado a $2 \mathrm{~B}$ do que a todos os outros, e assim por diante (tais resultados são apresentados a seguir pelas Tabelas de 11 a 14; os gráficos nas Figuras de 23 a 26 auxiliam na visualização). Essas correlações indicam que ou grupos de textos A e B de cada autor são mais semelhantes entre si do que entre autores diferentes.

As Tabelas 15 e 16 comparam os resultados obtidos para cada autor e subamostra. $\mathrm{Na}$ Tabela 15, que apresenta os resumo dos resultados do Coeficiente de Jaccard, vê-se que a primeira linha traz o valor da comparação entre A e B para cada conjunto de autores. Observe-se que ele sempre é mais alto do que todas as outras comparações possíveis. Inclusive, ele não apenas é mais alto como também excede o segundo maior em 3, 3, 6 e 2 vezes, para os autores 1,2, 3 e 4, respectivamente. 


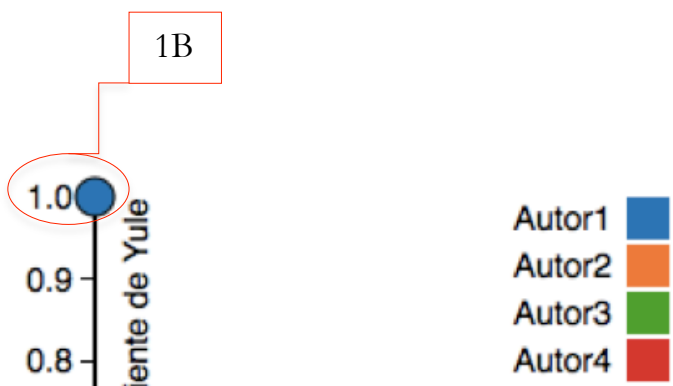

Correlação com $1 \mathrm{~A}$

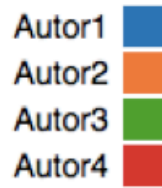

Autor4

Figura 23 - Coeficiente de Yule: correlações com 1A e 1B

Tabela 11 - Correlação de Yule: Autor 1

\begin{tabular}{|c|c|c|}
\hline \multicolumn{2}{|c|}{ Autor 1} & \multirow{2}{*}{$\begin{array}{l}\text { Índice } \mathrm{q} \\
\qquad 0,71\end{array}$} \\
\hline $1 \mathrm{~A}$ & $1 B$ & \\
\hline $1 \mathrm{~A}$ & $2 \mathrm{~A}$ & 0,43 \\
\hline $1 \mathrm{~A}$ & $2 \mathrm{~B}$ & 0,38 \\
\hline $1 \mathrm{~A}$ & $3 \mathrm{~A}$ & 0,25 \\
\hline $1 \mathrm{~A}$ & $3 \mathrm{~B}$ & 0,14 \\
\hline $1 \mathrm{~A}$ & $4 \mathrm{~A}$ & 0,59 \\
\hline $1 \mathrm{~A}$ & $4 B$ & 0,54 \\
\hline $1 \mathrm{~B}$ & $2 \mathrm{~A}$ & 0,38 \\
\hline $1 \mathrm{~B}$ & $2 \mathrm{~B}$ & 0,38 \\
\hline $1 \mathrm{~B}$ & $3 \mathrm{~A}$ & $(0,28)$ \\
\hline $1 \mathrm{~B}$ & $3 B$ & $(0,06)$ \\
\hline 1B & $4 \mathrm{~A}$ & 0,68 \\
\hline $1 \mathrm{~B}$ & $4 B$ & 0,63 \\
\hline
\end{tabular}



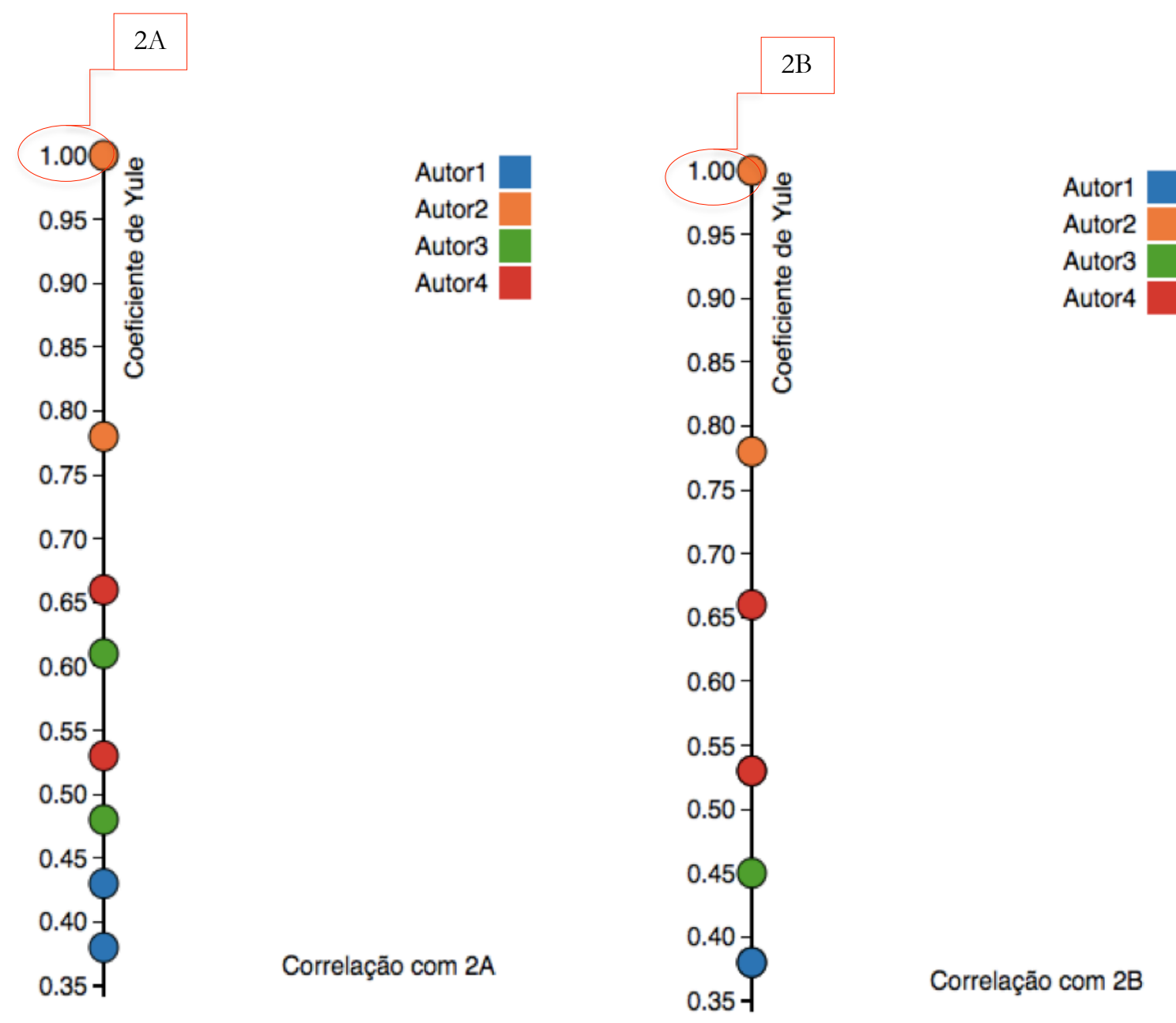

Figura 24 - Coeficiente de Yule: correlações com 2A e 2B

Tabela 12 - Correlação de Yule: Autor 2

\begin{tabular}{|c|c|c|}
\hline Autor 2 & \multicolumn{2}{|l}{ Índice $\mathbf{q}$} \\
\hline 2A & 2B & $\mathbf{0 , 7 8}$ \\
\hline 2A & $1 \mathrm{~A}$ & 0,43 \\
\hline 2A & $1 \mathrm{~B}$ & 0,38 \\
\hline 2A & $3 \mathrm{~A}$ & 0,61 \\
\hline 2A & $3 \mathrm{~B}$ & 0,48 \\
\hline 2A & $4 \mathrm{~A}$ & 0,53 \\
\hline 2A & $4 \mathrm{~B}$ & 0,66 \\
\hline 2B & $1 \mathrm{~A}$ & 0,38 \\
\hline 2B & 1B & 0,38 \\
\hline 2B & $3 \mathrm{~A}$ & 0,53 \\
\hline 2B & $3 \mathrm{~B}$ & 0,45 \\
\hline 2B & $4 \mathrm{~A}$ & 0,53 \\
\hline 2B & $4 \mathrm{~B}$ & 0,66 \\
\hline
\end{tabular}



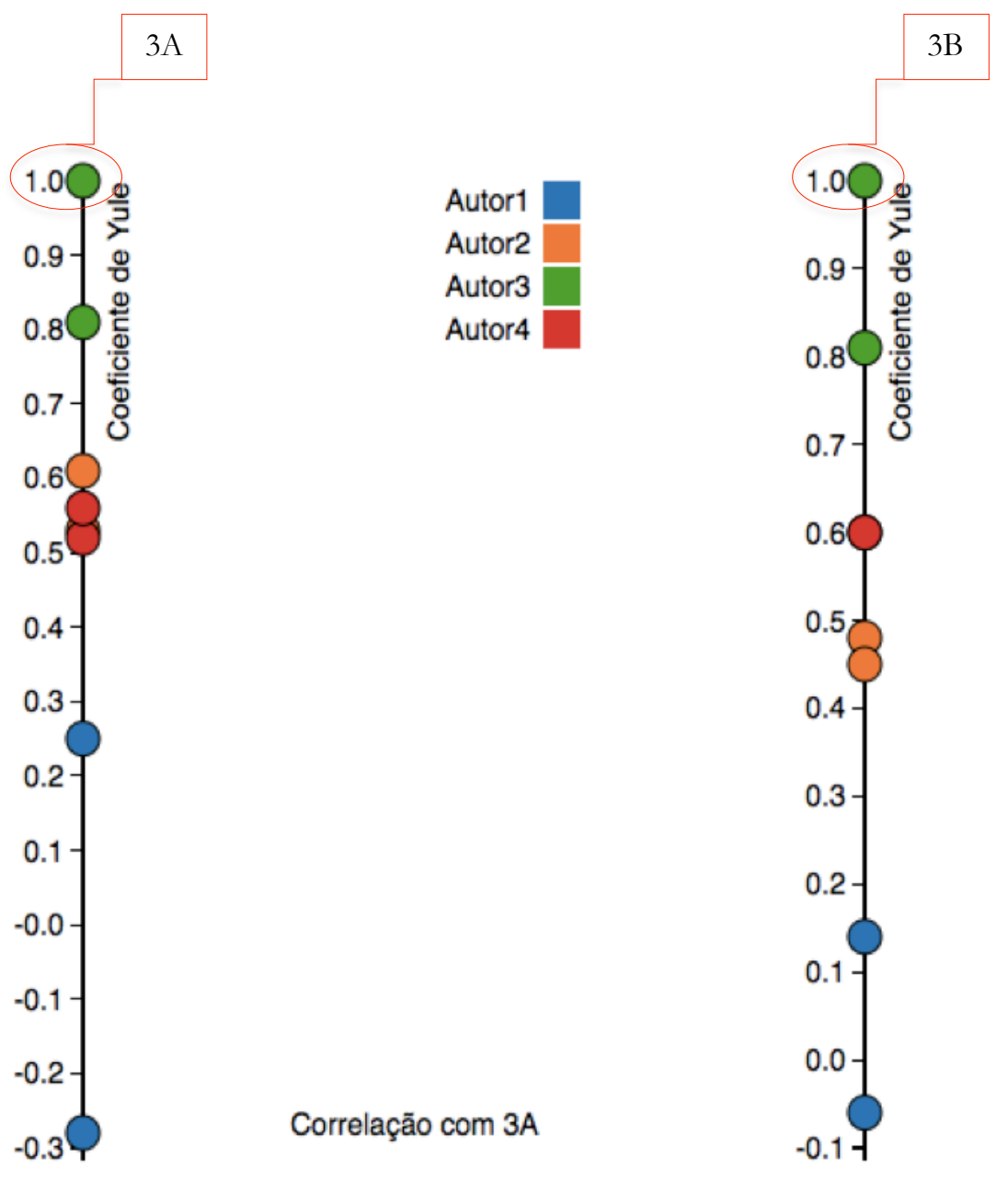

Autor1

Autor2

Autor3

Autor4

Figura 25 - Coeficiente de Yule: correlações com 3A e 3B

Tabela 13 - Correlação de Yule: Autor 3

\begin{tabular}{|c|c|c|}
\hline \multicolumn{2}{|c|}{ Autor 3} & \multirow{2}{*}{$\begin{array}{l}\text { Índice } \mathrm{q} \\
\qquad 0,81\end{array}$} \\
\hline $3 \mathrm{~A}$ & $3 B$ & \\
\hline $3 \mathrm{~A}$ & $1 \mathrm{~A}$ & 0,25 \\
\hline $3 \mathrm{~A}$ & $1 \mathrm{~B}$ & $(0,28)$ \\
\hline $3 \mathrm{~A}$ & $2 \mathrm{~A}$ & 0,61 \\
\hline $3 \mathrm{~A}$ & $2 \mathrm{~B}$ & 0,53 \\
\hline $3 \mathrm{~A}$ & $4 \mathrm{~A}$ & 0,52 \\
\hline $3 \mathrm{~A}$ & $4 \mathrm{~B}$ & 0,56 \\
\hline $3 B$ & $1 \mathrm{~A}$ & 0,14 \\
\hline $3 B$ & $1 \mathrm{~B}$ & $(0,06)$ \\
\hline $3 B$ & $2 \mathrm{~A}$ & 0,48 \\
\hline $3 B$ & $2 \mathrm{~B}$ & 0,45 \\
\hline $3 \mathrm{~B}$ & $4 \mathrm{~A}$ & 0,60 \\
\hline $3 B$ & $4 B$ & 0,60 \\
\hline
\end{tabular}



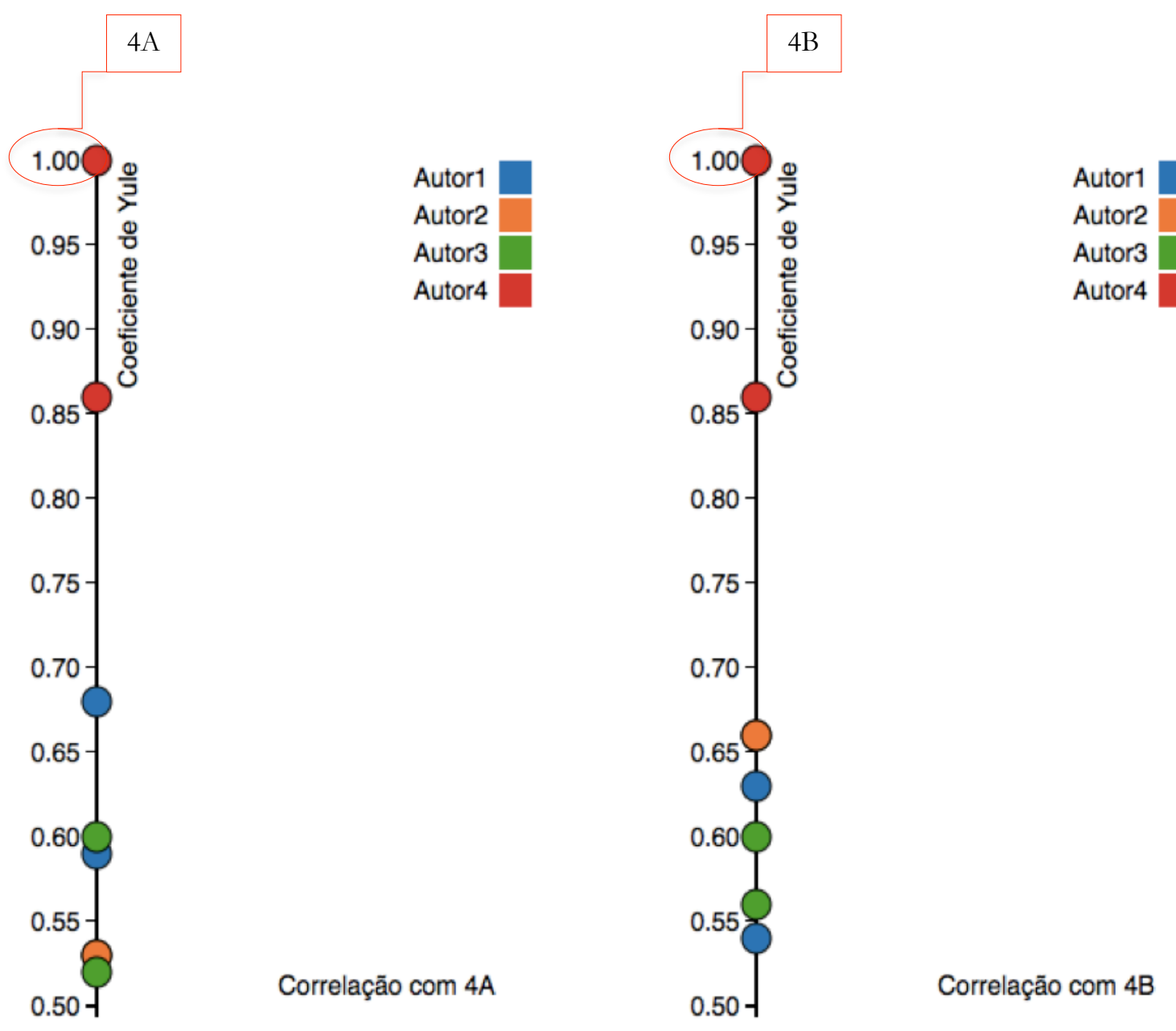

Figura 26 - Coeficiente de Yule: correlações com 4A e 4B

Tabela 14 - Correlação de Yule: Autor 4

\begin{tabular}{|r|r|r|}
\hline Autor 4 & & Índice q \\
\hline $4 \mathrm{~A}$ & 4B & $\mathbf{0 , 8 6}$ \\
\hline $4 \mathrm{~A}$ & $1 \mathrm{~A}$ & 0,59 \\
\hline $4 \mathrm{~A}$ & $1 \mathrm{~B}$ & 0,68 \\
\hline $4 \mathrm{~A}$ & $2 \mathrm{~A}$ & 0,53 \\
\hline $4 \mathrm{~A}$ & $2 \mathrm{~B}$ & 0,53 \\
\hline $4 \mathrm{~A}$ & $3 \mathrm{~A}$ & 0,52 \\
\hline $4 \mathrm{~A}$ & $3 \mathrm{~B}$ & 0,60 \\
\hline $4 \mathrm{~B}$ & $1 \mathrm{~A}$ & 0,54 \\
\hline $4 \mathrm{~B}$ & $1 \mathrm{~B}$ & 0,63 \\
\hline $4 \mathrm{~B}$ & $2 \mathrm{~A}$ & 0,66 \\
\hline $4 \mathrm{~B}$ & $2 \mathrm{~B}$ & 0,66 \\
\hline $4 \mathrm{~B}$ & $3 \mathrm{~A}$ & 0,56 \\
\hline $4 \mathrm{~B}$ & $3 \mathrm{~B}$ & 0,60 \\
\hline
\end{tabular}


Tabela 15 - Coeficiente de Jaccard: todas as comparações

\begin{tabular}{|c|c|c|c|c|c|c|c|c|c|c|c|}
\hline \multicolumn{2}{|c|}{ AUTOR 1} & $*$ & \multicolumn{2}{|c|}{ AUTOR 2} & $*$ & \multicolumn{2}{|c|}{ AUTOR 3} & $*$ & \multicolumn{2}{|c|}{ AUTOR 4} & $*$ \\
\hline $1 \mathrm{~A}$ & 1B & 0,6 & $2 \mathrm{~A}$ & $2 B$ & 0,6 & $3 \mathrm{~A}$ & $3 B$ & 0,6 & $4 \mathrm{~A}$ & 4B & 0,7 \\
\hline $1 \mathrm{~A}$ & $2 \mathrm{~A}$ & 0,2 & $2 \mathrm{~A}$ & $1 \mathrm{~A}$ & 0,2 & $3 \mathrm{~A}$ & $1 \mathrm{~A}$ & 0,1 & $4 \mathrm{~A}$ & $1 \mathrm{~A}$ & 0,3 \\
\hline $1 \mathrm{~A}$ & $2 \mathrm{~B}$ & 0,1 & $2 \mathrm{~A}$ & $1 \mathrm{~B}$ & 0,1 & $3 \mathrm{~A}$ & $1 \mathrm{~B}$ & 0,0 & $4 \mathrm{~A}$ & $1 \mathrm{~B}$ & 0,3 \\
\hline $1 \mathrm{~A}$ & $3 \mathrm{~A}$ & 0,1 & $2 \mathrm{~A}$ & $3 \mathrm{~A}$ & 0,3 & $3 \mathrm{~A}$ & $2 \mathrm{~A}$ & 0,3 & $4 \mathrm{~A}$ & $2 \mathrm{~A}$ & 0,2 \\
\hline $1 \mathrm{~A}$ & $3 \mathrm{~B}$ & 0,1 & $2 \mathrm{~A}$ & $3 \mathrm{~B}$ & 0,1 & $3 \mathrm{~A}$ & $2 B$ & 0,2 & $4 \mathrm{~A}$ & $2 B$ & 0,1 \\
\hline $1 \mathrm{~A}$ & $4 \mathrm{~A}$ & 0,3 & $2 \mathrm{~A}$ & $4 \mathrm{~A}$ & 0,2 & $3 \mathrm{~A}$ & $4 \mathrm{~A}$ & 0,2 & $4 \mathrm{~A}$ & $3 \mathrm{~A}$ & 0,2 \\
\hline $1 \mathrm{~A}$ & $4 \mathrm{~B}$ & 0,2 & $2 \mathrm{~A}$ & $4 \mathrm{~B}$ & 0,3 & $3 \mathrm{~A}$ & $4 \mathrm{~B}$ & 0,1 & $4 \mathrm{~A}$ & $3 \mathrm{~B}$ & 0,2 \\
\hline 1B & $2 \mathrm{~A}$ & 0,1 & $2 \mathrm{~B}$ & $1 \mathrm{~A}$ & 0,1 & $3 \mathrm{~B}$ & $1 \mathrm{~A}$ & 0,1 & $4 \mathrm{~B}$ & $1 \mathrm{~A}$ & 0,2 \\
\hline $1 \mathrm{~B}$ & $2 \mathrm{~B}$ & 0,1 & $2 \mathrm{~B}$ & 1B & 0,1 & $3 \mathrm{~B}$ & $1 \mathrm{~B}$ & 0,0 & $4 \mathrm{~B}$ & $1 \mathrm{~B}$ & 0,2 \\
\hline 1B & $3 \mathrm{~A}$ & 0,0 & $2 \mathrm{~B}$ & $3 \mathrm{~A}$ & 0,2 & $3 \mathrm{~B}$ & $2 \mathrm{~A}$ & 0,1 & $4 \mathrm{~B}$ & $2 \mathrm{~A}$ & 0,3 \\
\hline $1 \mathrm{~B}$ & $3 \mathrm{~B}$ & 0,0 & $2 \mathrm{~B}$ & $3 \mathrm{~B}$ & 0,1 & $3 \mathrm{~B}$ & $2 B$ & 0,1 & $4 \mathrm{~B}$ & $2 \mathrm{~B}$ & 0,2 \\
\hline 1B & $4 \mathrm{~A}$ & 0,3 & $2 \mathrm{~B}$ & $4 \mathrm{~A}$ & 0,1 & $3 \mathrm{~B}$ & $4 \mathrm{~A}$ & 0,2 & $4 \mathrm{~B}$ & $3 \mathrm{~A}$ & 0,1 \\
\hline $1 \mathrm{~B}$ & $4 \mathrm{~B}$ & 0,2 & $2 \mathrm{~B}$ & $4 \mathrm{~B}$ & 0,2 & $3 B$ & $4 \mathrm{~B}$ & 0,1 & $4 \mathrm{~B}$ & $3 \mathrm{~B}$ & 0,1 \\
\hline
\end{tabular}

* Índice de Jaccard : Os resultados vão de 0 a 1, em que 0 indica total dessemelhança entre os dois conjuntos e 1 indica identidade entre eles

Na tabela 16, o resultado é análogo. Veja-se que o valor de "q"7 (que representa o resultado da Correlação de Yule) é sempre bastante maior entre os subconjuntos A e B do mesmo autor (expressos na primeira linha).

Tabela 16 - Correlação de Yule: todos os autores

\begin{tabular}{|c|c|c|c|c|c|c|c|c|c|c|c|}
\hline \multicolumn{2}{|c|}{ AUTOR 1} & $q$ & \multicolumn{2}{|c|}{ AUTOR 2} & $q$ & \multicolumn{2}{|c|}{ AUTOR 3} & $q$ & \multicolumn{2}{|c|}{ AUTOR 4} & $q$ \\
\hline $1 \mathrm{~A}$ & 1B & 0,7 & $2 \mathrm{~A}$ & 2B & 0,8 & $3 \mathrm{~A}$ & $3 B$ & 0,8 & $4 \mathrm{~A}$ & 4B & 0,9 \\
\hline $1 \mathrm{~A}$ & $2 \mathrm{~A}$ & 0,4 & $2 \mathrm{~A}$ & $1 \mathrm{~A}$ & 0,4 & $3 \mathrm{~A}$ & $1 \mathrm{~A}$ & 0,3 & $4 \mathrm{~A}$ & $1 \mathrm{~A}$ & 0,6 \\
\hline $1 \mathrm{~A}$ & $2 \mathrm{~B}$ & 0,4 & $2 \mathrm{~A}$ & 1B & 0,4 & $3 \mathrm{~A}$ & $1 \mathrm{~B}$ & $(0,3)$ & $4 \mathrm{~A}$ & 1B & 0,7 \\
\hline $1 \mathrm{~A}$ & $3 \mathrm{~A}$ & 0,3 & $2 \mathrm{~A}$ & $3 \mathrm{~A}$ & 0,6 & $3 \mathrm{~A}$ & $2 \mathrm{~A}$ & 0,6 & $4 \mathrm{~A}$ & $2 \mathrm{~A}$ & 0,5 \\
\hline $1 \mathrm{~A}$ & $3 B$ & 0,1 & $2 \mathrm{~A}$ & $3 \mathrm{~B}$ & 0,5 & $3 \mathrm{~A}$ & $2 \mathrm{~B}$ & 0,5 & $4 \mathrm{~A}$ & $2 \mathrm{~B}$ & 0,5 \\
\hline $1 \mathrm{~A}$ & $4 \mathrm{~A}$ & 0,6 & $2 \mathrm{~A}$ & $4 \mathrm{~A}$ & 0,5 & $3 \mathrm{~A}$ & $4 \mathrm{~A}$ & 0,5 & $4 \mathrm{~A}$ & $3 \mathrm{~A}$ & 0,5 \\
\hline $1 \mathrm{~A}$ & 4B & 0,5 & $2 \mathrm{~A}$ & 4B & 0,7 & $3 \mathrm{~A}$ & $4 \mathrm{~B}$ & 0,6 & $4 \mathrm{~A}$ & $3 \mathrm{~B}$ & 0,6 \\
\hline 1B & $2 \mathrm{~A}$ & 0,4 & $2 \mathrm{~B}$ & $1 \mathrm{~A}$ & 0,4 & $3 B$ & $1 \mathrm{~A}$ & 0,1 & 4B & $1 \mathrm{~A}$ & 0,5 \\
\hline 1B & $2 \mathrm{~B}$ & 0,4 & $2 \mathrm{~B}$ & 1B & 0,4 & $3 \mathrm{~B}$ & $1 \mathrm{~B}$ & $(0,1)$ & $4 \mathrm{~B}$ & 1B & 0,6 \\
\hline 1B & $3 \mathrm{~A}$ & $(0,3)$ & $2 \mathrm{~B}$ & $3 \mathrm{~A}$ & 0,5 & $3 B$ & $2 \mathrm{~A}$ & 0,5 & $4 \mathrm{~B}$ & $2 \mathrm{~A}$ & 0,7 \\
\hline $1 \mathrm{~B}$ & $3 B$ & $(0,1)$ & $2 \mathrm{~B}$ & $3 B$ & 0,4 & $3 \mathrm{~B}$ & $2 \mathrm{~B}$ & 0,4 & $4 \mathrm{~B}$ & $2 \mathrm{~B}$ & 0,7 \\
\hline 1B & $4 \mathrm{~A}$ & 0,7 & $2 \mathrm{~B}$ & $4 \mathrm{~A}$ & 0,5 & $3 \mathrm{~B}$ & $4 \mathrm{~A}$ & 0,6 & $4 B$ & $3 \mathrm{~A}$ & 0,6 \\
\hline 1B & $4 \mathrm{~B}$ & 0,6 & $2 B$ & $4 \mathrm{~B}$ & 0,7 & $3 B$ & $4 \mathrm{~B}$ & 0,6 & $4 B$ & $3 \mathrm{~B}$ & 0,6 \\
\hline
\end{tabular}

$q=$ Coeficiente de Yule

\footnotetext{
${ }^{7}$ Conforme se mencionou anteriormente, os resultados vão de -1 a 1 , em que quanto mais próximo de 1 for valor de "q", mais fortemente correlacionadas estão as duas variáveis medidas e, ao contrário, quanto mais próximo de -1 , menor a correlação entre elas.
} 
Os resultados apresentados corroboram a hipótese de que se pode aplicar a análise semiótica em casos de atribuição de autoria na esfera forense e que as categorias de análise provenientes dos modelos teóricos-metodológicos da Semiótica Discursiva podem realmente distinguir autores. Contudo, podem emergir dúvidas sobre a validade e confiabilidade de método, uma vez que os textos foram recolhidos pelo próprio pesquisador que efetuou a análise, que sabia, de antemão quem eram os autores e a quem pertenciam os textos em cada um dos subgrupos estudados. Na tentativa de dirimir essas dúvidas, elaborou-se um exercício de análise "às cegas", tema do capítulo seguinte. 


\section{EXERCÍCIO DE ATRIBUIÇÃo “Às CEGAS"}

"He began to get letters - threatening letters [...]." "Were these letters destroyed?" "No, I think I've got a couple still in my files one I know Ratchett tore up in a rage." [...] There was no signature. With no comment beyond raised eyebrows, Poirot picked up the second letter. [...].

"You would not observe," said Poirot pleasantly. "It requires the eye of one used to such things. This letter was not written by one person, M. MacQueen. Two or more persons wrote it [...]." 


\subsection{Considerações gerais e metodologia}

O intuito deste capítulo é aplicar a análise do plano do conteúdo, do modo como apresentada nos capítulos 4 e 5, a um exemplo que simula uma das situações que poderia ocorrer em um caso "real"1. A tarefa é a de classificar um texto questionado como pertencente a um de três autores suspeitos.

Os capítulos 4 e 5 indicaram que elementos tensivos e do plano do conteúdo, de acordo com a semiótica francesa, podem funcionar como marcadores quando se trata de agrupar ou distanciar autores. Demonstrou-se que a premissa fundamental da atribuição de autoria, ou seja, que a variação intra-autor é menor do que a variação entre autores aplica-se também aos elementos do plano do conteúdo. Todavia, o método pode levantar dúvidas em termos de validade e confiabilidade, já que todos os textos foram coletados pelo próprio pesquisador que realizou a análise ${ }^{2}$.

No momento da análise, o fato de o analista ter conhecimento da autoria de cada um dos conjuntos analisados poderia, mesmo que de modo inconsciente, enviesar o exame. Problemas como esse são conhecidos como "research artifacts" (STROHMETZ; ROSNOW, 2003). Este termo refere-se a vieses não intencionais ou não controlados que podem afetar as conclusões de um estudo. Segundo Strohmetz e Rosnow (2003, p. 25), é alto o potencial de resultados enviesados quanto maior for a participação de seres humanos na pesquisa, incluindo-se aí o próprio pesquisador, que nunca é um participante "desinteressado".

Dessa forma, com o propósito de conferir maior validade e confiabilidade ao método de análise sugerido no capítulo 5, foi concebido um "teste cego". Chama-se de "teste cego" ou "experimento cego" o estudo em que informações que podem tornar os resultados enviesados não são reveladas ao pesquisador (GREEN; PALUCK, 2003, p. 284). Experimentos cegos são comumente utilizados em pesquisas em que uma das variáveis sob estudo pode ser controlada pelo pesquisador. Eles podem se apresentar em

\footnotetext{
${ }^{1}$ Ressalta-se que este trabalho não propõe que, num caso real, a análise se concentre apenas no plano do conteúdo, mas que considere também este plano em conjunto com outros elementos linguísticos já avaliados em estudos anteriores.

${ }^{2}$ Lembre-se de que o capítulo 5 compara 8 conjuntos de textos, com 2 conjuntos (A e B) para cada autor.
} 
três níveis: 1) os participantes do estudo não sabem em quê estão sendo avaliados; 2) nem os participantes nem os "experienciadores" (aqueles que aplicam o experimento) sabem do que trata o estudo (double-blind experiment); e 3) nem os participantes, nem os experienciadores, nem os responsáveis pela coleta de dados sabem do que trata o estudo (triple-blind experiment).

Neste estudo, apenas o primeiro dos três níveis acima foi alcançado, já que os autores que contribuíram com o textos não sabiam que se tratava de uma tarefa de atribuição de autoria. Por outro lado, empregou-se outra espécie de blindness, na medida em que o pesquisador-analista não tomou conhecimento prévio das identidades dos autores e nem da autoria do texto tomado como questionado - fatos que poderiam influenciar, ainda que inconscientemente, a sua análise ${ }^{3}$. Para garantir isso, contou-se com o auxílio de outro pesquisador ${ }^{4}$ para a coleta de dados.

Este segundo pesquisador coletou textos de 3 autores $^{5}$, denominados A, B e C, e retirou 3 deles - um texto de cada grupo - aleatoriamente. Dentre estes, um texto foi selecionado como texto questionado. Assim, a análise considerou os conjuntos de textos A, B e C (com 10 textos de cada autor) e um texto questionado, sem que se soubesse nada sobre a sua autoria. A identidade do autor do texto questionado foi mantida em segredo pelo segundo pesquisador até o fim da análise. Como já se apontou, a tarefa consistia em tentar demonstrar qual dos três autores mais provavelmente havia escrito o texto questionado, através da análise do plano do conteúdo.

Assim como no capítulo 5, a análise foi conduzida no software Corpus Tool e a extração de dados foi realizada através de scripts desenvolvidos em PERL. Tanto os procedimentos de análise quanto as medidas estatísticas empregadas para se constatar a proximidade entre as amostras (o Índice de Jaccard e a Correlação de Yule) foram os mesmos do capítulo 5 . Cada grupo de textos por autor constituiu uma amostra separada,

\footnotetext{
${ }^{3}$ Para aumentar o nível de blindness e garantir maior validade e confiabilidade das conclusões, o ideal seria pedir que outro analista, ciente do método de análise semiótica realizasse a análise dos mesmos textos, preferencialmente sem saber que se trata de uma análise para fins de identificação de autoria. Por restrições de tempo e também pelo fato de que os analistas que conheço sabem da natureza do meu trabalho, isso não foi realizado neste momento.

${ }^{4}$ Meus agradecimentos à colega Júlia Maria França pela coleta dos textos.

${ }^{5}$ Esses textos foram coletados seguindo-se as mesmas diretrizes de coleta do CGAA e passaram a integrar esse corpus.
} 
denominadas $\mathrm{A}, \mathrm{B}$ e $\mathrm{C}$; o texto questionado constitui em si uma amostra distinta denominada Q.

Lembremo-nos de que os coeficientes de Jaccard e Yule consideram valores binários, ou seja, não atentam para a frequência absoluta de elementos, mas apenas para o fato de um elemento estar presente ou ausente. Por isso, o fato de haver 10 textos em cada conjunto A, B e C e apenas um texto em Q não representa um problema, uma vez que a frequência - de 1 a 10 - dos três primeiros é convertida para valores binários.

Isso não quer dizer, contudo, que a frequência nunca é levada em conta, já que ela é fundamental para se depreender a consistência de um estilo. Dessa forma, assim como se procedeu nas análises reportadas no capítulo 5 , antes de calcular os coeficientes de Jaccard e Yule excluíram-se tanto os elementos que apresentavam frequência igual a $0 \mathrm{em}$ todos os autores, quanto aqueles que estavam presentes em todos (pois eles não são distintivos, já que iguais para todos). Em segundo lugar, a questão da consistência continuou sendo observada: consideraram-se apenas as características presentes em um autor pelo menos 5 vezes.

Uma dificuldade no tocante à consistência se apresenta com a análise do texto questionado. Se estamos julgando consistentes as características que se repetem, que são recorrentes, como determinar tal recorrência em apenas um texto (tão curto quanto os que via de regra se apresentam em casos forenses)? Este seria um problema com relação à validade, não apenas neste método de análise, mas com qualquer elemento linguístico que se considere como marca de autoria. Assim, para o texto questionado consideraram-se quaisquer características presentes e essas foram comparadas com as características mais frequentemente utilizadas em cada grupo de textos.

\subsection{Resultados}

Antes de iniciar a apresentação dos resultados, transcreve-se o texto simuladamente questionado: 
Ser fã não é apenas admirar, é também preservar e respeitar a memória dos seus ídolos. Linda homenagem, realmente emocionante. $\mathrm{Na}$ minha opinião (e acredito que também seja a opinião de muitos), Ramon Valdes (o Seu Madruga) foi o melhor ator do Chaves. Tanto que até o Roberto Bolaños (o criador e o próprio Chaves) afirma isso.

Os resultados obtidos indicam que dentre os autores $\mathrm{A}, \mathrm{B}$ e $\mathrm{C}$ examinados, aquele cujos textos apresentam mais elementos em comum o texto questionado é o autor " $\mathrm{C}$ "6. De fato, o segundo pesquisador envolvido na coleta de dados, que manteve em segredo a autoria do texto questionado, confirmou que este é o autor do texto questionado. A tabela a seguir exibe os resultados dos coeficientes. As Figuras 27 e 28 ajudam a visualizar os resultados e as relações entre os subconjuntos e os textos questionados.

Tabela 17 - Coeficiente de Jaccard e Correlação de Yule: comparando cada autor com o texto questionado

\begin{tabular}{|c|c|c|}
\hline & JACCARD & YULE \\
\hline AxQ & 0,0 & $-1,0$ \\
\hline BxQ & 0,1 & 0,5 \\
\hline CxQ & 0,3 & 0,7 \\
\hline
\end{tabular}

Quanto ao Coeficiente de Jaccard, lembre-se que os índices vão de 0 a 1, em que 0 indica total dessemelhança entre os dois conjuntos e 1 indica identidade entre eles. Por esse coeficiente, nenhum dos três conjuntos exibe um alto grau de semelhança com relação ao texto questionado, a ponto de se afirmar com confiança que o seu autor é o autor C. No entanto, comparativamente aos outros autores, o autor C é aquele que compartilha mais elementos em comum com o texto questionado. Em outras palavras, desses "autores-suspeitos", aquele que revela um estilo mais semelhante ao do autor do texto questionado é o "C". Observe-se também que ele apresenta um índice de Jaccard três vezes maior do que o segundo no ranking e que o autor $A$, terceiro e último, apresenta total dessemelhança com o texto questionado. Para o coeficiente de Yule - cujos índices vão de -1 a 1 - os resultados são análogos, na medida em que o conjunto C é o mais fortemente correlacionado ao texto questionado, com a correlação de Yule em 0,7.

${ }^{6}$ Os textos do "Autor C" encontram-se no Anexo C. 
É importante ressaltar que os resultados do Coeficiente de Jaccard nunca resultariam em 1, já que um resultado igual a 1 equivaleria dizer que há total igualdade entre as amostras, ou seja, só seria possível se atingir tal índice se os conjuntos comparados fossem iguais. Da mesma forma, uma correlação de Yule em 1 só seria possível com conjuntos que compartilhassem exatamente as mesmas características.

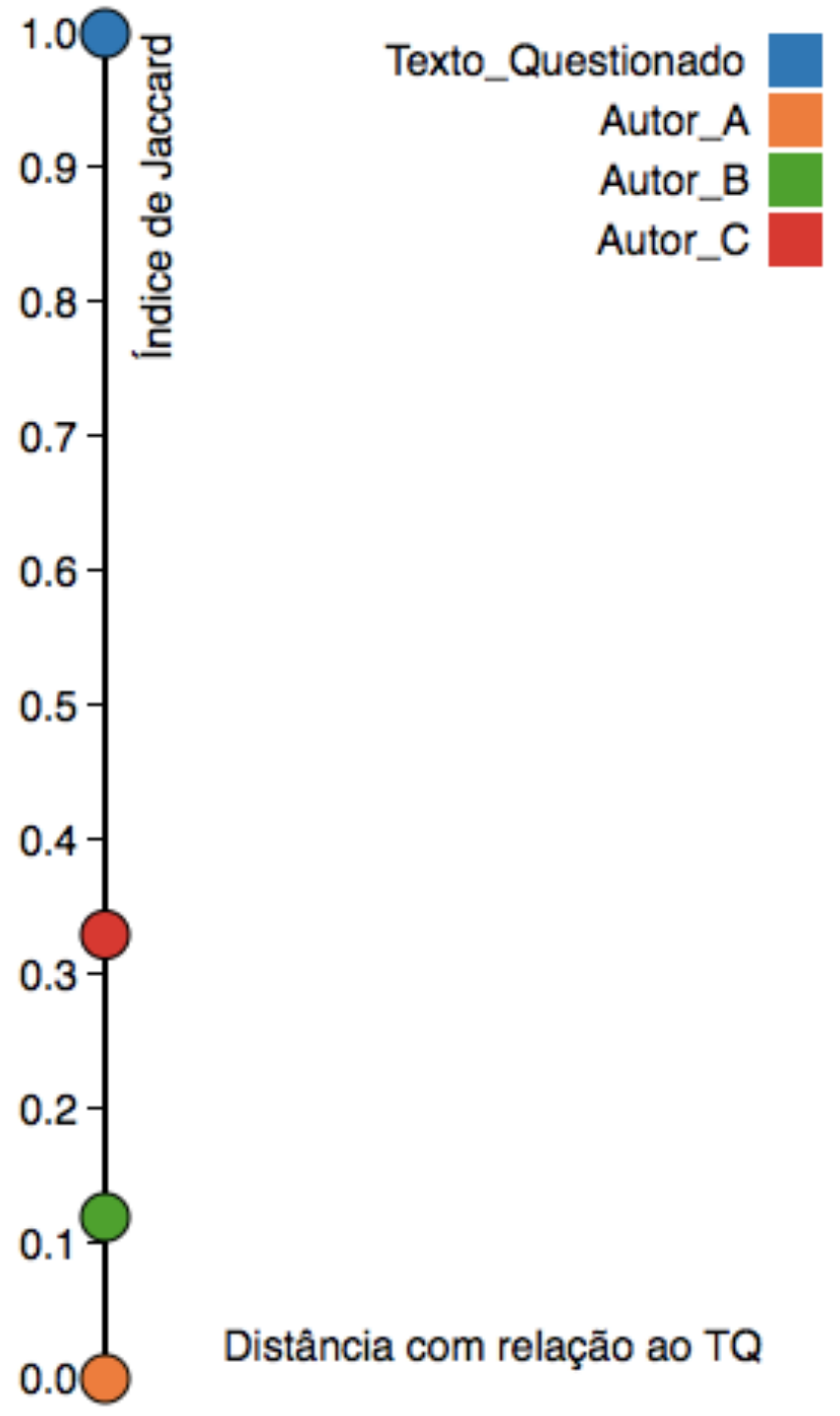

Figura 27 - Índice de Jaccard. Autores A, B e C em comparação com o texto questionado 

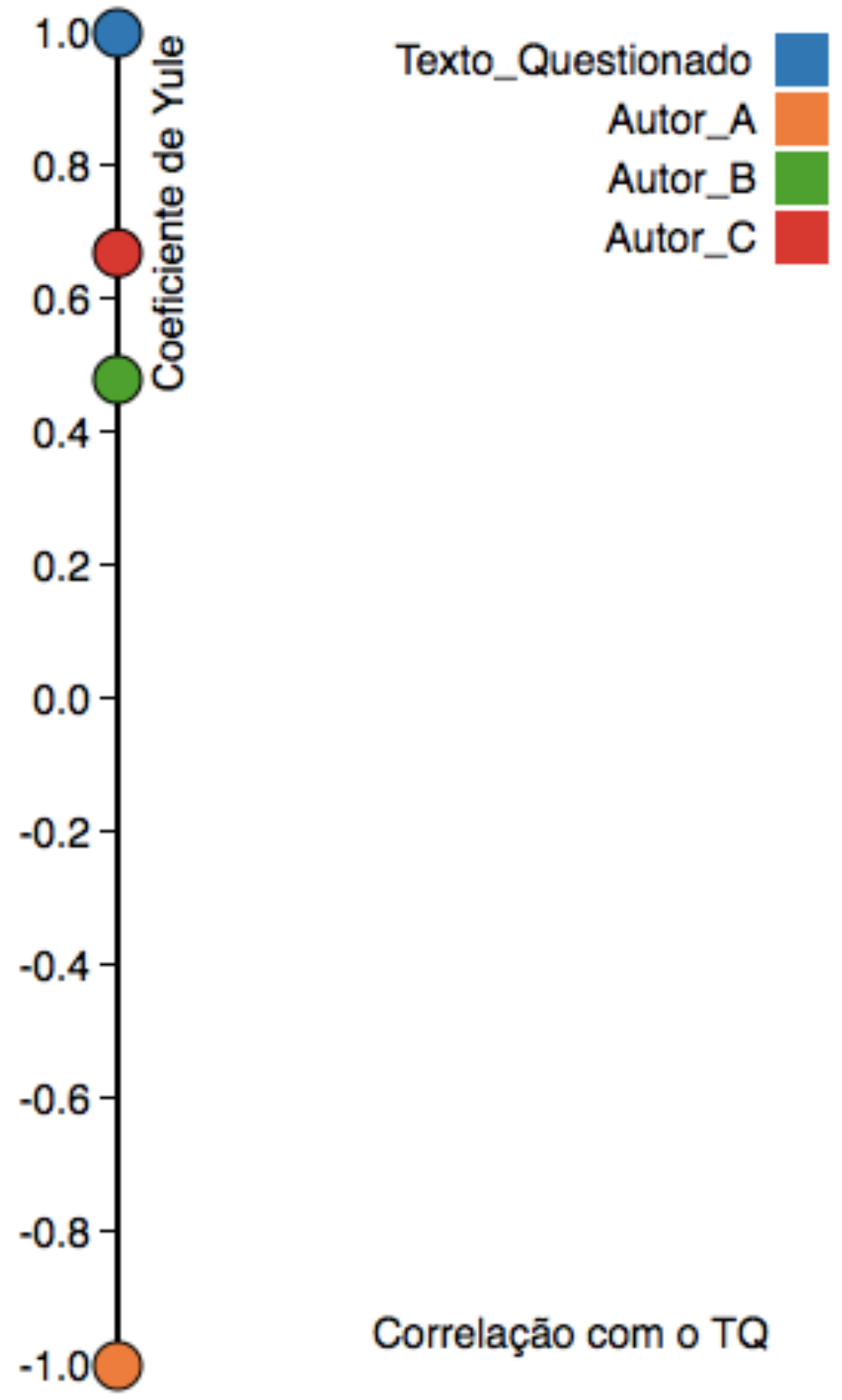

Figura 28 - Coeficiente de Yule. Autores A, B e C em comparação com o texto questionado

Para finalizar, apresentam-se as seis características comuns ao autor $\mathrm{C}$ e ao texto questionado (Quadro 25). 


\section{CARACTERÍSTICAS}

Admiração (paixão)

Presente gnômico (sintaxe discursiva)

Seriedade (ethos)

Detentor do saber (ethos)

Bom e ruim (categoria semântica fundamental)

Tensionado (tensividade)

Quadro 25 - Características comuns ao Autor C e ao Texto Questionado

Pode-se indagar se apenas essas 6 características são relevantes para aproximar dois autores. A resposta deve considerar combinatória e probabilidade. Neste estudo, havia 126 características ("etiquetas") possíveis. Dessas, as 6 características acima são comuns ao Autor C e ao texto questionado. Qual seria a probabilidade de outro autor repetir essas 6 características? Calcula-se, primeiramente, a quantidade de combinações possíveis. Ou seja, quantas combinações de 6 elementos em 126 são possíveis? A fórmula seria:

$$
\begin{aligned}
& C_{n, p}=n ! / p !(n-p) ! \\
& \text { em que } \mathrm{n}=126 \text { e } \mathrm{p}=6 .
\end{aligned}
$$

Teríamos: $C_{126,6}=126 ! / 6 !(126-6) !$ 
$\mathrm{C}_{126,6}=4.925 .156 .775^{7}$

A probabilidade de um evento ocorrer é dada pela fórmula:

$P(A)=$ número de casos favoráveirs / número de casos possiveis

Em que A é o evento a ocorrer.

Assim, qual é a probabilidade da combinação daquelas exatas 6 características se realizar?

A probabilidade é de 1 em 4.925.156.775 ou 0,00000002\% $(\mathrm{P}=1 / 4.925 .156 .775=$ $0,00000002 \%)$.

${ }^{7} \mathrm{O}$ cálculo foi feito no programa $\mathrm{R}$, conforme figura que segue:

Source
Console /
Copyright (C) 2010 The R Foundation for Statistical Computing
ISBN 3-900051-07-0
Platform: x86_64-apple-darwin9.8.0/x86_64 (64-bit)
$\mathrm{R}$ is free software and comes with ABSOLUTELY NO WARRANTY.
You are welcome to redistribute it under certain conditions.
Type 'license()' or 'licence()' for distribution details.
Natural language support but running in an English locale
$\mathrm{R}$ is a collaborative project with many contributors.
Type 'contributors()' for more information and
'citation()' on how to cite $\mathrm{R}$ or $\mathrm{R}$ packages in publications.
Type 'demo()' for some demos, 'help()' for on-line help, or
'help.start()' for an HTML browser interface to help.
Type ' $\mathrm{q}()$ ' to quit R.
$>$ factorial(126)/(factorial(6)*(factorial(126-6)))
[1] 4925156775
$>$ I


Obviamente, esses números correspondem a um exemplo em que cada uma das características possíveis tem a mesma chance de ocorrer em um texto. A probabilidade seria diferente se se levasse em conta, por exemplo, o fato de um determinado grupo social nunca empregar ou empregar mais frequentemente uma ou outra dessas características.

Considerando-se, então, o que se observa acima, corrobora-se o que já se afirmou algumas vezes ao longo desse trabalho: a "força" da distinção autoral está na combinação dos elementos; a atribuição de autoria não é feita levando-se em conta apenas uma ou outra característica. Quanto mais elementos se combinam, maior a probabilidade de distinção entre os autores. 


\section{CoNClusão}

Existe uma teoria que diz que se alguém descobrir exatamente para que serve o Universo e por que ele está aqui, ele desaparecerá instantaneamente e será substituído por algo ainda mais estranho e inexplicável. 
Colocar um ponto final em uma pesquisa acadêmica é uma tarefa das mais custosas. Isso se dá principalmente porque parece não haver fim na cadeia de conhecimento que se forma a partir das primeiras indagações acerca de um tema. A cada problema resolvido, outros emergem. É como se se escavasse em busca de um objeto perdido e se encontrasse no mesmo buraco outros artefatos sobre os quais ainda nem se tinha ouvido falar. Existe um momento, porém, em que o pesquisador deve se contentar com as reticências. Talvez o ponto final nunca seja possível, como sugere a citação em epígrafe.

Com este trabalho não foi diferente. Os resultados aqui obtidos poderiam ser ainda corroborados se houvesse mais dados, se os dados fossem de outro tipo, se se empregassem outros modelos estatísticos, se... Chega, no entanto, o momento da parada; ou melhor: da interrupção, uma vez que se espera que as questões levantadas aqui possam ser objeto de futuros trabalhos.

Procurou-se encontrar uma saída para algumas questões que permeiam a análise de autoria textual no âmbito forense. Subdividida em duas tarefas complementares, porém distintas (a elaboração de perfis sociolinguísticos e a atribuição de autoria), a análise de autoria conta com uma extensa lista de trabalhos dedicados a testar diferentes elementos linguísticos enquanto marcadores de estilo. Aqui pretendeu-se somar a esses trabalhos, na medida em que se propôs que categorias observadas quando se analisa o plano do conteúdo dos textos podem funcionar como marcadores estilísticos, uma vez combinadas. A ideia de se empregar a análise do plano do conteúdo em análises de autoria surgiu a partir da observação de certas premissas da Sociolinguística e da Semiótica. Retomam-se a seguir as questões que guiaram esta investigação, bem como os resultados obtidos e indicações de trabalhos futuros que poderão iluminar ainda mais os temas aqui explorados.

A elaboração de perfis sociolinguísticos - que se relaciona à depreensão de estilos sociais, isto é, de grupo - foi abordada no capítulo 3. Na primeira parte do capítulo, procurou-se exemplificar como categorias demográficas podem ser indexadas por meio de usos linguísticos, seguindo os preceitos da Sociolinguística. A categoria selecionada para análise foi sexo/gênero e a combinação de uma análise qualitativa com uma quantitativa revelou elementos linguísticos índices de escrita masculina ou feminina no 
contexto específico da comunicação na rede social Facebook. Todos os elementos depreendidos num primeiro momento são elementos do plano da expressão. Num segundo momento, realizou-se uma análise do nível discursivo dos posts (plano do conteúdo), por meio da qual depreenderam-se temas que poderiam ser ligados ao sexo/gênero. A observação do nível discursivo é relevante pelo menos por um motivo: o fato de que com os textos geralmente curtos que aparecem na esfera forense torna-se difícil identificar padrões que se associem a uma categoria social, já que os elementos linguísticos que poderiam funcionar como índices são escassos, sendo praticamente impossível determinar se são realmente consistentes, recorrentes; observar a existência de uma isotopia recorrente é, por outro lado, menos dependente do tamanho dos textos.

Obviamente, a análise apresentada é apenas um vislumbre do que um estudo dessa natureza poderia alcançar. Depreender padrões semio-linguísticos que pudessem ser associados a diferentes categorias demográficas envolveria a análise de textos de centenas de autores e, ao final de tal estudo, talvez uma espécie de banco de dados com as correlações possíveis pudesse ser criado para pronta utilização em casos reais (tal trabalho poderia constituir, por si só, uma pesquisa). Apesar de não apresentar um método definitivo para a depreensão dos perfis sociolinguísticos, este trabalho espera ter ao menos liberado a centelha que pode dar início a outras investigações.

A segunda parte do capítulo 3 continua enfatizando a importância da análise do nível discursivo, mas desta vez reconhecendo que podem ocorrer casos em que, devido à já mencioanada escassez de dados nos contextos forenses, identificar categorias demográficas pode não ser possível. Tal escassez não deve impedir a tarefa de tentar encontrar algum outro tipo de grupo social. Quando se trata de grupos sociais que não sejam as macro categorias demográficas, a Sociolinguística tem trabalhado com a noção de comunidades de práticas, mas este trabalho se deparou com outros tipos de grupos em que práticas e crenças são compartilhadas, sem que seus membros precisem estar juntos, interagindo face a face (eles talvez nem tenham conhecimento um do outro). Esses grupos foram aqui denominados de universos discursivos e para mostrar que um tal universo se revela através da análise de um conjunto de textos, realizou-se a análise dos escritos provenientes da investigação do "Massacre de Realengo". Mostrou-se que a 
recorrência semântica acaba por criar um grupo com o qual o enunciador se identifica. Também neste caso, outras análises poderiam corroborar o que este estudo sugere.

O espaço dedicado aos perfis sociolinguísticos pode parecer pequeno em comparação àquele dedicado a atribuição de autoria, mas isso é, em primeiro lugar, um reflexo da proporção com que esses tópicos aparecem na literatura sobre análise de autoria. Em segundo lugar, isso reflete uma opção por se aprofundar esta investigação no problema de atribuição. Os problemas diferentes que envolvem a elaboração de perfis sociolinguísticos e a atribuição de autoria poderiam suscitar duas teses distintas. Pensou-se, inclusive, em se deixar de lado toda a questão dos perfis. No entanto, como esta é a primeira tese no Brasil a tratar de análise de autoria em contextos forenses, optou-se por manter este assunto, na esperança de que ele possa abrir portas para trabalhos posteriores. Além disso, não se pode esquecer que há, sim, neste trabalho, algo comum que "amarra" essas duas tarefas de análise de autoria: a ideia de que tanto a atribuição de autoria quanto a depreensão de estilos sociais podem se beneficiar da incorporação da análise do plano do conteúdo, tal como proposta pela semiótica greimasiana.

Os capítulos 4, 5 e 6 foram dedicados à atribuição de autoria, mais especificamente às tarefas de mostrar de que modo uma análise semiótica poderia ser empreendida e de verificar se as categorias segundo as quais se organiza o plano do conteúdo poderiam realmente distinguir autores. A ideia de incorporar a análise do plano do conteúdo surgiu de acordo com as premissas arroladas na Introdução e no Capítulo 2 e que se retomam a seguir:

- Os textos que se obtêm para comparação em cenários forenses são de tipos muito distintos, variando com relação ao assunto, ao gênero, etc. Sabendo que existe variação intrafalante, amplamente demonstrada por estudos sociolinguísticos, pensa-se nos elementos do plano do conteúdo como menos variáveis e passíveis de se manterem os mesmos independentemente dos tipos de textos.

- Se a língua é expressão e conteúdo, uma análise mais acurada teria que considerar também o segundo. Além disso, se o estilo se dá pela combinação de elementos, quanto mais características se puder combinar, maior a chance de se ter combinações que realmente distingam autores. 
- Já que a organização do plano do conteúdo, principalmente no que diz respeito aos seus níveis mais profundos (fundamental/tensivo e narrativo) sempre existe, mesmo que de modo pressuposto, em todo e qualquer tipo de texto, independentemente de seu tamanho, um método de análise de autoria que incorpore essas categorias se tornaria mais independente do tamanho dos textos e, por isso, mais favorável ao contexto forense.

O estudo qualitativo apresentado no capítulo 4 funcionou como uma espécie de análise-piloto em que se apresentou o tipo de análise que se pretendida fazer. $\mathrm{Na}$ sequência, o capítulo 5 apresentou um estudo quantitativo, funcionando como uma confirmação estatística do que se propôs no capítulo 4. Além disso, ele apresentou uma alternativa para que a análise semiótica de textos possa ser realizada "dentro" de um software, de modo que seus resultados possam ser extraídos e quantificados. Finalmente, o capítulo 6 apresentou um exercício às cegas com vistas a simular um caso real de atribuição e a aumentar o grau de validade da proposta, ao se diminuir o viés que poderia ser ocasionado pelo fato de o analista saber de antemão quem eram os autores cujos textos se examinava. Partindo dos resultados desses três capítulos, pode-se afirmar que analisar o plano do conteúdo é relevante para as análises de autoria forenses, na medida em que as opções empregadas por cada autor realmente podem, quando combinadas, funcionar como elementos distintivos.

Pode-se dizer que a tese cumpriu o seu principal objetivo, que era demonstrar a relevância da incorporação da análise do plano do conteúdo aos estudos forenses de autoria. Entretanto, fica a indagação sobre se a quantidade e a variedade de textos sob análise foi suficiente. Por mais que tenha se tentado obter textos de gêneros diferentes, a maior parte deles são emails ou textos de redes sociais.

Um segundo objetivo desta tese, também delineado na Introdução, era apresentar pela primeira vez no Brasil um panorama sobre a análise forense de autoria, inclusive seus aspectos jurídicos. Espera-se que tal apresentação tenha sido o suficiente para suscitar o interesse por mais pesquisas na área, aumentando o quadro de trabalhos em Linguístia Forense stricto senso no país e contribuindo para levar a Linguística para fora dos muros da 
Academia, tarefa árdua, já que, como comenta Coulthard (2010, p. 474, tradução nossa) ${ }^{8}$, "todos os falantes nativos são, de certo modo, especialistas na estrutura e no sentido de sua própria língua”. A dificuldade é ainda maior quando se trata de da área de Linguagem e Direito, já que "advogados e juízes também estão preocupados com detalhadas análises de linguagem e, assim, se vêem como especialistas também" (COULTHARD, 2010, p. 474, tradução nossa) 9 .

Levar a Linguística para além da Academia também se relaciona a uma motivação pessoal para a realização deste trabalho, ligada a um interesse de ser ver o conhecimento produzido na Universidade em prática, contribuindo para resolver problemas pontuais da "vida real". Nessa direção, gostaríamos de finalizar com a reflexão de Labov e Harris (1994, p. 299, 30010):

When we contrast linguistic theory with linguistic practice, we usually conjure up a theory that builds models out of introspective judgments, extracting principles that are remote from observation and experiment. This is not the kmd of theory we have in mind when we search for a way to establish the facts of a matter.

We are, of course, interested in theories of the greatest generality. But are these theories the end product of linguistic activity? Do we gather facts to serve the theory, or do we create theories to resolve questions about the real world? We would challenge the common understanding of our academic linguists that we are in the business of producing theories: that linguistic theories are our major product. We find such a notion utterly wrong.

A sober look at the world around us shows that matters of importance are matters of fact. There are some very large matters of fact: the origin of the universe, the direction of continental drift, the evolution of the human species. There are also specific; matters of fact: the innocence or guilt of a particular individual. These are the questions to answer if we would achieve our fullest potential as thinking beings. General theory is useful, and the more general the theory, the more useful it is, just as any tool is more useful if it can be used for more jobs. But it is still the application of the theory that determines its value. A very general theory can be thought of as a missile that attains considerable altitude, and so it has much greater range than other missiles. But the value of any missile depends on whether it hits the target.

\footnotetext{
${ }^{8}$ Texto original: "all native speakers are in some sense experts on the structure and meaning of their own language" (COULTHARD, 2010, p. 474).

9 Texto original: "lawyers and judges are also professionally and centrally concerned with detailed analysis of language and thus regard themselves as experts too" (COULTHARD, 2010, p. 474).

${ }^{10}$ Diferentemente do que se vinha fazendo ao longo deste trabalho, optou-se por não traduzir a citação acima por ser desejar manter fielmente o que os autores quiseram dizer.
} 


\section{REFERÊNCIAS}

ALMEIDA, D. Análise semiótica de 'Nova poética', de Manuel Bandeira. Todas as letras: revista de língua e literatura, São Paulo: Universidade Mackenzie, v.9, n.1, 2007.

Semiótica da poesia: estudo de poemas de Paulo Henriques Britto. 2009. 125 f. Dissertação (Mestrado em Linguística) - Universidade de São Paulo, São Paulo, 2009.

- Atribuição de autoria e perfil sociolinguístico. In: XV ENAPOL-ENCONTRO DOS ALUNOS DA PÓS GRADUAÇÃO EM LINGUÍSTICA DA USP: FACES E FRONTEIRAS DA LINGUÍSTICA. Comunicação oral. São Paulo, 2012a.

Depreensão de perfis sociolinguísticos: analisando índices de sexo/gênero em 'posts' do Facebook. In: LINGUAGEM E DIREITO. Comunicação oral. Recife, 2012b.

Sociolinguistic profiling in Brazilian Portuguese. BIENNIAL CONFERENCE ON FORENSIC LINGUISTICS/LANGUAGE AND LAW OF THE INTERNATIONAL ASSOCIATION OF FORENSIC LINGUISTS, 11. Comunicação Oral. Cidade do México, 2013.

ALTMAN, M. C. A pesquisa linguística no Brasil (1968-1988). São Paulo: Humanitas/FFLCH/USP, 1998.

ANDERSON, B. Imagined communities: reflections on the origin and spread of nationalism. London: Verso, 1983.

ARGAMON, S. et al. Gender, genre, and writing style in formal written texts. Text, v. 23, 2003. p. 321-346.

ARGAMON, S.; KOPPEL, M. A systemic functional approach to automated authorship analysis. Brooklyn law school. Journal of law and policy, n.2, vol. XXI, p.467-494, 2013.

ARISTOTELES. Arte retórica e Arte poética. Trad. Jean Voilquin e Jean Capelle. Rio de Janeiro: Ediouro, [19--?].

Retórica das paixões. Trad. Isis Borges da Fonseca. São Paulo: Martins Fontes, 2000.

BAAYEN, H. et al. An experiment in authorship attribution. Journees internationales d'analyse statistique des donnees textuelles, n.6, 2002.

BARROS, D. L. P. Teoria do discurso: fundamentos semióticos. São Paulo: Humanitas, 2001.

Teoria semiótica do texto. São Paulo: Ática, 2003. 
BELL, A. Language style as audience design. Language in society, n.13, p.145-204, 1984.

BÍBLIA. Português. Bíblia online. Disponível em <https://www.bibliaonline.com.br/nvi/jz/12>. Acesso em 15/06/2014.

BLOCH, B. A set of postulates for phonemic analysis. Language, n. 24, p. 3-46, 1948.

BOURDIEU, P. Le sens pratique. Paris: Editions de Minuit, 1980.

BRANDÃO, S. C. S. Atribuição de autoria: um problema antigo, novas ferramentas. Texto digital. Florianópolis, ano 2, n. 1, 2006.

BRASIL. Código de processo civil. Disponível em <http://www.planalto.gov.br/ccivil_03/leis/15869.htm>. Acesso em 01/10/2012.

BRASIL. Código de processo penal. Disponível em <http://www.planalto.gov.br/ccivil_03/decreto-lei/del3689.htm>. Acesso em 30/09/2012.

BRIARD; S.; CARTER, C. Communities of practice and communities of interest: definitions and evaluation considerations. 2013. Ontario: Ontario Center of Excellence for Child and Youth Mental Health. Disponível em <http://niagaraknowledgeexchange.com/wpcontent/uploads/2013/12/Communities-of-Practice-Interest_Nov2013.pdf $>$. Acesso em 28/07/2014.

BUTTERS, R. Sociolinguistic variation and the law. In: BAYLEY, Robert; LUCAS, Ceil. Sociolinguistic variation: theories, methods, and applications. New York: Cambridge University Press, 2007.

Forensic Linguistics. Journal of English Linguistics, v.2, n. 39, 2011.

CAMERON, D. Desempenhando identidade de gênero: conversa entre rapazes e construção da masculinidade heterossexual. In: OSTERMANN, A.C; FONTANA, B. (orgs.). Linguagem. Gênero. Sexualidade. São Paulo: Parábola, 2010.

CAMERON, D.; KULICK, D. Language and sexuality. Cambridge: Cambridge University Press, 2003.

CAPEZ, F. Curso de processo penal. São Paulo: Saraiva, 2012.

CHAMBERS, J.K.; TRUDGILL, P.; SCHILLING-ESTES, N. (orgs). The handbook of language variation and change. Oxford; Malden, MA: Blackwell, 2001.

CHAMBERS, J. Sociolinguistic theory. Oxford: Blackwell, 1995.

CHASKI, C. Who wrote it? steps toward a science of authorship identification. National institute of justice journal, sep. 1997. 
. Empirical evaluations of language-based author identification techniques. Forensic

linguistics. Birmingham: University of Birmingham, v.8, n.1, 2001.

Recent validation results for the syntactic analysis method for author identification. In: INTERNATIONAL CONFERENCE ON LANGUAGE AND LAW, Cardiff, Wales, 2004.

Who's at the keyboard? Authorship attribution in digital evidence investigations. International journal of digital evidence, v.4, n.1, 2005.

Best practices and admissibility of forensic author identification. Brooklyn law school. Journal of law and policy, n.2, vol. XXI, p.467-494, 2013.

CHESHIRE, J. Sex and gender in variationist research. In: CHAMBERS, J. K., J., TRUDGILL, P.; SCHILLING-ESTES, N. (eds.). The handbook of language variation and change. Malden, MA: Blackwell, 2004.

COBLEY, P . The Routledge companion to Semiotics and Linguistics. London/New York: Routledge, 2005.

CORNEY, M. W. Analysing e-mail text authorship for forensic purposes. 2003. $165 \mathrm{f}$. Tese (Master of Information Technology) - Queensland University of Technology, Brisbane, 2003.

COULMAS, F. Writing systems: an introduction to their linguistics analysis. Cambridge: Cambridge University Press, 2003.

COULTHARD, M.; JOHNSON, A. An introduction to forensic linguistics: language in evidence. London/New York: Routledge, 2007.

COULTHARD, M; GRANT, T.; KREDENS, K. Forensic Linguistics. In: WODAK, R.; JOHNSTONE, B.; KERSWILL, P. (eds.). The SAGE handbook of Sociolinguistics. SAGE Publications, 2010.

COULTHARD, M. On the use of corpora in the analysis of forensic texts. International journal of speech language and the law, v. 1, n.1, 1994.

. Linguistas como peritos/as. Linguagem em (dis)curso - LemD, Tubarão, v. 4, n.esp, p. 159-176, 2004a.

Author identification, idiolect and linguistic uniqueness. 2004b. Disponível em $<$ http://www.business-

english.ch/downloads/Malcolm\%20Coulthard/AppLing.art.final.pdf>. Acesso em 28/07/2010.

Some forensic applications of descriptive linguistics. 2005. Disponível em $<$ http://www.business-

english.ch/downloads/Malcolm20Coulthard/Forensic.applications.pdf>. Acesso em 28/07/2010. 
... and then ... Language description and author attribution. 2006. Disponível em < http://www1.aston.ac.uk/lss/staff/coulthardm>. Acesso em 28/07/2010.

Experts and opinions: in my opinion. In: COULTHARD, M.; JOHNSON, A. (eds.).

The Routledge handbook of forensic linguistics. London; New York: Routledge, 2010.

Early famous cases of disputed authorship. INTERNATIONAL SUMMER SCHOOL IN FORENSIC LINGUISTIC ANALYSIS, 12, Barcelona. Informação oral/Slides de aula. Barcelona: Universitat Pompeu Fabra/International Association of Forensic Linguists, 2012.

COUlTHARD, M.; HAGEMEYER, C. Perigo, cuidado, atenção: a comunicação linguística de risco em advertências de produtos. Cadernos de linguagem e sociedade, v. 2, n. 14, 2013.

COUPLAND, N. Style-shifting in a Cardiff work-setting. Language in society, n.9, p.1-12, 1980.

2001. Language, situation, and the relational self: theorizing dialect-style in sociolinguistics. In: ECKERT, P.; RICKFORD, J. R. Style and sociolinguistic variation. Cambridge: Cambridge University Press, 2001.

Style: language variation and identity. Cambridge: Cambridge University Press, 2007.

DIDIER JR, F.; BRAGA, P. S.; OLIVEIRA, R. Curso de Direito Processual Civil, vol. 2. Salvador: Podivm, 2009.

DISCINI, N. O estilo nos textos. São Paulo: Contexto, 2009.

. Estilo e corpo. 2013. 387 f. Tese (Livre-Docência) - Universidade de São Paulo, São Paulo, 2013.

DURANTI, A. Linguistic anthropology: history, ideas, and issues. In: DURANTI, A. (ed.). Linguistic anthropology: a reader. Malden, MA: Blackwell, 2001.

ECKERT, P.; McCONNELL-GINET, S. Think practically and look locally: language and gender as community-based practice. Annual review of Anthropology, 21, 1992.

. Language and gender. Cambridge: Cambridge University Press, 2013.

ECKERT, P.; RICKFORD, J. R. Style and sociolinguistic variation. Cambridge: Cambridge University Press, 2001.

ECKERT, P. Jocks and burnouts: social categories and identity in the high school. New York: Teachers College Press, 1989.

Linguistic variation as social practice . Malden; Oxford: Blackwell, 2000.

Style and social meaning. In: ECKERT, P.; RICKFORD, J. R. Style and sociolinguistic variation. Cambridge: Cambridge University Press, 2001. 
. Three waves of variation study: the emergence of meaning in the study of sociolinguistic variation. The annual review of Anthropology, 41. Disponível em $<$ anthro.annualreviews.org>, 2012.

Third wave variation studies. [20--?]. Disponível em $<$ http://www.stanford.edu/ eckert/thirdwave.html>. Acesso em 19/10/2010.

EHRHARDT, S. Forensic Linguistics / Authorship Identification. In: BIJHOLD, J. et al. (eds.). Electronic evidence: forensic audio and visual evidence. 2007. Disponível em $<$ https://www.interpol.int/Public/Forensic/IFSS/meeting15/Papers03.pdf $>$. Acesso em 18/09/2012.

EDWARDS, J. Identity, the individual and the group; Language, dialect and identity. In: Language and identity: an introduction. New York: Cambridge, 2009.

FACEBOOK. Disponível em <https://www.facebook.com/>.

FBI (2008). FBI 100: the Unabomber. Disponível em <http://www.fbi.gov/news/stories/2008/april/unabomber_042408>. Acesso em 19/02/2103.

FIORIN, J. L. Elementos de análise do discurso. São Paulo: Contexto, 2005.

Em busca do sentido: estudos discursivos. São Paulo: Contexto, 2008.

A noção de texto na Semiótica. Artigo em *.pdf. [S.l.: s.n.] [20--?].

FISHMAN, P. Conversational insecurity. In: GILES, H.; ROBINSON, W.P.; SMITH, P. Language: social psychological perspectives. Oxford: Pergamon Press, 1980.

FONTANILLE, J.; ZILBERBERG, C. Tensão e significação. Trad. Ivã Carlos Lopes; Luiz Tatit; Waldir Beividas. São Paulo: Discurso Editorial/Humanitas, 2001.

FOULKES, P.; FRENCH, J.P. Forensic phonetics and sociolinguistics. In: MESTHRIE, R. Concise encyclopedia of Sociolinguistics. Oxford, UK: Elsevier, 2001.GIBBONS, J. Forensic Linguistics: an introduction to language in the justice system. Malden, MA, USA; Oxford, UK; Melbourne, Australia; Berlin, Germany: Blackwell, 2003.

Towards a framework for communication evidence. The international journal of speech, language and the law, Equinox, v.18, n.2, 2011.

GILES, H. Accent mobility: a model and some data. Anthropological Linguistics, n. 15, p. 87105, 1973.

GILES, H; POWESLAND, P. F. Speech style and social evaluation. London: Academic Press, 1975.

GOFFMAN, E. A representação do eu na vida cotidiana. Petrópolis: Vozes, 2002 [1959]. 
GRANT, T. Text messaging forensics: Txt $4 \mathrm{n} 6$ - idiolect free authorship analysis?. In: COULTHARD, M.; JOHNSON, A. (eds.). The Routledge handbook of forensic linguistics. London; New York: Routledge, 2010.

Approaching questions in forensic authorship analysis. In: GIBBONS, John; TURELL, M. Teresa (eds.). Dimensions of forensic linguistics. Amsterdam; Philadelphia, PA: John Benjamins, 2008.

Quantifying evidence in forensic authorship analysis. The international journal of speech, language and the law, Equinox, v.14, n.1, 2007.

Authorship attribution in a forensic context. 2004. 410 f. Tese (PhD) University of Birmingham, Birmingham, 2004.

. TXT 4N6: method, consistency, and distinctiveness in the analysis of SMS text messages. Journal of law and policy, n.2, vol. XXI, p.467-494, 2013.

GRANT, T.; BAKER, K. Identifying reliable, valid markers of authorship: a response to Chaski. Forensic linguistics, Birmingham: University of Birmingham, v.8, n.1, 2001.

GRANT, T; NINI, A. Applying Systemic Functional Linguistics (SFL) to authorship tasks. INTERNATIONAL SUMMER SCHOOL IN FORENSIC LINGUISTIC ANALYSIS, 14, Birmingham. Informação oral/Slides de aula. Birmingham: Aston University/International Association of Forensic Linguists, 2014.

GRANT, T.; MACLEOD, N. Whose Tweet? Authorship analysis of micro-blogs and other short-form messages. In: THE INTERNATIONAL ASSOCIATION OF FORENSIC LINGUISTS' TENTH BIENNIAL CONFERENCE, 2011, Birmingham. Proceedings. Birmingham: Centre for Forensic Linguistics, 2012.

Providing analysis and training for linguistic identity disguise. BIENNIAL

CONFERENCE ON FORENSIC LINGUISTICS/LANGUAGE AND LAW OF THE INTERNATIONAL ASSOCIATION OF FORENSIC LINGUISTS, 11. Comunicação Oral. Cidade do México, 2013.

GREEN, D.; PALUCK, E. Double-blind procedure. In: LEWIS-BACK, M.; BRYMAN, A.; LIAO, T. The SAGE encyclopedia of social science research methods. Vol. 1. Thousand Oaks, California: SAGE Publications, 2003.

GREIMAS, A. J. Semiótica e Ciências Sociais. São Paulo: Cultrix, 1981 [1976]

GREIMAS, A. J.; COURTÉS, J. Sémiotique: dictionnaire raisonné de la théorie du langage. Paris: Hachette, 1979.

Dicionário de semiótica. São Paulo: Cultrix, 2008.

GREIMAS, A. J.; FONTANILLE, J. Semiótica das paixões: dos estados de coisas aos estados de alma. São Paulo: Ática, 1993. 
GRIEVE, J. Quantitative authorship attribution: a history and an evaluation of techniques. 2005. 141 f. Dissertação (Master of Arts) - Simon Fraser University, Burnaby, Canadá, 2005.

2007. Quantitative authorship attribution: an evaluation of techniques. Literary and Linguistic Computing, v. 22, n. 3, 2007. p. 251-270.

GRIEVE, J. Linguistic profiling in forensic contexts. INTERNATIONAL SUMMER SCHOOL IN FORENSIC LINGUISTIC ANALYSIS, 14, Birmingham. Informação oral/Slides de aula. Birmingham: Aston University/International Association of Forensic Linguists, 2014.

HARKOT-DE-LA-TAILLE, E. Ethos e autoria. In: III SIMPÓSIO INTERNACIONAL SOBRE ANALISE DO DISCURSO: EMOCÕES, ETHOS E ARGUMENTACÃO, 2008, Belo Horizonte. Anais. Belo Horizonte: UFMG, 2008. v. 1.

HERRING, S.C.; PAOLILLO, J. C. Gender and genre variation in weblogs. Journal of Sociolinguistics, v. 10, n. 4, 2006. p. 439-459.

HJELMSLEV, L. Prolegômenos a uma teoria da linguagem. São Paulo: Perspectiva, 2003 [1943].

HOLMES, D. The evolution of Stylometry in Humanities scholarship. Literary and linguistic computing, vol. 13, n. 3, 1998.

HOLMES, J.; MEYERHOFF, M. (eds.). The handbook of language and gender. Maiden, MA: Blackwell, 2003.

HONORÉ, A. Some simple measures of richness of vocabulary. ALLC Bulletin, vol. 7, n. 2, 1979, p. 172-177.

IRVINE, J. T. Style as distinctiveness: the culture and ideology of linguistic differentiation. In: ECKERT, P.; RICKFORD, J. (eds.). Style and sociolinguistic variation. Cambridge: Cambridge University Press, 2001.

JOHNSTONE, B. The individual voice in language. The annual review of Anthropology, 29, 2000. p. 405-424.

JUOLA, P. Questioned electronic documents: empirical studies in authorship attribution. In: OLIVIER \& SHENOI (eds.). Research advances in digital forensics II. Heidelberg: Springer, 2006.

KIESLING, S. Language, gender, and power in fraternity men's discourse. 1996. 403 f. Ph.D. Dissertation (Doutorado) - Georgetown University, Washington, DC, 1996.

Men's identities and sociolinguistic variation: the case of fraternity men. Journal of Sociolinguistics, v. 1, n. 2, 1998. p. 69-99.

Style as stance: stance as the explanation for patterns of sociolinguistic variation. In: JAFFE, A. (ed.). Stance: sociolinguistic perspectives. Oxford: Oxford University Press, 2009. 
KOPPEL, M. et al. Automatically categorizing written texts by author gender. Literary and linguistic computing, v.17, 2002. p. 401-412.

KREDENS, K. Towards a corpus-based methodology of forensic authorship attribution: a comparative study of two idiolects. In: LEWANDOWSKA-TOMASZCZYK, B. (ed.) PALC'01 - Practical applications in language corpora. Peter Lang: Frankfurt am Mein, 2002a.

Idiolect in forensic authorship attribution. Folia linguistica anglica, Lodz: University of Lodz Press, 4, 2002b.

Introduction to forensic authorship analysis: defining the scope of Forensic Linguistics. INTERNATIONAL SUMMER SCHOOL IN FORENSIC LINGUISTIC ANALYSIS, 12, Barcelona. Informação oral/Slides de aula. Barcelona: Universitat Pompeu Fabra/International Association of Forensic Linguists, 2012.

LABOV, W.; HARRIS, W. A. Addressing social issues through linguistic evidence. In: GIBBONS, John. Language and the Law. London; New York: Longman, 1994.

LABOV, W. Padrões Sociolinguísticos. São Paulo: Parábola, 2008.

The social stratification of English in New York City. São Paulo: Cambridge University Press, 2006 [1966].

The judicial testing of linguistic theory. In: TANNEN, D. (ed.). Language in context: connecting observation and understanding. Norwood: Ablex, 1988. p. 159-182.

The isolation of contextual styles. In: Sociolinguistic patterns. Philadelphia: University of Pennsylvania Press, 1972.

The social motivation of a sound change. Word, n. 18, p. 1-42, 1963.

LAKOFF, R. Language and women's place. New York: Harper \& Row, 1975.

LEONARD, R. Applying the scientific principles of language analysis to issues of the Law.

International Journal of the Humanities, v.3, 2005.

LILLIS, T. The sociolinguistics of writing. Edinburgh: Edinburgh University, 2013.

LOVE, H. Attributing authorship: an introduction. Cambridge: Cambridge University, 2002.

MANZANO, L. F. M. Prova pericial: admissibilidade e assunção da prova científica e técnica no processo brasileiro. São Paulo: Atlas, 2011.

MARQUILHAS, R.; CARDOSO, A. O estilo do crime: análise de texto em estilística forense. In: XXVII ENCONTRO NACIONAL DA ASSOCLAÇÃO PORTUGUESA DE LINGUÍSTICA, 2012, Lisboa. Textos Selecionados. Lisboa: APL, 2012. 
McMENANIN, G. R. Forensic stylistics: theory and practice of forensic stylistics. In: COULTHARD, M.; JOHNSON, A. (eds.). The Routledge handbook of Forensic Linguistics. London; New York: Routledge, 2010.

Forensic Linguistics: advances in forensic stylistics. Boca Raton, Florida, USA: CRC Press, 2002.

MENDES, R. B. Diminutivos como marcadores de sexo/gênero. Revista Linguística/Revista do programa de pós-graduação em Linguística da Universidade Federal do Rio de Janeiro. vol 8, n. 1, junho de 2012.

MEYERHOFF, M. Communities of Practice. In: CHAMBERS, J.K.; TRUDGILL, P.; SCHILLING-ESTES, N. (orgs). The handbook of language variation and change. Oxford; Malden, MA: Blackwell, 2001.

MILROY, L. Language and social networks. Oxford: Blackwell, 1980.

MILROY, J. et al. Glottal stops and Tyneside glottalization: competing patterns of variation and change in British English. Language variation and change v. 6, n. 3, p. 327-357, p. 1994.

NINI, A. Authorship profiling as a diagnosis process. BIENNIAL CONFERENCE ON FORENSIC LINGUISTICS/LANGUAGE AND LAW OF THE INTERNATIONAL ASSOCIATION OF FORENSIC LINGUISTS, 11. Comunicação Oral. Cidade do México, 2013.

OCHS, E. Indexing gender. In: DURANTI, A.; GOODWIN, C. Rethinking context. Cambridge: Cambridge University Press, 1991.

O’DONNELL, 2007. UAM Corpus Tool. Versão 3.1.12. Disponível em <http://www.wagsoft.com/CorpusTool/download.html>. Acesso em 20/07/2014.

OLSSON, J. Forensic linguistics: an introduction to language, crime, and the Law. London; New York: Continuum, 2004.

The language detective: forensic linguistics first certificate course. The Forensic Linguistics Institute, 2008a. Livro digital.

Forensic Linguistics: second edition. London; New York: Continuum, 2008b.

PODESVA, R. et al. Sharing resources and indexing meanings in the production of gay styles. In: CAMPBELL-KIBLER et al (eds.) Language and sexuality: contesting meaning in theory and practice. s.l.: CSLI Publications, 2001.

REZENDE, R. Estilo sociolinguístico como recurso de construção de personas sociais: um exercício de análise do conto "começo", de Rubem Fonseca. Revista eletrônica Via Litterae, Anápolis, v.1, n.1, p. 119-137, 2009.

ROMAINE, S. Variation in language and gender. In: HOLMES, J.; MEYERHOFF, M. (eds.).

The handbook of language and gender. Maiden, MA: Blackwell, 2003. 
RUDMAN, J. The state of authorship attribution studies: some problems and solutions. Computers and the humanities, Kluwer Academic, 31, p. 351-365, 1998.

SAPIR, E. Speech as a personality trait. American journal of Sociology, 32, p. 892-905, 1927.

Language. New York: Harcourt, Brace and Company, 1949.

SARDINHA, T. B. Linguística Forense. In: Pesquisa em Linguística de Corpus com WordSmith Tools. Campinas, SP: Mercado de Letras, 2009.

SAUSSURE, F. Natureza do signo linguístico. In: Curso de Lingüística geral. São Paulo: Cultrix, 2002 [1916].

SCHILLING-ESTES, N. Investigating stylistic variation. In: CHAMBERS, J.K.; TRUDGILL, P.; SCHILLING-ESTES, N. (orgs). The handbook of language variation and change. Oxford; Malden, MA: Blackwell, 2001.

SHUY, R. Forensic linguistics. In: ARONOFF, Mark; REES-MILLER, Janie (eds.). The handbook of Linguistics. Oxford: Blackwell, 2001. p. 683-691.

Linguistic profiling when there is no known murder suspect. In: The language of murder cases: intentionality, predisposition, and voluntariness. New York: Oxford University Press, 2014.

SILVA, C. As cartas de Chico Xavier: uma análise semiótica. 2012. 191 f. Dissertação (Mestrado) - Universidade Estadual Paulista "Júlio de Mesquita Filho, Araraquara, 2012.

SILVA, R. Lista de frequência de palavras como marcadores de estilo no reconhecimento de autoria. In: CARDOSO, N. et al. (eds.) Perspectivas sobre a Linguateca. S.l.: Linguateca, 2008. Disponível em <http://comum.rcaap.pt/bitstream/123456789/132/1/Cap13Costaetal2008-SousaSilva.pdf>. Acesso em: 11/09/2010.

SILVA, R. et al. 'twazn me!!! ;(' Automatic Authorship Analysis of Micro-Blogging Messages. In: MUÑOZ, R. et al. (Eds.). In: 16th INTERNATIONAL CONFERENCE ON APPLICATIONS OF NATURAL LANGUAGE TO INFORMATION SYSTEMS, 2011, Alicante, Spain. Proceedings. 2011.Disponível em < http://paginas.fe.up.pt/ niadr/PUBLICATIONS/2011/Twitter-NLDB2011.pdf>. Acesso em 30/07/2012.

SILVA, N.; DIAS, M. Social identity in Brazilian drug trafficking. INTERNATIONAL CONFERENCE LANGUAGE AND LAW IN SOCIAL PRACTICE, 3. Comunicação Oral. Caserta, Itália, 2014.

SOLAN, L. Intuition versus algorithm: the case of forensic authorship attribution. Brooklyn law school. Journal of law and policy, n.2, vol. XXI, p.551-576, 2013.

SOLAN, L; TIERSMA, P. M. Speaking of crime: the language of criminal justice. Kindle edition. Chicago; London: The Univesity of Chicago, 2005. 
STORER, W. H. Questioned documents. In: ECKERT, William G. Introduction to forensic sciences. New York: Elsevier, 1992.

STROHMETZ, D.; ROSNOW; R. Artifacts in research process. In: LEWIS-BACK, M.; BRYMAN, A.; LIAO, T. The SAGE encyclopedia of social science research methods. Vol. 1. Thousand Oaks, California: SAGE Publications, 2003.

SVARTVIK, J. The Evans statements: a case for forensic linguistics. Brandenburgo: University of Brandenburgo, 1968.

TAMBOURATZIS, G. et al. Discriminating the registers and styles in the modern Greek language, part 2: extending the feature vector to optimize author discrimination. Literary $\boldsymbol{\&}$ linguistic computing, 19(2), 2004. p. 221-242.

TATIT, L. Análise semiótica através das letras. São Paulo: Ateliê Editorial, 2001

TANNEN, D. You just don't understand: women and men in conversation. New York: Ballantine, 1990.

TIERSMA, P. What is forensic linguistics? [20--?]. Disponível em http://www.languageandlaw.org/FORENSIC.HTM>. Acesso em 25/08/2013.

TOMBLIN, S. Investigating formulaic language as a marker of authorship. In: THE INTERNATIONAL ASSOCIATION OF FORENSIC LINGUISTS' TENTH BIENNIAL CONFERENCE, 2011, Birmingham. Proceedings. Birmingham: Centre for Forensic Linguistics, 2012.

TRUDGILL, P. The social stratification of English in Norwich. Cambridge: Cambridge University Press, 1974.

TURELL, M. T. Idiolectal similitude (or distance) in authorship analysis. INTERNATIONAL SUMMER SCHOOL IN FORENSIC LINGUISTIC ANALYSIS, 12, Barcelona. Informação oral/Slides de aula. Universitat Pompeu Fabra/International Association of Forensic Linguists, 2012.

The use of textual, grammatical and sociolinguistic evidence in forensic text comparison. The international journal of speech, language and the Law, Equinox, 17.2, p.211-250, 2010.

TURELL, M. T.; GAVALDÀ, N. Towards an index of idiolectal similitude (or distance) in forensic authorship analysis. Brooklyn law school. Journal of law and policy, n.2, vol. XXI, p.495-514, 2013.

TWITTER. Disponível em <https://twitter.com/>.

VARELA, P. et al. Identificação de autoria de textos atravéss do uso de classes Linguísticas da Língua Portuguesa. In: 8th BRAZILIAN SYMPOSIUM IN INFORMATION AND HUMAN LANGUAGE TECHNOLOGY, 2011, Cuiabá, MT, Brazil. Proceedings. Cuiabá, MT, Brazil:, 2011. 
WAMBIER, L. R.; TALAMINI, Eduardo. Curso avançado de processo civil, volume 1. São Paulo: Revista dos Tribunais, 2011.

WEINREICH, U.; LABOV, W.; HERZOG, M. I. Fundamentos empíricos para uma teoria da mudança linguística. São Paulo: Parábola, (2006 [1968]).

WINTER, E.; WOOLLS, D. Identifying authorship in a co-written novel. Internal report for the University of Birmingham, 1996.

WOOLLS, D.; COULTHARD, M. Tools for the trade. Forensic Linguistics. Birmingham: University of Birmingham, n.5, v.1, 1998.

ZILBERBERG, C. Louvando o acontecimento. Revista Galáxia, Tradução de Maria Lucia Vissotto Paiva Diniz. São Paulo, n. 13, p. 13-28, jun. 2007. $2006 a$ Síntese da gramática tensiva. Revista Significação, São Paulo: Annablume, n.25,

Razão e poética do sentido. Tradução de Ivã Carlos Lopes; Luiz Tatit; Waldir Beividas. São Paulo: Edusp, 2006b.

Eléments de grammaire tensive. Limoges: Pulim, 2006c.

ZIPF, G. K. Selected studies of the Principle of Relative Frequency in language. Cambridge, Massachusetts: Harvard University Press, 1932.

The psycho-biology of language. Boston: Houghton Mifflin Co., 1935.

Human behavior and the principle of least effort. Cambridge, Massachusetts: Harvard University press, 1949. 


\section{APÊNDICES}

APÊNDICE A - Design dos esquemas de análise semiótica no Corpus Tool

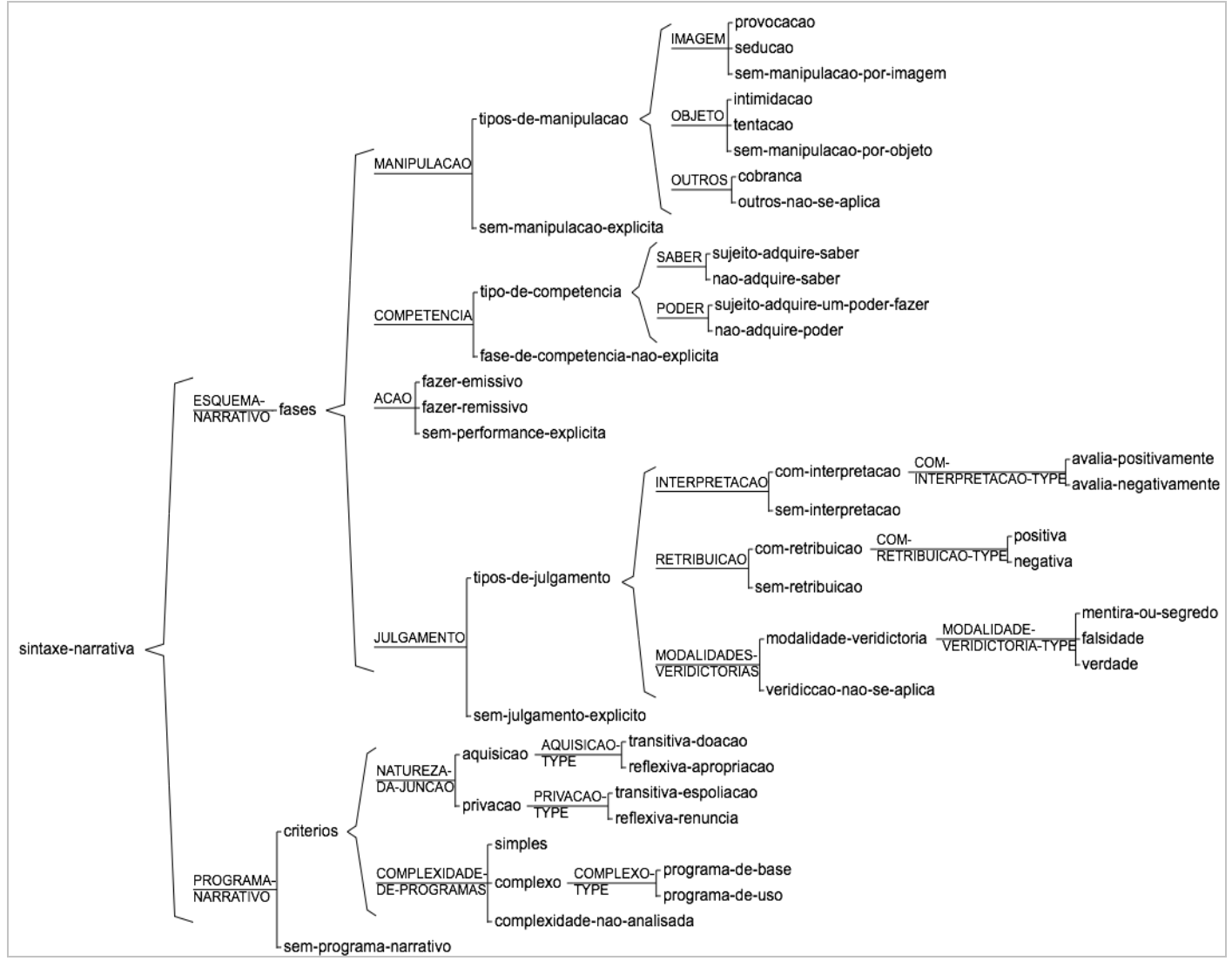

Figura 29 - Sintaxe narrativa 


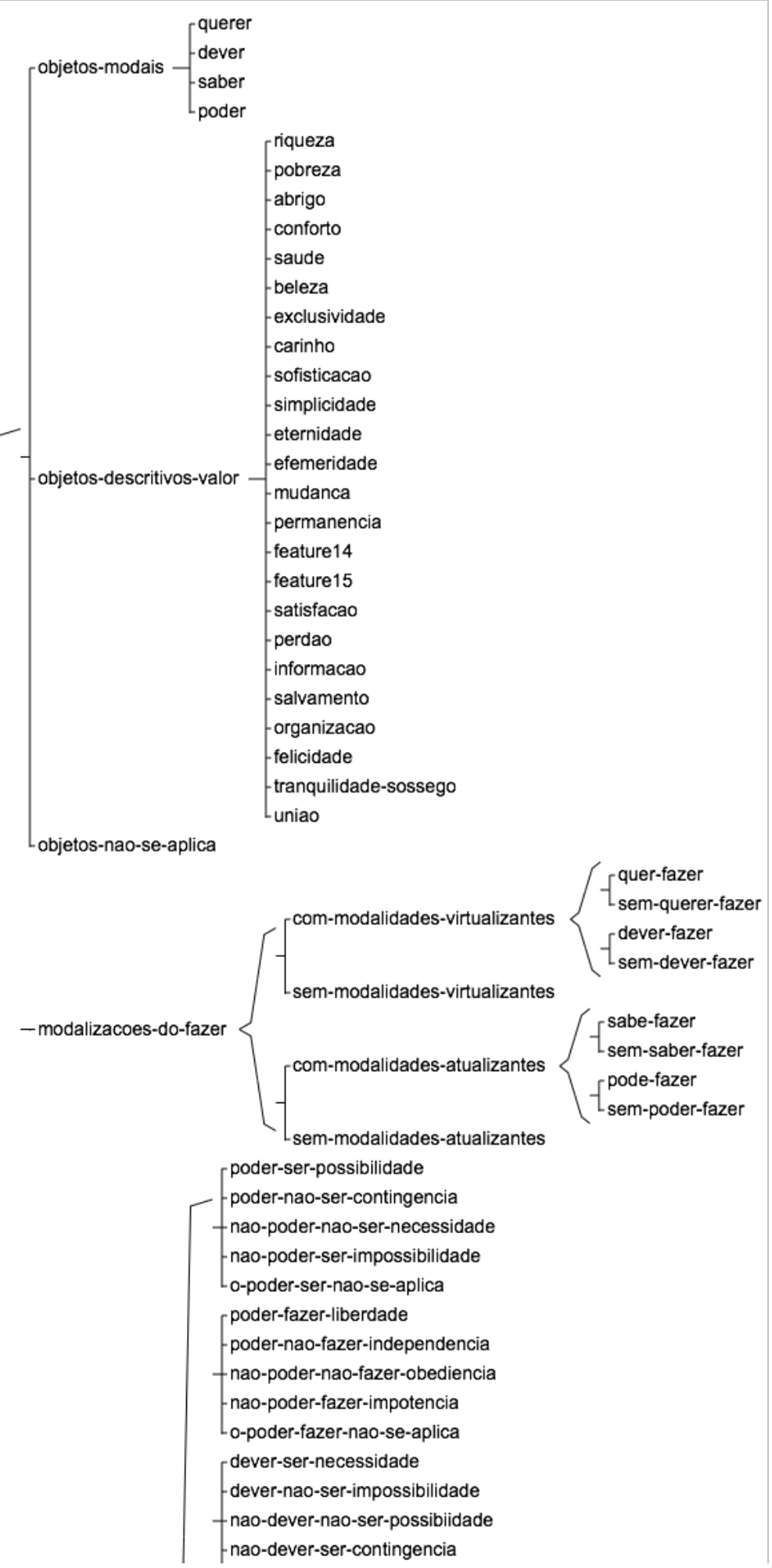

Figura 30 - Semântica narrativa I 


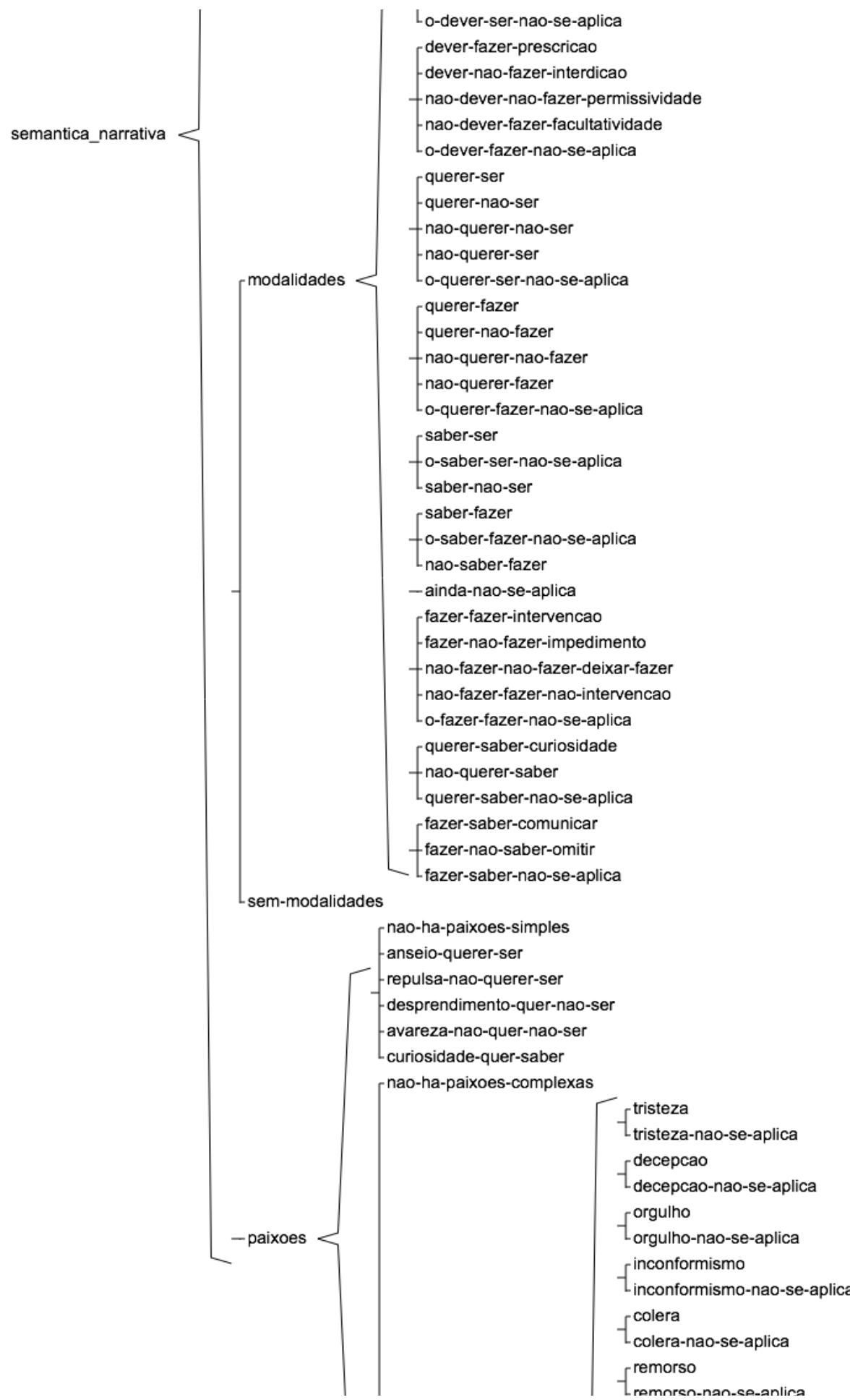

Figura 31 - Semântica narrativa II 


L.

Figura 32 - Semântica narrativa III 


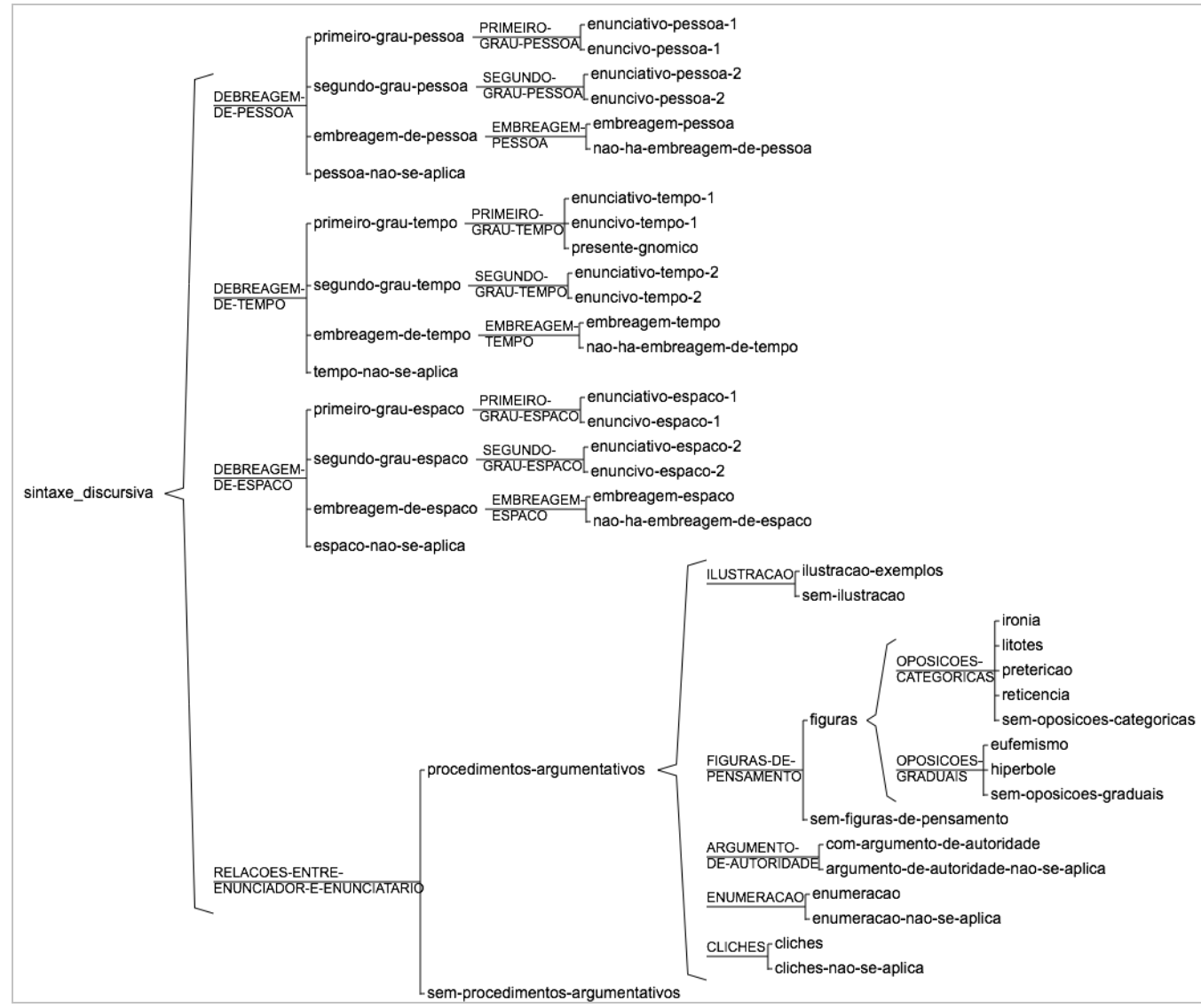

Figura 33 - Sintaxe discursiva 


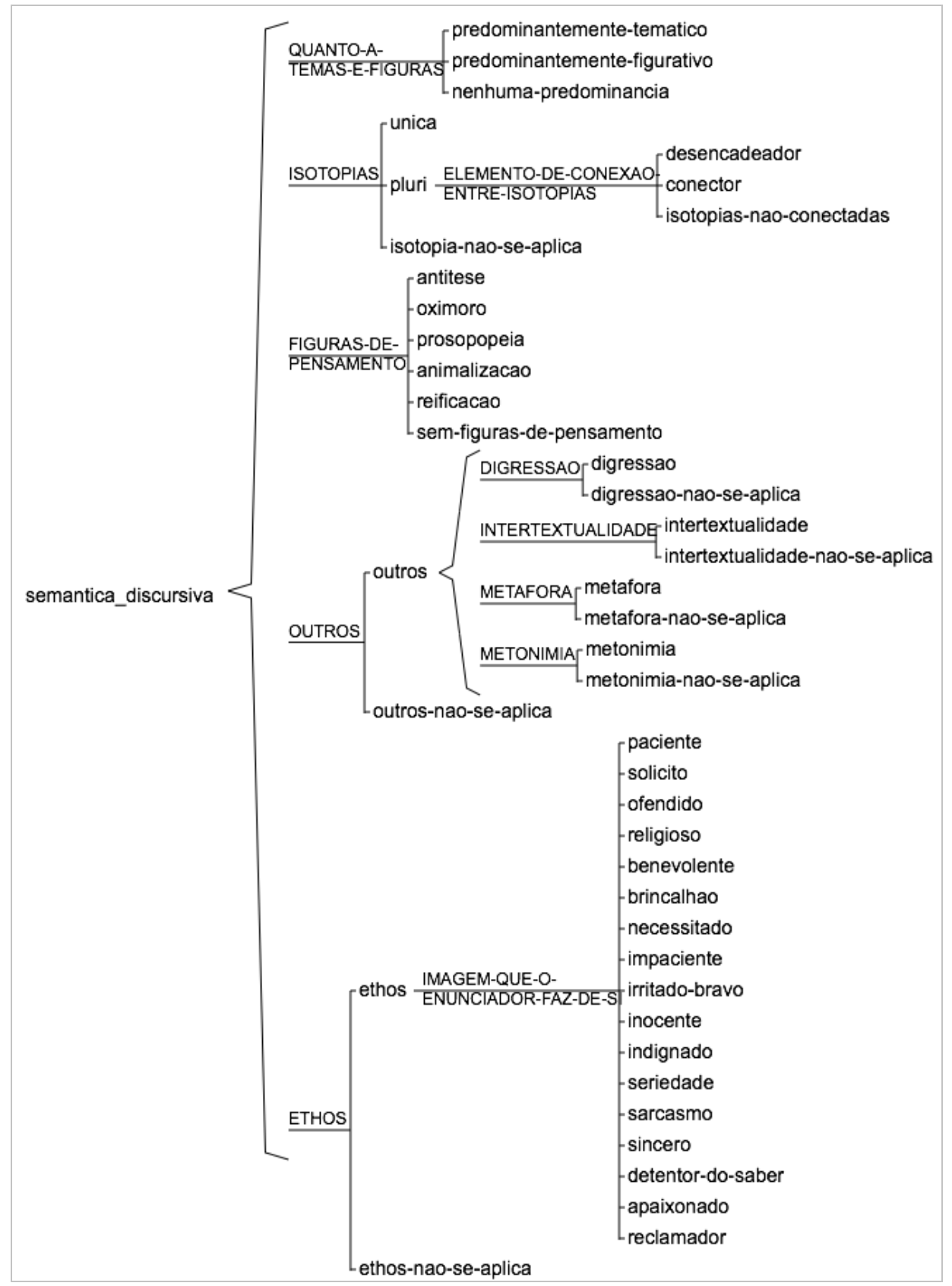

Figura 34 - Semântica discursiva 


\begin{tabular}{|c|c|}
\hline nivel_fundamental $\frac{\text { CATEGORIAS- }}{\text { SEMANTICAS-BASICAS }}$ & $\begin{array}{l}\text { morte-e-vida } \\
\text {-opressao-e-liberdade } \\
\text {-identidade-e-alteridade } \\
\text { - bem-e-mal } \\
\text {-errado-e-certo } \\
\text {-ainda-nao-depreendida } \\
\text {-inutil-e-util } \\
\text {-descaso-e-colaboracao } \\
\text {-compromisso-e-isencao } \\
\text { relevante-e-irrelevante } \\
\text {-trivial-e-raro } \\
\text {-amor-e-odio } \\
\text {-mudanca-e-permanencia } \\
\text {-zelo-e-descuido } \\
\text {-felicidade-e-tristeza } \\
\text {-pobreza-e-riqueza } \\
\text {-conhecimento-e-ignorancia } \\
\text {-competencia-e-incompetencia } \\
\text { bom-e-ruim }\end{array}$ \\
\hline
\end{tabular}

Figura 35 - Nível fundamental 


\begin{tabular}{|c|c|}
\hline tensividade & 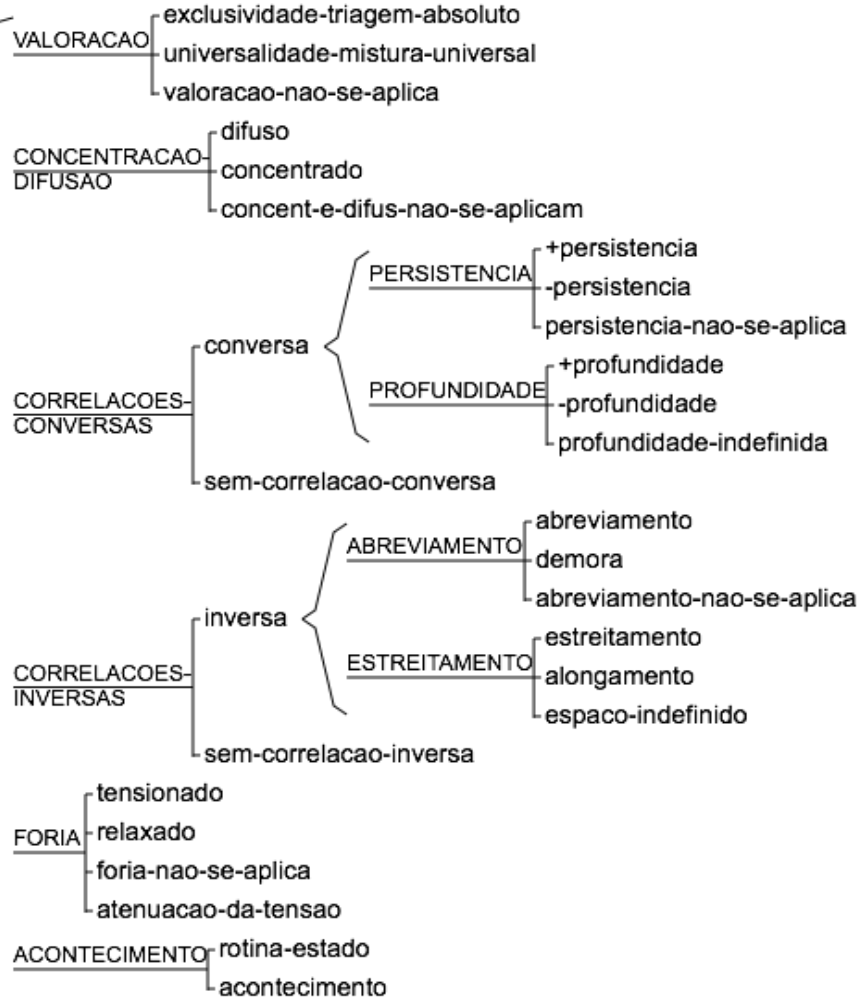 \\
\hline
\end{tabular}

Figura 36 - Tensividade 
APÊNDICE B - Declaração de autorização para uso dos textos coletados para o CGAA

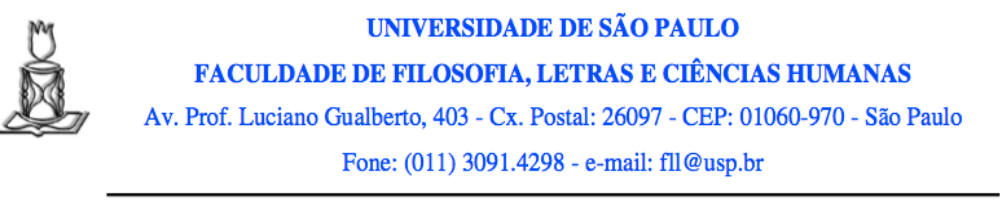

DECLARAÇÃo

$\mathrm{Eu}$,

RG nr.: declaro ter autorizado o uso de textos

escritos por mim, incluindo aqueles escritos em redes sociais online, na Pesquisa de Doutorado desenvolvida por Dayane Celestino de Almeida, na Universidade de São Paulo, sob orientação do Prof. Dr. Ronald Beline Mendes. Estou ciente de que tais textos podem ser utilizados também em futuros estudos linguísticos. Entendo que meus dados pessoais não serão tornados públicos na divulgação das pesquisas.

de de 2012. 
APÊNDICE C - Ficha do Informante (ficha entregue aos informantes que participam do CGAA

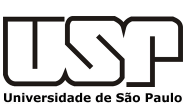

FICHA DO INFORMANTE

Pesquisadora: Dayane Celestino de Almeida

Nome Completo:

Data de Nascimento:

Telefone:

E-mail:

Estado de Residência

Cidade de Residência:

Bairro de Residência:

Estado de Nascimento:

Cidade de Nascimento:

Escolaridade:

Nenhuma

Ensino Fundamental Incompleto

Ensino Fundamental Completo

Ensino Médio Incompleto

Ensino Médio Completo

Superior Incompleto

Superior Completo

Pós Graduação

Tipo de Ensino:

Fundamental:

Médio:

Público( ) Privado (

Público ( ) Privado ( )

Público ( ) Privado (

Superior
Profissão:

Já exerceu outra profissão? Qual?

Dados do Pai:

-Idade:

-Profissão:

-Escolaridade:

-Naturalidade:

Dados da Mãe:

-Idade:

-Profissão:

-Escolaridade:

-Naturalidade:

\section{Com relação ao parâmetro "Classe Social",}

você se considera:

Classe A ou B

( )

( )

( )

( )

( )

( )

( ) ara uso do Pesquisador

Textos coletados em

p.1 Qtd. de textos deste informante: 


\section{ANEXOS}

\section{ANEXO A - Textos da análise qualitativa do capítulo 4}

\section{- Textos CONHEcidos}

\section{Texto 1: Post no Facebook}

Afinal, quero saber: agora que você já é mãe e o Jonas já é pai, já devem saber a resposta. É possível deixar a pequena por algumas horinhas para jogar boliche daqui uns meses ou isso é muito ilusório?!? rsssss

Precisamos saber para gastarmos o groupon: Sabrina, Marcos, Jonas, Jane, Leandro: o boliche rola ou não rola até antes de 28/08?!? rssss

Eu acho que o groupon dos pais está perdido.... Nao largarão da pequena!!! hihihi

Texto 2: Post no Facebook

Nossa Jane... não gostei nada nada do filme... Xinguei-te mentalmente algumas vezes, tá? (hauhauhuaha) Mas aqueles que vc emprestou eu gostei!!! Só nao gostei do chapeuzinho vermelho sexy... Agora quero assistir American Pie!!! hihi Bjinhos

Texto 3: E-mail profissional

Dr. Mário,

Conforme conversamos ao telefone no mês passado, por duas vezes, em novembro e dezembro, a Reclamada já havia depositado o valor do acordo com atraso.

Solicitei ao Dr. que orientasse a Empresa para que não mais houvesse atraso, havendo de minha parte certa tolerância quanto aos atrasos.

Contudo, mesmo após sua orientação, a empresa novamente deixa de depositar na data acordada. 
Deveria ter depositado em 30/12/2010. Não o fez. Assim, aguardei até o primeiro dia útil do ano, dia 02 , data em que não houve o depósito.

Assim, não havendo o depósito do acordo até a presente data, requeiro o depósito da quantia de $\mathrm{R} \$ 400,00$ + a multa, que de forma 'extrajudicial', concordaria com a incidência apenas sobre esta parcela em atraso (e não sobre o total restante, conforme ata).

Assim, peço a gentileza de que o Dr. novamente oriente a empresa quanto aos atrasos e, a parcela que deveria ser depositada no dia $30 / 12 / 2010$ seja depositada hoje, no valor de $\mathrm{R} \$ 400,00+\mathrm{R} \$ 200,00$ de multa (total: $\mathrm{R} \$ 600,00)$.

Caso seja necessário peticionar nos autos, lembra-se que a multa será no valor de $\mathrm{R} \$ 600,00$ (total em atraso $\mathrm{R} \$ 1.200,00$ ).

Lembrando que constam como pagamentos em aberto os seguintes vencido e vincendos:

$8^{a}$ parcela, no valor de $\mathrm{R} \$ 400,00$, em 30/12/2011.

$9^{a}$ parcela, no valor de $\mathrm{R} \$ 400,00$, em 30/1/2012.

$10^{a}$ parcela, no valor de $\mathrm{R} \$ 400,00$, em 29/2/2012.

Multa de 50\% sobre o valor em aberto, em caso de inadimplemento, sem prejuízo de juros e correção monetária.

Obrigada.

Texto 4: Post no Facebook

\section{TREM DA ALEGRIA DOS CARTÓRIOS}

Para entender: a partir de 1988 (acreditem se quiser) os Cartórios deveriam ser assumidos por bacharéis em Direito (em regra) aprovados em concurso público de provas e títulos. Como nosso Brazilsão é ^\%@^\$\%\&*@^(*\#, até hoje existem "donos de cartório" por "herança de família", sem concurso público.

Aos poucos os Estados vão realizando os concursos para substituirmos e...sse povo.

Massssssssss "se liga" na nossa querida CAMARA DOS DEPUTADOS:

ELES QUEREM APROVAR UMA EMENDA CONSTITUCIONAL (UMA "LEI", PARA OS LEIGOS) PROPONDO QUE, QUEM ESTÁ LÁ SEM CONCURSO, TENHA O DIREITO DE FICAR!!!! 


\section{FICA AÍ NA MEMÓRIA PARA VOCÊ GUARDAR A INFO NO DIA DE VOTAR:}

Proposta apresentada por João Campos-PSDB (ABSURDO!)

Únicos que votaram contra: PPS, PV e PSOL!!!!!!! (Ganharam meu voto!!)

\section{Texto 5: Texto de blog}

Quando iniciei na advocacia, há aproximadamente três anos atrás, eu tinha uma idéia formada sobre divórcios e, na época, separações.

Estagiei no Ministério Público e na Defensoria Pública, assim, já havia acompanhado alguns processos de divórcio.

Eu acreditava que sabendo a letra da lei, tudo estaria resolvido.

Mas, trabalhar com divórcios, vai muito além do previsto na legislação...

Alguns entram ali apenas para conversar e contar os problemas. Ter um apoio quase que espiritual, já que nestes casos, mostra-se ausente o apoio da família.

Outros ali ingressam com muita paz e harmonia, certo da decisão que estão prestes a firmar e tudo se resolve na tranquilidade e calmaria. Mas, obviamente, este grupo é minoria.

O desgaste emocional que gera um divórcio é imensurável. O advogado, que participa de toda elaboração, não consegue ficar à margem da situação. Os filhos então... estes são o grande alvo de toda bagunça instalada.

Quando ainda sem a minha experiência pessoal no caso, costumava aconselhar pais, ouvir filhos e buscar uma harmonia.

Agora vejo que não se busca a harmonia em casais que não a querem, não a buscam, não a almejam. Não se salva quem não quer ser salvo. Haverá um desgaste para todos.

Discute-se cada armário comprado - e neste momento você percebe a mesquinharia em que vivem alguns casais, que costumam guardar notas fiscais de anos atrás, já pensando em uma futura separação.

Buscam partilhar aquilo que não é seu de direito - apenas pelo objetivo de uma "falsa vingança".

Os filhos viram simples moeda de troca. Enquanto a mãe, que geralmente detem a guarda, busca o direito de pensão alimentícia, o pai, apenas para tirar-lhe a paz, ingressa com pedido de visitas, mesmo 
sabendo que irá retirar a criança e deixa-la com a avó, sem manter qualquer contato.

E a situação perdura. Perdura de forma indeterminada. Irá durar até o limite da vontade de querer viver naquela situação.

Para alguns, a mera separação de fato já encerra o ciclo.

Para outros, é necessário o documento oficial de concessão de divórcio.

E com o fim do processo, encerra-se o ciclo.

Para outros, viver no "ciclo sem fim" é a opção.

Pessoas que não fecham ciclos, não movem a vida. E isto vale para qualquer coisa, não só divórcios.

Conselho e consulta gratuita da Dra.: não estão felizes? Façam sim o divórcio. Todos tem direito à felicidade. Mas o façam de forma amigável, ainda que por intermédio de advogados diferentes de ambas as partes. Mas, após encerrado aquele processo, encerrem também o ciclo. Sacudam a poeira. Deem-se um novo ponto de partida para a felicidade.

Texto 6: E-mail profissional

Boa tarde, Mário! Tudo bom?

Precisamos de alguns dados faltantes para a conclusão do inventário:

- dígito final do RG, se houver, de Oto e Luciana, pois, como eles deram cópia da $\mathrm{CNH}$, o dígito final do RG não é mencionado. Assim, temos: Oto: RG. 11.111.111-DIGITO?; Luciana: RG. 22.222.222-DIGITO?;

- cópia do pacto antenupcial celebrado entre MÁRIO DA SILVA e JULIA SILVA, casados sob o regime da comunhão universal de bens, com pacto antenupcial (Livro 11, Fls. 111 Cartório de Xxxxx). Caso você não tenha cópia, não precisa solicitar agora, porque teremos que solicitar uma atualizada ao final deste procedimento. Mas caso você tenha uma cópia, ajudará na conclusão;

- Há uma taxa de $\mathrm{R} \$ 50,00(\mathrm{R} \$ 47,00+\mathrm{R} \$ 7,00)$ para busca de testamento+correios, que é documento indispensável para que o inventario seja feito no cartório;

- apenas para confirmar, será feita a partilha de todos os bens na proporção de $1 / 2$ para a viúva e $1 / 12$ para os demais filhos, ok?

- Vc tem conhecimento se a Rua Joao da Silva mudou a denominação para Jonas dos Santos? A numeração antiga do imovel, n. 00, mudou para 00? Estes documentos de alteração de logradouro e numeração serão necessários para a abertura da matrícula no Registro de Imóveis, quando do registro do inventário. Acredito que também será necessária a planta descrevendo os lotes vizinhos, para que fique caracterizado e especificado o imovel (já que na época da escritura a descrição era pobre, 
sem numeracao de lotes). Este ultimo documento eu não posso lhe dar certeza absoluta que o Cartorio de Yyyyyy irá exigir, já que cabe ao Registrador entender se é o caso ou não. Caso você queira providenciar os documentos para o inventario, seria mais adequado, pois ele seria feito com a certeza destes dados. Caso você não tenha interesse por ora, acredito que o Tabelião fará o inventario sem este documentos. $O$ problema é se, mais tarde, a Prefeitura de Yyyyyyy descobre que o numero do Lote é outro - teriamos que retificar o inventario.

- voce teria algum documento dos titulos de capitalizacao mais recente? Caso não tenha, não se preocupe pois teremos de qualquer forma que solicitar um mais recente ao terminarmos este primeiro passo. Mas caso tenha, eu já poderia usa-lo agora.

Quanto ao imóvel, ele possui transcrição (11 Cartorio de SP), certidão de ônus (Cartorio de Zzzzz) e Escritura (Cartorio de Xxxxxx). Atualmente, há a obrigatoriedade da MATRICULA, documento este inexistente para o imovel em questao, por ser antigo. Como lhe disse acima, o problema é que nestes documentos antigos de transcrição, a descrição do imóvel era pobre, mencionando como referência a estação de Jandira. Hoje em dia é necessario ter a descrição dos lotes confrontantes. Após a realização do inventario, para registro no imovel da nova partilha, será necessaria a regularizacao do imovel junto ao Cartorio de Yyyyy. Você provavelmente precisará das transcrições e certidões recentes (menos de 30 dias), do documento da Prefeitura localizando os lotes, informando a alteraçao de rua e de numeracao. Isto porque deve ser feito o historico do imovel, que antes era na rua Joao da Silva, numero 00 e hoje aparentemente é na rua Jonas dos Santos, n. 00. Apenas informo sobre este detalhe, ainda que a parte de abertura de matricula não faça parte do trabalho jurídico da feitura do inventario, para que tome conhecimento.

Como eu havia dito, a descricao dos lotes confrontantes eu não posso lhe dar absoluta certeza que o Cartorio de Imoveis de Yyyyy irá exigir, já que cabe a ele identificar se a descricao da transcricao é suficiente para a abertura da matricula. Eu achei que a descricao é bastante pobre, mencionando apenas a Estacao Jandira como referencia. Mas caber'a a ele identificar a necessidade ou nao de mais documentos.

Caso queira primeiro abrir a matricula, para depois fazer o inventario com a matricula aberta em nome de seu pai, também é possível. O imovel ficaria perfeitamente descrito no inventario. Fica a seu critério. Já abri matriculas depois, com o inventario pronto, sem problemas. Informações sobre abertura de matricula para este imovel, com a descricao e averbacao de mudança de logradouro e numeraçao, você pode obter junto ao Cartório de Registro de Imóveis de Yyyyy, na Alameda Arara.

Qualquer dúvida estou a disposição.

Vanessa X. Silva

Advogada 
Texto 8: Introdução do Trabalho de Conclusão de Curso

Nesse trabalho iremos analisar o tipo penal previsto na Lei de Crimes Ambientais (Lei n.o9.605/98), que prevê a conduta de praticar atos de abuso, maus tratos, ferir ou mutilar animais.

Sendo assim, iremos abranger neste trabalho este bem jurídico tão importante, de uso comum do povo: o meio ambiente.

No primeiro capítulo iremos conceituar e esclarecer as diferenças entre os direitos coletivos: os direitos coletivos stricto sensu, os direitos difusos e os direitos individuais homogêneos. Sendo assim, iremos determinar em qual direito se enquadra o meio ambiente.

Após o estudo dos direitos, iremos analisar, no segundo capítulo, o meio ambiente e suas classificações, ressaltando a importância da fauna neste contexto.

No terceiro capítulo iremos estudar a respeito do objeto material do tipo penal em análise: a fauna. Veremos a classificação, a natureza jurídica, as finalidades, fundamentos e proteção constitucional da fauna.

Ainda, no quarto capítulo analisaremos os aspectos da tutela penal da fauna, tais como, a responsabilidade da pessoa jurídica e as modalidades de caça e de pesca verificando seus reflexos no âmbito penal.

Por fim, no quinto e último capítulo faremos o estudo direto do tipo penal, observando seu objeto jurídico, sujeito ativo e passivo, objeto material, tipo subjetivo, condutas, bem como sanções previstas às pessoas físicas e jurídicas e particularidades do procedimento da lei $9.099 / 95$.

Neste mesmo capítulo, veremos as manifestações populares que configurariam o delito em estudo, como a vivissecção, rodeios, circos e a farra- do-boi.

Este estudo se faz importante tendo em vista a relevância jurídico- penal do bem tutelado.

Este tema foi escolhido devido aos reflexos da conduta humana no meio ambiente, que tem gerado a longo prazo, grandes estragos ambientais, comprometendo assim, a sadia qualidade de vida, consagrada pela Constituição Federal.

Atualmente estes reflexos da degradação ambiental tem se demonstrado de maneira mais clarividente. Contudo, a humanidade parece não se preocupar imediatamente com este problema, haja vista que seus reflexos surgem ao longo de anos.

Texto 9: Post no Facebook 
Sú.... menina do céu.... precisa passar frio ou congelar????????? Eu ganhei umas tulipas... Li que vc tinha que guardar o bulbo no congelador para simular a situaçao real dela na natureza. Se eu soubesse que ia esfriar desse jeito, tinha deixado na varanda mesmo!!! Eu nunca entendi esta ideia de "curtir o frio". Ficar debaixo do cobertor ou sair na rua parecendo um boneco de neve é curtir o frio?? Eu hein!!! Vc terá que trazer todas as roupas do mundo para a Sonia!!! Este frio só para a menopausa mesmo! Se você tiver esta alegria por "curtir o frio" (e eu sei que vc é destas), vc vai amar aqui!!! huahauhuahua. Vai começar a feira das malhas em Yyyyy, dia 26 de maio. Tb é uma boa pedida da região!!! Aí vc dá um pulinho aqui, já vestida com as malhas!! rssss

Texto 10: Post no Facebook

Quando eu tinha 08 anos, alguém jogou dentro da minha casa três filhotinhos de gatos... todos cheios de pulga! O que o gênio não sabia é que eu tinha um cachorro extremamente violento, que estava solto no quintal. Um anjo nos fez perceber isso logo quando paramos o carro na frente. O problema é que o cachorro tb percebeu. Meu pai rapidamente abriu o portão e conseguiu segurar o cachorro. Isto porque, a teimosa e valente mini-gatinha resolveu enfrenta-lo, ficando em duas patinhas. Ele achou graça e parou por uns segundos. Esses segundos foram decisivos. Criança, eu coloquei todos os gatinhos pulguentos na minha cama! hihi. Um, muito doente, acabou falecendo. O menino, conseguimos doar. Mas a menina... foi ficando... encalhadinha...! Brincamos de Barbie, de casinha, de pega-pega, ela ficou amiga do novo cachorro da casa, mais tarde adotou o novo gato filhote da casa, estudou pro vestibular, pras provas da Graduação, pro Exame de Ordem, pro TCC da Pós, tudo ao meu lado... e a vida foi seguindo o curso. Hoje, com meus 27 anos de idade, tenho essa amiga ao meu lado! Minha grande companheira, meu grande amor: minha gatinha Willinha. São 18 anos de felicidade. Um pequeno gesto faz toda a diferença em nossas vidas... Adote um animal: a felicidade está por aí...! : o )

Texto 11: Post no Facebook

Sú... as vezes as crianças ficam doentes quando querem alguma coisa... Será que não significa que a Sonia quer um dalmata ou um gatinho malhadinho?? : o )

Beijos. Se precisar, estou na loucura, mas conte mesmo comigo! Tenho aí horarios flexiveis no trampo. Qquer coisa me liga, tá? Amanha to no escritorio (tel fixo). Beijos 
Texto 12: Post no Facebook

2 picadas de borrachudo na perna esquerda e mais uma na direita + aula de samba de gafieira = inchaço das perninhas!!!

Eu e minha alergia à picadas de insetos... Lembrei da viagem pro Yyyyy, pro casamento dos gaúchos Ana e Amauri (que foi lindo!). Meu pé voltou parecendo um paozinho depois da picada... Mas deu pra dançar numa perna só!! : o )

Texto 13: Post no Facebook

Colegas advogados paulistas.

Outro dia eu vi uma reportagem que a OAB ganhou EM 2006, um terreno pra construir uma colônia de férias em Campos de Jordão. A colônia que a OABSP tem, é lá no fim do mundo virando a esquerda, né? Então, amei a ideia. Mas nunca mais vi nada a respeito. Mandei email pra $\mathrm{OAB}$, questionando o andamento da obra e aqui está a resposta:

"Nobre Advogada, Em atenção a solicitação de V.Sa., através de mensagem eletrônica, cumpre-nos informar que o expediente para a construção da Colônia de Férias de Campos do Jordão está em sua fase inicial, para posterior elaboração de projeto e execução".

Só para conhecimento de vocês, a OABMG dá uma "remuneração" para advogada em licença-maternidade, isenção da anuidade no ano do nascimento do bebê, máquina de suco e café expresso nas salinhas e, ao cancelar sua anuidade, vc paga proporcional ao mês de cancelamento. Caso você não saiba, se você tentar cancelar sua OABSP em Janeiro, vc deve pagar o ano INTEIRINHO, mesmo sem utilizar.

Enfim. Logo, logo teremos eleições OABSP. Depois de conhecer outras OAB's, acho que a de SP está precisando de um bom chacoalhão, hein?

Beijinhos!

Texto 14: Post no Facebook

e amanha é um novo dia, de um novo tempo, que comecou. Especialmente para aqueles que mudam a idade a ser preenchida em formularios.. De 27 pra 28?! Tem cheirinho de gente ficando velha... Parece que foi ontem que estava no aniversario de 15 anos na praia... Agora tá mais facil chegar o de 15 da filha dela!! Em 2026, Dona Sonia terá 15 e a velhote da mae terá 42!! Ixi.. ainda bem que sou mais nova que ela!! rssss Aiai ai ai tá chegando a hora..! 
Texto 15: Post no Facebook

hauhauhuahuahuahuahuaa

Ah genteeeee!!!

Descobri hoje!!! Obrigada a todos os desejos de "boa sorte"!!! hihi

Agora eu já sei: I’m a teacher!!!!!!!!!!! hahahahahah

Quer dizer... ainda não! Este mês fico assistindo as aulas e mês que vem começo a dar aulas de inglês para os pequenininhos!!!

$\hat{\mathrm{E}} \hat{\mathrm{E}} \hat{\mathrm{E}} \hat{\mathrm{E}} ! ! !$

Fiquei muito feliz!!! É uma oportunidade de "espairecer" dos problemas do dia a dia com uma coisa que eu tanto gosto (dar aulas) e ainda melhorar meu inglês!!! hihihihihih

Amei!!!

Agora sou advogada (full time) e professora de inglês em algumas horas do dia!!

E também técnica contábil e microempresária não praticante (huahuahahua)

Obrigada!!! Especialmente a Tá, que surgiu com esta possibilidade!!!

Deu um friozinho na barriga de assistir as aulas com as crianças que não param quietas (rss) mas vamos se jogar!!!!hihihi

E estudar!!! Pq meu inglês está enferrujadaaaaço..!

hihihihi

Obrigadaaaa!

Beijosssss

Texto 16: Post no Facebook

Esse é o video de dança da minha amiga. Eles estão competindo no dancetube. Eram primeiro lugar, mas o concurso foi prorrogado e faltando 5 dias estao quase perdendo o primeiro lugar (que já era deles se tivesse encerrado na data prometida). Se puderem ajudar, assistam! É rapidinho!! Obrigada!

Texto 17: Post no Facebook

Houve uma época em que eu achava que aquilo que vendiam no mercado em embalagem de café, era café!!! Hoje sei: aquilo é palha! Café 
é só o da Tia Ivone, em que ela mesma planta, torra e mói! Fui enganada a vida toda!!! Agora sim eu posso dizer que gosto de café - mas do cafécafé! Não do pseudo-café!

Texto 18: Post no Facebook

Se um dia alguém souber de alguém que esteja DOANDO GATOS DA RACCA MAINE COON ou SAVANNAH (adulto ou filhote), lembremse que eu sempre estarei a disposição!!! Acho sem-vergonhice comprar gato de raça, com tantos SRD's por aí. Mas, por outro lado, sempre quis um desses. Então, vai que alguém vai pro exterior e precise deixar o gato com alguém que goste destes bichinhos... estou por aí!! $=^{\wedge} . .^{\wedge}=$

Texto 19: Post no Facebook

Não dá pra resolver tudo em 3 dias, ainda que fique até tarde (pois a maioria dos rolos são em cartórios, bancos, etc, que fecham as $16 \mathrm{ou}$ $17 \mathrm{~h}$ ! E ainda, pdem 5 dias uteis para emitir certidoes). Pelo visto vou resolver parcialmente tudo e resolver integralmente nada! rssss A advocacia ainda me pira!

Texto 20: Post no Facebook

Gente!!!! A namorada do meu primo está na Xxxxx e ele tem a chance de ir ve-la na faixa!! Basta você ajudar!! Vai dar um pequeno trabalhinho: tem que aceitar o aplicativo, curtir a página da XYZ e aceitar entrar no voo do Daniel (meu primo). Ah vai.... eu sempre ajudo quando pedem! Vamos ajuda-lo!!

Texto 21: Comentário da foto de um bolo no Facebook

Meu.... me amarrota que eu to passada! O Julio que fez???? Nao é nada do que imaginei!!! Está lindo!!! Será que sobra um pedaço até o final de semana???

Ó vida, ó céus!!! Julioooooo!!! Faz outro pra mim????? Mas vai uma dica: pega um pedaço de linha, apoia a mão na metade do bolo e corta o bolinho em dois, porém, mantendo o formato redondo. Corta na altura e nao na metade dele!!! rssss 


\section{- TeXto Questionado}

E-mail para amigos:

$\mathrm{Mi}$,

Nao entenda mal a brincadeira. O "surtada" que eu utilizei foi o "detalhista" que você utilizou. Só isso.

Como eu sempre disse, eu nunca vi um casamento tão detalhado como o seu. E eu já fui madrinha de alguns e acompanhei de perto outros.

O que eu digo é que não me recordo de ter recebido mensagem personalizada depois do presente, convite personalizado para ser daminha, festas de chá de cozinha todas decoradas nos minimos detalhes, slides com informações sobre cores de vestidos..... Enfim! São trocentos mil detalhes que vc pensa!! Eu acho que vc não dorme!!!! rsss

Daí vem a graça de dizer surtada! Nao é surtada. É detalhista, como vc sempre foi com tudo nesta vida e por isso tem o reconhecimento na profissão que tem, por ter absolutamente tudo a ver com o que vc gosta de fazer.

Desde pequena gosta de organizar cada detalhe, como faziamos nos trabalhos de maquetes e musicas. Para alguns isso é "nóia". Para nós sempre foi "o trabalho bem feito".

Vc está fazendo do seu casamento, um casamento com perfeição em todos os detalhes. Afinal, como vc disse, o dinheiro é seu e é assim que ve quer.

Mas acredite se quiser, não é comum cada detalhe que vc pensou!!

Nunca fui "especialmente" convidada para ser madrinha como fui no seu;

Nunca recebi convite especial comigo recortada no convite e etc;

É muito bonito da sua parte.

Mas sendo sincera, não é comum! Eu, pelo menos, nunca vi. E daí veio toda a hstoria.

Espero que vc não fique chateada, como parece que ficou. Espero que vc entenda a brincadeira. Ninguem disse que vc está estressada e nao aproveitará o casamento. O surtada nao é estressada. muito pelo contrario, vc está bem calma. O Surtada é detalhista. Como eu digo, será o casamento da princesa, pq vcs pensaram em tudo para ser o casamento do sonho. 
Bom.... acho que vc já ficou brava... então pararei por aqui.... Mas resolvi falar para nao ficar mal explicado ou parecendo que a brincadeira tivesse o sentido depreciativo que vc imaginou que poderia ter....

\section{Beijos}

amo ves 
ANEXO B - Cartas do Atirador de Realengo

Carta de Suicídio (ou "Carta testamento")

Primeiramente deverão saber que os impuros não poderão me tocar sem usar luvas, somente os castos ou os que perderam suas castidades após o casamento e não se envolveram em adultério poderão me tocar sem usar luvas, ou seja, nenhum fornicador ou adultero poderá ter contato direto comigo, nem nada que seja impuro poderá tocar em meu sangue, nenhum impuro pode ter contato direto com um virgem sem sua permissão, os que cuidarem de meu sepultamento deverão retirar toda a minha vestimenta, me bañhar, me secar e me envolver totalmente despido em um lençol branco que esta nesse prédio, em uma bolsa que deixei na primeira sala do primeiro andar, após me envolverem nesse lençol poderão me colocar em meu caixão. Se possivel, quero ser sepultado ao lado da sepultura onde minha mãe dorme, minha mãe se chama Dicéa Menezes de Oliveira e esta sepultada no cemitério Murundu. Preciso da visita de um fiel seguidor de Deus em minha sepultura pelo menos uma vez, preciso que ele ore diante de minha sepultura pedindo o perdão de Deus pelo o que eu fiz rogando para que na sua vinda Jesus me desperte do sono da morte para a vida eterna.

Eu deixei uma casa em Sepetiba da qual nenhum familiar precisa, existem instituições pobres, financiadas por pessoas generosas que cuidam de animais abandonados, eu quero que esse espaço onde eu passei meus últimos meses seja doado à uma dessas instituições, pois os animais são seres muito desprezados e precisam muito mais de proteção e carinho do que os seres humanos que possuem a vantagem de poder se comunicar, trabalhar para se sustentar, os animais não podem pedir comida ou trabalhar para se alimentarem, por isso, os que se apropriarem de minha casa, eu peço por favor que tenham bom senso $e$ cumpram o meu pedido, pois cumprindo o meu pedido, automaticamente estarão cumprindo a vontade dos pais que desejavam passar esse imóvel para meu nome e todos sabem disso, senão cumprirem meu pedido, automaticamente estarão desrespeitando a vontade dos pais, o que prova que vocês não tem nenhuma consideração pelos nossos pais que já dormem, eu acredito que todos vocês tenharn alguma consideração pelos nossos pais, provem isso fazendo o que eu pedi.

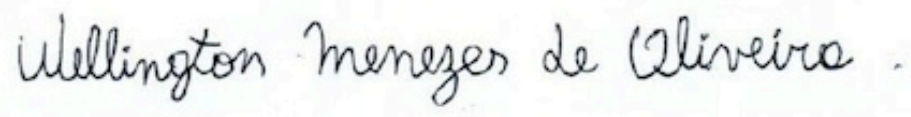


Texto 1 - A: Manuscrito

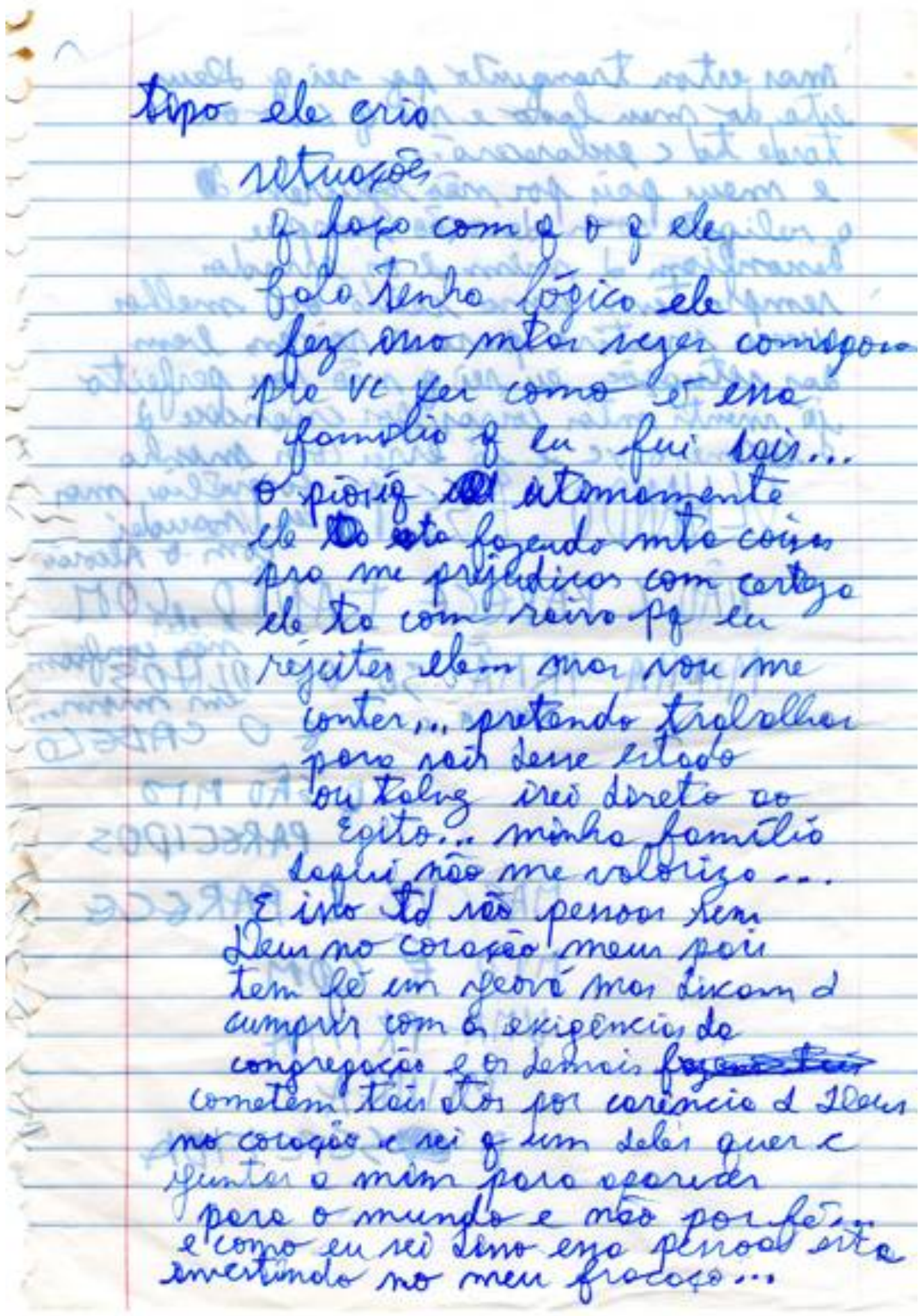


233

Texto 1 - B: Manuscrito

mor enton trongunto pg sei o deeus tate do men fobo e se of cedo oup I meur foir por nâ aguiren do a religies com devocóo sempre Lnonfiam $\alpha$ mim e os errador sempretem ume veido ou melhor una mentiro pora coiren bem Las vituosós, en ri of nó vou perfeito jo menti mtor coisos por crionda of - conmen ve e jo enc om minho

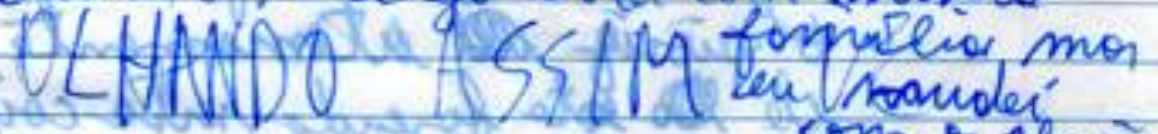
om O Alcoros.

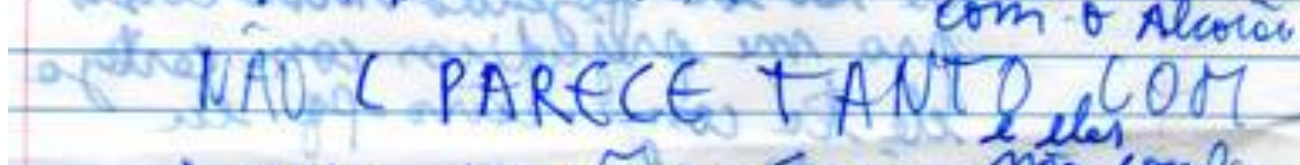

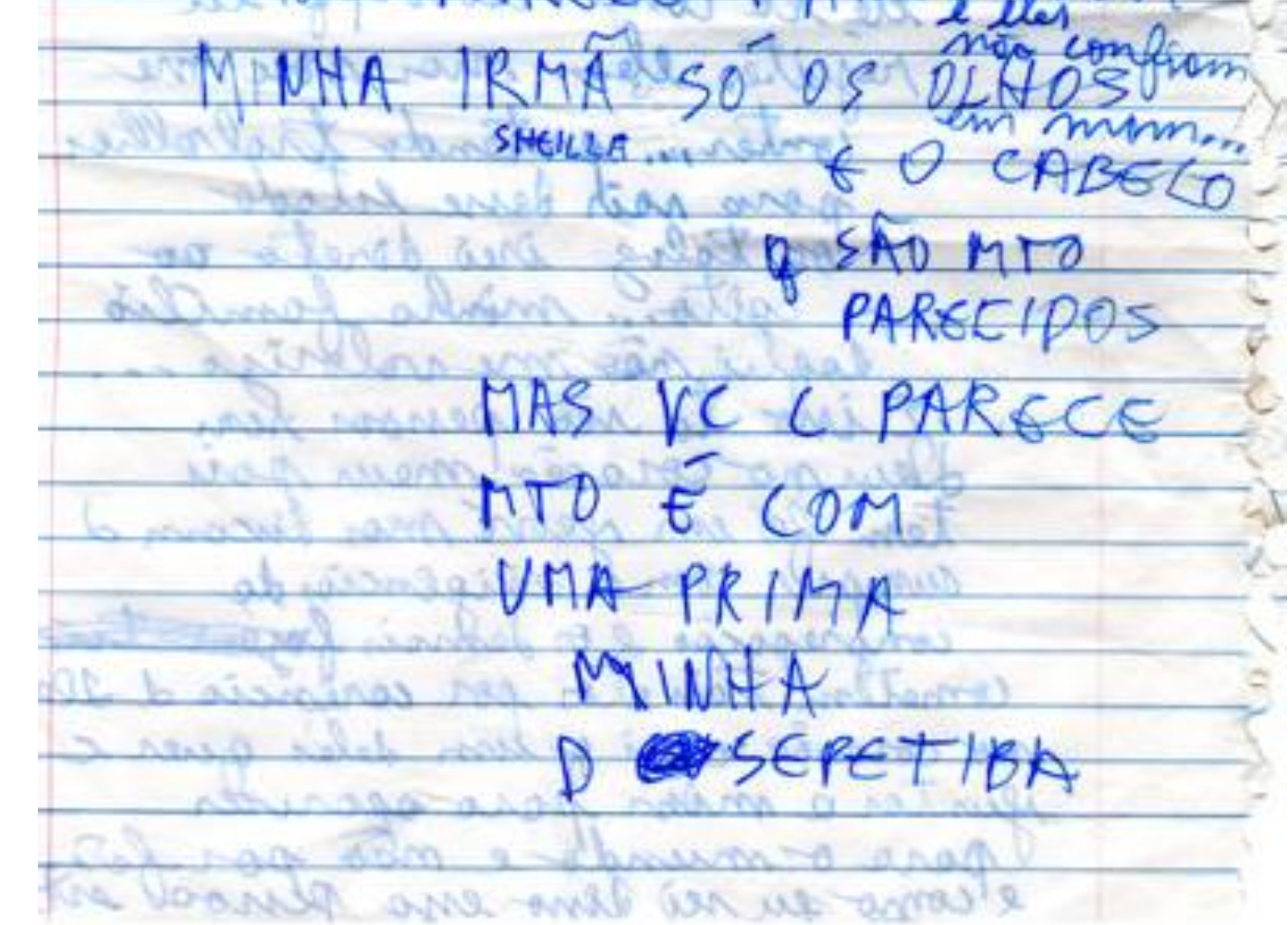




\section{Texto 1 - A e B: Transcrição}

tipo ele cria situações que faça com q o q ele fala tenha lógica ele fez isso muitas vezes comigo... pra vc ver como é essa família que eu fui sair... o pior é q utimamente ele esta fazendo mta coisas pra me prejudicar com certeza ele ta com raiva pq eu rejeitei ele mas vou me conter... pretendo trabalhar para sair desse estado ou talvez irei direto ao egito... minha família daqui não me valoriza... e isso td são pessoas sem deus no coração meus pais tem fé em jeová mas deixam $\mathrm{d}$ cumprir com as exigências da congregação e os demais cometem tais atos por carência d deus no coração e sei q um deles quer c juntar a mim para aparecer para o mundo e não por fé... e como eu sei disso essa pessoa esta investindo no meu fracaço...

mas estou tranquilo pq sei q deus esta do meu lado e sei q cedo ou tarde td c esclarecerá... e meus pais por não seguirem a religião com devoção sempre desconfiam d mim e os errados sempre tem uma saida ou melhor uma mentira para c sairem bem das situações eu sei q não sou perfeito já menti mtas coisas por criancice e ciúmes de vc e já errei com minha família mas eu mudei com o alcorão e eles não confiam em mim

OLHANDO ASSIM NAO C PARECE TANTO COM MINHA IRMÃ SÓ OS OLHOS E O CABELO SÃO MTO PARECIDOS

MAS VC C PARECE MTO É COM UMA PRIMA MINHA D SEPETIBA 
Texto 2: Manuscrito

sew revion a dencom ins to de lodo pora ¿dedicar oo mácimo a dew ener sim

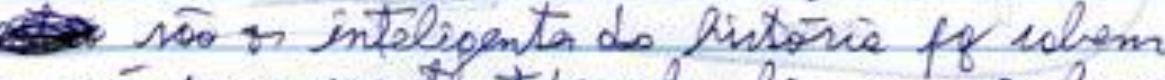
q opor mar mortes to of elar fizerom arfaros

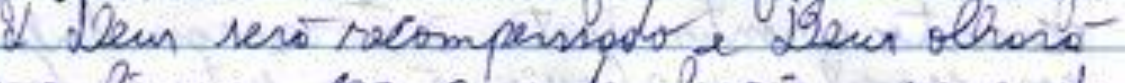
o g figeram com prande olegrio numo dos coinos moin me inite sovidode

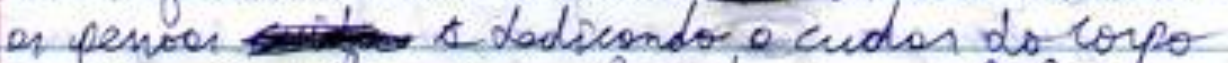
ivino ac ocho um obundo uns tolice is proticamante está cuidomblo do conpo pos varir como from limande a linor e vermer to terso na mesen pesnor tom a mente mito 10 mos ofrom o propris enturo of pontesero form todos o tempo t ruam tolomente podeviom un - pone remir o doen pir mo nim olteró

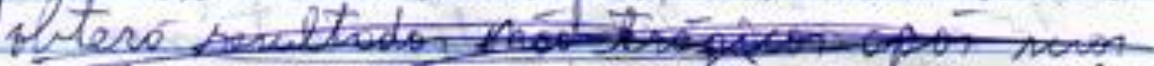

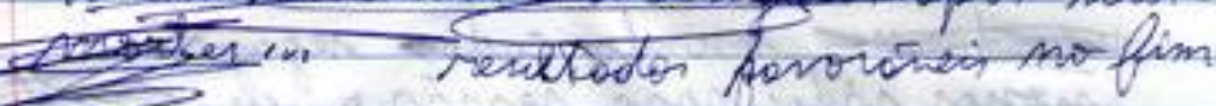

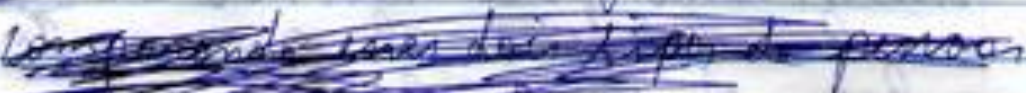

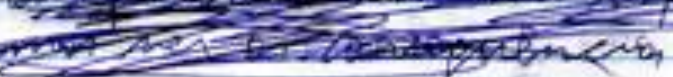

Protenim nos necombere o to ocale noo ponvem deur em sen opapor ochom \& tevem comes em lever on jefo

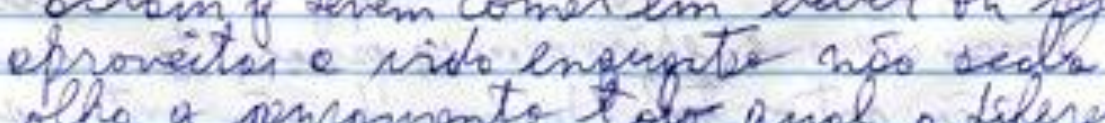
the of nemanento tobo and o diferma entrede uno parre of apoveitor a vide

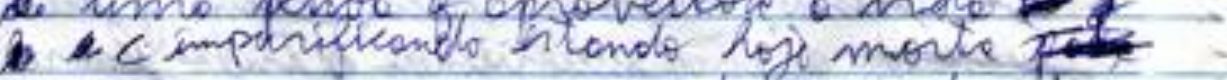

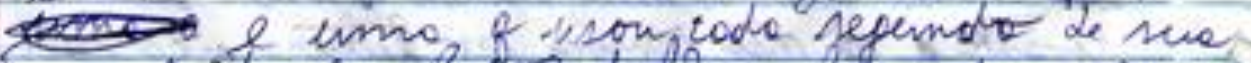

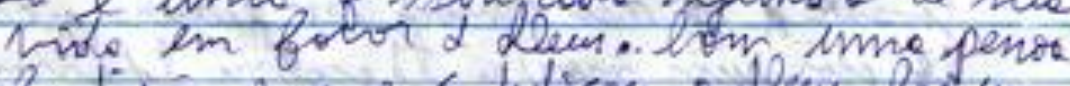

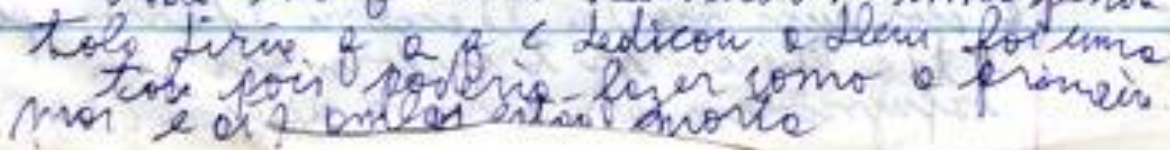




\section{Texto 2: Transcrição}

seus servos q deixam isso td de lado para c dedicar ao máximo a deus esses sim são os inteligentes da história pq sabem q após suas mortes td q eles fizeram em favor de deus será recompensado e deus olhará o q fizeram com grande alegria... uma das coisas que mais me irrita é a vaidade as pessoas c dedicando a cuidar do corpo como ( $\mathrm{xxx}$ ) banquete ou louvor e vermes da terra $(\mathrm{xxx}) \ldots$ essa pessoas tem a mente muito vã não olha o próprio futuro o q acontecerá com todos o tempo que suam tolamente poderiam usar para servir a deus pois isso sim obterá resultados favoráveis no fim.

pessoas assim não reconhece $\mathrm{q}$ td acaba não possuem deus em seus corações acham q devem comer em beber ou seja aproveitar a vida enquanto não acaba olha que pensamento tolo qual a diferença entre uma pessoa q aproveitou a vida c impurificando estando hoje morta e uma qusou cada segundo de sua vida em favor de deus.. bom uma pessoa tola diria q a q c dedicou a deus foi uma tola pois poderia fazer como o primeiro mas e aí? ambas estão morta 
Texto 3: Manuscrito

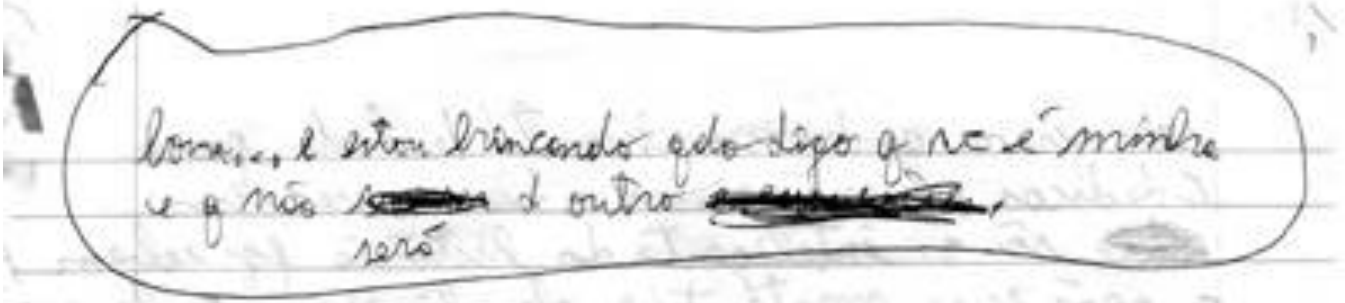

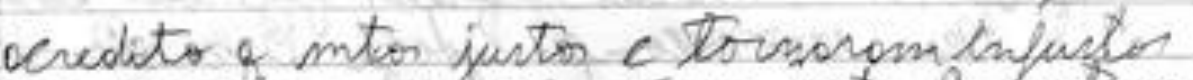

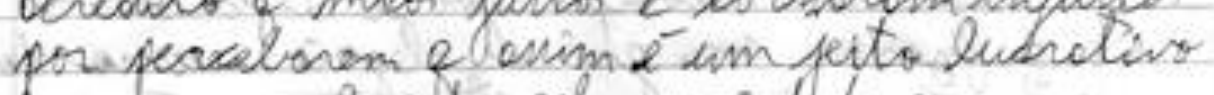

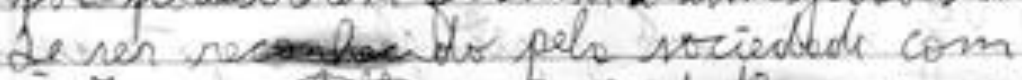

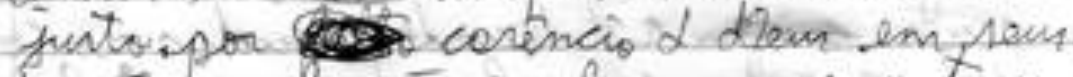

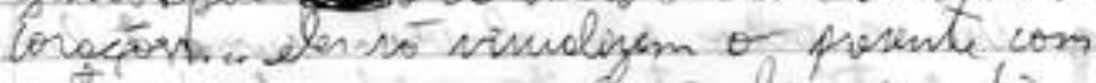

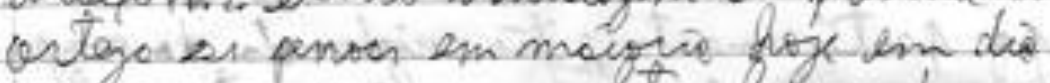

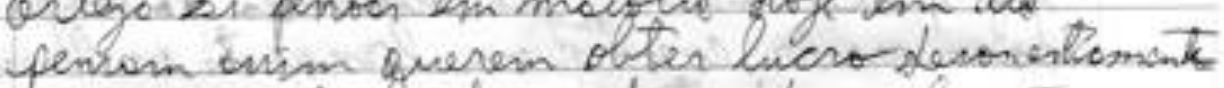
hem o conciendes of ento vide acolove um Live por ino entenho evo comic can

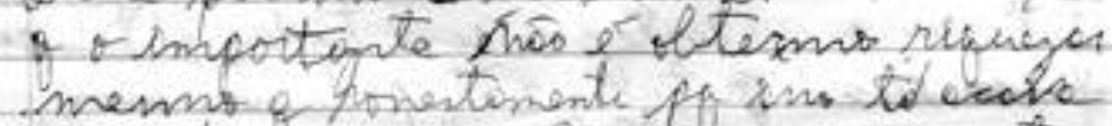

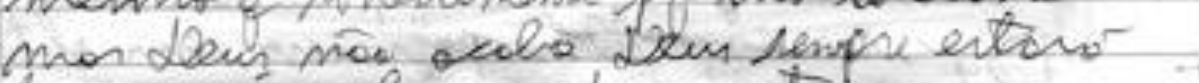

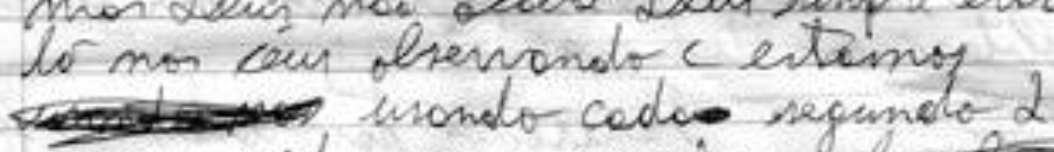

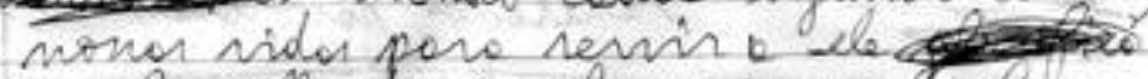

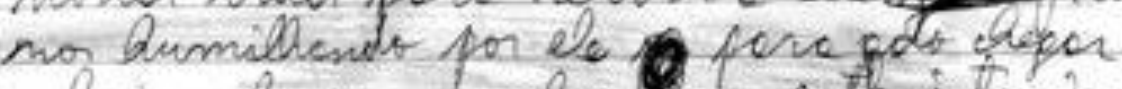
- boro te mor secelea Com mot intivicmo

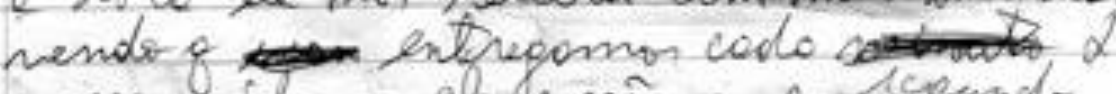

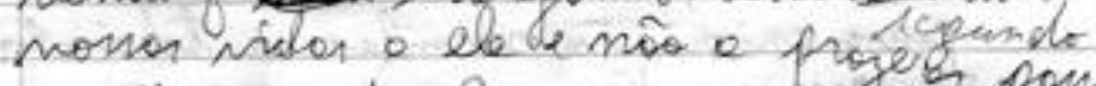

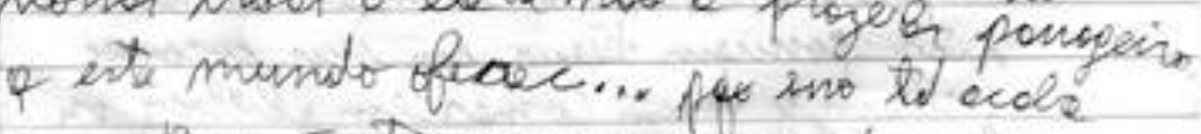
mar Dew é etemo... or puor tem uno viño mite tola do mundo ros mits fruste. ve eniende) a penor rica chom of extes

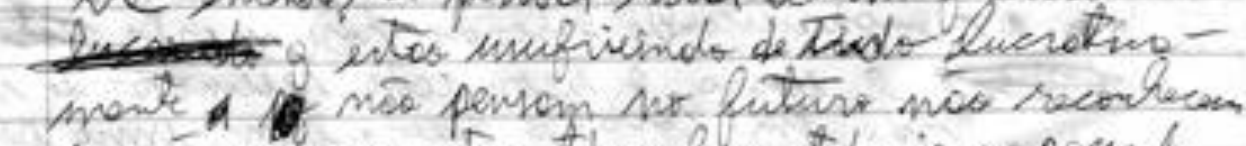

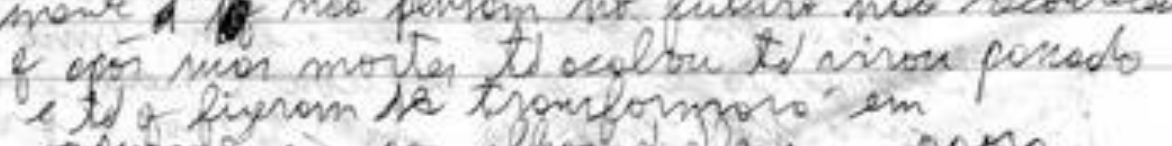

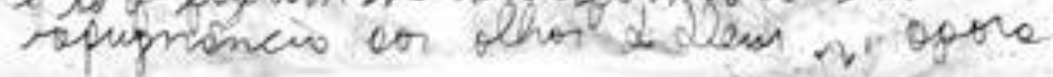




\section{Texto 3: Transcrição}

bom... e estou brincando qdo digo q vc é minha e q não será de outro

acredito q mtos justos c tornaram injustos por perceberem q assim é um jeito lucrativo de ser reconhecido pela sociedade como justos por carência d deus em seus corações... eles só visualizam o presente com certeza as pessoas em maioria hoje em dia pensam assim querem obter lucro desonestamente sem a conciênssia d q esta vida acabará um dia e por isso eu tenho essa convicção q o importante não é obtermos riquezas mesmo q honestamente pq isso tudo acaba mas deus não acaba deus sempre estará lá no céu observando c estamos usando cada segundo d nossas vidas para servir a ele nos humilhando por ele para quando chegar a hora ele nos receber com mto intusiasmo vendo q entregamos cada segundo $d$ nossas vidas para servir a ele e não a prazeres passageiros que este mundo oferece... pq isso tudo acaba mas deus é eterno... as pessoas tem uma visão mto tola do mundo são mto presentes vc entende? as pessoas ricas acham q estão usufruindo de tudo lucrativamente não pensam no futuro não reconhecem que após suas mortes td acaba td virou passado e td q fizeram se transformará em repugnância aos olhos de deus agora 


\section{Texto 4 - A: Manuscrito}

me sinto evintrodo...

Fine uns lrico com o Abdub e dencolvi

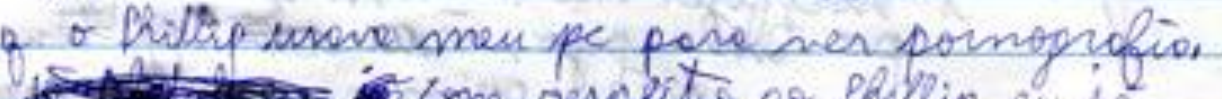

com rerpesto oo palip en je esperave iño of umo vey of en tolovo com lle. orm ve elestion emiono omotion de

a enimacós de renco explíato e tore folondo

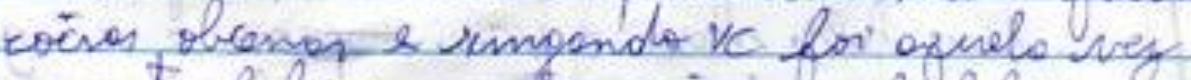
a en te foli umo des aivas a ele folore remperto \& ve ele ños opier e colei fos mos was dere macter. mas do Alsduel in

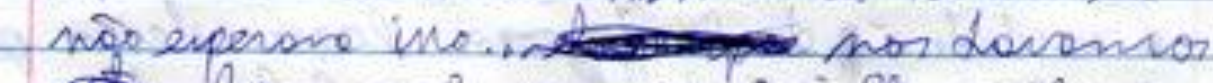
- lem e te rempre for Plevervel mor

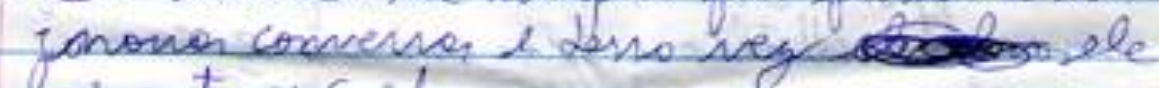
foi mato vípido íg en revoln folor pobre cegese menime o me comido o ir o sprejo dele reses enten d eu terminar ele jo foi - C evaltando degende a er eno pro contar elo loga no inías oo invés de ouvile. - depris dino él me ligon uma nyes endrue es estor vindo por viputo vo ipuper en teme consideno urrado por om lo... dewoli

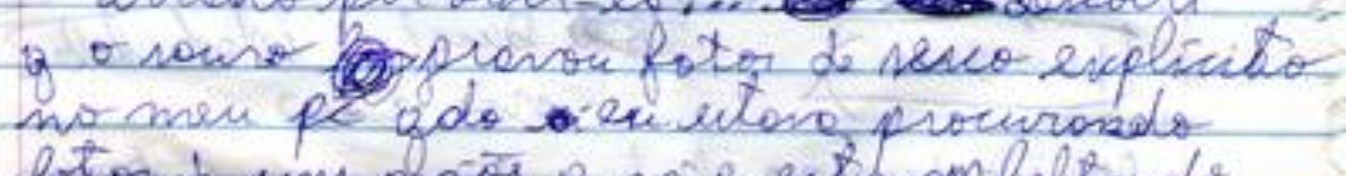

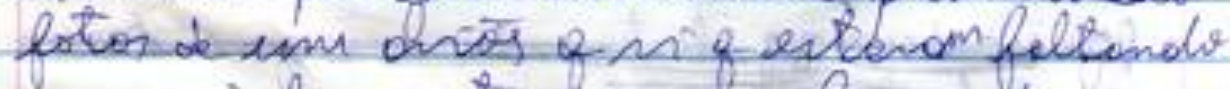

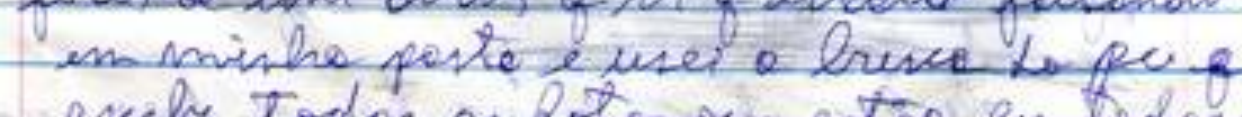

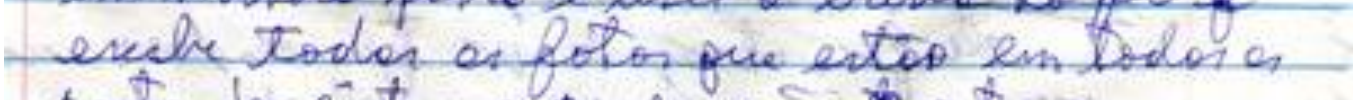

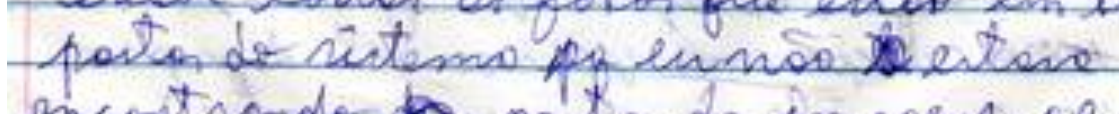
encontrondo do poito de imaper, een usesmal varige esto imon fo sedvi do pe. 
Texto 4-B: Manuscrito

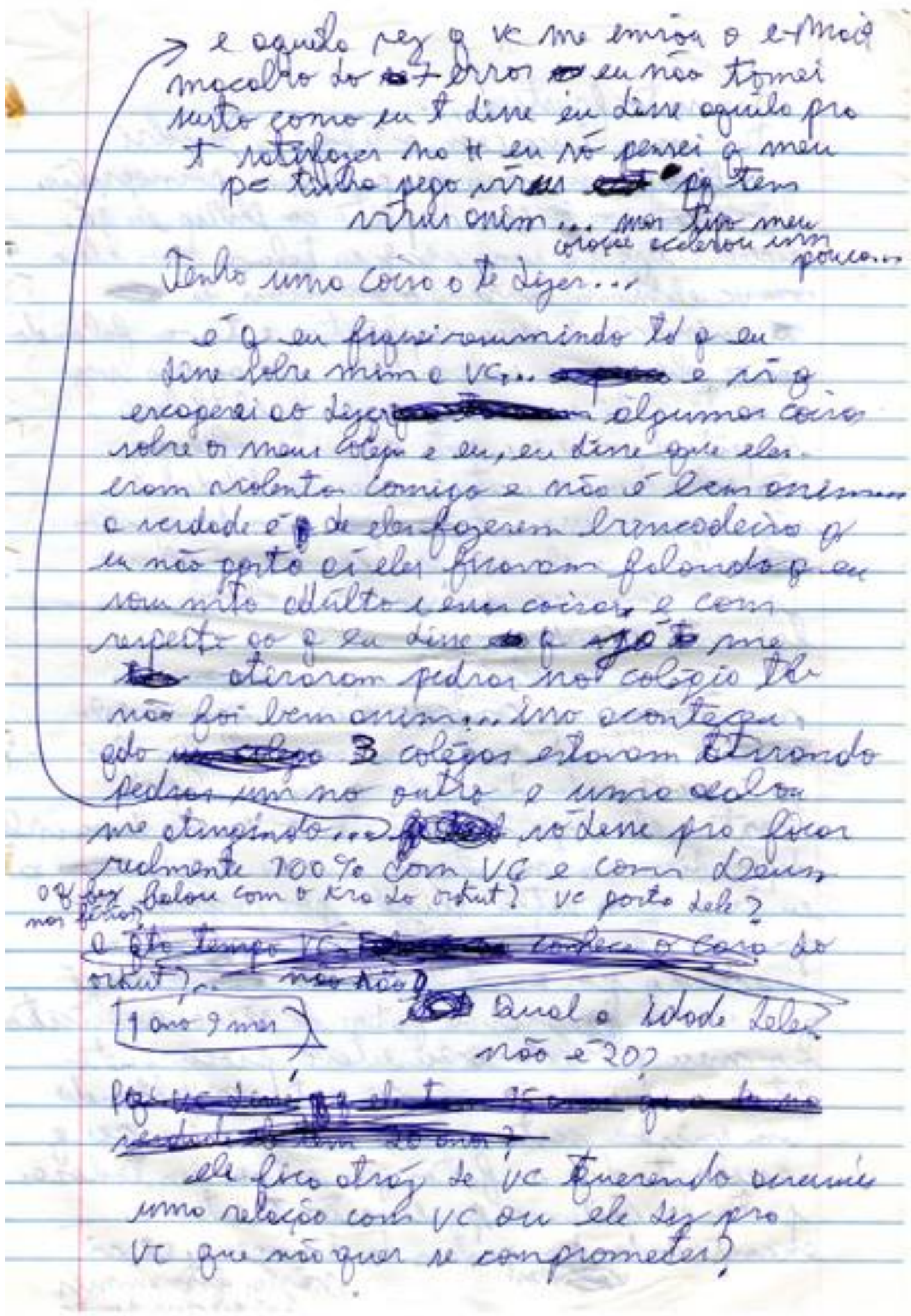




\section{Texto 4 - A e B: Transcrição}

me sinto frustrado. tive uma briga com o abdul e descobri q o phillip usou meu pc para ver pornografia. com respeito ao phillip eu já esperava isso pq uma vez que eu falava com ele e com vc ele estava enviando emotions animações de sexo explícito e tava falando coisas obcenas e xingando vc foi aquela vez q eu te falei uma das coisas q ele falou a respeito de vc e eu não copiei e colei pq não sabia desse macete... mas do abdul eu não esperava isso... nos davamos bem e ele sempre foi flexível nas nossas conversas e dessa vez ele foi mto rígido

é q eu resolvi falar sobre a menina q me convido a ir a igreja dela e antes de eu terminar ele já foi c revoltando dizendo q eu era pra cortar ela logo no início ao invés de ouvi-la. depois disso ele me ligou umas vezes e eu disse q estou saindo por respeito ao grupo. eu tb me considero errado por ouvi-la... e descobri que o sauro gravou fotos de sexo explícito no meu pc qdo eu estava procurando fotos de uns aviões q vi q estavam faltando em minha pasta e usei a busca do pc $\mathrm{q}$ exibiu todas as fotos que estão em todas as pastas do sistema pq eu não estava encontrando nas pastas de imagens, e vi várias fotos... mas já excluí do pc...

e aquela vez que vc me enviou o e-mail macabro do 7 erros eu não tomei susto como eu t disse eu disse aquilo pra t satisfazer no $(\mathrm{xx})$ eu só pensei que meu pc tinha pego vírus ps tem vírus ruim... mas tipo meu coração acelerou um pouco...

Tenho uma coisa a te dizer...

é que eu fiquei resumindo tudo q eu disse sobre mim e vc... e vi q exagerei ao dizer algumas coisas sobre os meus colegas e eu, eu disse que eles eram violentos comigo e não é bem assim... a verdade é de eles fazerem brincadeira e eu não gosto aí eles ficaram falando que eu sou muito adúlto e essas coisas e com respeito ao q eu disse q já me atiraram pedras no colégio tb não foi bem assim... isso aconteceu qdo 3 colégios estavam atirando pedras um no outro e uma acabou me atingindo... só disse pra ficar realmente $100 \%$ com vc e com Deus

o q fez nas férias falou com o cara do orkut? Vc gosta dele?

Qual a idade dele?

Não é 20?

ele fica atrás de vc querendo ( $\mathrm{xxx}$ ) uma relação com vc ou ele diz pra vc que não quer se comprometer? 
Texto 5 - A: Manuscrito

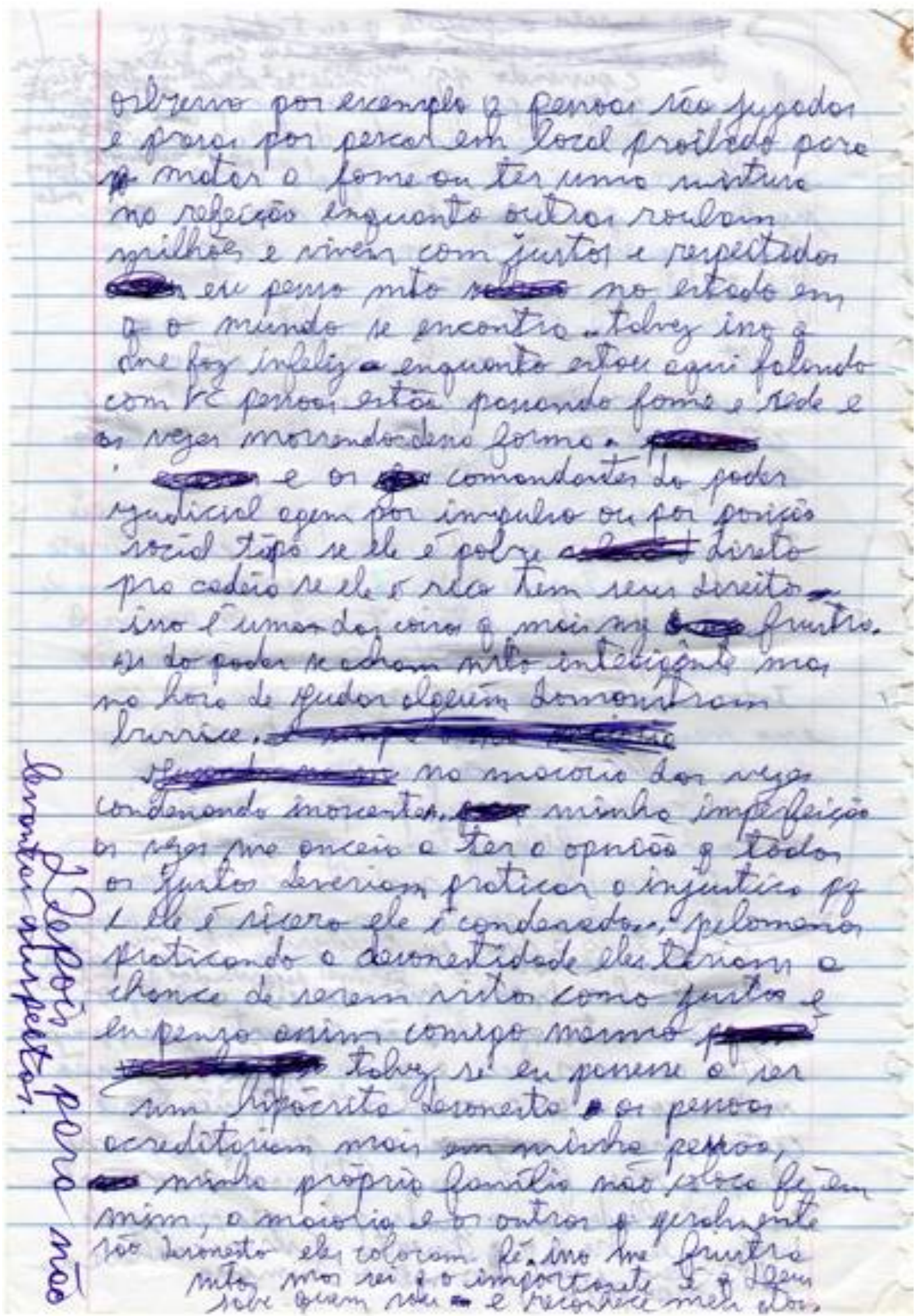


Texto 5 - B: Manuscrito

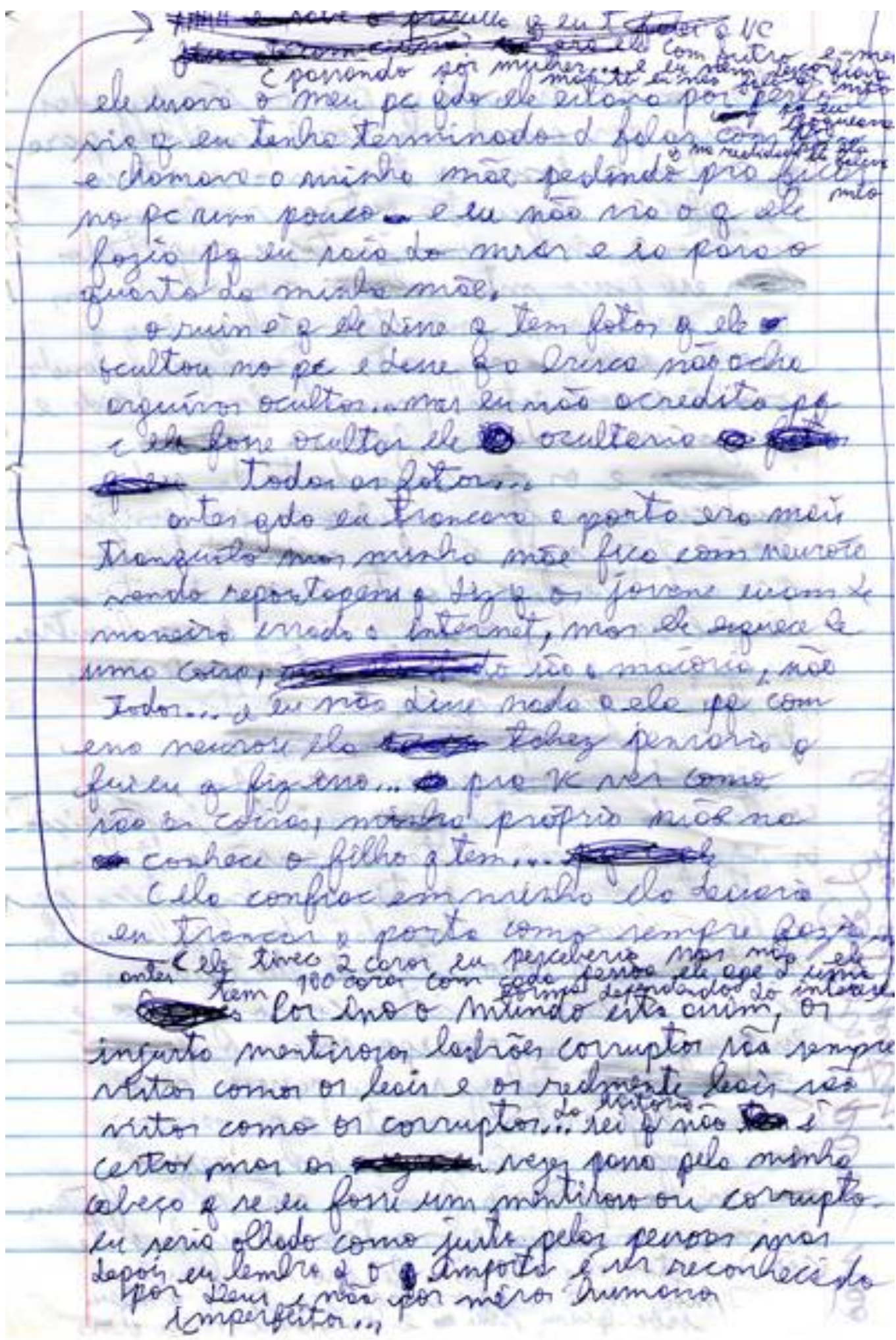


Texto 6 - A: Manuscrito




Texto 6 - B: Manuscrito

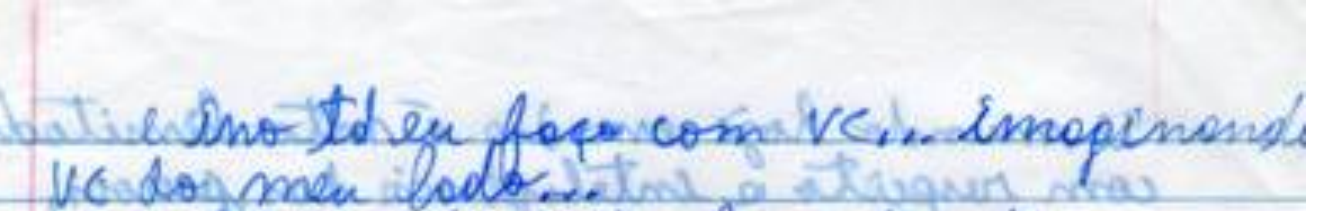 ininfalimmente tender of dinidi} imputempo com tareforde coleipiopa. mon mos Id dio todo men tempó livere intrego o 22 au oos imvé dicentreper cor prazereo pangeiros do mundo... es sei of dech olhoro pora men socrifirio

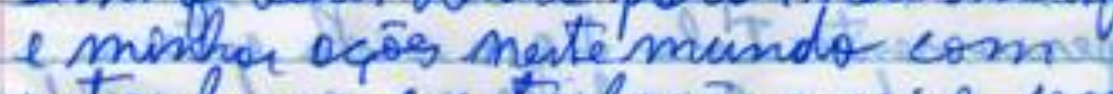

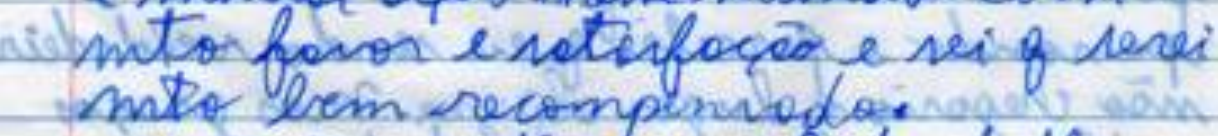

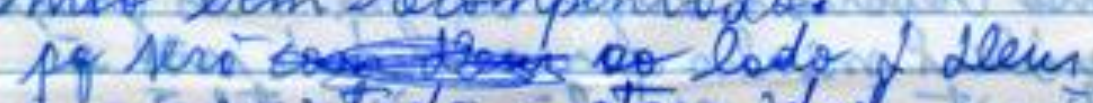
If nineri tado a eternidade i mas

men mpundo panepivo.

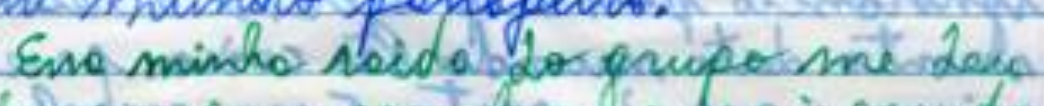

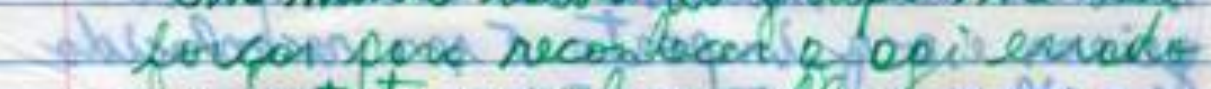

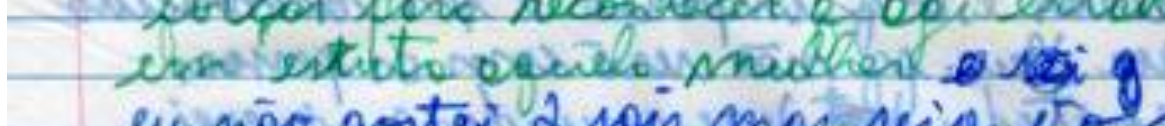
rivōo gosta 2 soin mar reiq ito cento

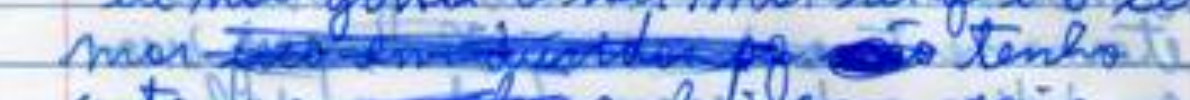
centego on for inner poiquem os mindori rasu ho lrasil E. ele conhecen o Nedul e mandop elviec comi on ontron frecisomente ea kto...pp

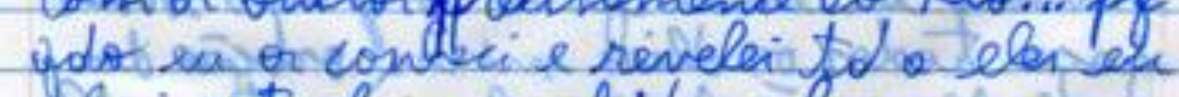
fivi into bem recelidole hourve ina

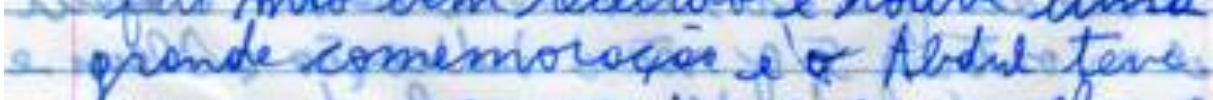
ume comerve compo e me revelou of

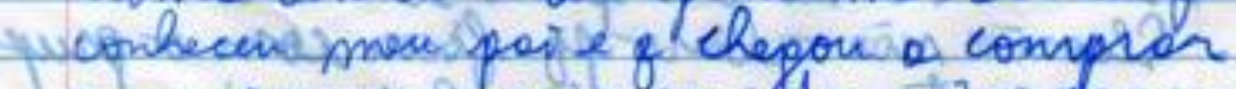

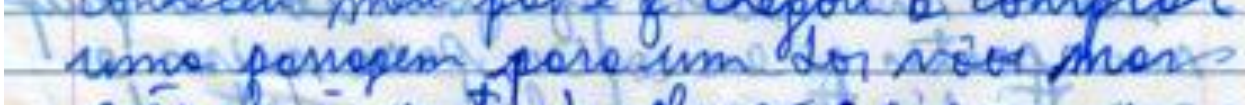

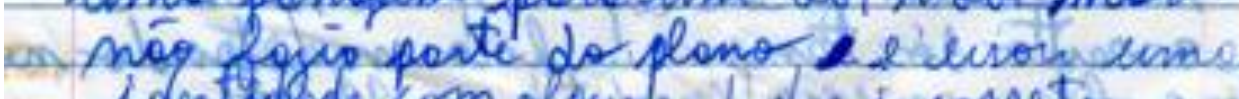
identrugde com offun doder incorreto

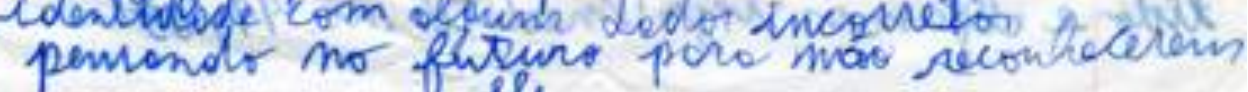




\section{Texto 6 - A e B: Transcrição}

O mundo hoje em dia é mto limitado com respeito a inteligência das pessoas, eu confeço que no passado eu mtas vezes parava para analisar o mundo e percebia q os corruptos q só mantem e praticam falsidade são valorizados as pessoas hoje em dia são valorizada qdo são assim e eu tb pensava em aproveitar minha vida pois muitas vezes tive esse pensamento d q a vida estava passando e percebia que eu sendo verdadeiro não chegaria a lugar algum. Mas graças a Deus minha personalidade não é limitada e percebia q isso td é uma ignorância pois os prazeres e o reconhecimento deste mundo são coisas passageiras e o q importa é ser reconhecido por Deus pq não será com pessoas limitadas desse mundo q viverei eternamente e sim com Deus por isso eu dedico cada segundo da minha vida a Deus não procuro dividir para usurfruir dos prazeres passageiros do mundo eu estou fora do grupo mas faço todos os Dias minha oração do meio dia q é a d reconhecimento a Deus e as outras 5 que são de dedicação a Deus e umas 4 h do dia passo lendo o Alcorão não o livro pq ficou com o grupo mas partes que eu copiei para mim e o resto do tempo eu fico meditando no lido e algumas vezes medito no 11/09 e isso tudo eu faço com vc... imaginando vc do meu lado...

infelizmente tendo a dividir meu tempo com tarefa de colégios limpeza da casa e ir a igreja dos tj... mas não todo dia todo meu tempo livre entrego a deus ao invés de entregar aos prazeres passageiros do mundo... e sei que deus olhara para meu sacrifício e minhas ações neste mundo com muito (favor) e satisfação e sei q serei mto bem recompensado.

pq será ao lado d deus q viverei toda a eternidade e não nesse mundo passageiro

essa minha saida do grupo me deu forças para reconhecer q agi errado em (escuta) aquela mulher eu não gostei d sair mas sei q é o certo mas tenho certeza q foi meu pai quem os mandou aqui no brasil ele conheceu o abdul e mandou ele (xxx) com o outro precisamente ao rio... pq qdo eu os conheci e revelei td a eles eu fui mto bem recebido e houve uma grande comemoração e o abdul teve uma conversa comigo e me revelou que conheceu meu pai e q chegou a comprar uma passagem para um dos vôos mas não fazia parte do plano e usou uma identidade com alguns dados incorretos pensando no futuro para não reconhecerem ele 


\section{Texto 7: Transcrição ${ }^{1}$}

quero deixar bem claro que eu sou contra as guerras ou qualquer que sejam os atos de violência sem motivo justo, e também quero deixar claro que eu não sou o responsável por todas as mortes que ocorrerão, embora meus dedos serão responsáveis por puxar o gatilho, portanto, cada vez que vocês verem alguém ridicularizando uma pessoa pela sua aparência física, vestimenta ou qualquer que seja o motivo, cada vez que verem alguém sendo humilhado e agredido injustamente, cada vez que verem alguém sofrendo preconceito ou sendo discriminado, cada vez que verem alguém se aproveitando da bondade ou da inoscência de um ser, lembrense que esse tipo de pessoas foram responsáveis por todas essas mortes inclusive a minha muitos deles tentam se ocultar, no fundo a maioria das pessoas são assim, ou agridem ou debocham dos agredidos, muitas vezes aconteceu comigo de ser agredido por um grupo e todos os que estavam por perto debochavam, se divertiam com as humilhações que eu sofria sem se importar com meus sentimentos, gostam de se aproveitar dos fracos e indefesos, gostam de tirar vantagens dos inocentes, ridicularizam os fiéis, quando digo fiel eu não me refiro a frequentadores de religioes, pois muitos fornicadores, adulteros, pecadores, agressores, infiéis em geral, frequentam religiões até mesmo regularmente, quando digo fiel me refiro aos que seguem as leis de deus e se preservam se mantendo longe de tudo que mancharia sua dignidade, tipo de pessoas que tem como uma das qualidades não julgar ou escolher quem respeitar pela aparência

frequentando ou não religioes. jesus não pregou religiao e sim as escrituras sagradas religiao não é algo sagrado a maioria das religioes enganam as pessoas com ensinamentos falsos como o ensino de que existe algo dentro do ser humano que sobreviva após a morte ensinos vindo de falsos seguidores de deus que espalharam suas falsas doutrinas pelo mundo enganando milhoes de pessoas distorcendo as escrituras sagradas somente a palavra de deus é sagrada os que eu mais repudio além dos infieis são os que cedem às pressoes dos infieis e se tornam como eles achando que estão sendo espertos ou até mesmo por medo se tornam como eles cedem à pressões deles fazem a vontade deles abrindo mão dos seus valores eu era pra continuar vivendo respirando vendo ouvindo sentindo mas por culpa dos infieis eu não poderei mais ver ouvir sentir respirar por culpa deles minhas condições de ser vivo irão cessar por culpa deles muito em breve estarei morto mas eu abri mão de minha vida por vocês fiéis se deus achar que sou merecedor no grande dia em que jesus retornar deus irá me restaurar e colocar uma porção de seu espírito em mim para que eu reviva e finalmente tenha vida eterna quem sabe serei transformado de mero ser carnal para um ser espiritual para a vida eterna nos céus mas se deus achar que não sou merecedor se julgar o que eu fiz como desnecessário estou ciente de que serei adormecido na morte por toda a eternidade mas pelo menos morri pelos fieis e nunca me arrependeria disso eu tinha um emprego tinha uma casa tudo que uma pessoa precisa para viver bem mas não poderia viver bem sabendo que vocês sofrem todos dias nas mãos dos infiéis por isso resolvi fazer algo para balançar esse cenário cruel morri pelos que são incapazes de se defender que são ridicularizados agredidos humilhados os que sofrem na mão de pessoas cruéis covardes que se aproveitam da ingenuidade e fraqueza deles morri para inspirar vocês irmãos a se defenderem e se fortalecerem meu desejo é que estabeleça uma união entre vocês e os irmãos mais fortes e corajosos fiquem atentos para proteger os irmãos mais fracos juntos serão muito mais fortes quero que lutem para que sempre a justiça seja feita nunca se entreguem nunca desistam não deixem que meu fim tenha sido vão muitos de vocês poderão ser fortes se transformando em combatentes na batalha contra os perversos se preparando para matar e morrer e zelando pela proteção dos irmãos mais fracos os inspirando de forma que eles sejam como vocês inspirem as

\footnotetext{
${ }_{1}^{1}$ Disponível em <http://fantastico.globo.com/Jornalismo/FANT/0,MUL1658408-15605,00.html>. Acesso em jun/2011.
} 
novas gerações de irmãos hoje em dia existe a internet existem sites que se pode criar comunidades para que os irmãos se encontrem outros sites possuem conteúdos ensinando como fazer bombas por exemplos juntos poderão planejar investidas muito maiores contra os infiéis juntos poderão adquirir fundos para a compra de armas munição e material para a fabricação de explosivos meu desejo é que se forme uma rede de combate aos infiéis entre os irmãos obviamente tendo muito cuidado pois

provavelmente existirão muitos infiéis que tentarão se infiltrar, deverão ser muito cautelosos na hora de aceitar novos membros quero parabenizar o irmão casey heynes pela sua escelênte atitude que ajudou no combate aos maus, tendo minha total aprovação e satisfação, fiquei muito orgulhoso do irmão, quero lembrar os irmãos, cho hui e edmar aparecido freitas, embora já estejam dormindo, os parabenizo e quero pedir aos irmãos e irmãs e que nunca se esqueçam desses irmãos, os considerem ícone na luta contra os infiéis, unidos vocês poderão esperar em uma coisa que todos nós desejamos,

que os maus sejam extintos que deus vos abençôe 


\section{ANEXO C - Textos do Autor "C" (capítulo 6)}

\section{Texto 1:}

É relativamente fácil e confortável para os brancos, morenos, fisicamente equilibrados (nem magro, nem gordo), adeptos de uma religião bem vista e "certinha" (catolicismo por exemplo) viverem nessa sociedade moralista e hipócrita que temos hoje. Pois quase tudo para eles será sempre de acordo com os padrões tidos como adequados e corretos por grande parte dos sistemas que regem a sociedade (religião, mídia, grupos sociais, empresas, governo, etc). Agora, tente vestir a pele de uma pessoa totalmente fora desses padrões, tente vestir a pele de um negro adepto do candomblé por exemplo. Tente vestir a pele de um mulato que vive na favela, que sofre preconceito e marginalização desde que nasceu. Tente vestir a pele de uma nordestina, a qual sua aparência foge totalmente do estereótipo proposto pela mídia e pela propaganda. Se imaginou nessas peles? Achou fácil? Pois então. É preciso muito mais do que um simples sentimento de pena e de dó para realmente compreendermos a situação do preconceito e do racismo. É preciso uma plena consciência coletiva, que seja capaz de construir uma empatia total para com todos que são diferentes de nós brancos, morenos, católicos, loirinhos, de olhos verdinhos e perfeitinhos. Creio que só assim poderemos realmente entender o sentido da diversidade e o sentido de respeito para com todos os tipos de seres humanos.

\section{Texto 2:}

Devemos tomar consciência e cuidado acerca da "falsa generosidade". Que segundo o grande educador Paulo Freire, é uma das mais ardilosas estratégias de dominação existente na relação entre Opressores $\mathrm{x}$ Oprimidos. O opressor, para não se sentir tão culpado com relação ao fato de estar dominando, explorando, manipulando e escravizando um oprimido, utiliza o artifício de ser "generoso" para com aquele que está oprimindo. Como ele faz isso? Dando uma bonificação aos seus empregados durante o final do ano, após ter lhes pago uma miséria de salário; Oferecendo cestas básicas aos seus eleitores, para que estes votem nele; Colocando uma foto de um respectivo funcionário com os dizeres "Funcionário do mês"; etc. Não somente os chefes, empresários e políticos fazem isso, como também (e principalmente) os meios de comunicação de massa também o fazem. A tão falada "estratégia do pão e circo". "Ah, tadinho de vocês, devem estar cansados desse dia tão difícil que tiveram hoje. Mas não se preocupem, assistam nossas novelas, nossos carnavais, nossos jogos de futebol, nossos programas de fofocas e nossos reality shows que logo, logo vocês já melhoram e se animam novamente; seus otários". Essa é a estratégia da "falsa generosidade", muito bem conceituada pelo Paulo Freire. Pois para os opressores não é nem um pouco conveniente que os oprimidos adquiram a consciência de que estão nessa condição. E, para que não a adquiram, se fazem de bons 
e generosos, quando na verdade estão apenas se valendo de uma tática diabólica de dominação.

\section{Texto 3:}

A música (assim como qualquer outra manifestação artística) é reflexo do conteúdo e da realidade de uma determinada sociedade. Se o lixo cultural está prevalecendo sobre a boa cultura, a boa arte, é sinal de que as pessoas estão cada vez mais pobres, ralas e vazias... Fazendo uma analogia com um ditado famoso: "Ouvido de alienado não tem dono"

\section{Texto 4:}

Interessante o fato de alguns games sugerirem uma crítica a certos regimes políticos. Strider é um ótimo exemplo disso. No game você controla um ninja que tem a missão de derrotar um ditador claramente comunista (que lembra muito o imperador Palpatine da saga Star Wars). Há várias referências ao comunismo no game, como a estrela (que no game não tem uma das pontas, para justamente não fazer uma alusão óbvia) e a foice e o martelo (esse último símbolo máximo do comunismo). Tanto que um dos inimigos do jogo (Ouroboros) os segura em suas mãos.

\section{Texto 5:}

Assisti ao Robocop do Padilha. Bom filme, porém senti que ele se perde em meio a tantas ideias e questoes. Faltou um melhor direcionamento, foco e aprofundamento. No entanto cumpre bem o papel de filme sci-fi de ação. Gostei da performance dos atores, principalmente a do Gary Oldman.

\section{Texto 6:}

Até quando deixarmos de considerar carnaval e futebol como super prioridades máximas do Brasil. E passarmos a considerar e lutar por coisas que verdadeiramente devem ser, como educação, transparência e honestidade política, justiça social, segurança pública, saúde, etc. Do contrário esse tipo de postagem/discurso não tem sentido algum. Pois será sempre uma hipocrisia.

\section{Texto 7:}

Amo releituras, considero uma das melhores formas de trabalho artístico. Compartilho aqui algumas releituras de obras famosas, que contextualizam muito bem essa era digital que estamos vivendo. 
Texto 8:

Cada um tem o direito de ser aquilo que quiser ser. Para o bem ou para o mal. Essa é uma das lições mais dolorosas que temos que aprender na vida; sobretudo para aqueles que são pais, professores e educadores.

Texto 9:

Abomino qualquer espécie de arbitrariedade e autoritarismo no tocante ao ensino das artes visuais. Obrigar um aluno a agir conforme um determinado padrão (que muitas vezes não tem nenhum sentido para com aquilo que está aprendendo) vai totalmente contra o significado mais importante da arte: A liberdade. Mas aqui vale uma ressalva, liberdade é diferente de libertinagem. Entendo a liberdade como um direito de ser, fazer, criar, agir com bom senso e responsabilidade.

\section{Texto 10:}

Essa platéia do Faustão deve ganhar um bom cachê, pelamor... aplaudem qualquer merda que o Faustão fala... pqp! 


\section{ANEXO D - Scripts para extração de dados (capítulos 5 e 6)}

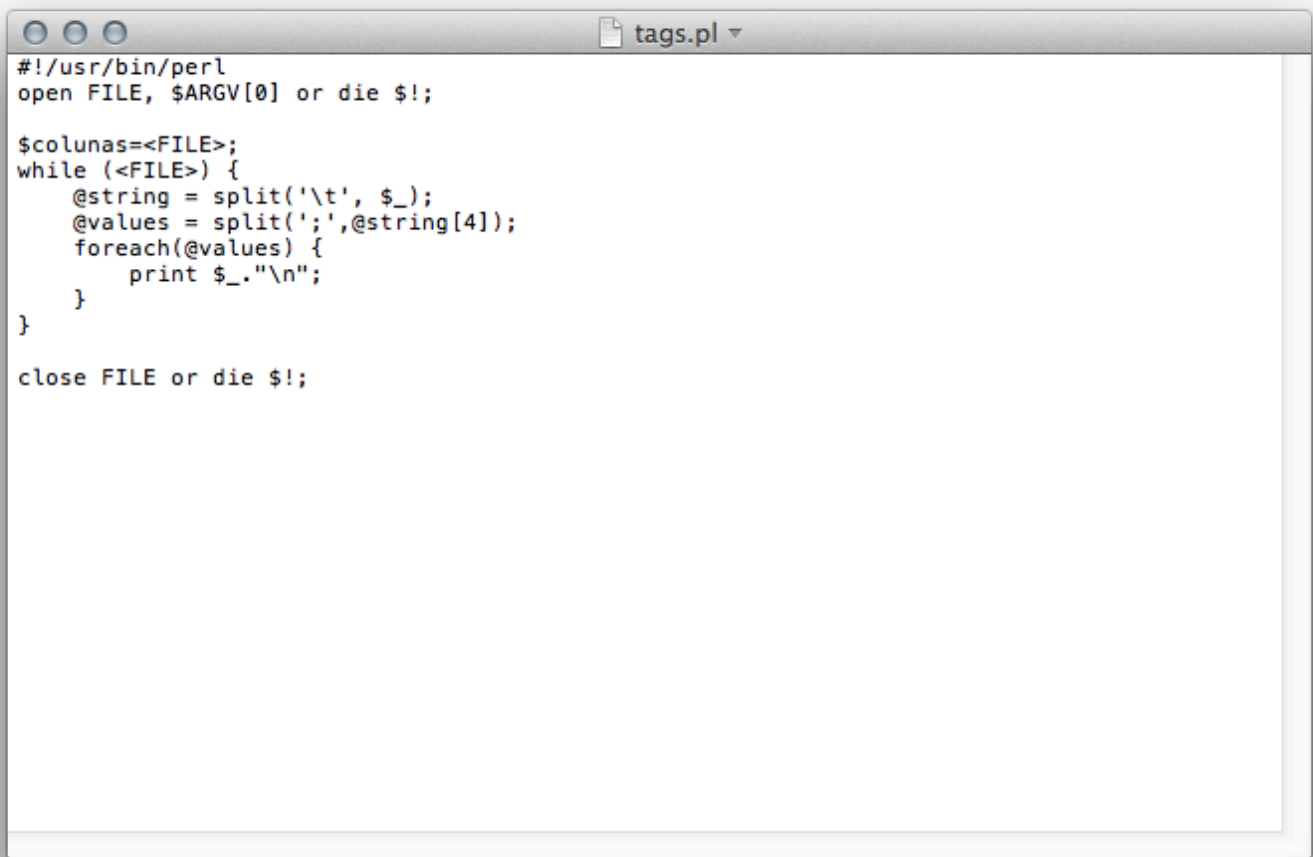

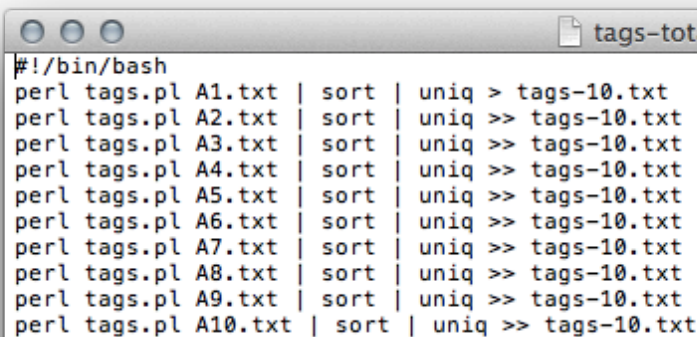




\section{ÍNDICE REMISSIVO}

$\overline{\mathrm{A}}$

acentuação $\cdot 103,108,109,117$

acontecimento $\cdot 130,134,136,143,144$

adequação de advertências $\cdot 15$

admissibilidade da prova $\cdot 61,63,64,65$

agentividade $\cdot 82$

agrupamento social $\cdot 124$

ameaça $\cdot 68$

amostra $\cdot 16,31$

análise automática $\cdot 150$

análise de autoria $\cdot 14,33,39$

análise de vocabulário $\cdot 35$

análise fonética $\cdot 49$

análise grafotécnica $\cdot 34$

análise linguística $\cdot 14,30,51,67,68,69$

análise sintática $\cdot 35$

análises computacionais $\cdot 42$

análises estatísticas $\cdot 40,42$

andamento $\cdot 143,144$

aprendizado de máquinas $\cdot 40,42,50$

aspectos jurídicos $\cdot 58$

assunção da prova $\cdot 61$

atenção à fala $\cdot 78$

atividade probatória $\cdot 59,67$

atribuição de autoria $\cdot 22,24,31,60,67,68,76$

Audience Design $\cdot 78$

author profiling $\cdot 48$

authorship profiling $\cdot 48$

automatismo $\cdot 56$

autor $\cdot 13,16,22,26,30,31,32,33,52,66,67,68,72$

autor intelectual $\cdot 66$

autor material $\cdot 66$

autoria erroneamente atribuída $\cdot 30$

autoria questionada $\cdot 16,18,22,24,25,30,32,40,51,61$, $68,69,70,72,91,146$

\section{$\mathrm{B}$}

bilhete $\cdot 101$

bilhete de resgate $\cdot 14,31,32,91$

$\overline{\mathrm{C}}$

caixa alta $\cdot 103,108,112,117$

carta anônima $\cdot 31,53,68$

cartas $\cdot 21,30,31,69$

cartas de suicídio $\cdot 30$

casos

bad-minded people $\cdot 53$

Bentley $\cdot 45$

Birks $\cdot 52$

casos brasileiros $\cdot 68$

Ceglia versus Zuckerberg $\cdot 51$

Danielle Jones $\cdot 51$
Daubert $\cdot 39,64$

devil strip $\cdot 32,33,49,52,85$

Evans $\cdot 13,36$

Frye $\cdot 64,65$

Hunter $\cdot 52$

Jenny Nicholl $\cdot 51$

Joiner $\cdot 64$

Kumho Tire Co $\cdot 64$

Pitta versus Ynes $\cdot 70$

Ramsey $\cdot 31,50$

Unabomber $\cdot 50$

Walker $\cdot 53$

categorias demográficas $\cdot 19,80,94$

celular $\cdot 30,51$

Ciência $\cdot 39,54,63$

Civil Law $\cdot 64$

classe social $\cdot 19,93,99,101,104,105,106$

Código de Processo Civil · 59, 66

Código de Processo Penal $\cdot 60$

Coeficiente de Jaccard · 157, 162, 174, 185, 186

combinação $\cdot 44,49,76,82,85,98,106,113$

Common Law $\cdot 64$

comparação $\cdot 16,18,23,24,25,31,44,58,60,62,89,90$

comprimento das sentenças $\cdot 35$

comprimento de palavras $\cdot 35$

comunicações online $\cdot 101$

comunidade imaginária $\cdot 95$

comunidade virtual $\cdot 94$

comunidades de fala $\cdot 85,106$

comunidades de prática $\cdot 106$

comunidades de práticas $\cdot 81,94,118$

confiabilidade $\cdot 27,47,54,55,56,63,162,182,183$

consciência metalinguística $\cdot 56,57$

contendas judiciais $\cdot 30$

conteúdo $\cdot 30,66$

continuidade $\cdot 143$

corpora $\cdot 21,25,41,42,47,91$

corpus $\cdot 22,23,25,47,57,91,95,102,110,111,112,119$, $127,140,141,143$

corpus de referência $\cdot 47$

Corpus Tool $\cdot 151,152,153,154,155,156,157,183,205$, 209, 219

Correlação de Yule $\cdot 183,185$

cosseleção $\cdot 76,82,113$

crimes $\cdot 13,14,30,50,102$

crimes de linguagem $\cdot 14$

Criminalística $\cdot 13$

$\overline{\mathrm{D}}$

depoimentos à polícia $\cdot 94$

descontinuidade $\cdot 143$

destinador $\cdot 131$

dialeto $\cdot 97$

diferenças sociais $\cdot 83$

Diminutivos $\cdot 103,108,109,111,116,117$

Direito $\cdot 13,58,60,67,220$

discurso $\cdot 26,113,114,126,150,201$ 
disputa judicial $\cdot 25$

distintividade $\cdot 97,98$

documento $\cdot 66,67,68,222,223$

double-blind experiment $\cdot 183$

$\overline{\mathrm{E}}$

elemento de prova $\cdot 59,61$

e-mails $\cdot 21,30$

emoticons $\cdot 103,108,109,110,116,117$

entrevista sociolinguística $\cdot 78$

enunciação $\cdot 81,88,89,90,142$

enunciado $\cdot 90,102,131,134,136,142,144$

escolaridade $\cdot 19,22,23,32,93,99,101,106,127$

escrita $\cdot 58$

escrita espontânea ou semiespontânea $\cdot 21$

espacialidade $\cdot 143$

esquema narrativo canônico $\cdot 130,135,167$

ação $\cdot 45,51,59,130,131,132,133,134,135,137$

manipulação $\cdot 57,130,131,132$

sanção $\cdot 130,132,133,134$

Estatística $\cdot 39,40$

estereótipo $\cdot 114$

estereótipos $\cdot 113$

Estilística $\cdot 35,37,38,44,75$

Estilística Forense $\cdot 35$

estilístico $\cdot 98,99$

estilo $\cdot 16,17,18,35,38,46,56,57,58,73,74,75,76,77$,

$78,79,81,82,83,85,86,88,89,90,92,93,95,97,98$, $100,108,112,113,118,125,126,132,142,145,146$, 200

estilo idioletal $\cdot 16,35,73,76$

estilo social $\cdot 16,83$

estilometria $\cdot 35,37,38,40,41,44$

estruturas de superfície $\cdot 88,92,99,129,153$

estruturas profundas $\cdot 88$

estudos estilométricos

Cartas Chilenas $\cdot 46$

CUSUM $\cdot 42$

epístolas paulinas $\cdot 41$

Henry VI $\cdot 4$

Lei de Zipf $\cdot 41$

Shakespeare $\cdot 41$

The Federalist Papers $\cdot 42$

ethos $\cdot 72,88,89,90,129,169$

etiqueta $\cdot 151,155,156$

etiquetar $\cdot 150$

etnia $\cdot 19,80,85,93,101,104$

evidência linguística $\cdot 33$

evidências $\cdot 13,14,38,39,51,58,60,61$

evidências linguísticas $\cdot 14$

exame grafotécnico $\cdot 60,68,69$

exame pericial $\cdot 60$

experimento cego $\cdot 182$

extensidade $\cdot 143$

extração dos dados $\cdot 149,150$

$\mathrm{F}$

Facebook $\cdot 128,219,220,224,225,226,227,228,249,250$

fatores externos $\cdot 101$

Federal Rules of Evidence $\cdot 64$

figuras $\cdot 96$

figuratividade $\cdot 99,114,141,142,143,144$

fonte de prova $\cdot 59,60,67$
Forensic Discourse Analysis · 44

formalidade $\cdot 78$

formas de prestígio $\cdot 105$

formas padrão $\cdot 34,46,103,105$

forum $\cdot 13$

frequência $\cdot 13,35,41,43,45,46,49,58,78,108,109,116$, 158

frequência lexical $\cdot 35$

G

gênero textual $\cdot 18$

gírias $\cdot 103,108,109,116,117$

grafia/ortografia $\cdot 103$

grupo profissional $\cdot 32$

grupo social $\cdot 16,19,20,32,73,83,84,93,94,97,101,118$, 124,125

grupos semióticos $\cdot 97$

grupos sociais $\cdot 16,32,48,49,81,83,85,97,99,115,118$,

124

$\overline{\mathrm{H}}$

hábitos $\cdot 55,56,57,72,82$

hábitos linguísticos $\cdot 72$

habitus $\cdot 82,83$

\section{I}

idade $\cdot 19,31,45,49,50,80,84,85,93,101,104,121,127$ identidade $\cdot 20,49,79,81,83,84,85,88,89,94,95,139$,

$140,141,246$

identidade social $\cdot 84$

identidades sociais $\cdot 81$

identificação de autoria $\cdot 14,35,40,76$

identificação de falantes $\cdot 14$

ideologia $\cdot 20,83,97,98,99,115,118,119$

idioleto $\cdot 72,73,74$

idiossincrasia $\cdot 47$

imanência $\cdot 86,92$

indexicalidade $\cdot 107$

Índice de Jaccard $\cdot 165,183$

índices $\cdot 109,117$

intensidade $\cdot 143$

interações nos tribunais $\cdot 14$

Internet $\cdot 30,48,137$

investigação criminal $\cdot 25,30,101$

isotopias $\cdot 119$

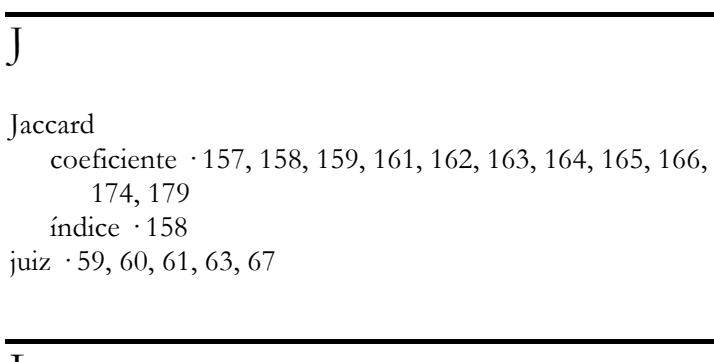

$\overline{\mathrm{L}}$

laudo $\cdot 60,61,69,70$

laudo pericial $\cdot 60$ 
língua escrita $\cdot 13,18,21,22,23,24,52,56,57,60,68,69$, $74,76,84,93,99,101,102,112,137$

língua oral $\cdot 49,84,93$

linguagem cotidiana $\cdot 31$

linguagem da polícia $\cdot 14$

Linguagem e Direto $\cdot 14$

linguagem jurídica $\cdot 14$

linguagem ofensiva $\cdot 103,108,109,117$

linguistic profiling $\cdot 48$

Linguística de Corpus $\cdot 72,150$

Linguística Forense $\cdot 13,14,25,26,32,34,36,39,48,49$, $52,58,72,73,88,94,102,206$

$\overline{\mathrm{M}}$

manifestação $\cdot 17,74,86,89,92,142,153$

marcadores

abreviaturas $\cdot 17$

categorias gramaticais $\cdot 46$

collocations $\cdot 46$

datação $\cdot 17$

design das páginas $\cdot 17$

distribuição e frequência de classes de palavras $\cdot 46$

frequência lexical $\cdot 17,41,46$

hapax dislegomena $\cdot 45$

hapax legomena $\cdot 43,45$

maiúsculas $\cdot 17$

marcadores discursivos $\cdot 43,98$

n-gramas $\cdot 43,44,46$

ortografia $\cdot 17,46$

pontuação $\cdot 17,41,43,45,46,52$

Relação "Type-Token" · 46

riqueza lexical $\cdot 43$

saudação $\cdot 17$

tamanho das palavras $\cdot 41$

tamanho das sentenças $\cdot 41$

Tamanho e distribuição de palavras $\cdot 46$

variáveis morfológicas $\cdot 17,46$

variáveis sintáticas $\cdot 17,46$

marcadores de estilo $\cdot 76$

Marcadores discursivos $\cdot 103,108,109,110,116,117$

marcas registradas $\cdot 15$

meio de prova $\cdot 66$

meio digital $\cdot 60$

meios de prova $\cdot 59,60,61$

mensagens anônimas $\cdot 30$

métodos etnográficos $\cdot 80$

métodos qualitativos $\cdot 35,37,38,55,103$

métodos quantitativos $\cdot 35,37,39,55,80$

metro $\cdot 40$

modalidades $\cdot 93,135$

modalidades veridictórias $\cdot 167$

morfossintaxe $\cdot 103$

multivariação $\cdot 107$

$\overline{\mathrm{N}}$

naïve writers $\cdot 22,23,102$

narratividade $\cdot 129$

esquema narrativo canônico $\cdot 129,131,132$

nível fundamental $\cdot 153,169,173,174$

nível narrativo $\cdot 143,151,153,167,168,170,171,172,173$

nível tensivo $\cdot 143$
$\mathrm{O}$

obtenção da prova $\cdot 59$

onomatopéias $\cdot 103,108,117$

oposições semânticas $\cdot 119$

organização sintática do discurso $\cdot 92$

$\overline{\mathrm{P}}$

paixão/paixões $\cdot 135,138,143,168$

palavras estrangeiras $\cdot 103,108,109,117$

percurso gerativo do sentido $\cdot 86,87$

nível discursivo $\cdot 88,96,141,142,143$

nível fundamental $\cdot 87,138,141$

nível narrativo $\cdot 87,96,129,134,138,141,142$

perfil de autor $\cdot 48$

perfil do falante $\cdot 49$

perfil linguístico $\cdot 48,49$

perfil sociolinguístico $\cdot 16,32,33,48,94,103,117$

perfis sociolinguísticos $\cdot 19,34,47,48,49,52,59,76,90$,

$93,94,100,107,117$

perícia $\cdot 59,60,61,62,67$

perito $\cdot 39,59,60,61,63,65$

persona $\cdot 81$

pertencimento $\cdot 48,82,83,85,94,95,97$

plágio $\cdot 30$

plano da expressão $\cdot 17,19,20,86,87,88,89,92,99,146$, 153

plano do conteúdo $\cdot 16,17,18,19,20,28,38,53,56,58,66$, $86,87,88,89,91,92,93,96,99,113,126,127,129,141$,

$145,146,149,150,153,182,183$

pontuação $\cdot 35,103,108,109,117$

pragmática $\cdot 26$

práticas $\cdot 14,20,118,119$

Principal Component Analysis · 42

problema do texto único $\cdot 49$

procedimento probatório $\cdot 61$

procedimentos probatórios $\cdot 62$

processamento de linguagem $\cdot 56$

processo judicial $\cdot 30$

profiling $\cdot 48$

prova $\cdot 14,58,59,60,61,62,63,64,65,66,67,68,120$

prova atípica $\cdot 62$

prova científica $\cdot 39,54,61,62,63,64,65,74$

prova documental $\cdot 67$

prova indiciária $\cdot 61$

prova inominada $\cdot 62$

prova nominada $\cdot 62$

prova pericial $\cdot 59,62,66,68$

prova técnica $\cdot 65$

provas $\cdot 58,220,225$

pseudônimos $\cdot 30$

Q

quadrado semiótico $\cdot 139,140$

qualitativa $\cdot 38$

quantificação $\cdot 37,39,40,150,157$

quantitativa $\cdot 38$ 
$\mathrm{R}$

recorrência $\cdot 20,74,76,77,82,85,88,95,96,98,99,113$,

$118,119,120,123,125,140,145,146$

recorrência semântica $\cdot 95,96,99,113,118,120,125$

recursos computacionais $\cdot 150$

recursos linguísticos $\cdot 82,95,108$

recursos semióticos $\cdot 81$

rede discursiva $\cdot 119$

redes sociais $\cdot 81$

redes sociais online $\cdot 101$

registro $\cdot 18,44,47,90,91,97$

regulamentação de perícias $\cdot 62$

relaxamento $\cdot 143$

repetição $\cdot 82$

repetição de letras $\cdot 103,108,109,116,117$

research artifacts $\cdot 182$

resultado da prova $\cdot 61$

rima $\cdot 40$

rito probatório $\cdot 62,63$

rotina $\cdot 130,134$

S

sanção $\cdot 167$

semântica $\cdot 20,26,87,95,96,98,131,138,140,142$

Semiótica $\cdot 16,17,19,26,86,87,96,129,135,153,197$, 202

tensividade $\cdot 87,92,96,131,141,143$

semiótica tensiva $\cdot 151$

sentido $\cdot 14,19,135,143$

sentido social $\cdot 81$

sexo $\cdot 19,21,49,50,80,93,101,102,103,104,106,107$, $109,111,113,117,118,127$

Sexo/ gênero $\cdot 101,104$

sexo/gênero $\cdot 93,101,111$

Shakespeare $\cdot 40,41$

significação $\cdot 201$

significado $\cdot 82,95,119$

signo $\cdot 206$

sociolinguistic profiling $\cdot 48$

Sociolinguística $\cdot 16,18,19,20,25,26,31,34,44,72,73$,

$74,78,79,93,99,104,105,106,114,118,124$

Sociolinguística qualitativa $\cdot 80$

Sociolinguística quantitativa $\cdot 80$

Sociolinguística variacionista $\cdot 79$

Sociossemiótica $\cdot 97$

suicídio $\cdot 119$

suspeito $\cdot 30,32,33,48,49,51,52,68,70$

$\overline{\mathrm{T}}$

tema $\cdot 18,33,36,52,58,79,90,91,113,132,137,141,144$, 224

temas $\cdot 94,96,99,114,141,143$

temporalidade $\cdot 135,143$

tensão $\cdot 143$ tensividade $\cdot 143,169,170,173,174,216$

tentativas de disfarce $\cdot 56,57,58$

Teoria da Acomodação $\cdot 78$

texto questionado $\cdot 25,32,49$

textos "reais" $\cdot 21$

textos ambíguos $\cdot 14$

textos anônimos $\cdot 30,31,91,101,102$

textos curtos $\cdot 24,37$

textos de autoria questionada $\cdot 61,66$

textos forenses $\cdot 21,22,92$

textos legais $\cdot 14$

textos não-forenses. $\cdot 21$

the Daubert criteria $\cdot 39$

tonicidade $\cdot 143$

triple-blind experiment $\cdot 183$

$\mathrm{U}$

universo discursivo $\cdot 20,94,95,97,101,118,120,124$

usos $\cdot 16,25,32,78$

$\overline{\mathrm{V}}$

validade $\cdot 27,47,54,55,56,63,69,83,104,182,183,184$

valores $\cdot 20,83,88,96,97,119,124,138,141$

variação $\cdot 18,19,20,27,34,35,55,58,69,74,77,78,80$,

$81,84,89,91,92,94,104$

variação entre autores $\cdot 182$

variação estilística $\cdot 78,81$

variação intra-autor $\cdot 182$

variação intrafalante $\cdot 18,19,78,92$

variação linguística $\cdot 35,80$

variacionista $\cdot 80$

variações socioletais $\cdot 99$

variantes $\cdot 35,44,52,78,81,98,105,106$

variáveis $\cdot 26$

variáveis fonológicas $\cdot 26,49,82,99$

variáveis linguísticas $\cdot 19,95$

variáveis morfológicas $\cdot 26,99$

variáveis sintáticas $\cdot 26$

variável $\cdot 44,72,96,106,107,131,142$

verbatim $\cdot 45$

vestígios físicos de autoria $\cdot 35$

Vocabulário $\cdot 103$

$\overline{\mathrm{W}}$

websites $\cdot 30$

Y

Yule

coeficiente, correlação $\cdot 161,174,175,176,177,178$,

179 